Universidade de São Paulo

Instituto de Física de São Carlos

Dalcimar Casanova

Redes complexas em visão computacional com aplicações em bioinformática 



\section{Dalcimar Casanova}

\section{Redes complexas em visão computacional com aplicações em bioinformática}

Tese apresentada ao Programa de PósGraduação em Física do Instituto de Física de São Carlos da Universidade de São Paulo, para obtenção do título de doutor em Ciências.

Área de Concentração: Física Aplicada: Opção Computacional

Orientador: Prof. Dr. Odemir Martinez Bruno

Versão Original

São Carlos 
AUTORIZO A REPRODUÇÃO E DIVULGAÇÃO TOTAL OU PARCIAL DESTE TRABALHO, POR QUALQUER MEIO CONVENCIONAL OU ELETRÔNICO, PARA FINS DE ESTUDO E PESQUISA, DESDE QUE CITADA A FONTE.

Ficha catalográfica elaborada pelo Serviço de Biblioteca e Informação do IFSC, com os dados fornecidos pelo(a) autor(a)

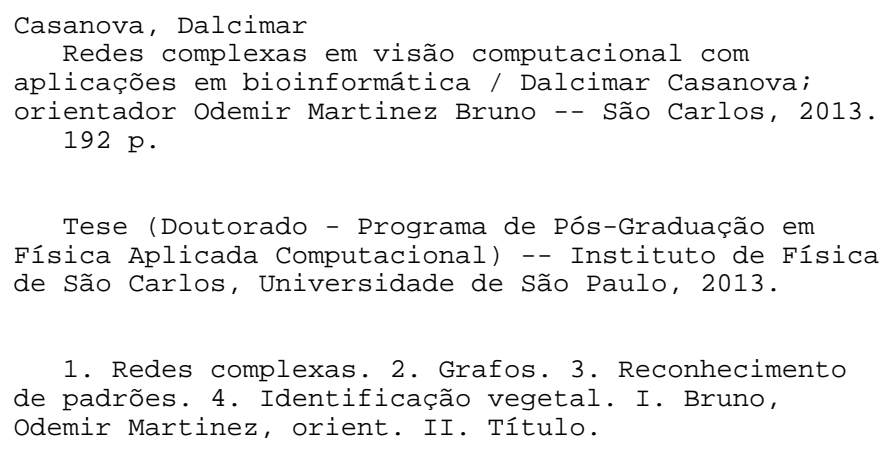




\section{FOLHA DE APROVAÇÃO}

Dalcimar Casanova

Tese apresentada ao Instituto de Física de São Carlos da Universidade de São Paulo para obtenção do título de Doutor em Ciências.

Área de Concentração: Fisica Aplicada Opção: Fisica Computacional.

Aprovado(a) em: 01/07/2013

Comissăo Julgadora

Prof(a). Dr(a). Odemir Martinez Bruno

Instituiçäo: IFSC/USP

Prof(a). Dr(a). Milton Groppo Junior

Instituiçäo: FFCLRP/USP

Prof. Dr(a). Zhao Liang

Instituiçăo: ICMC/USP

Prof(a). Dr(a). Adriano Defini Andricopulo

Instituiçăo: IFSC/USP

Prof(a). Dr(a). Luiz Antônio Pereira Neves

Instituiçăo: UFPR/Curitiba 



\section{AGRADECIMENTOS}

Aos meus pais Darci e Acioní, que mesmo à distância, me apoiam e me encorajaram em todos os momentos.

A minha amada namorada Larissa, pela felicidade a mim proporcionada, pela compreensão, carinho e companhia oferecida durante o tempo em que me mantive distante.

Ao meu orientador Prof. Dr. Odemir Martinez Bruno, pela confiança depositada em mim, orientação e amizade.

Aos amigos que fiz no convívio diário da universidade, e aos amigos do ciclismo, que me proporcionaram viagens, diversão e experiências únicas.

Aos professores e funcionários do IFSC - USP e a todos que, direta ou indiretamente, colaboraram comigo.

À FAPESP pelo apoio financeiro. 

Eu não tenho ídolos. Tenho admiração por trabalho, dedicação e competência.

Ayrton Senna 



\section{RESUMO}

CASANOVA, D. Redes complexas em visão computacional com aplicações em bioinformática. 2013. 192 p. Tese (Doutorado) - Instituto de Física de São Carlos, Universidade de São Paulo, São Carlos, 2013.

Redes complexas é uma área de estudo relativamente recente, que tem chamado a atenção da comunidade científica e vem sendo aplicada com êxito em diferentes áreas de atuação tais como redes de computadores, sociologia, medicina, física, matemática entre outras. Entretanto a literatura demonstra que poucos são os trabalhos que empregam redes complexas na extração de características de imagens para posterior analise ou classificação. Dada uma imagem é possível modela-la como uma rede, extrair características topológicas e, utilizando-se dessas medidas, construir o classificador desejado. Esse trabalho objetiva, portanto, investigar mais a fundo esse tipo de aplicação, analisando novas formas de modelar uma imagem como uma rede complexa e investigar diferentes características topológicas na caracterização de imagens. Como forma de analisar o potencial das técnicas desenvolvidas, selecionamos um grande desafio na área de visão computacional: identificação vegetal por meio de análise foliar. A identificação vegetal é uma importante tarefa em vários campos de pesquisa como biodiversidade, ecologia, botânica, farmacologia entre outros.

Palavras-chave: Redes complexas. Grafos. Reconhecimento de padrões. Identificação vegetal. 



\section{ABSTRACT}

CASANOVA, D. Complex networks in computer vision, with applications in bioinformatics. 2013. 192 p. Tese (Doutorado) - Instituto de Física de São Carlos, Universidade de São Paulo, São Carlos, 2013.

Complex networks is a relatively recent field of study, that has called the attention of the scientific community and has been successfully applied in different areas such as computer networking, sociology, medicine, physics, mathematics and others. However the literature shows that there are few works that employ complex networks in feature extraction of images for later analysis or classification. Given an image, it can be modeled as a network, extract topological features and, using these measures, build the classifier desired. This work aims, therefore, investigate this type of application, analyzing new forms of modeling an image as a complex network and investigate some topological features to characterize images. In order to analyze the potential of the techniques developed, we selected a major challenge in the field of computer vision: plant identification by leaf analysis. The plant identification is an important task in many research fields such as biodiversity, ecology, botany, pharmacology and others.

Keywords: Complex network. Graphs. Pattern recognition. Plant identification. 



\section{LISTA DE FIGURAS}

2.1 Caracterização de redes complexas . . . . . . . . . . . . . . p. 37

2.2 Medidas obtidas após transformação $t \ldots \ldots$. . . . . . . . . . . . . p. 44

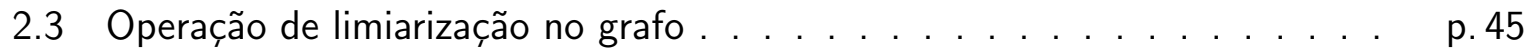

$2.4 \quad$ Grafo hierárquico de tamanho $L=2 \ldots \ldots \ldots \ldots$ p. 46

2.5 Operação de optimum-path forest aplicado sobre o grafo $\ldots \ldots$. . . . . . p. 47

3.1 Grafo por adjacência de pixeis, lattice 4-conectada . . . . . . . . . . p. p. 53

3.2 Grafo por adjacência de pixeis, lattice 8-conectada . . . . . . . . . . p p. 53

3.3 Grafo por adjacência de pixeis, lattice completa. . . . . . . . . . . . . . p. 54

3.4 Grafo por adjacência de pixeis, lattice conectada por raio. . . . . . . . . . p. p. 54

3.5 Grafo por adjacência de pixeis, lattice 4-conectada pirâmede. $\quad$. . . . . . . p. 55

3.6 Grafo por adjacência de pixeis, lattice k-vizinhos . . . . . . . . . . . . p. 55

3.7 Grafo por adjacência de regiões . . . . . . . . . . . . . . . . . . p. 55

3.8 Grafo por adjacência de cores . . . . . . . . . . . . . . . p. 56

4.1 Visão geral dos métodos propostos . . . . . . . . . . . . . . p 67

4.2 Visão geral dos modelos propostos $\mathrm{x}$ análise de imagens $\ldots . . . . \quad$ p. 68

4.3 Textura modelada como um PAG lattice 4-conectada. . . . . . . . . . . . p. p. 69

4.4 Textura modelada como um PAG lattice 8 -conectada. . . . . . . . . . . . p. p. 72

4.5 Composição da 1a e 2a variável canônica, modelo PAG lattice 8-conectada. p.74

4.6 Variância total explicada pelas 10 primeiras variáveis canônicas, modelo PAG lattice 8-conectada. . . . . . . . . . . . . . . . . . . . . . . . p.74

4.7 Textura modelada como um PAG lattice r-conectada . . . . . . . . . . . . p $\quad$ p. 75 
4.8 Composição da 1a e 2a variável canônica, modelo PAG lattice r-conectada. p. 76

4.9 Variância total explicada pelas 10 primeiras variáveis canônicas, modelo PAG lattice r-conectada. . . . . . . . . . . . . . . . . . . . . p. 77

4.10 Textura modelada como um PAG lattice completo . . . . . . . . . . . . . p. p 78

4.11 Textura modelada como um PAG lattice k-vizinhos . . . . . . . . . . . . . p p.79

4.12 Composição da 1a e 2a variável canônica, modelo PAG lattice k-vizinhos. . p. 81

4.13 Variância total explicada pelas 10 primeiras variáveis canônicas, modelo PAG lattice k-vizinhos. . . . . . . . . . . . . . . . . . . . . . . . . . . . . . . p p. 81

4.14 Textura modelada como um PAG lattice small-world . . . . . . . . . . . . p p. 82

4.15 Composição da 1a e 2a variável canônica, modelo PAG lattice small-world. p. 83

4.16 Variância total explicada pelas 10 primeiras variáveis canônicas, modelo PAG lattice small-world. . . . . . . . . . . . . . . . . . . . . . p. 83

4.17 Textura modelada como um CPAG . . . . . . . . . . . . . . . . p. 85

4.18 Composição da 1a e 2a variável canônica, modelo CPAG. . . . . . . . . . p. p. 86

4.19 Variância total explicada pelas 10 primeiras variáveis canônicas, modelo CPAG. p. 86

4.20 Textura modelada como um $M A G \quad \ldots \ldots$. . . . . . . . . . . . . . . . . 88

4.21 Composição da 1a e 2a variável canônica, modelo MAG. . . . . . . . . . . p. p. 89

4.22 Variância total explicada pelas 10 primeiras variáveis canônicas, modelo MAG. p. 90

4.23 Textura modelada como um $R A G$ estático $\ldots \ldots \ldots$. . . . . . . . . . . . . . . . $\quad$ p.92

4.24 Resultado segmentação por Watershed . . . . . . . . . . . . . . . . . . . . $\quad$ p.92

4.25 Composição da 1a e 2a variável canônica, modelo RAG estático. . . . . . . . p p.93

4.26 Variância total explicada pelas 10 primeiras variáveis canônicas, modelo RAG estático. . . . . . . . . . . . . . . . . . . . . . . . . p. 94

4.27 Resultado segmentação por Watershed com diferentes parâmetros . . . . . . p. 95

4.28 Composição da 1a e 2a variável canônica, modelo RAG dinâmico. . . . . . . p p. 95

4.29 Variância total explicada pelas 10 primeiras variáveis canônicas, modelo RAG dinâmico. . . . . . . . . . . . . . . . . . . . . . . . . p. 96

4.30 Textura modelada como um CAG . . . . . . . . . . . . . . . . . . p. 97 
4.31 Composição da 1a e 2a variável canônica, modelo CAG. . . . . . . . . . . . p. 100

4.32 Variância total explicada pelas 10 primeiras variáveis canônicas, modelo CAG.p. 100

4.33 Textura modelada como um CHAG . . . . . . . . . . . . . . . . . . . p. 104

4.34 Composição da 1a e 2a variável canônica, modelo CHAG. . . . . . . . . . p. 105

4.35 Variância total explicada pelas 10 primeiras variáveis canônicas, modelo CHAG.p. 105

4.36 Contorno modelado como um aPAG completo contorno . . . . . . . . . p p. 107

4.37 Propriedade de invariância à escala. . . . . . . . . . . . . . . . . . p. 108

4.38 Propriedade de invariância à rotação. . . . . . . . . . . . . . . . . . p. p. 108

4.39 Grau médio calculado para uma mesma imagem em duas diferentes escalas p. 109

4.40 Composição da 1a e 2a variável canônica, modelo aPAG completo contorno. p. 110

4.41 Variância total explicada pelas 10 primeiras variáveis canônicas, modelo aPAG completo contorno. . . . . . . . . . . . . . . . . . . . p. 111

4.42 Esqueleto modelado como um aPAG completo esqueleto . . . . . . . . . . p. 111

4.43 Composição da 1a e 2a variável canônica, modelo aPAG completo esqueleto. p. 112

4.44 Variância total explicada pelas 10 primeiras variáveis canônicas, modelo aPAG completo esqueleto. . . . . . . . . . . . . . . . . . . . . . . . . p.113

4.45 Textura modelada como um aPAG completo textura . . . . . . . . . . p. 113

4.46 Contorno modelado como um aPAG interno . . . . . . . . . . . . . . p. 114

4.47 Composição da 1a e 2a variável canônica, modelo aPAG interno. . . . . . . p. 116

4.48 Variância total explicada pelas 10 primeiras variáveis canônicas, modelo aPAG interno. . . . . . . . . . . . . . . . . . . . . . . p. 116

4.49 Contorno modelado como um aPAG externo . . . . . . . . . . . . p. 117

4.50 Composição da 1a e 2a variável canônica, modelo aPAG externo. $\quad$. . . . . p. 117

4.51 Variância total explicada pelas 10 primeiras variáveis canônicas, modelo aPAG externo. . . . . . . . . . . . . . . . . . . . . p. 117

5.1 Robustez dos métodos em formas incompletas. . . . . . . . . . . . . . . . p. 127

5.2 Robustez dos métodos em formas degradadas randomicamente. . . . . . . . p. 128 
6.1 Superfícies adaxial, adaxial e corte . . . . . . . . . . . . . . . p. 135

6.2 Variação da cor em uma folha de Cotinus coggygria . . . . . . . . . . . . p. 135

6.3 Variação na textura de uma folha de Miconia langsdorfii. . . . . . . . . . . p. 135

6.4 Variação do formato geral de uma folha de Corylus avellana . . . . . . . . p. 136

6.5 Variação de tamanho de uma folha de Sophora japonica. . . . . . . . . . . p. 136

6.6 Variação na margem de uma folha de Quercus ilex . . . . . . . . . . . . p. 136

6.7 Variação no número de leaflets de uma folha de Fraxinus angustifolia . . . p. 137

6.8 Variação na posição dos leaflets de uma folha de Vitex agnus-castus. . . . . p. 137

6.9 Variação no número de lobos de uma folha de Ficus carica . . . . . . . . . p. 137

6.10 Clarificação e processo de filtragem de venação $\ldots$. . . . . . . . . . . . . . p. 144

6.11 Epiderme foliar de 8 diferentes espécies $\ldots \ldots \ldots$. . . . . . . . . . . . . . . 145

6.12 Acerto para diferentes números de folhas retornadas na consulta. . . . . . p. 150

6.13 Matriz de confusão para as 124 espécies $\ldots \ldots$. . . . . . . . . . . . . . p. 150

6.14 Ranking das imagens recuperadas para consulta de Viburnum opulus . . . p. 151

6.15 Ranking das imagens recuperadas para consulta de Crataegus monogyna . p. 151

6.16 Ranking das imagens recuperadas para consulta de Rhamnus cathartica . . p. 151

6.17 Ranking das imagens recuperadas para consulta de Platanus $x$ hispanica. . p. 152

6.18 Ranking das imagens recuperadas para consulta de Morus nigra . . . . . . $\quad$ p. 152

6.19 Ranking das imagens recuperadas para consulta de Ginkgo biloba . . . . . p 152

6.20 Ranking das imagens recuperadas para consulta de Fraxinus ornus . . . . . p. 153

6.21 Ranking das imagens recuperadas para consulta de Mespilus germanica . . p. 153

6.22 Ranking das imagens recuperadas para consulta de Pittosporum tobira . . p. 153

6.23 Ranking das imagens recuperadas para consulta de Diospyros kaki . . . . . p p. 153

6.24 Ranking das imagens recuperadas para consulta de Cercis siliquastrum . . p. 154

6.25 Ranking das imagens recuperadas para consulta de Quercus pubescens . . p. 154

6.26 Curvas de precisão/revocação para as 12 consultas realizadas $\ldots$. . . . . . p. 155 
A.1 Exemplos de textura da base de dados Brodatz. . . . . . . . . . . . . . . p. 181

A.2 Exemplos de textura da base de dados Vistex. . . . . . . . . . . . . . p. 181

A.3 Exemplos de textura da base de dados Outex. . . . . . . . . . . . . . . . p. 182

A.4 Exemplos de formas da base de dados Genérica. . . . . . . . . . . . . . . p. 182

A.5 Exemplos de formas da base de dados Peixes. . . . . . . . . . . . . . . p. 183

A.6 $\quad$ Exemplos de formas da base de dados MPEG-7. . . . . . . . . . . . . . . . p. 183

A.7 Exemplos de forma com ruído. . . . . . . . . . . . . . . . . . . . . . . . p. 184

A.8 Exemplos de degradação contínua aplicada às formas de folhas . . . . . . p. 184

A.9 Exemplos de degradação randômica aplicada às formas de folhas. $\ldots$. . . . . p. 184 



\section{LISTA DE TABELAS}

2.1 Lista do primeiro conjunto de descritores utilizados. . . . . . . . . . . p. 43

4.1 PAG lattice 4-conectada: Resultados obtidos para diferentes funções de peso $w_{i j}$, análise subgrafos. . . . . . . . . . . . . . p. 70

4.2 PAG lattice 4-conectada: Resultados obtidos para diferentes conjuntos de limiares, análise subgrafos. . . . . . . . . . . . . . . . . p.70

4.3 PAG lattice 4-conectada: Resultados obtidos para diferentes quantidades de conjuntos de sementes, análise OPF. . . . . . . . . . . . . . . . . . p.71

4.4 PAG lattice 8-conectada: Resultados obtidos para diferentes funções de peso $w_{i j}$, análise subgrafos. . . . . . . . . . . . . . . p.72

4.5 PAG lattice 8-conectada: Resultados obtidos para diferentes conjuntos de limiares, análise subgrafos. . . . . . . . . . . . . . . . . p. 72

4.6 PAG lattice 8-conectada: Resultados obtidos para diferentes quantidades de conjuntos de sementes, análise OPF. . . . . . . . . . . . . . . p.73

4.7 PAG lattice r-conectada: Resultados obtidos para diferentes valores de raio, análise subgrafos. . . . . . . . . . . . . . . . . . . . . . . . . . p p 74

4.8 PAG lattice r-conectada: Resultados obtidos para diferentes conjuntos de limiares, análise subgrafos. . . . . . . . . . . . . . . . . . . . . . . p.75

4.9 PAG lattice r-conectada: Resultados obtidos para diferentes quantidades de conjuntos de sementes, análise OPF. . . . . . . . . . . . . . . . p.76

4.10 PAG lattice completa: Resultados obtidos para diferentes conjuntos de limiares, análise subgrafos. . . . . . . . . . . . . . . . . . . . p. 78

4.11 PAG lattice k-vizinhos: Resultados alcançados para diferentes valores de $k$, análise direta. 
4.12 PAG lattice k-vizinhos: Resultados alcançados para diferentes valores de $k$, análise hierárquica. . . . . . . . . . . . . . . . . . . . . . . . . p.79

4.13 PAG lattice k-vizinhos: Resultados obtidos para diferentes conjuntos de limiares, análise subgrafos. . . . . . . . . . . . . . . . . . . . p p 80

4.14 PAG lattice k-vizinhos: Resultados obtidos para diferentes quantidades de conjuntos de sementes, análise OPF. . . . . . . . . . . . . p. 80

4.15 PAG lattice small-world: Resultados obtidos para diferentes conjuntos de limiares, análise subgrafos. . . . . . . . . . . . . . . . p. 82

4.16 PAG lattice small-world: Resultados obtidos para diferentes quantidades de conjuntos de sementes, análise OPF. . . . . . . . . . . . . . . . . p. 82

4.17 CPAG: Resultados obtidos para diferentes conjuntos de limiares, análise subgrafos. . . . . . . . . . . . . . . . . . . . p. 85

4.18 CPAG: Resultados obtidos para diferentes quantidades de conjuntos de sementes, análise OPF. . . . . . . . . . . . . . . . . p. 85

4.19 Resultados alcançados para diferentes níveis multiescala para o modelo MAG. p. 88

4.20 MAG: Resultados obtidos para diferentes conjuntos de limiares, análise subgrafos. . . . . . . . . . . . . . . . . . . . . . . . . . p. 88

4.21 MAG: Resultados obtidos para diferentes quantidades de conjuntos de sementes, análise OPF. . . . . . . . . . . . . . . . . . p. 89

4.22 RAG estático: Resultados obtidos para diferentes funções de peso, análise direta. . . . . . . . . . . . . . . . . . . . . . p. 92

4.23 RAG estático: Resultados obtidos para diferentes conjuntos de limiares, análise subgrafos. . . . . . . . . . . . . . . . . . . . . . . . . . . . . . p. 93

4.24 RAG estático: Resultados obtidos para diferentes níveis hierárquicos, análise hierárquica. . . . . . . . . . . . . . . . . . . . . p. 93

4.25 RAG estático: Resultados obtidos para diferentes quantidades de conjuntos de sementes, análise OPF. . . . . . . . . . . . . . . . . . . . . p. 94

4.26 RAG dinâmico: Resultados obtidos para diferentes segmentações, análise direta. 
4.27 CAG: Resultados obtidos para diferentes valores de pré-quantização, análise direta . . . . . . . . . . . . . . . . . . . . . . . . . 98

4.28 CAG: Resultados obtidos para diferentes conjuntos de limiares, análise subgrafos.

4.29 CAG: Resultados obtidos para diferentes níveis hierárquicos, análise hierárquica. p. 99

4.30 CAG: Resultados obtidos para diferentes quantidades de conjuntos de sementes, análise OPF. . . . . . . . . . . . . . . . . . . p. 99

4.31 CAG: Resultados obtidos para diferentes valores de pré-quantização, análise direta e caracterização por fractais. . . . . . . . . . . . . . . . . . . . . . p. 101

4.32 Resultados alcançados para diferentes espaços de cores e modelagem CAG e sua respectiva quantização ótima. . . . . . . . . . . . . . . . . . . . . . p. 102

4.33 CHAG: Resultados obtidos para diferentes valores de pré-quantização, análise por subgrafos. . . . . . . . . . . . . . . . . . . . . . . . . . . . . . . . p. 104

4.34 CHAG: Resultados obtidos para diferentes conjuntos de limiares, análise subgrafos. . . . . . . . . . . . . . . . . . . . . . . . . p. 104

4.35 aPAG completo contorno: Resultados obtidos para diferentes conjuntos de limiares, análise subgrafos. . . . . . . . . . . . . . . . . . . . . . . . . p. 110

4.36 aPAG completo esqueleto: Resultados obtidos para diferentes conjuntos de limiares, análise subgrafos. . . . . . . . . . . . . . . . . . . p. 112

4.37 aPAG completo textura: Resultados obtidos para diferentes conjuntos de limiares, análise subgrafos. . . . . . . . . . . . . . . . . . . . . . . . . . . p. 114

4.38 aPAG interno: Resultados obtidos para diferentes conjuntos de limiares, análise subgrafos. . . . . . . . . . . . . . . . . . . . . . . p. 115

4.39 aPAG externo: Resultados obtidos para diferentes conjuntos de limiares, análise subgrafos.

5.1 Comparação do método com diversos descritores de textura. Alta discriminação obtida para todas as bases de dados. . . . . . . . . . . . . . . . p. 121

5.2 Comparação do método com diversos descritores de textura. Alta discriminação obtida para todas as bases de dados. 
5.3 Resultados alcançados por diversos métodos de análise de formas em 3 bases de dados. . . . . . . . . . . . . . . . . . . . . . . . p. 126

5.4 Resultados para bases de dados com diferentes níveis de ruído. . . . . . . . p. 127

5.5 Resultados alcançados por diversos métodos de análise de esqueletos em 3 bases de dados. . . . . . . . . . . . . . . . . . . . . . . . . . . . . . . . . . . . . p. 129

5.6 Resultados alcançados por diversos métodos de análise de formas em 3 bases de dados. . . . . . . . . . . . . . . . . . . . . . . . . . . . . . . . p. 131

5.7 Tempo de execução dos métodos propostos. $\ldots \ldots$. . . . . . . . . . . . . . 132

6.1 Base de dados foliar: relação das espécies e número de folhas por espécie . p. 147

6.2 Resultados obtidos para os diversos métodos propostos e da literatura nos diferentes caracteres morfológicos em análise foliar. . . . . . . . . . . . . . p. 148 


\section{SUMÁRIO}

\begin{tabular}{llr}
\hline 1 & Introdução & p. 27
\end{tabular}

1.1 Justificativa e Motivação . . . . . . . . . . . . . . . . . . . . . . . . p. 27

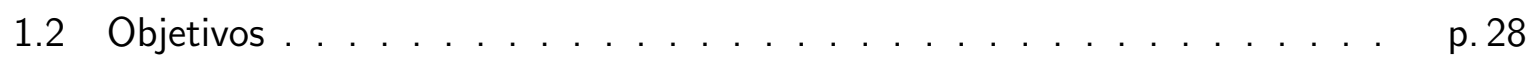

1.3 Principais contribuições $\ldots \ldots \ldots$. . . . . . . . . . . . . . . . . 29

1.4 Organização $\ldots \ldots \ldots \ldots \ldots$. . . . . . . . . . . . . . . . . . . . . . 30

$\begin{array}{lll}2 & \text { Teoria dos grafos e redes complexas } & \text { p. } 31\end{array}$

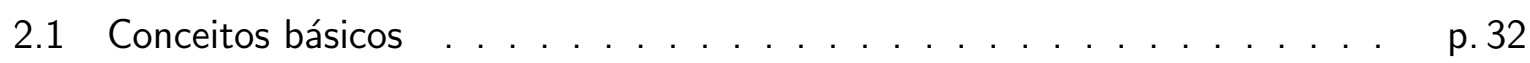

2.2 Modelos clássicos de redes complexas . . . . . . . . . . . . . . p. 36

2.2 .1 Rede Aleatória $\ldots \ldots \ldots$. . . . . . . . . . . . . . . . . . 36

2.2 .2 Rede Pequeno Mundo . . . . . . . . . . . . . . . . . . . . p. 36

2.2 .3 Rede Livre de Escala $\ldots \ldots \ldots$. . . . . . . . . . . . . . . . . . . . . . . . $\quad$ p. 37

2.3 Medidas estatísticas $\ldots \ldots \ldots \ldots$. . . . . . . . . . . . . . . . . . . 37

2.3 .1 Grau e Conectividade . . . . . . . . . . . . . . . . . . . p. 38

2.3 .2 Caminhos e distância $\ldots \ldots \ldots$. . . . . . . . . . . . . . . . .

2.3 .3 Aglomeração e ciclos . . . . . . . . . . . . . . . . . . . . . . . . p. p. 41

2.3 .4 Complexidade . . . . . . . . . . . . . . . . . . p. 42

2.3 .5 Resumo das medidas . . . . . . . . . . . . . . . . . . . p. 43

2.4 Análise de grafos . . . . . . . . . . . . . . . . . . . . . . . . . . . . p. 44

2.4 .1 Análise direta $\ldots \ldots \ldots \ldots$. . . . . . . . . . . . . . . . . . . 45 
2.4 .2 Análise de subgrafos . . . . . . . . . . . . . . . . . . p. 45

2.4 .3 Análise hierárquica $\ldots \ldots \ldots$. . . . . . . . . . . . . . . . . . . p. 46

2.4 .4 Análise OPF . . . . . . . . . . . . . . . . . . . . . . . . p. 47

3 Grafos e redes complexas em imagens $\quad$ p. 49

3.1 Modelagem de imagens por grafo . . . . . . . . . . . . . . . . . p p. 49

3.1 .1 Vértices . . . . . . . . . . . . . . . . p. 50

3.1 .2 Arestas . . . . . . . . . . . . . . . . . . p. 53

3.2 Métodos que utilizam modelagem imagem/grafo em processamento de imagens p. 55

3.2 .1 Segmentação de Imagens . . . . . . . . . . . . . . . . p. 56

3.2 .2 Extração de características de textura . . . . . . . . . . . . . . p. 60

3.2 .3 Refinamento de bordas . . . . . . . . . . . . . . . . . . . p 61

3.2 .4 Compressão de imagens . . . . . . . . . . . . . . . . . . p. 61

3.2 .5 Extração de características de contorno . . . . . . . . . . . . . . p. 62

3.2 .6 Aproximação poligonal . . . . . . . . . . . . . . . . . . . . . . . . p p. 63

3.2.7 $\quad$ Extração de características de esqueleto . . . . . . . . . . . . . . p. 63

3.2 .8 Localização e reconhecimento de objetos na cena. . . . . . . . . . . p. 64

3.2 .9 Recuperação de imagens por conteúdo . . . . . . . . . . . . . . p. 65

4 Métodos de análise de imagens propostos $\quad$ p. 67

4.1 PAG - Grafo por adjacência de pixel . . . . . . . . . . . . . . . p 68

4.1 .1 PAG lattice 4-conectada . . . . . . . . . . . . . . . . . . . p 69

4.1 .2 PAG lattice 8 -conectada . . . . . . . . . . . . . . . . . p 71

$4.1 .3 \quad$ PAG lattice r-conectada $\ldots \ldots \ldots$. . . . . . . . . . . . . . . . . . 73

4.1 .4 PAG lattice completo $\ldots \ldots \ldots \ldots$

4.1 .5 PAG lattice k-vizinhos $\ldots \ldots \ldots$. . . . . . . . . . . . . . . . . 78

4.1 .6 PAG lattice Small-World . . . . . . . . . . . . . . . . . . . . . . . . p 80

4.2 CPAG - Grafo por adjacência de cor pixel . . . . . . . . . . . . . p. 83 
4.3 MAG - Grafo por adjacência multiescala $\ldots \ldots$ p. . . . . . . . . . 86

4.4 RAG - Grafo por adjacência de regiões $\ldots \ldots$. . . . . . . . . . . . . . 89

4.4 .1 RAG estático . . . . . . . . . . . . . . . . . . . . . . . p 91

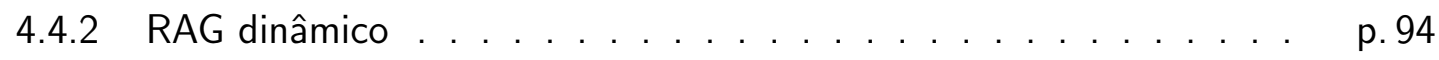

4.5 CAG - Grafo por adjacência de cores . . . . . . . . . . . . p. 96

4.6 CHAG - Grafo por adjacência de cores do histograma . . . . . . . . . . . p. 102

4.7 aPAG - Grafo por adjacência de alguns pixeis . . . . . . . . . . . . p. 106

4.7 .1 aPAG completo contorno . . . . . . . . . . . . . . . . . p. 107

4.7 .2 aPAG completo esqueleto . . . . . . . . . . . . . . p. 111

4.7 .3 aPAG completo textura . . . . . . . . . . . . . . p. 113

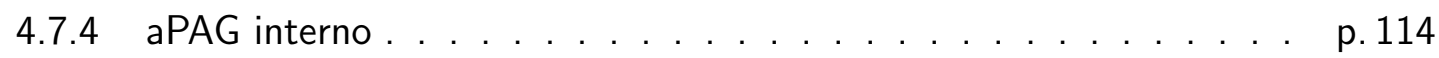

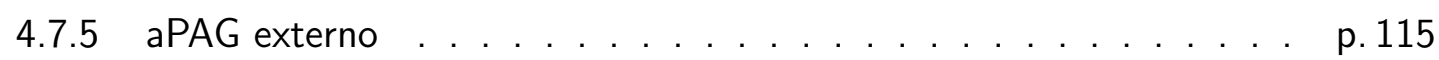

5 Resumo dos resultados e avaliação $\quad$ p. 119

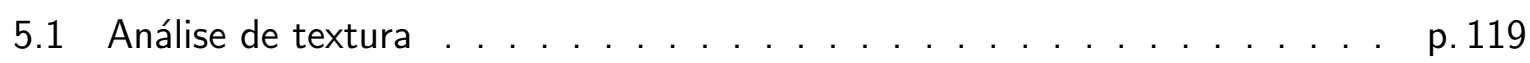

5.2 Análise de cor . . . . . . . . . . . . . . . . . . . . . . . p. 125

5.3 Análise de forma $\ldots \ldots \ldots \ldots \ldots$. . . . . . . . . . . . . . . . . . . . . p. 125

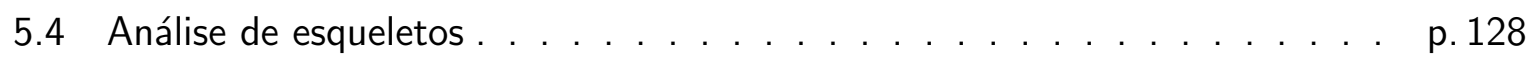

5.5 Análise dos modelos via correspondência inexata de grafos . . . . . . . . . p. 129

$5.5 .1 \quad$ Métodos de comparação . . . . . . . . . . . . . . . . . . . . . . . p. 130

5.6 Análise de tempo de execução . . . . . . . . . . . . . . . . . . . . . p. 132

6 Classificação de espécies vegetais baseada em análise foliar $\quad$ p. 133

6.1 Morfologia foliar . . . . . . . . . . . . . . . . . . . . . . . . . . p. 134

6.2 Caracteres taxonômicos . . . . . . . . . . . . . . . . . . . . . . . . . p. 139

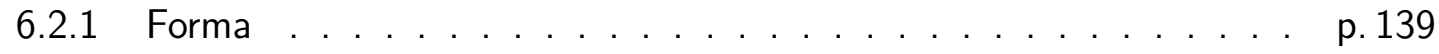

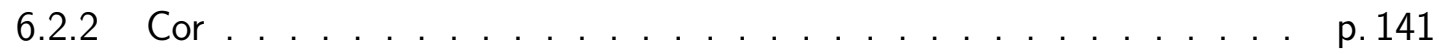

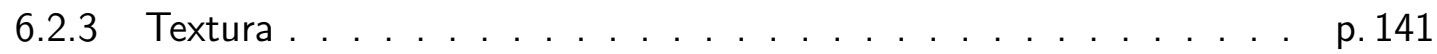


6.2 .4 Venação . . . . . . . . . . . . . . . . . . . . . . . . . . p. 143

6.2 .5 Cortes seccionais . . . . . . . . . . . . . . . . . . . . . p. 145

6.3 Avaliação . . . . . . . . . . . . . . . . . . . . . . . . . . p. 146

6.4 Resultados e discussão . . . . . . . . . . . . . . . . . . . . . . . p. 148

$\begin{array}{lll}7 \text { Conclusão } & \text { p. } 157\end{array}$

7.1 Trabalhos futuros . . . . . . . . . . . . . . . . . . . . . p. 158

7.2 Principais contribuições e publicações . . . . . . . . . . . . . . . . . . p. 159

$\begin{array}{ll}\text { REFERÊNCIAS } & \text { p. } 163\end{array}$

\begin{tabular}{ll}
\hline APÊNDICE A - Bases de dados & p. 181
\end{tabular}

A.1 Bases de dados de textura . . . . . . . . . . . . . . . . . . . p. 181

A.2 Bases de dados de forma . . . . . . . . . . . . . . . . . . . . . p. 182

A.2.1 Tolerância ruído . . . . . . . . . . . . . . . . . . . . p. 183

A.2.2 Robustez à contornos parciais $\ldots \ldots \ldots$. . . . . . . . . . . p. 184

A.2.3 Robustez à contornos parciais II . . . . . . . . . . . . . . . . . . p. p. 184

A.3 Base de dados de esqueletos . . . . . . . . . . . . . . . . . . p. p. 185

\begin{tabular}{|l|l|}
\hline APÊNDICE B - Reconhecimento de padrões & p. 187
\end{tabular}

B.1 Análise discriminante linear $\ldots \ldots \ldots$. . . . . . . . . . . . p. 187

B.2 Classificador bayesiano . . . . . . . . . . . . . . . . . . . . . p. p. 189

B.3 Classificador $\mathrm{Knn} \ldots \ldots \ldots$. . . . . . . . . . . . . . . . . . . . . p. 189

B.4 Métricas para avaliação de desempenho dos classificadores . . . . . . . . . p. p. 190 


\section{CAPÍTULO 1}

\section{Introdução}

\subsection{Justificativa e Motivação}

Redes complexas é uma área de estudo relativamente recente que utiliza o formalismo matemático da teoria dos grafos e emprega métodos estatísticos e/ou ferramentas e métodos da física estatística para caracterizar, criar modelos e analisar a sua estrutura. Essa área tem sua origem atribuída aos trabalhos de Erdös e Rényi (1) e Milgram (2) nas décadas de 50, 60. Mais recentemente, a aplicação do formalismo de grafos em redes reais começou a mostrar que as conexões em sistemas sociais e biológicos não eram aleatórias. Os principais trabalhos que precederam a revolução no estudo de sistemas complexos por meio de grafos incluem Watts e Strogatz (3) com investigações sobre Redes Pequeno-Mundo (que em um contexto social, confirmam o famoso experimento do psicólogo Milgram (2) nos anos 60 onde duas pessoas quaisquer estão conectadas por, em média, seis graus de separação) e, posteriormente em 1999, a descoberta de que a relação entre páginas da world wide web (www) também não era aleatória, mas seguia um mecanismo que privilegiava determinadas páginas conforme sua popularidade (caracterizando os modelos livres de escala de Barabási e Albert (4)). Tais trabalhos definitivamente motivaram a busca pelas estruturas presentes em sistemas naturais e artificiais e, a partir de então, os grafos passaram a ser a base matemática da nova teoria das redes complexas. A teoria das redes complexas não só estende o formalismo da teoria dos grafos, mas principalmente, propõe medidas e métodos fundamentados em propriedade reais do sistema (5).

Embora as redes complexas sejam aplicadas com muito sucesso em diferentes áreas do conhecimento (e.g. redes sociais, economia, transportes, neurociência) e, entre elas a computação (arquitetura, inteligência artificial e redes) (6), poucos são os trabalhos que empregam redes complexas na extração de características de imagens para posterior análise ou classificação. Segundo Costa et al.(5), dada uma imagem é possível modelá-la como uma rede, extrair características topológicas e, utilizando-se dessas medidas, construir o classificador de- 
sejado. Utilizando tal premissa os trabalhos de (7-10) desenvolvem os primeiros estudos nessa direção.

Os resultados alcançados por esses trabalhos sinalizam a existência de uma linha de pesquisa nova, promissora e com amplo espaço para desenvolvimento. Esse trabalho objetiva, portanto, investigar mais a fundo o potencial das redes em análise de imagem. Diversos aspectos podem ser investigados como, por exemplo, novas formas de modelar uma imagem como uma rede complexa ou utilização de diferentes características topológicas. Tais variações podem apresentar ótimos resultados, em especial em operações de reconhecimento de padrões.

Como forma de verificar o potencial das técnicas desenvolvidas, foi selecionado um grande desafio na área de visão computacional: identificação vegetal por meio de análise foliar. A identificação vegetal é uma importante tarefa em vários campos de pesquisa como biodiversidade, ecologia, botânica, farmacologia entre outros.

Neste contexto, os herbários vegetais são ferramentas imprescindíveis no trabalho dos taxonomistas na identificação de espécies arbóreas. Estes grandes bancos de dados naturais têm por objetivo concentrar todas as espécies coletadas na natureza, bem como suas características em um único local, como forma de facilitar a análise e pesquisa. Contudo, apesar da existência dos herbários e da alta tecnologia hoje existente, todo o trabalho de identificação e caracterização continua sendo realizado manualmente. Neste âmbito o uso de métodos de visão artificial e modelos matemáticos pode permitir o desenvolvimento de técnicas de aferição e extração de informações de forma automatizada, contribuindo para uma análise mais criteriosa da morfologia, anatomia e até mesmo fisiologia do vegetal.

Nesse sentido o grupo de computação científica, coordenado pelo Prof. Dr. Odemir M. Bruno, vem desenvolvendo pesquisa nessa linha há mais de 10 anos. A análise de imagens de folhas é um desafio para a visão computacional uma vez que existe uma grande variação intra-classes, mesmo para as amostras colhidas da mesma planta e, por outro lado, apresenta similaridades entre diferentes espécies. Devido à dificuldade do problema, acredita-se que ele é um ótimo mecanismo para avaliar os métodos baseados em redes complexas desenvolvidos e confrontá-los com os existentes na literatura.

\subsection{Objetivos}

Visando explorar essa nova área de pesquisa, esse trabalho objetiva o estudo e desenvolvimento de novos métodos baseados na teoria de redes complexas para visão computacional, processamento de imagens e análise de imagens, em especial métodos que utilizam carac- 
terísticas topológicas das redes para tal.

As atividades de pesquisa (no tangente à visão computacional e redes complexas) estão concentradas em basicamente em dois aspectos: (1) métodos para modelar imagens como uma rede complexa (e.g. os vértices são formados por elementos de uma imagem e arcos representam relações entre tais elementos); (2) desenvolvimento de técnicas de reconhecimento de padrões/análise de imagens baseadas em redes (onde se utiliza aspectos topológicos da rede como características). No aspecto biológico pretende-se utilizar tais métodos em um estudo de caso para identificação foliar (i.e. taxonomia vegetal através de folhas).

\subsection{Principais contribuições}

No decorrer desse trabalho são relatadas diversas contribuições nas áreas de computação, física e biologia. A principal delas é a exploração uma nova área de aplicação da teoria das redes complexas: a visão computacional. As redes complexas vêm sendo utilizadas em larga escala na análise de outros problemas do mundo real, porém em processamento de imagens sua aplicabilidade ainda é reduzida. Este trabalho traz justamente algumas propostas de como fazer uso dessa teoria na solução de problemas de visão computacional.

Nesse sentido são propostos aqui novos métodos para análise de textura, contorno, cor e esqueletos. Na análise de textura especial atenção deve ser devotada aos métodos chamados de PAG lattice completo e CAG que resultaram em artigos na Information Science (11), Journal of Physics (12) e Lecture Notes in Computer Science (13).

Em análise de textura, além dos resultados mais recentes aqui apresentados, o destaque deve ser dado ao método de aPAG completo, que resultou em artigo publicado na Pattern Recognition (14).

A análise de esqueletos também é outra área que teve resultados interessantes, tendo um artigo curto publicado no Journal of Physics (15).

Além dos métodos de análise de imagens uma taxonomia das diversas formas de se modelar uma imagem como grafo é proposta. Tal taxonomia é importante, pois também permite a implementação, síntese e classificação de modelos análogos utilizados em outras áreas da visão computacional (e.g. segmentação de imagens).

Para a biologia a principal contribuição é a proposta de um método alternativo para solução de problema prático da biologia: a identificação vegetal. Uma extensa revisão dos métodos automatizados de análise foliar é realizada ao longo do texto mostrando o atual interesse da 
comunidade científica nessa área de pesquisa e observando-se que não há na literatura uma solução única ou adequada ao problema. Nesse sentido o ImageCLEF (concurso internacional de recuperação de imagens por conteúdo) vêm abrindo nos últimos 2 anos uma área dedicada somente ao reconhecimento de espécies baseado em análise foliar. Utilizando os métodos de análise de imagens por redes complexas aqui apresentados uma proposta de solução foi enviada ao ImageCLEF, obtendo o primeiro e terceiro melhor resultado nos anos de 2011 e 2012 respectivamente $(16,17)$.

\subsection{Organização}

O presente trabalho encontra-se divido em mais 6 capítulos.

A seguir no Capítulo 2 apresenta-se a teoria dos grafos e redes complexas, modelos básicos, medidas e formas de análise das redes. Tal capítulo, além de introdutório, tem a intenção de elucidar o leitor no processo de extração de características de redes complexas.

O Capítulo 3 apresenta um esquema geral de modelagem de imagens como grafos bem como os trabalhos de processamento de imagens que utilizam tais modelos.

O Capítulo 4 apresenta, com base nas regras gerais apresentadas na seção anterior, os modelos específicos propostos para análise de textura, contorno, cor e esqueletos. A análise dos parâmetros envolvidos em cada modelo é realizada de forma conjunta com sua apresentação.

A avaliação desses modelos em termos comparativos com outros métodos da literatura, bem como suas propriedades é realizada no Capítulo 5.

O potencial dos métodos desenvolvidos é por fim verificado no Capítulo 6 com aplicação desses no problema de identificação vegetal por meio de análise foliar.

Por fim o Capítulo 7 apresenta as conclusões, contribuições e trabalhos futuros sugeridos. 


\section{CAPÍTULO 2}

\section{Teoria dos grafos e redes complexas}

Existem vários marcos históricos para o estudo das Redes Complexas, cujos primeiros fundamentos se baseiam na origem da Teoria dos Grafos. Segundo Biggs et al. (18) o artigo de Euler (19), em 1736, sobre o problema das sete pontes de Königsberg, é considerado o primeiro resultado da teoria dos grafos. A questão era saber se era possível atravessar as sete pontes da cidade sem passar duas vezes pela mesma ponte, o que Euler provou ser impossível, criando uma regra para aplicar a qualquer rede de pontes de qualquer cidade.

As redes complexas ( $R C$ ), por outro lado, tem como principais marcos aos trabalhos de Erdös e Rényi (1), Milgram (2), Watts e Strogatz (3) e Barabási e Albert (4). Erdös e Rényi (1) iniciaram em 1960 o estudo dos grafos aleatórios e, através de métodos probabilísticos, estudaram as propriedades dos grafos em função do crescimento de ligações entre vértices. Bem mais tarde, em 1998 Watts e Strogatz (3) realizaram um descoberta surpreendente baseada no trabalho de Milgram (2) de 1967. O experimento de Milgram (2) consistia em enviar aleatoriamente cartas entre cidadãos americanos. Se a pessoa que estivesse com a carta não conhecesse o destinatário ela deveria reenviar a carta a um amigo que teria chance maior de conhecê-lo. Ao repassar a carta, a pessoa deveria colocar seu nome na mesma. Ao todo 160 cartas e curiosamente Milgram notou que, em média, cada carta passava por seis pessoas antes de chegar ao destinatário. Tal resultado ficou conhecido como seis graus de separação ou efeito pequeno mundo. Um ano depois Barabási e Albert (4) publicaram um artigo com a proposta de um modelo genérico de construção de redes, semelhante à estrutura encontrada em redes genéricas ou redes da internet. Estas redes foram chamadas de redes livres de escala.

De fato a teoria de redes usa o formalismo matemático da teoria dos grafos, porém em redes complexas geralmente são utilizados métodos estatísticos para se caracterizar a estrutura de conexões da rede e/ou são empregadas ferramentas e métodos da mecânica estatística para criar modelos e analisar a estrutura e dinâmica das redes.

Nesse trabalho de análise de imagens especificamente, quando se faz menção a um método 
baseado em teoria das redes complexas, logo se deve interpretar que tal método possui um processo geral que é imagem $\rightarrow$ modelo(grafo) $\rightarrow$ extração de características via medidas estatísticas. Ou seja, dado um grafo extraem-se medidas deste. Já quando se faz menção a um método baseado na teoria dos grafos deve-se interpretar que tal método possui um processo do tipo imagem $\rightarrow$ modelo(grafo) $\rightarrow$ transformação do modelo. Ou seja, dado um grafo outro grafo(s) ou subgrafo(s) cujos nós representam alguma propriedade da imagem (e.g. regiões) é obtido. Logo se percebe que a diferença básica entre redes complexas em imagens, e grafos em imagens, está no uso ou não de medidas estatísticas.

Embora os grafos e redes complexas sejam de diferentes origens históricas e possuam essa sutil diferença conceitual, os grafos e as redes complexas muitas vezes são usados como sinônimos em muitos trabalhos da literatura.

As próximas seções desse capítulo serão devotadas primeiro à formalização dos conceitos básicos de grafos/redes e apresentação resumida dos modelos clássicos. Em seguida são expostas as medidas estatísticas de redes utilizadas no desenvolvimento desse trabalho, bem como as diferentes formas de análise de redes complexas.

\subsection{Conceitos básicos}

Redes complexas são descritas por um conjunto de vértices (nós) que estão ligados por arestas. Essas redes podem ser estáticas, quando não há variação no número de vértices, arestas ou mesmo na configuração das ligações; ou dinâmicas, sendo que, nesse caso é possível modelar o seu crescimento pela análise da variação da sua estrutura no tempo. Embora as redes reais sejam dinâmicas, elas podem ser analisadas como estáticas dentro de um intervalo de tempo em que as variações são inexistentes ou pouco importantes (20).

Matematicamente uma rede ou grafo é uma estrutura $G(V, E)$, onde $V=v_{1}, v_{2}, \ldots, v_{n}$ é um conjunto não-vazio de nós (vértices) $v_{i}$ e $E=e_{1}, e_{2}, \ldots, e_{m}$ é um conjunto de arcos (arestas) que conectam dois vértices.

Computacionalmente uma rede $G$ com $n$ vértices pode ser representada por uma matriz de adjacência $A$ de $n x n$ :

$$
a_{i j}=\left\{\begin{array}{l}
1, \text { se }\{v, u\} \in E, \\
0, \text { caso contrario. }
\end{array}\right.
$$


De forma geral o valor $a_{i j}$ guarda informações sobre como os vértices $v_{i}$ e $v_{j}$ estão relacionados (isto é, informações se há ou não adjacência de $v_{i}$ e $v_{j}$ ). Chamamos este grafo de grafo binário.

Um grafo também pode ser representado por uma matriz de pesos $W$ de $n x n$ (grafo com pesos), onde cada aresta possui um peso $w_{i j}$ associado, descrevendo alguma característica inerente à aresta. A obtenção da contraparte binária $A$ de um grafo com pesos $W$ é realizável através de uma aplicação de uma função de limiar ou binarização. Essa operação é aplicada a cada elemento da matriz de pesos $W$, obtendo uma matriz de adjacência $A$ na forma:

$$
A=\left\{\begin{array}{l}
a_{i j}=1, \text { se } w_{i j} \neq 0 \\
a_{i j}=0, \text { caso contrário }
\end{array}\right.
$$

O resultante da operação de binarização é um grafo que indica apenas a existência de uma aresta entre dois vértices, sem qualquer informação deste.

Um grafo direcionado, ou dígrafo, é um grafo cujas arestas possuem direção, ou seja, $a_{i j}$ não é necessariamente igual a $a_{j i}$. A contraparte não direcionada de um dígrafo por ser obtida por uma operação de simetria. Seu resultante matemático é uma matriz quadrada de ordem $n$, que satisfaz $A^{t}=A$. É um processo de simplificação muito útil

Um laço é uma aresta cujas terminações estão no mesmo vértice. Chamamos de arestas paralelas duas arestas ligando os mesmos vértices. Um grafo simples é um grafo sem laços nem arestas paralelas.

O número de vértices $n=|V|$ é chamado ordem do grafo e o número de arestas $m=|E|$ é chamado de tamanho do grafo. Definimos como densidade do grafo $G(V, E)$ como sendo a razão do numero de arestas existentes com seu máximo número possível,

$$
\delta=\frac{m}{\left(\frac{n}{2}\right)}
$$

Um grafo com densidade 1 é chamado de completo. Um grafo é planar se este pode ser representado em um plano sem que nenhuma de suas arestas se cruzem.

Se $i, j \in E$, dizemos que $i$ é um vizinho de $j$ (também chamado de vértice adjacente). O conjunto de vizinhos de um dado vértice $i$ é chamado de vizinhança de $i$ e é denotado por $\Gamma(i)$.

O grau $k_{i}$ de um nó $i$ é o número de arestas conectadas a esse nó, ou o número de vizinhos 
$|\Gamma(i)|$ do mesmo:

$$
k_{i}=\sum_{j} a_{i j}
$$

Para grafos com peso a definição de grau apresentada acima também pode ser utilizada, porém outra medida chama de força $s_{i}$ do nó $i$ pode ser definida como a soma dos pesos $w_{i} j$ das arestas conectadas a esse nó:

$$
k_{i}^{w}=\sum_{j} w_{i j}
$$

Um grafo é regular se todos os seus vértices possuem o mesmo grau. Se o conjunto de arestas $E$ for vazio então este é um grafo nulo.

Um caminho entre os vértices $i$ e $j$ é uma sequencia de arestas iniciando do vértice $i$ e terminando no vértice $j$. Se um dado caminho existe entre $i$ e $j$ esses são ditos conectados. $\mathrm{O}$ caminho é dito simples se nenhum vértice é repetido.

O comprimento do caminho é o numero de vértices que o compõe, e a distância entre $i$ e $j$ é o comprimento da distância mínima conectando-os, também chamado de distância geodésica $d_{i j}$.

$$
d_{i j}=\sum_{a_{u v} \in g i \leftrightarrow j} a_{u v}
$$

onde $g i \leftrightarrow j$ é o menor caminho entre $i$ e $j$. Note que $d_{i j}=\infty$ para todos os pares $i, j$ não conectados e a distancia de um vértice para ele mesmo é zero (i.e. o caminho de um vértice para ele mesmo é uma sequencia vazia de arestas). A excentricidade $e_{i}$ de um vértice é dada pela maior distância geodésica deste para qualquer outro vértice.

O grafo é conectado se existe caminhos entre todos os pares de vértices. Se algum vértice não pode ser alcançado por outros o grafo é desconectado. O número mínimo de arestas que devem ser removidas para tornar um grafo desconexo é chamado de conjunto de corte do grafo.

Vértices com $k_{i}=0$ são chamados de vértices isolados e para $k_{i}=1$ de vértice-pendente. Vértices que estão associados com um grande número de outros vértices são chamados hubs. 
Um ciclo é um caminho simples que inicia e termina no mesmo vértice. Grafos que não contém ciclos são chamados de acíclicos. Caso seja acíclico, mas não conexo, ele é dito uma floresta. Caso seja acíclico mas conexo é chamado de árvore.

Um caminho Euleriano em um grafo $G$ é um caminho que usa todas as arestas de $E$ exatamente uma vez. Um caminho Hamiltoniano é um ciclo que contém todos os vértices do grafo. Para um caminho Hamiltoniano de peso mínimo dá-se o nome de problema do caixeiro viajante.

A uma partição dos vértices $V$ de $G(V, E)$ em dois conjuntos não-vazios $S$ e $\bar{S}$ damos o nome de corte. O conjunto de corte corresponde às arestas que conectam os vértices de $S$ em $\bar{S}$ e o tamanho do corte é o número de arestas presentes no conjunto de corte:

$$
c(S, \bar{S})=|\{\{v, u\} \in E \mid u \in S, v \in \bar{S}\}|
$$

Para grafos valorados o tamanho do corte é geralmente redefinido como a soma dos pesos das arestas que conectam os vértices de $S$ em $\bar{S}$. O tamanho de corte mínimo entre $S$ em $\bar{S}$ é denominado corte mínimo. O fluxo máximo $f(S, \bar{S})$ entre $S$ e $\bar{S}$ é equivalente ao corte mínimo que separa $S$ e $S, \bar{S}$.

Um grafo hierárquico $G_{i}^{\prime}$ pode ser obtido considerando os vértices que estão a uma distância $L$ do vértice. Consiste em um grafo com mesmo número de vértices, onde uma aresta é incorporada entre os vértices $i$ e $j$ se existir um caminho de tamanho $L$ entre esses nós no grafo original.

Um subgrafo $G^{\prime}=\left(V^{\prime}, E^{\prime}\right)$ de $G=(V, E)$ é composto por um conjunto de vértices $V^{\prime} \subseteq V$ e um conjunto de arestas $E^{\prime} \subseteq E$ de tal forma que $\{v, u\} \in E^{\prime}$ implica que $v, u \in V^{\prime}$. O grafo $G$ é um super grafo de $G^{\prime}$.

Um subgrafo conectado acíclico que inclui todos os vértices de $G$ é chamado de árvore geradora. A árvore geradora possui, necessariamente, exatamente $n-1$ arestas. Para grafos valorados, a árvore geradora com menor peso total é chamada de árvore geradora mínima. Um grafo $G$ pode ter diversas árvores geradoras mínimas.

Um subgrafo induzido de $G=(V, E)$ é um grafo com um conjunto de vértices $V^{\prime} \subseteq V$ e com um conjunto de arestas $E^{\prime}$ que inclui todas as arestas $\{v, u\}$ em $E$ que conectam todos os vértices $v$ e $u$ do conjunto $V^{\prime}$ : 


$$
E^{\prime}=\left\{\{v, u\} \mid v \in V^{\prime}, u \in V^{\prime},\{v, u\} \in E\right\}
$$

Um subgrafo induzido completo é chamado de clique (i.e. todos os nós do subgrafo são mutualmente adjacentes). Um maximal clique é um clique que nenhum outro vértice pode ser adicionado. Um maximum clique é um clique que possui a máxima cardinalidade. Um subgrafo induzido que possui um conjunto de arestas vazio é chamado de conjunto independente.

Dois grafos $G=(V, E)$ e $G^{\prime}=\left(V^{\prime}, E^{\prime}\right)$ são chamados isoformos se existe uma função bijetiva (um para um) mapeando $f: V \rightarrow V^{\prime}$ para cada aresta $\{v, u\} \in E$ se, e somente se, $\{f(v), f(u)\} \in E^{\prime}$.

\subsection{Modelos clássicos de redes complexas}

A teoria das redes complexas tem se consolidado nos últimos anos por seu caráter interdisciplinar, relativa simplicidade conceitual e ampla aplicabilidade na modelagem de sistemas reais, inclusive com algumas aplicações em imagens (6). Uma das principais contribuições dessa área de pesquisa é a descoberta do fato de que muitos sistemas reais adequam-se basicamente a um dos 3 modelos clássicos de redes complexas. São eles:

\subsubsection{Rede Aleatória}

Do inglês Random Graph, a rede aleatória, desenvolvida por Rapoport (21) e, de forma independente por Erdös e Rényi (1), pode ser considerada o modelo mais básico de redes complexas. Este modelo, também conhecido como grafo de Erdös e Rényi (ER), é definido por um número de vértices $N$ e com uma probabilidade $p$ de que exista uma aresta entre dois vértices quaisquer. $\mathrm{O}$ grau esperado de um vértice qualquer é:

$$
k_{i}=p(N-1)
$$

\subsubsection{Rede Pequeno Mundo}

Do inglês Small-world network, foi proposta por Watts e Strogatz (3), este modelo apresenta (1) a propriedade mundo pequeno, i.e., todos os vértices podem ser alcançados por qualquer outro através de um número pequeno de arestas (caminho médio pequeno) e (2) apresenta um número alto de laços de tamanho três, i.e., se o vértice $i$ é conectado ao vértice 
$j$ e $k$, então há uma alta probabilidade dos vértices $j$ e $k$ também serem conectados (alto coeficiente de aglomeração).

Para construir uma rede pequeno mundo, segundo modelo de (3), inicia-se um grafo regular com $N$ vértices, cada um conectado a $\kappa$ vizinhos, onde $N>>\kappa>>\ln (N)>>1$. Cada vértice então é randomicamente redirecionado com probabilidade $p$. Quando $p=0$ temos um grafo regular, para $p=1$ temos um grafo aleatório. Watts e Strogatz (3) mostraram que, para um valor intermediário de $p$, temos a formação de uma rede com caminho médio pequeno e alto coeficiente de aglomeração.

\subsubsection{Rede Livre de Escala}

Do inglês Scale-free networks, este tipo de rede possui alguns vértices altamente conectados (hubs) enquanto os demais possuem poucas conexões (4). A distribuição dos graus segue a lei de potência:

$$
P(k) \approx k^{-\gamma}
$$

A rede livre de escala é criada inicialmente com $m_{0}$ vértices, e a cada passo de tempo, um vértice com um número $m$ de arestas é adicionado à rede. Essas arestas se conectam preferencialmente aos vértices da rede com maior grau uma vez que os vértices de maior grau possuem uma grande probabilidade de receber novas arestas.

\subsection{Medidas estatísticas}

As redes complexas podem apresentar diferentes topologias dependendo dos mecanismos de sua modelagem. Para quantificar a estrutura das ligações diversas medidas tem sido propostas (5). Através dessas medidas é que as redes podem ser analisadas, caracterizadas e classificadas (Figura 2.1).

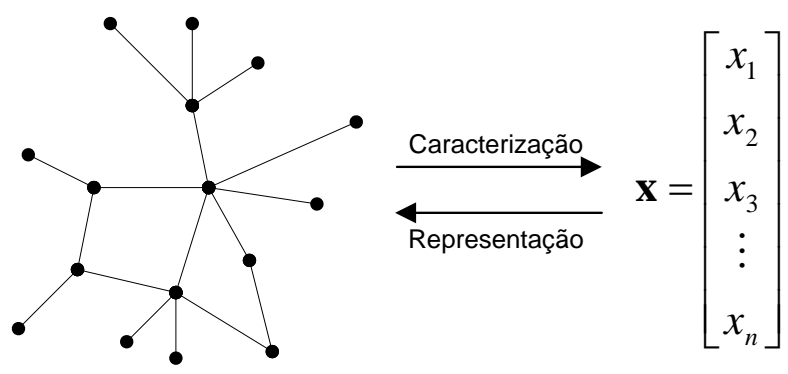

Figura 2.1 - Caracterização de redes complexas. Adaptado de (5). 
A classificação de redes pode ser realizada agrupando-se em uma mesma classe as redes cujas medidas estruturais forneçam valores estatisticamente semelhantes. A escolha das medidas é, portanto, fundamental, uma vez que a utilização de medidas pouco discriminativas ou redundantes podem gerar classificações equivocadas.

Embora a maioria dos modelos de redes complexas apresente-se na forma de grafos direcionados com peso, optou-se no decorrer desse trabalho pela utilização de medidas apenas para grafos não direcionados. É possível, no entanto, partindo do modelo mais geral (i.e. dígrafos) obter sua contraparte não direcionada pela simples aplicação da operação de simetria apresentadas anteriormente.

De forma análoga a operação de binarização pode ser empregada para obtenção de grafos binários quando esses se fizerem necessários para o cálculo das medidas a seguir apresentadas.

\subsubsection{Grau e Conectividade}

Uma medida simples associada a rede é a medida de densidade da rede, definida por:

$$
\delta=\frac{m}{\left(\frac{n}{2}\right)}
$$

A densidade informa o quão conectada está a rede, ou seja, se ela se aproxima de um grafo completo ou se encontra-se esparsamente distribuída.

Outra medida relacionada à conectividade é grau dos vértices. Baseado no grau dos vértices e sua distribuição $P(k)$ é possível derivar outras medidas da rede. Uma das mais simples é o grau médio $k_{\mu}$ que é dado por:

$$
k_{\mu}=\frac{1}{n} \sum_{i} k_{i}
$$

que por conseguinte permite o calculo da força média $k_{\mu}^{w}$ da rede, dada pela média das forças individuais de cada nó:

$$
k_{\mu}^{w}=\frac{1}{n} \sum_{i} k_{i}^{w}
$$

A energia $k_{e}$, entropia $k_{h}$ e contraste $k_{c}$ dos graus, que medem a heterogeneidade da rede, são outras medidas estatísticas obtidas a partir da distribuição $P(k)$ : 


$$
\begin{gathered}
k_{e}=\sum_{i} P\left(k_{i}\right)^{2} \\
k_{h}=-\sum_{i} P\left(k_{i}\right) \log P\left(k_{i}\right) \\
k_{c}=\sum_{i} P\left(k_{i}\right) k_{i}^{2}
\end{gathered}
$$

O grau máximo também é uma das medidas mais simples utilizadas para caracterizar uma rede:

$$
k_{\kappa}=\max _{i} k_{i}
$$

Outra medida interessante é verificar as correlações entre os graus de diferentes vértices (grau conjunto). A abordagem mais natural para realizar tal medida é considerar a correlação entre dois vértices conectados por uma aresta. Essa correlação pode ser expressa pela distribuição probabilidade condicional $P\left(k^{\prime} \mid k\right)$, i.e. a probabilidade de um nó arbitrário de grau $k$ estar conectado com um nó de grau $k^{\prime}$. Para tal probabilidade, considerando $k=k^{\prime}$ podemos obter a média, energia e entropia da seguinte forma:

$$
\begin{gathered}
j d_{\mu}=\frac{1}{n} \sum_{i} P\left(k^{\prime}, k\right)_{i} \\
j d_{e}=\sum_{i} P\left(k^{\prime}, k\right)_{i}^{2} \\
j d_{h}=-\sum_{i} P\left(k^{\prime}, k\right)_{i} \log P\left(k^{\prime}, k\right)_{i}
\end{gathered}
$$

\subsubsection{Caminhos e distância}

As medidas de caminho e distância são importantes por caracterizar a estrutura interna das redes. Uma das mais simples é o diâmetro da rede, dada pela máxima excentricidade de qualquer vértice $i$ : 


$$
D=\max _{i} e_{i}
$$

Outra medida para quantificar as distâncias existentes na rede é distância geodésica média $\ell$ dada por:

$$
\ell=\frac{1}{N(N-1)} \sum_{i \neq j} d_{i j}
$$

Como o menor caminho de dois vértices desconectados é $d_{i j}=\infty$, apenas os vértices conectados são incluídos nessa definição acima. Outra medida relacionada é a eficiência global dada por:

$$
E=\frac{1}{N(N-1)} \sum_{i \neq j} \frac{1}{d_{i j}}
$$

onde a soma considera todos os pares de vértices. Essa medida quantifica a eficiência da rede em enviar informações entre os vértices, assumindo que a eficiência em se enviar informação entre dois vértices $i$ e $j$ é proporcional à sua distância.

\subsubsection{Vulnerabilidade}

Em redes de infraestrutura (como a Internet), tais hubs são ditos críticos, pois se desconectados levam a um grande impacto na rede. Assim, outra característica interessante é medir a vulnerabilidade da rede olhando para os vértices mais vulneráveis. Se nós associarmos a performance da rede à sua eficiência global, a vulnerabilidade de um vértice pode ser definida a partir da queda de desempenho quando o vértice e todas as suas arestas são removidos da rede:

$$
v_{i}=\frac{E-E_{i}}{E}
$$

onde $E$ é a eficiência global da rede original e $E_{i}$ é a eficiência após remover o vértice $i$ e todas as suas arestas. A vulnerabilidade máxima da rede é uma medida bastante interessante dada por:

$$
V=\max _{i} v_{i}
$$




\subsubsection{Centralidade}

Com relação aos caminhos existentes na rede é possível quantificar a importância de um vértice em termos de sua centralidade, ou seja, o quão importante é esse vértice na manutenção de todos os caminhos mínimos existentes na rede. Tal medida é definida por:

$$
b_{i}=\sum_{u j} \frac{\sigma(u, i, j)}{\sigma(u, j)}
$$

onde $\sigma(u, i, j)$ é o número de caminhos mínimos entre os vértices $u$ e $j$ que passam pelo vértice $i$ e $\sigma(u, j)$ é o número total de caminhos mínimos existentes na rede para todos os pares de vértices $u$ e $j$. Pela distribuição obtida de $b_{i}$ podemos obter a centralidade média e máxima da rede na forma:

$$
\begin{aligned}
& b e_{\mu}=\frac{1}{n} \sum_{i} b_{i} \\
& b e_{\kappa}=\max _{i} b_{i}
\end{aligned}
$$

\subsubsection{Aglomeração e ciclos}

A quantidade de ciclos com comprimento 3 é uma característica muito investigada em redes. O chamado coeficiente de aglomeração é probabilidade média de dois vértices vizinhos de um outro mesmo vértice sejam, eles próprios adjacentes:

$$
C=\frac{3 N_{\Delta}}{N_{3}}
$$

onde $N_{\Delta}$ é o número de triângulos na rede e $N_{3}$ é o número de triplas conectadas. Um triângulo é um conjunto de três vértices com arestas entre cada par destes. Uma tripla conectada é um conjunto de três vértices onde cada vértice pode ser alcançado por outro (direta ou indiretamente). Assim definidos:

$$
\begin{gathered}
N_{\Delta}=\sum_{i>j>k} a_{i j} a_{i k} a_{j k} \\
N_{3}=\sum_{i>j>k}\left(a_{i j} a_{i k}+a_{j i} a_{j k}+a_{k i} a_{k j}\right)
\end{gathered}
$$


Outra característica interessante é medir o quão cíclica uma rede é. O coeficiente de ciclos de um vértice $i$ é dado por:

$$
\theta_{i}=\frac{2}{k_{i}\left(k_{i}-1\right)} \sum_{k>j} \frac{1}{S_{i j k}} a_{i j} a_{i k}
$$

onde $S_{i j k}$ é o tamanho do menor ciclo que passa pelos vértices $i, j$ e $k$. Note que se os vértices $j$ e $k$ foram conectados, o menor ciclo é um triangulo e $S_{i j k}=3$. Se não há conexão entre $i, j$ e $k$ então $S_{i j k}=\infty$. Logo o coeficiente de ciclos da rede é uma média do coeficiente de ciclos de todos os vértices:

$$
\theta=\frac{1}{N} \sum_{i} \theta_{i}
$$

\subsubsection{Complexidade}

A complexidade trata-se de um termo rico de significados e portanto ambíguo. Em termos geométricos determinados tipos de redes os vértices possuem uma posição espacial definida pelas propriedades reais do sistema. Analisar a distribuição espacial desses vértices remete a uma medida relacionada à complexidade do modelo, ou seja, procura-se mensurar o quão caótico ou organizados estão os objetos representados pelos vértices. Interpretação análoga podemos realizar em termos da conectividade da rede. A complexidade nesse caso mede nível de organização das conexões da rede.

A Teoria dos Fractais (22) é um dos métodos que permite tal tipo de análise. Em termos geométricos, dada uma nuvem de pontos (i.e. vértices/objetos com posições espaciais bi ou tri-dimensionais definidas) é possível determinar a dimensão fractal desse conjunto pela utilização de dimensão fractal volumétrica (23, 24). O mesmo método, se aplicado à matriz de adjacência da rede, pode mensurar de forma indireta a complexidade em termos de sua conectividade(12). Essa matriz de adjacência, no entanto não pode ser trivial (e.g. grafo completo) e deve possuir uma relação de ordem nos nós especificada pelo problema proposto.

De forma geral a dimensão fractal pelo método acima é dada pela sequinte equação:

$$
D=2-\lim _{r \rightarrow 0} \frac{\log (A(r))}{\log (r)}
$$

onde $A(r)$ é a área ocupada pelos objetos quando dilatados por um raio $r$. Uma versão volumétrica do método é dada por: 


$$
D=3-\lim _{r \rightarrow 0} \frac{\log V(r)}{\log (r)}
$$

As características fractais são fornecidas pela lei de potência da função $u$ na forma:

$$
u: \log (r) \rightarrow \log (A(r))
$$

ou seu equivalente 3-dimensional. Para caracterizar as redes a função $u$ pode ser utilizada diretamente. Como o cálculo das dilatações se dá no espaço discreto o vetor de características $\mathbf{x}$ fica composto pela área ou volume de todas as distâncias possíveis até um raio $r$.

\subsubsection{Resumo das medidas}

Considerando-se as medidas apresentadas acima 2 vetores de características pode ser compostos com objetivo de realizar análise das imagens via teoria das redes complexas. $\mathrm{O}$ primeiro deles é composto pela simples concatenação das medidas de grau e conectividade, caminhos e distância e aglomeração. A Tabela 2.1 apresenta um resumo das medidas dessas

\begin{tabular}{|c|c|c|c|}
\hline Medida & Simbolo & Equação & Referência \\
\hline Densidade & $\delta$ & 2.3 .1 & $(1)$ \\
\hline Grau médio & $k_{\mu}$ & 2.3 .2 & (2) \\
\hline Energia dos graus & $k_{e}$ & 2.3 .4 & (3) \\
\hline Entropia dos graus & $k_{h}$ & 2.3 .5 & (4) \\
\hline Contraste dos graus & $k_{c}$ & 2.3 .6 & (5) \\
\hline Grau máximo & $k_{\kappa}$ & 2.3 .7 & (6) \\
\hline Grau conjunto médio & $j d_{\mu}$ & 2.3 .8 & (7) \\
\hline Energia grau conjunto & $j d_{e}$ & 2.3 .9 & (8) \\
\hline Entropia grau conjunto & $j d_{h}$ & 2.3 .10 & (9) \\
\hline Diâmetro da rede & $D$ & 2.3 .11 & (10) \\
\hline Distância geodésica média & $\ell$ & 2.3 .12 & (11) \\
\hline Eficiência global & $E$ & 2.3 .13 & (12) \\
\hline Vulnerabilidade máxima & $V$ & 2.3 .15 & (13) \\
\hline Centralidade média & $b e_{\mu}$ & 2.3 .17 & (14) \\
\hline Centralidade máxima & $b e_{\kappa}$ & 2.3 .18 & (15) \\
\hline Coeficiente de aglomeração & $C$ & 2.3 .19 & (16) \\
\hline
\end{tabular}
medidas e seu número de referência utilizado no decorrer do texto:

Tabela 2.1 - Lista do primeiro conjunto de descritores utilizados.

O vetor de características fica então composto por 16 características da seguinte forma:

$$
\mathbf{x}=\left[\delta, k_{\mu}, k_{e}, k_{h}, k_{c}, k_{\kappa}, j d_{\mu}, j d_{e}, j d_{h}, D, \ell, E, V, b e_{\mu}, b e_{\kappa}, C\right]
$$


Um segundo vetor é composto exclusivamente pelas características de complexidade dadas pela função $u$, ficando assim composto:

$$
\mathbf{x}=[A(1), A(\sqrt{2}), A(2), \ldots, A(r)]
$$

\subsection{Análise de grafos}

A caracterização via medidas de redes complexas utilizando as medidas acima listadas podem ser obtidas de diferentes maneiras. A mais simples é a obtenção de forma direta, calculando tais medidas sem qualquer pré-processamento do grafo. Essa abordagem, porém, pode não apresentar propriedades suficientemente distintas para caracterização de tal rede. Pode-se, no entanto, obter tais medidas após determinadas transformações $t$ no grafo, concatena-las de forma a obter uma caracterização mais eficaz. Um exemplo de tal caracterização pode ser visto na Figura 2.2

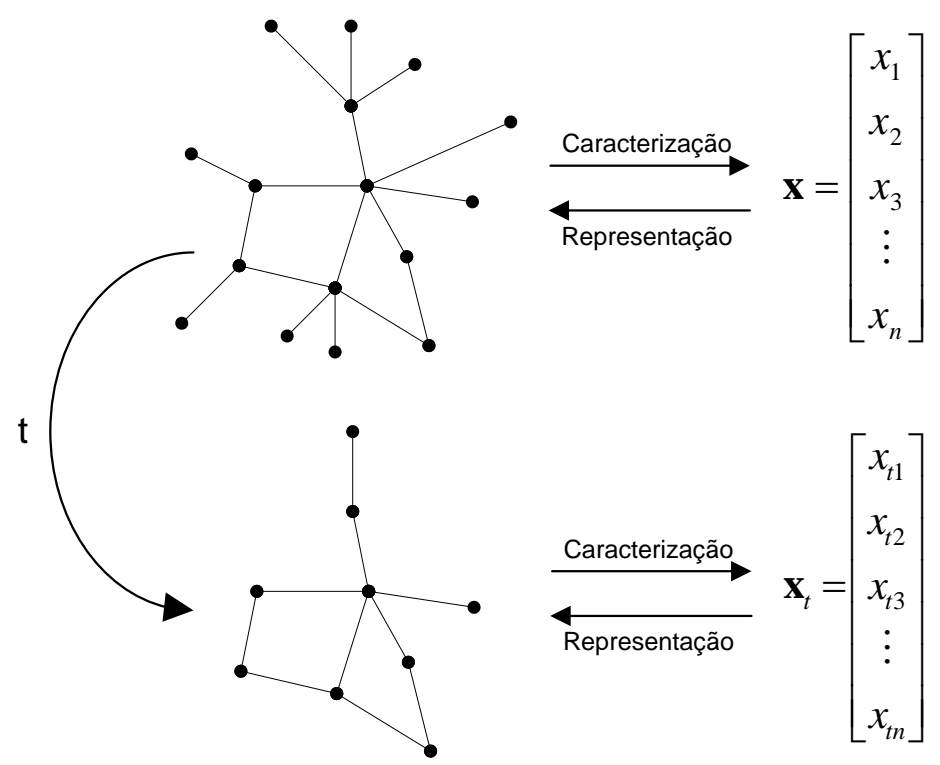

Figura 2.2 - Medidas adicionais da rede complexa podem ser obtidas após aplicação de uma transformação $t$ na rede original obtendo vetor de características complementar $\mathbf{x}_{t}$. Adaptado de (5)

Várias são as escolhas possíveis das transformações que podem ser realizadas sobre o grafo. As diferentes transformações nos chamamos de formas de análise. Nesse trabalho utilizaram-se as seguintes abordagens abaixo. 


\subsubsection{Análise direta}

Nessa forma de análise as medidas são extraídas diretamente do modelo obtido, sem qualquer processamento auxiliar. Tal tipo de abordagem só é possível quando o modelo proposto não apresenta comportamento trivial (e.g. grafo completo). Para análise direta os 2 vetores de características (Equações 2.3.27 e 2.3.28 podem ser obtidos.

\subsubsection{Análise de subgrafos}

Uma forma eficaz de análise de grafos é utilizar subgrafos derivados. Tais subgrafos podem conter características distintas entre si, facilitando o processo de caracterização. Há diversas formas de se realizar tal operação, uma das formas mais simples de se obter um subgrafo é pela aplicação de um limiar $t$ no conjunto de arestas $E$ de grafos valorados. De forma análoga diversos subgrafos podem ser obtidos por um conjunto de limiares constantes com incremento de $t$ na forma $T=\left[t_{1}, t_{2}, \ldots, t_{L}\right]$. Essa operação é aplicada a cada elemento da matriz de pesos $W$, obtendo uma matriz de pesos $W_{t}$ na forma:

$$
W_{t}=\left\{\begin{array}{l}
w_{i j}=w_{i j}, \text { se } w_{i j}>t_{i} \\
w_{i j}=0, \text { caso contrário }
\end{array}\right.
$$

Tal operação pode ser aplicada tanto a grafos direcionados e não direcionados. A Figura 2.3 mostra um exemplo de aplicação.

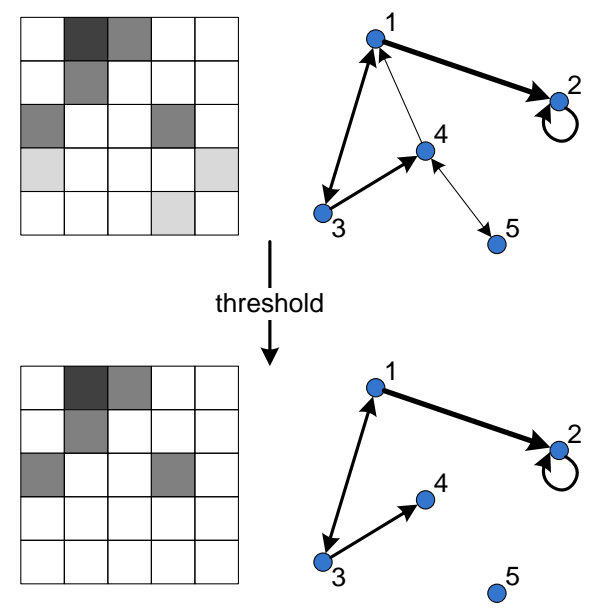

Figura 2.3 - Operação de limiarização no grafo. Observa-se que o subgrafo obtido, e sua contraparte matriz de adjacência, possui menos arestas que grafo original.

Para cada subgrafo obtido com limiar $t$ o vetor de características da Equação 2.3.27 é calculado e concatenado com os demais limiares. 
Por questões práticas na escolha do conjunto $T$ uma normalização da matriz $W$ é realizada na forma:

$$
\forall w_{i j}=\frac{w_{i j}}{\max _{w_{i j}}}
$$

Tal normalização garante que um mesmo conjunto de limiares irá gerar os mesmos efeitos em diferentes redes.

\subsubsection{Análise hierárquica}

A análise dos grafos hierárquicos correspondentes é outra possível maneira de obter uma caracterização mais eficaz. A obtenção de tal representação no entanto possui alto custo computacional (especialmente para valores elevados de $L$ ), uma vez que é necessário percorrer o grafo para cada nó e somar o peso das conexões entre $i$ e $j$. Há no entanto o conceito de L-expansion, utilizado em (7) que pode obter quantos caminhos há entre o nó $i$ e $j$ de tamanho $L$, bastando para isso uma multiplicação de matrizes do tipo:

$$
A_{t}=A^{2}
$$

Um exemplo de um grafo hierárquico de tamanho $L=2$ pode ser visto na Figura 2.4

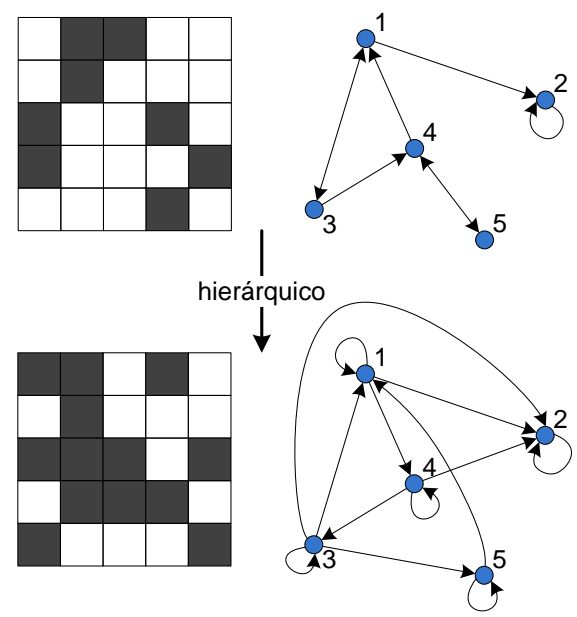

Figura 2.4 - Grafo hierárquico de tamanho $L=2$ derivado de seu original. $O$ grafo obtido demostra todos os caminhos de tamanho $L=2$ existentes.

Note que tal transformada só pode ser realizada sobre uma matriz de adjacência binária. É opcional realizar a remoção dos laços através da seguinte equação: 


$$
a_{i j}=\left\{\begin{array}{l}
a_{i j}=a_{i j}, \text { se } i \neq j \\
a_{i j}=0, \text { caso contrário }
\end{array}\right.
$$

Assim como na análise por subgrafos para cada $A_{t}$ o vetor de características da Equação 2.3.27 é calculado.

\subsubsection{Análise OPF}

Uma operação muito utilizada em grafos/segmentação de imagens (25) é a transformada de floresta de caminhos ótimos ou OPF (do inglês Optimum-Path Forest). Nesse processo alguns vértices são escolhidos como sementes do grafo, e a OPF é então dada pelo simples cálculo dos caminhos mínimos entre os vértices restantes e essas sementes (Figura 2.5), sendo o grafo resultante uma floresta de caminhos ótimos. A adjacência nesse caso não depende apenas da medida de distância imediata entre o pixel e seu vizinho, mas sim dos caminhos intermediários formados, ou seja, é impossível saber se um vértice será adjacente a outro sem antes conhecer os caminhos que levam às sementes.

Há várias formas de se escolher tais sementes: aleatoriamente, através de algum procedimento matemático heurístico ou manualmente. No âmbito deste trabalho utilizou-se apenas a forma aleatória onde grafos diversos são obtidos por diferentes conjuntos de sementes com $s$ sementes cada. Fixou-se de forma empírica em 10 o número de conjuntos e em $s=n * 0.01$ o número de sementes, gerando assim 10 manifestações diferentes das redes analisadas. Para tal transformada ser efetiva na análise de diferentes redes é necessário garantir que tais redes possuam vértices 'correspondentes', ou seja, um vértice $i$ de uma rede deve representar o mesmo objeto $i$ em outra rede.

Tal transformada é obtida através de uma adaptação do algoritmo de Dijkstra (detalhes em (25)). A Figura 2.5 demonstra um exemplo de tal operação.

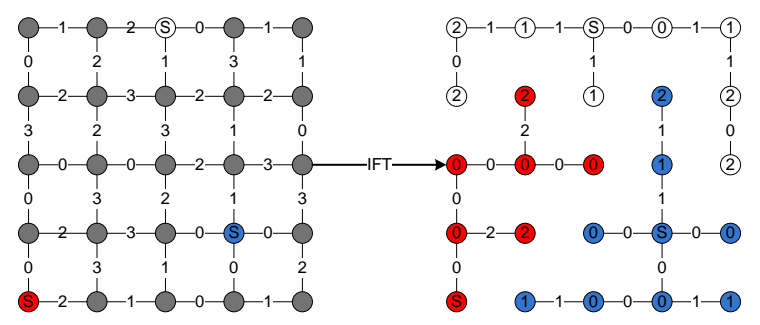

Figura 2.5 - Operação de optimum-path forest aplicado sobre o grafo. No exemplo 3 vértices são escolhidos como sementes ( $S$ azul, $S$ branco, $S$ vermelho). O resultado é um grafo tripartido onde cada vértice conecta-se à semente mais próxima (optimum-path forest).

Assim como na análise por subgrafos para cada conjunto de sementes, e consequentemente 
cada novo grafo obtido, é caracterizado pelo conjunto de características da Equação 2.3.27. A OPF é chamada de IFT (do inglês Image Foresting Transform) quando o modelo de grafo obtida da imagem é uma lattice conectada (25). 


\section{CAPÍTULO 3}

\section{Grafos e redes complexas em imagens}

Esse capítulo apresenta uma proposta de taxonomia das diversas formas de modelagem de imagens por grafo. Essa visão geral generaliza a modelagem dos vértices e expõe algumas regras mais comuns na modelagem das arestas. Essa síntese é importante pois permite organizar os modelos que tem características comuns. Em sequência alguns métodos de processamento de imagens que utilizam modelagem imagem/grafo são apresentados.

\subsection{Modelagem de imagens por grafo}

Com fundamentos matemáticos bem definidos, os grafos podem ser utilizados para resolver um número muito grande de problemas que utilizam imagens. Basicamente o processo se resume a 1) modelar a imagem como um grafo, respeitando alguns parâmetros e restrições inerentes ao problema e então 2) utilizar técnicas de teoria dos grafos na solução de problemas específicos. Há dessa forma forte interdependência entre problema-modelagem-técnica de grafo. Tal interdependência apresenta soluções diversas, podendo o usuário iniciar pela escolha da modelagem ou pela escolha da técnica de teoria dos grafos a ser utilizada para resolver um determinado problema.

Há, portanto, duas formas de se apresentar os métodos de visão computacional baseados em grafos: 1) classificá-los segundo as técnicas de teoria dos grafos utilizadas, as modelagens aceitas e os problemas resolvidos; 2) classificá-los segundo o tipo de modelagem imagem-grafo empregada, apresentando a subsequente técnica de teoria dos grafo empregada, e o problema resolvido. A segunda abordagem parece ser mais intuitiva, pois é mais facilmente percebida ao longo dos trabalhos que as empregam.

A essência desta sessão é, portanto, mostrar as diferentes formas de representar uma imagem, ou qualquer informação dela derivada, em um grafo. Tais modelos serão posteriormente empregados na análise de imagens extração de características. Tal tarefa aqui é chamada 
de modelagem de imagens por grafo. Não é do escopo deste trabalho detalhar das técnicas de teoria dos grafos que são empregadas com outros objetivos (e.g. segmentação, correspondência), uma vez que estas estão bem documentadas na literatura e não fazem parte do objetivo principal desse trabalho.

O objetivo da modelagem de imagens por grafos (graph image modelling) é: dada uma imagem (ou uma informação dela derivada) representa-la através de um conjunto de vértices e arestas $G(V, E)$. Para tal é necessário definir o conjunto de vértices $V$ e arestas $E$ e suas respectivas propriedades.

\subsubsection{Vértices}

Um vértice pode representar desde estruturas primárias da imagem (e.g. o pixel), ou então estruturas de mais alto nível representadas por um conjunto de pixeis (e.g. objetos, elementos geométricos). Também é necessário definir se existirá um único tipo de vértice, representando um único tipo de informação, ou se haverá vértices com diferentes propriedades.

Seguindo uma definição de que cada vértice representa um subconjunto qualquer de pixeis, podemos chamar cada subconjunto de $S_{i}$. A coleção desses subconjuntos $S_{i}$ chamamos de conjunto universo $C$. Sejam $V$ e $C$ dois conjuntos, podemos afirmar sem perda de generalidade que existe uma função bijetiva $f$ de $C$ em $V$ tal que, para cada $S_{i} \in C$ existe um único $v_{i} \in V$. Essa função pode ser indicada por:

$$
f: C \rightarrow V
$$

onde $V=\left\{v_{1}, v_{2}, \ldots, v_{n}\right\}$ é um conjunto não-vazio de nós do grafo $G(V, E)$ e $C=$ $\left\{S_{1}, S_{2}, \ldots, S_{m}\right\}$ uma coleção de subconjuntos $S$ da imagem $I$. Em outras palavras, cada vértice pode representar um subconjunto qualquer de pixeis da imagem $I$, tais subconjuntos por sua vez podem representar um único pixel, objetos ou outras informações quaisquer da imagem. A definição dos subconjuntos $S_{i}$ é, portanto, o ponto central da modelagem.

De forma geral cada subconjunto de pixeis $S_{i}$, representado no grafo por um vértice $v_{i}$, possui duas propriedades fundamentais:

Quantidade de pixeis existentes em $\boldsymbol{S}_{\boldsymbol{i}}$ : Essa propriedade diz respeito ao número de pixeis contidos em cada subconjunto $S_{i}$. Tal propriedade pode assumir 4 diferentes estados: 
1. No primeiro caso cada subconjunto $S_{i}$, e consequentemente cada vértice $v_{i}$, representa um único pixel da imagem. Logo, a cardinalidade de todo conjunto $S_{i}$ é sempre unitária:

$$
\left|S_{i}\right|=1 \text {, para todo } S_{i} \in C
$$

2. No segundo caso um ou mais subconjuntos $S_{i}$ de $C$ podem conter mais de um pixel. Em outras palavras, existe um ou mais vértices $v_{i}$ em $V$ que representam um conjunto de pixeis. Logo a cardinalidade de $S_{i}$ pode ser definida por:

$$
\left|S_{i}\right|>1, \text { para algum } S_{i} \in C
$$

3. O inverso do segundo caso pode ocorrer quando um ou mais subconjuntos $S_{i}$ não contem nenhum pixel, ou seja $S_{i}=\oslash$. Isso pode ocorrer, por exemplo, quando um vértice representa um ponto de controle ou uma semente (seed), recurso muito utilizado em segmentações dirigidas. Esse terceiro caso tem como definição:

$$
\left|S_{i}\right|=0, \text { para algum } S_{i} \in C
$$

4. Um caso híbrido dos 2 anteriores também pode ocorrer. Nessa forma o conjunto $V$ pode conter diferentes vértices $v_{i}$ que representam simultaneamente zero ou mais pixeis da imagem.

Relação dos pixeis em $S_{i}$ : Segundo a primeira propriedade um subconjunto $S_{i}$ pode conter um ou mais pixeis. A relação desses pixeis representados pelo vértice $v_{i}$ dá origem a segunda propriedade. Essa relação pode assumir basicamente 2 diferentes estados:

1. O primeiro estado apresenta um restrição onde cada pixel contidos em $S_{i}$ deve possuir um outro pixel também em $S_{i}$ adjacente a ele na imagem $I$. Ou seja, tais pixeis devem formar uma região 4 ou 8-conectada na imagem. Assim cada vértice $v_{i}$ representa uma região conectada da imagem. A modelagem é definida por:

$$
\forall p \in S_{i} \exists q \in S_{i} \mid p \text { e } q \text { são adjacentes. }
$$

2. Caso a restrição apresentada acima não esteja presente um vértice $v_{i}$ pode representar um conjunto de pixeis arbitrário. Tal caso pode ocorrer por exemplo quando um vértice $v_{i}$ representa o conjunto de pixeis que possuem a mesma cor, mas que não necessariamente 
são conectados entre si. A modelagem é definida por:

$$
\exists p \in S_{i} \exists q \in S_{i} \mid p \text { e } q \text { não são adjacentes. }
$$

Além das propriedades individuais de cada subconjunto $S_{i}$ é necessário considerar as propriedades globais do conjunto universo $C$, são elas:

Quantidade dos pixeis representados em $C$ : A primeira propriedade do conjunto universo $C$ diz respeito à quantidade de pixeis da imagem que estão contidos em $C$. Tal propriedade pode assumir dois estados:

1. É quando todos os pixeis da imagem estão presentes em $C$, ou seja, o grafo representa a totalidade dos pixeis na forma:

$$
\bigcup_{S_{i} \in C} S_{i}=I
$$

2. É quanto apenas alguns pixeis estão presentes em $C$, ou seja, o grafo representa apenas uma parcela dos pixeis da imagem (e.g. bordas, esqueleto, contorno). Formalmente pode ser definido por:

$$
\bigcup_{S_{i} \in C} S_{i} \neq I
$$

Relação entre cada subconjunto $S_{i}$ de $C$ : A segunda propriedade do conjunto universo diz respeito à relação entre os pixeis representados pelos diferentes subconjuntos $S_{i}$. Aqui também dois diferentes estados podem existir:

1. A primeira relação é quando a interseção de todos os conjuntos $S_{i}$ é igual ao conjunto vazio. Ou seja, não há 2 vértices distintos representando um mesmo pixel da imagem. Tal relação pode ser definida por:

$$
\bigcap_{S_{i} \in C} S_{i}=\oslash
$$

2. Obviamente a segunda relação nos indica que existe um pixel representado por 2 vértices distintos simultaneamente:

$$
\bigcap_{S_{i} \in C} S_{i} \neq \oslash
$$


Tais propriedades podem ser combinadas de diferentes maneiras de forma a construir diferentes modelos. Esse trabalho tenta estudar, mesmo que ainda de maneira limitada justamente essa variedade e liberdade de formas de se modelar imagens como grafos.

\subsubsection{Arestas}

O segundo definição refere-se à forma de conectar tais vértices. Qual regra é usada para se definir a adjacência e para determinar o peso de cada aresta. É necessário verificar, por exemplo, se a modelagem resultará em um grafo simples ou se existirão laços ou arestas paralelas.

De fato é mais difícil definir as propriedades da aresta do que dos vértices. Porém, algumas construções de adjacência e algumas medidas de peso são mais frequentes literatura. Embora a definição da adjacência entre dois vértices passe obrigatoriamente pela definição da função de peso $w_{i j}$, algumas construções são bastante utilizadas. São elas:

1. Lattice 4-conectada: Nessa modelagem cada vértice representa um pixel da imagem e uma aresta é adicionada entre dois vértices se estes representam pixeis vizinhos de 4 na imagem original (Figura 3.1). Tal tipo de adjacência enfatiza propriedades locais do grafo.
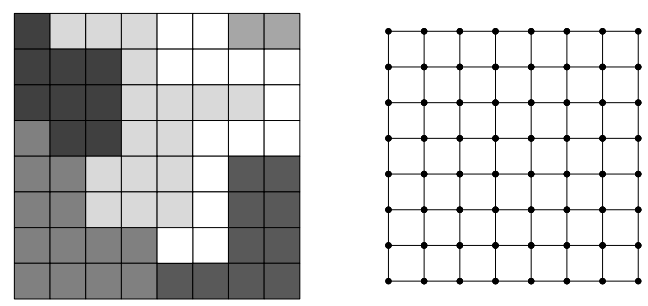

Figura 3.1 - Grafo por adjacência de pixeis, lattice 4-conectada

2. Lattice 8-conectada: Semelhante ao apresentado acima, porém uma aresta é adicionada entre dois vértices se estes representam pixeis vizinhos de 8 na imagem original (Figura 3.2). Assim como a lattice 4-conectada esse tipo de grafo é planar.
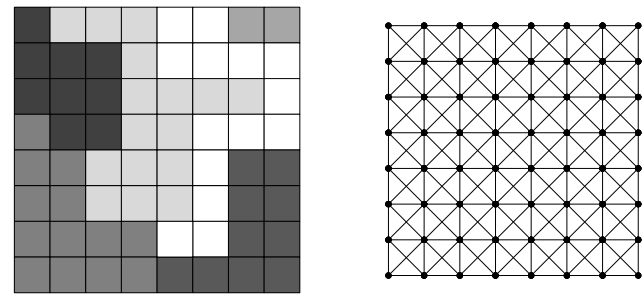

Figura 3.2 - Grafo por adjacência de pixeis, lattice 8-conectada 
3. Lattice completa: Outra estratégia é conectar todos com todos, gerando, por consequência, um grafo completo. Tal representação carrega além de informações locais informações globais da imagem. Essa estratégia resulta em um grafo não planar caso o número de pixeis da imagem seja maior que 4. Tal representação é pouco utilizada na prática, uma vez que o custo computacional da maioria dos algoritmos é extremamente alto. A Figura 3.3 ilustra tal conectividade.
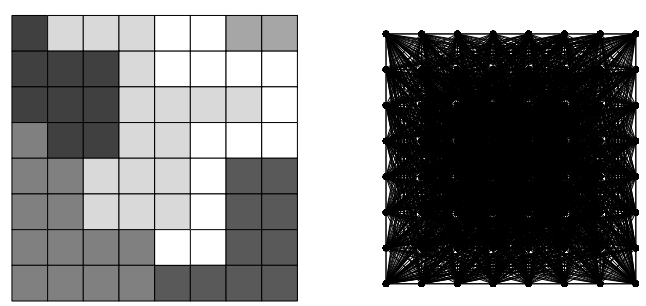

Figura 3.3 - Grafo por adjacência de pixeis, lattice completa.

4. Lattice conectada por raio: Nesse modelo conecta-se todos os vértices cujos pixeis que esses representam são vizinhos que estão a um raio $r$ sendo, portanto, o parâmetro $r$ chave nesse tipo de modelagem. Essa é uma maneira intermediária entre a conectividade limitada e a conectividade total, uma vez que a escolha apropriada do parâmetro $r$ ou de outra função de distância no espaço de características, melhora a representação da imagem, facilitando a propagação de afinidade local através das diferentes regiões e evita o alto custo computacional presente na conectividade total (ver Figura 3.4). Essa representação pode ou não gerar grafos planares, dependendo da função de distância utilizada.
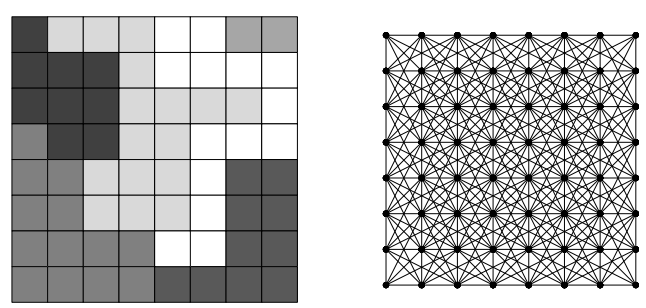

Figura 3.4 - Grafo por adjacência de pixeis, lattice conectada por raio.

5. Lattice 4-conectada pirâmide: representações multi-resolução da imagem são comumente utilizadas com objetivo de ganho de performance e/ou qualidade do processamento final. Em grafos uma representação multi-escala da imagem pode ser alcançada usando um mapeamento em forma de pirâmide, onde pequenos grupos de vértices são formados na forma 4-conectada e esses pequenos grupos são então recursivamente conectados a grupos vizinhos do mesmo tipo (ver Figura 3.5). 

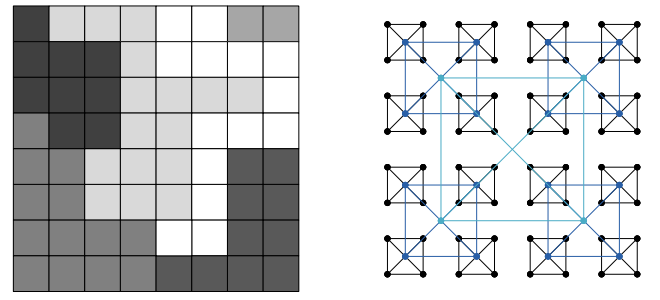

Figura 3.5 - Grafo por adjacência de pixeis, lattice 4-conectada pirâmede.

6. Lattice k-vizinhos: Nessa representação um vértice é conectado a k-vizinhos mais próximos com base em alguma regra de distância. Tal representação gera grafos esparsos e com certa representatividade multi-escala. Um bom exemplo pode ser visto na Figura 3.6 .
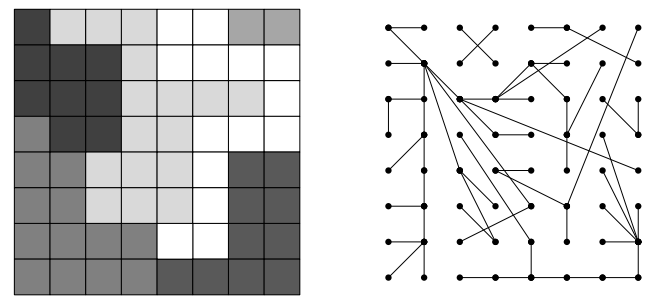

Figura 3.6 - Grafo por adjacência de pixeis, lattice k-vizinhos

7. Adjacência por regiões: Um modelo muito comum é conectar os vértices que representam regiões vizinhas na imagem. A Figura 3.7 apresenta uma imagem segmentada e seu consequente grafo formado.
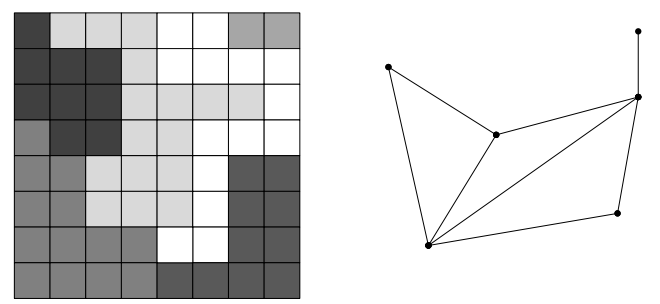

Figura 3.7 - Grafo por adjacência de regiões

8. Adjacência por cores: Outro modelo é quando cada vértices representa um componente cromático da imagem em um dado espaço de cores. Dois vértices são conectados se as cores que eles representam forem adjacentes na imagem. A Figura 3.8 apresenta tal conexão.

\subsection{Métodos que utilizam modelagem imagem/grafo em processamento de imagens}

Como já mencionado o objetivo deste trabalho é, de forma resumida, desenvolver formas de modelagens de imagens em grafos e utilizar os aspectos topológicos de redes complexas 

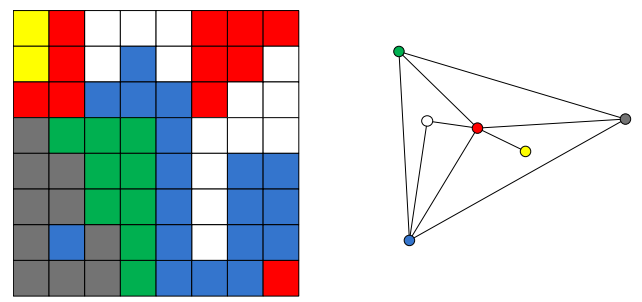

Figura 3.8 - Grafo por adjacência de cores. (a) Imagem colorida 5×5 image; (b) CAG resultante.

como características para posterior classificação.

A utilização de modelos imagem/grafos em processamento de imagens, no entanto, não é algo novo na literatura. Alguns modelos apresentados acima não são novos em sua essência, já tendo sido empregados com diferentes objetivos em análise de imagens. Nesse sentido abaixo se apresenta uma breve revisão bibliográfica de métodos que utilizam alguma forma de modelagem imagem/grafo em processamento de imagens.

É importante lembrar que, embora semelhantes, tais modelos são utilizados nesse trabalho com objetivos completamente distintos das aplicações abaixo apresentadas. Enquanto os trabalhos abaixo relatados utilizam técnicas mais comumente encontradas em teoria dos grafos (e.g. corte mínimo), nossa proposta é fazer uso de medidas estatísticas de redes complexas para caracterizar o modelo/imagem.

\subsubsection{Segmentação de Imagens}

Em visão computacional, segmentação se refere ao processo de dividir uma imagem digital em múltiplas regiões (conjunto de pixeis) ou objetos, com o objetivo de simplificar e/ou mudar a representação de uma imagem para facilitar a sua análise. O resultado da segmentação de imagens é um conjunto de regiões/objetos da imagem onde cada um dos pixeis em uma mesma região é similar com referência a alguma característica ou propriedade computacional, tais como cor, intensidade, textura ou continuidade. Regiões adjacentes devem possuir diferenças significativas com respeito a(s) mesma(s) característica(s).

\subsubsection{Segmentação com lattices 4 ou 8-conectadas}

A primeira forma de segmentação, e provavelmente a mais difundida, utiliza o sistema de vizinhança 4 ou 8 para definir as conexões entre os vértices. Uma aresta é adicionada a dois vértices se estes representam pixeis vizinhos de 4 ou 8 na imagem original. Tal tipo de adjacência enfatiza propriedades locais do grafo.

Morris et al. (26) apresenta um dos primeiros trabalhos utilizando tal representação. 
Nele o peso da aresta no sistema de vizinhos 8-adjacentes é tido como a diferença absoluta da intensidade de cinza entre os pixeis. Uma árvore geradora mínima então é obtida do modelo e uma segmentação da imagem em $r$ regiões distintas é obtida pelo simples corte das $r$ arestas com maior peso. Morris et al. (26) também propõe algumas formas de melhorar o resultado da segmentação, entre elas o cálculo da árvore geradora mínima de forma recursiva. Xu e Uberbacher (27) acrescentam algumas heurísticas ao método para tornar o processo de corte mais preciso e eficiente computacionalmente, e Vlachos e Constantinides (28) estende o trabalho de (26) para imagens coloridas, considerando a informação de cor no cálculo do peso da aresta. Uma abordagem hierárquica, utilizando wavelets na determinação dos pesos da aresta e das imagens multi-escala, é realiza no trabalho (29). Outra abordagem hierárquica utilizando pirâmides é dada por (30). Outros métodos não baseados em grafos também podem ser utilizados após segmentação por árvore geradora mínima com objetivo de melhorar a qualidade final da segmentação e diminuir a super segmentação obtida (31).

Wu e Leahy (32, 33) também definem o peso da aresta como uma função de similaridade entre os pixeis adjacentes. No entanto a segmentação é obtida pelo particionamento do grafo em subgrafos via corte de grafos. Esse particionamento é obtido removendo-se os arcos em $G$ que correspondem ao corte mínimo com menor peso entre todos os cortes mínimos de todos os pares de vértices em $G$. O autor argumenta que o corte com baixo valor correspondem à contornos fechados com bordas evidentes e, consequentemente, bordas isoladas não produzem regiões na imagem, um vez que há um alto custo associado à inclusão das arestas com baixo valor necessárias para formar um contorno fechado. Dessa forma buracos no contorno são penalizados ao passo que grandes regiões não sofrem nenhum tipo de restrição. Para tal particionamento o algoritmo de Gomory-Hu $(34,35)$ é inicialmente utilizado em (36). No entanto esse método apresenta um alto custo computacional e também apresenta uma super segmentação para algumas imagens. Em trabalhos subsequentes Wu e Leahy (33) calculam o corte mínimo com o algoritmo de Gomory-Hu modificado e otimizado visando minimizar o custo e tentar evitar a super segmentação. Cox et al. (37, 38) sugerem então outra forma de implementação muito similar utilizando chamada corte proporcional. Nesse método a função de custo é uma proporção do peso total das arestas podadas, normalizadas pelo tamanho das partições criadas (39).

Utilizando uma representação da imagem por dígrafo, Jermyn e Ishikawa (40) apresentam uma outra forma de segmentar imagens. Nessa representação o peso e a direção da aresta é determinada pelo produto do gradiente entre os pixeis vizinhos. A segmentação é obtida por encontrar um ciclo/borda fechada que isola um objeto da imagem, utilizando para isso a solução do ciclo de peso mínimo normalizado. 


\subsubsection{Segmentação com conectividade por raio ou knn}

Embora se obtenham bons resultados de segmentação com os métodos de conectividade limitada (i.e. árvore geradora mínima e corte de grafos com vizinhança 4-8), esses utilizam um critério de segmentação baseado em propriedades locais do grafo. Outra forma bastante utilizada para se determinar a adjacência entre os vértices é utilizar a conexão de k-vizinhos mais próximos, ou seja, mapear cada pixel para um espaço de características e então agregar os pixeis mais similares com uma aresta. Nesse tipo de adjacência uma aresta $e \in E$ e um peso $w_{i, j}$, representando o relacionamento e similaridade entre pixeis $i$ e $j$, são adicionados ao grafo se estes pixeis estão próximo no espaço de características.

De fato há diversas formas para se determinar tais características, sendo a mais comum conectar todos os pixeis vizinhos que estão a um raio $r$. De fato se apenas a característica de distância entre pixeis for utilizada para a conectividade knn, essa se reduz à conectividade por um raio apresentada anteriormente. O parâmetro $r$ é, portanto, chave nesse tipo de modelagem.

Essa representação pode ou não gerar grafos planares, dependendo da função de distância utilizada. O trabalho de Cour et al. (41) apresenta uma boa discussão nesse sentido e (42, 43) apresentam estudos de caso de segmentação para conectividade limitada e conectividade knn com diversas funções de distância.

O estudo realizado por Cour et al. (41) demostra que grandes valores de $r$ melhoram a representação da imagem e sua subsequente segmentação. Entretanto há o problema do custo computacional envolvido. Para resolver (41) propõe modelar o grafo com um valor de $r$ grande, em conjunto com uma metodologia baseada no particionamento do grafo em sub-grafos, obtendo assim uma segmentação eficiente tempo $O(N)$ com algoritmo de corte normalizado ótimo.

Ainda dentro desse contexto muitas são as soluções de corte empregadas com objetivo de segmentar a imagem modelada. Os trabalhos de Shi e Malik (44), por exemplo, propõem uma função de custo normalizada, chamada de corte normalizado, onde o fator de normalização é a conectividade total dos nós em cada partição para todos os nós do grafo. Outras funções de custo para corte incluem os trabalhos (45, 46). Soluções mais eficientes também podem ser alcançadas com utilização de versões recursivas (44), implementações hierárquicas (multiescala) (41, 46) e outras abordagens (43, 47, 48).

Outra forma para segmentação de imagens é dada por Costa (7) que utiliza um grafo hierárquico de $G_{i}^{\prime}=2$. Nesse grafo os hubs são identificados e os vértices mais próximos 
conectados a este hub são adicionados à região segmentada.

\subsubsection{Segmentação via IFT}

Outro modo utilizado para se determinar a relação de adjacência dos vértices no grafo é escolher, com base em alguma heurística, quais vértices serão conectados. Tal forma difere da conectividade Knn pelo fato de não haver um relação direta de similaridade (ou dissimilaridade) entre dois vértices adjacentes, ou seja, dado apenas os dois vértices é impossível saber se esses serão adjacentes ou não no grafo.

Um recente trabalho muito interessante nessa linha é apresentado por Falção et al. (25). Nele a chamada image foresting transform (IFT) é utilizada em aplicações de segmentação de imagens, detecção de bordas e esqueletonização via transformada da distância. A IFT é dada pelo simples cálculo dos caminhos mínimos entre os vértices e alguns pontos de controle. $\mathrm{O}$ grafo resultante é uma floresta de caminhos ótimos.

A medida de distância, escolha dos pontos e a função de custo utilizada são diversas e estão fortemente dependentes da aplicação. Para realizar a transformada da distância, por exemplo, as sementes correspondem aos pixeis do contorno da imagem. Já para aplicações de segmentação essas sementes podem ser escolhidas manualmente (segmentação dirigida) ou através de algum heurística. Diversos trabalhos exploram e propõem formas de melhorar a qualidade das aplicações utilizando IFT (49, 50).

\subsubsection{Segmentação com sementes}

Este tipo modelagem trata de segmentação dirigida, onde o fundo e objeto(s) de interesse são explicitamente pré-identificados manualmente. Semelhantemente à lattice 4 conectada apresentada anteriormente, esta modelagem atribui um vértices $v \in V$ para cada pixel, uma aresta (direcionada ou não) $e \in E$ e um peso $w_{i, j}$, representando o relacionamento e similaridade entre pixeis $i$ e $j$. A essas arestas dá-se o nome de n-links. Vértices especiais (chamados sementes ou terminais) são então adicionados ao grafo. No contexto de visão, estas sementes são rótulos atribuídos a determinados pixeis da imagem, representando que aquele pixel pertence ao fundo ou ao objeto(s) de interesse (51). Cada semente criada é então é conectada com uma aresta ( $\mathrm{t}$-links) a todos os vértices correspondentes aos pixeis da imagem.

Vários são os trabalhos $((51,52))$ que utilizam esta modelagem para realizar segmentação dirigida (onde o usuário indica quais são as sementes). Alguns trabalhos recentes focam esforços em determinar automaticamente quais são as sementes (regiões e objetos de inte- 
resse) através de uma pré-segmentação grosseira da imagem (53, 54), ficando a cargo da segmentação baseada em grafos obter um resultado mais refinado e preciso.

\subsubsection{Segmentação por regiões}

Nesse tipo de modelagem cada vértice $v_{i} \in V$ representa uma região distinta da imagem. Essas regiões são determinadas por uma pré-segmentação grosseira, muitas vezes apresentado uma imagem over-segmentada. Uma aresta (direcionada ou não) é então adicionada entre os vértices $v_{i}$ e $v_{j}$ se as regiões representadas por esses vértices forem vizinhas. Esse tipo de abordagem diminui o numero de vértices e arestas necessários para representar a imagem, diminuindo assim no custo computacional dos algoritmos de particionamento empregados, fato este que leva muitos trabalhos a empregarem tal metodologia (55, 56).

Várias são os métodos utilizados para se obter essa pré-segmentação, desde simples limiares, split-and-merge (36) e métodos mais refinados como Manford-Shah (57) e watershed (58). O objetivo, em geral, é agrupar pixeis semelhantes em pequenas regiões, obtendo uma imagem super segmentada, e após obter um refinamento desta segmentação utilizando modelagem em grafos.

\subsubsection{Extração de características de textura}

Alguns autores propõem uma modelagem imagem/grafo para posterior extração de características de textura. Em Chalumeau et al. (8-10), o peso da aresta é uma relação entre a distância entre os pixeis e a diferença de intensidade de cor. Arestas abaixo de um determinado limiar são retiradas do grafo inicial. Medidas baseadas em graus e coeficiente de aglomeração são extraídas considerando os grafos hierárquicos derivados deste.

Outra trabalho que utiliza heurística é dado por Backes et al. (59). Nesse trabalho a relação de adjacência entre os vértices é determinada pelas trajetórias produzidas pela caminhada determinística do turista na imagem. Inicialmente cada pixel corresponde a um vértice no grafo e seu respectivo conjunto de arestas é vazio. A ideia é que cada turista mova-se de um pixel a outro de acordo com uma regra determinística e uma memória. Para cada movimento obtido uma aresta não direcionada $\{u, v\}$ é adicionada ao conjunto de arestas $E$. Considera-se cada pixel como ponto de partida para um novo turista, esse conjunto de trajetórias resulta em trajetórias auto-repulsivas que são então utilizadas para determinar as arestas do grafo. Vários grafos são então obtidos utilizando diferentes regras e valores de memórias $\mu$. Medidas de grau médio e entropia do grau conjunto são extraídas de cada grafo para compor um vetor 
de características utilizado em classificação supervisionada de texturas.

\subsubsection{Refinamento de bordas}

Para muitas aplicações de visão computacional as informações locais de borda não são adequadas, tais pontos necessitam ser reorganizados em retas, semi retas ou curvas para prover informações estruturais. Tal conjunto de primitivas, chamadas de características curvilineares, pode ser utilizados para descrever a imagem, podendo descrever desde uma simples caixa à uma casa. O trabalho de Suk e Song (60) considera cada ponto das bordas da imagem como um vértice, uma árvore geradora mínima é então obtida de tal representação. Algumas heurísticas são então utilizadas para podar tal grafo retirando segmentos do grafo que não possuem continuidade. O grafo então é particionado em subgrafos de forma a nenhum vértice possuir grau maior que 2. Esse processo resulta em segmentos de retas, semi-retas e curvas que podem ser interpolados em processos adicionais de forma a suavizar sua representação e prover informações estruturais do objeto.

Ferrari et al. (61) também propõe uma forma heurística de conectar os pontos iniciais e finais de segmentos extraídos por um algoritmo de detecção de bordas. Utilizando um algoritmo de correspondência de subgrafos o autor desenvolve uma aplicação de reconhecimento de objetos utilizando um modelo conhecido a priori.

Outra abordagem semelhante a esta considera as extremidades das linhas que compõem uma forma como os vértices de um grafo (62). Os dois vértices que definem as extremidades de uma reta são, portanto, conectados por uma aresta. Além disso, entre cada dois pares de vértices não conectados, uma nova aresta, chamada aresta indireta, é adicionada, desde que a mesma não cruze nenhuma das arestas originais, chamadas arestas diretas. A cada vértice é atribuído um vetor de atributos, o qual representa o ângulo de incidência das arestas (visitadas no sentido horário), sejam elas diretas ou indiretas. Para cada ângulo um peso é associado de acordo com o restante dos ângulos associados aquele vértice. A comparação de dois grafos é realizada por uma versão própria de correspondência inexata de grafos.

\subsubsection{Compressão de imagens}

Dado o contorno das regiões em uma imagem Labelle et al. (63) propõe uma forma eficiente de armazenar tal informação usando compressão sem perdas. Nesse trabalho os pixeis que fazem intersecção de 3 ou mais regiões são tidos como vértices do grafo e um aresta é adicionada entre dois nós se esses vértices são adjacentes em relação à borda da 
região que eles representam (i.e. representam outro ponto da borda de uma mesma região). O grafo formado e o direcional chain codes, utilizado para estabelecer o caminho realizado pela borda entre 2 vértices, compõem a representação compacta da imagem.

Battiato et al. (64) aborda o problema de compressão de imagens coloridas sem perdas (lossless). Nesse trabalho cada nó representa um componente cromático da imagem e as arestas desse grafo são determinadas ligando-se os nós associados a existência de adjacência entre essas cores que eles representam na imagem. No modelo proposto cada vértice é conectado com todos os outros, formando assim um grafo com peso não direcionado completo. O peso de cada aresta é definido como sendo o número de coocorrência entre as cores $v, u$. Uma eficiente re-indexação das cores, que é a condição necessária para uma boa compressão sem perdas, é então obtida pela solução do caminho hamiltoniano de peso máximo (caixeiro viajante). De fato, por se tratar de um grafo completo tal caminho existe.

\subsubsection{Extração de características de contorno}

Em Zhao et al. (65), um grafo é construído selecionando-se pontos do contorno que estejam intervalados de $\Delta \theta$ graus, onde $\Delta \theta>5$. Para tanto, o centroide do contorno é inicialmente calculado, e uma aresta do centroide para os pontos selecionados é adicionada. As distâncias e ângulos são utilizados como peso da aresta criada. Invariância a rotação é obtida ao se rotacionar o espaço polar de modo que a a maior distância $\rho_{i}$ coincida com 0 grau. Características espectrais são utilizadas para a comparação entre dois grafos.

Uma abordagem similar, a qual também envolve o cálculo do centroide e a seleção de pontos do contorno, é descrita em (66). Nela, primeiramente o contorno da forma $S=\left[s_{1}, s_{2}, \ldots, s_{N}\right]$ é normalizado e seu centroide é deslocado de modo a coincidir com a origem das coordenadas. Essas transformações são realizadas com o intuito de garantir invariância a rotação, escala e translação da forma. Através de uma operação de redução de dimensionalidade, apenas $M$ pontos $(M<<N)$ são selecionados para a construção do grafo $G(V, E)$, sendo cada um dos pontos selecionados considerado com um vértice do grafo. Os pontos selecionados correspondem à aqueles cuja frequência é próxima a 0 . As arestas são adicionadas de modo a formar triângulos entre 2 vértices vizinhos e o centroide da forma, algo muito similar com a triangulação de Delaunay. O peso atribuído a cada aresta é a distância euclidiana entre os pontos da forma. Diferente da abordagem proposta em (65), essa abordagem emprega distância de edição de grafos para medir a similaridade entre grafos. A distância entre dois grafos é definida com o menor custo de operações de edição necessárias para converter um grafo $G_{1}$ em outro, $G_{2}$. Trata-se de uma medida de similaridade bastante tolerante 
a ruído e distorções.

\subsubsection{Aproximação poligonal}

De um dado contorno também é possível determinar sua aproximação poligonal utilizando uma representação por grafos. Nesse caso cada ponto do contorno é tido como um vértice (67), e o peso $w_{i, j}$ de cada aresta é calculado como sendo a norma $L_{2}$, i.e. a soma dos quadrados da distância de cada vértice entre os vértices $g_{i}$ e $g_{j}$. Dada tal representação a aproximação poligonal é obtida selecionando-se o subconjunto de vértices que formam o ciclo mínimo no grafo que utiliza o menor número de vértices possível com um custo aceitável (erro de aproximação).

\subsubsection{Extração de características de esqueleto}

A extração de características de esqueletos é outra aplicação que faz uso de grafos em vários métodos.

Várias são as formas de mapear a estrutura de um esqueleto em um grafo. Em (68) um grafo $G$ é construído considerando todos os pontos do esqueleto como vértices e, para cada par de vértices uma aresta com peso equivalente à distância euclidiana normalizada é adicionada. Para cada subgrafo obtido medidas de grau médio e grau máximo são extraídos e usadas em uma aplicação de reconhecimento de objetos por esqueleto. Em (69) uma abordagem similar é usada, porém medidas multi-escala do grau médio, máximo e mínimo são calculadas.

Diferentemente de utilizar todos os pontos do esqueleto como vértices, outra abordagem utiliza dois tipos de pontos particularmente interessantes, são eles os pontos de extremidade e pontos de junção. Um ponto do esqueleto que possua apenas um ponto adjacente é denominado um ponto de extremidade. Se, no entanto, ele possui três ou mais pontos adjacentes, então ele é considerado um ponto de junção. Nessa abordagem os vértices $V$ são compostos exclusivamente pelos pontos de extremidade e pontos de junção. Arestas são adicionadas entre dois vértices $v_{i}$ e $v_{j}$ sempre que existir um caminho entre os respectivos pontos no esqueleto (70, 71), sendo $w_{i, j} \in W$ o peso associado a está aresta, quando necessário. Como resultado final, temos uma simplificação do esqueleto por um grafo $G$, mantendo as posições relativas de cada vértice no esqueleto, bem como suas respectivas conexões.

Vários são os trabalhos da literatura que utilizam tal modelagem do esqueleto. Uma vez obtido tal grafo um algoritmo tradicional de correspondência de grafos ou correspondência inexata de grafos é empregado de modo a reconhecer qual objeto da cena mais se aproxima 
de um dado protótipo (72, 73). Outros trabalhos utilizam algoritmos de correspondência de grafos heurísticos para reconhecimento dos objetos (70, 71). Tais correspondências são baseadas nas relações existentes entre suas arestas. Medidas como o comprimento relativo e orientação das arestas do grafo, o tipo de conexão que essa aresta representa (pontos de extreminade-junção ou junção-junção) e a suas quantidades formam um conjunto de medidas permitem realizar uma correspondência heurística de forma efetiva.

Em Arrivault et al. (74), os valores das coordenadas polares (calculadas com base no centro de gravidade) dos pontos de extremidade e junção são associadas aos seus respectivos vértices, enquanto que para as arestas são atribuídos valores calculados a partir do comprimento de seu respectivo arco no esqueleto. Já em (75), o valor da transformada da distância (normalizado pelo maior valor) é associado a cada vértice do grafo. O peso de suas arestas $w_{i, j}$ é definido com base em diversas outras propriedades, sendo construído um novo grafo para cada propriedade analisada.

Outra classe de correspondência de grafos heurísticos utiliza os chamados caminhos de esqueletos. Esse método se baseia na comparação entre os caminhos existentes dentro de um grafo de esqueleto $G$ para definir quão similar dois esqueletos são (76-78). Dado 2 pontos de extremidade do esqueleto, $v_{i}$ e $v_{j}$, é possível calcular o menor caminho existente entre eles dentro do esqueleto $d_{i j}$. Partindo do princípio de que formas similares deverão apresentar distâncias similares, a classificação das duas formas é feita comparando-se a similaridade entre as distâncias dos pares de caminhos encontrados para cada par de pontos de extremidade. Para garantir que o método seja invariante à escala uma normalização baseada na transformada da distância é utilizada.

Outros métodos de análise de esqueleto incluem a classe dos grafos de choque. Esses são obtidos pela transformada do eixo médio, rotulados e agrupados de acordo com o valor do raio associado a ele e as variações locais da forma. Ao todo, quatro tipos de shocks (variações da forma) são definidos pela Shock Theory (79). Cada vértice do grafo representa uma sequencia de pontos do esqueleto que possuem o mesmo tipo de choques. Vértices são considerados adjacentes se tais segmentos também são adjacentes. Adicionalmente um segmento central é tomado como raiz do grafo, produzindo assim uma árvore.

\subsubsection{Localização e reconhecimento de objetos na cena}

Nesse tipo de representação Matas et al. (80) propôs uma representação onde cada nó representa um componente cromático da imagem em um dado espaço de cores (após uma quantização prévia da imagem para diminuir o número de nós obtidos e diminuir o custo com- 
putacional). Cada cor origina um nó e as arestas desse grafo são determinadas ligando-se os componentes de cores (nós) associados a existência de adjacência entre essas cores na imagem, o número de adjacências existentes é tido então como atributo da aresta (grafo direcionado sem peso). Adicionalmente são excluídas do grafo as arestas que representam cores adjacentes, cujo número adjacências seja menor que um determinado limiar. Essa representação então é utilizada para localização e reconhecimento de objetos na cena através da técnica de correspondência de subgrafos.

\subsubsection{Recuperação de imagens por conteúdo}

Uma variação do método de (80) é proposta no trabalho (81), com o intuito de desenvolver um algoritmo para recuperação de imagens por cor. Esse acrescenta a informação da quantidade de pixeis pertencentes à determinado componente de cor ao vértice e as arestas denotam adjacência entre as cores na imagem.

Além desse grafo, (81) também propõem o uso do grafo de variância espacial, um grafo usado para obter informações estatísticas a respeito da geometria de cada componente cromático. Esse é um grafo dual do modelo anterior no qual os nós recebem como atributo a variância espacial dos pixeis a ele pertencentes e as arestas recebem como atributo uma das variâncias relacionais. Isso fornece um modelo estatístico para a distribuição de cores no domínio espacial. 


\section{CAPÍTULO 4}

\section{Métodos de análise de imagens}

\section{propostos}

Observando-se as regras gerais para modelagem de imagens por grafos e caracterização de rede, essa seção apresenta os métodos de análise de imagens propostos. De forma geral os métodos aqui apresentados seguem uma sequencia padrão que é: (1) modelagem da imagem como grafo; (2) extração de medidas estatísticas para caracterização da topologia rede obtida; (3) aprendizado e redução de dimensionalidade dos dados; (4) classificação utilizando métodos de classificação supervisionada. Uma visão geral desse processo pode ser visto na Figura 4.1.

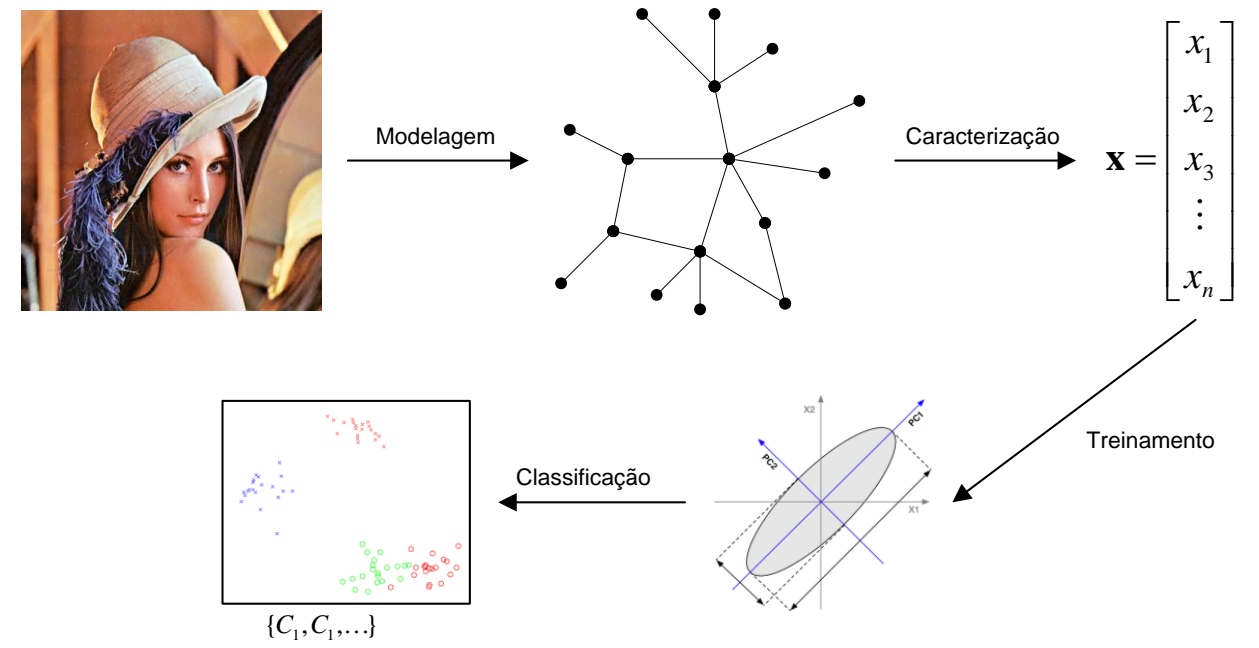

Figura 4.1 - Visão geral dos métodos propostos. (1) modelagem da imagem como grafo; (2) extração de medidas e (3) aprendizado e redução de dimensionalidade e (4) classificação.

Modelos específicos para análise de textura, contorno, cor e esqueletos são propostos com base nas regras gerais apresentadas na seção anterior. Todos esses modelos tem por objetivo a análise exclusiva de redes estáticas dentro do intervalo de tempo em que as imagens foram capturadas. Ou seja, não há variação no número de vértices, arestas ou mesmo na configuração das ligações provenientes de processos externos. Uma esquema geral dos modelos propostos e qual o tipo de análise esses podem realizar pode ser visto na Figura 4.2 .

Para cada modelo um estudo com relação aos parâmetros, medidas e diferentes formas 


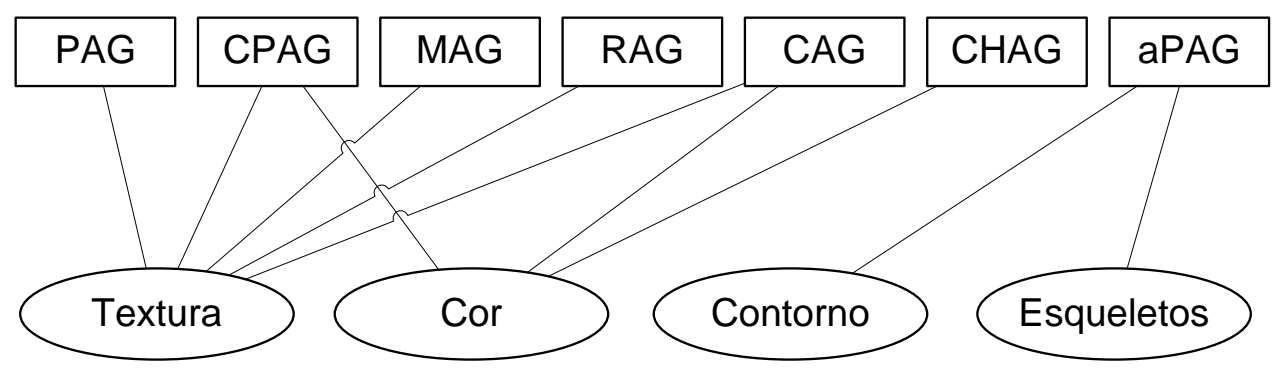

Figura 4.2 - Visão geral dos modelos propostos em relação ao tipo de análise de imagem que esses realizam.

de análise é realizado utilizando-se as bases de dados contidas no Anexo A. A classificação multiclasses é realizada utilizando o classificador LDA+Bayes apresentados no Anexos B.1] e B.2 e avaliados nesse primeiro momento pela acurácia (ou simplesmente taxa de acerto) dada pelo Anexo B.4.

As comparações dos métodos propostos com métodos tradicionais e estado da arte são realizadas em seção posterior.

\subsection{PAG - Grafo por adjacência de pixel}

A extração de características de texturas é a primeira aplicação apresentada que pode ser realizada utilizando grafos e redes complexas. Como já mencionado é necessário modelar a textura como um grafo e posteriormente extrair algumas características topológicas.

A primeira proposta é utilizar uma modelagem do tipo PAG (do inglês pixel adjacency graph) onde cada pixel é representado por um vértice, ou seja, cada conjunto $S_{i}$ representará um único pixel da imagem. Seguindo a regra geral temos:

- Quantidade de pixeis existentes em $S_{i}$ :

$$
\left|S_{i}\right|=1, \text { para todos } S_{i} \in C
$$

- Quantidade dos pixeis representados em $C$ :

$$
\bigcup_{S_{i} \in C} S_{i}=I
$$

- Relação entre cada subconjunto $S_{i}$ de $C$ :

$$
\bigcap_{S_{i} \in C} S_{i}=\oslash
$$

Algumas funções de peso $w_{i}$ básicas podem ser inferidas para esse modelo, sendo elas: 
- Distância entre dois pixeis $p\left(x_{i}, y_{j}\right)$ e $q\left(x_{i}, y_{j}\right)$ :

$$
w_{i j}=\sqrt{\left(x_{i}-x_{j}\right)^{2}+\left(y_{i}-y_{j}\right)^{2}}
$$

- Diferença de intensidade normalizada entre dois pixeis $p\left(x_{i}, y_{j}\right)$ e $q\left(x_{i}, y_{j}\right)$ :

$$
w_{i j}=\frac{p\left(x_{i}, y_{i}\right)-q\left(x_{j}, y_{j}\right)}{L}
$$

- Distância e diferença de intensidade normalizada entre dois pixeis $p\left(x_{i}, y_{j}\right)$ e $q\left(x_{i}, y_{j}\right)$ :

$$
w_{i j}=\frac{\sqrt{\left(x_{i}-x_{j}\right)^{2}+\left(y_{i}-y_{j}\right)^{2}}}{2 r}+\frac{p\left(x_{i}, y_{i}\right)-p_{j}\left(x_{j}, y_{j}\right)}{2 L}
$$

onde $p\left(x_{i}, y_{j}\right)$ e $q\left(x_{i}, y_{j}\right)$ denotam a intensidade do nível de cinza do pixel nas coordenadas $(x, y), L$ é o número máximo de níveis de cinza na imagem e $r$ o raio de conexão utilizado.

\subsubsection{PAG lattice 4-conectada}

Um primeiro sub-caso de PAG é quando temos um grafo do tipo PAG lattice 4-conectada. Nesse tipo de modelagem conecta-se todos os vértices se os pixeis que esses representem são 4-adjacentes na imagem original (Figura 4.3). Para cada aresta um peso $w_{i j}$ é associado sendo essa a diferença de intensidade normalizada dos mesmos (Equação 4.1.5). Um exemplo dessa transformada pode ser vista na Figura 4.3).
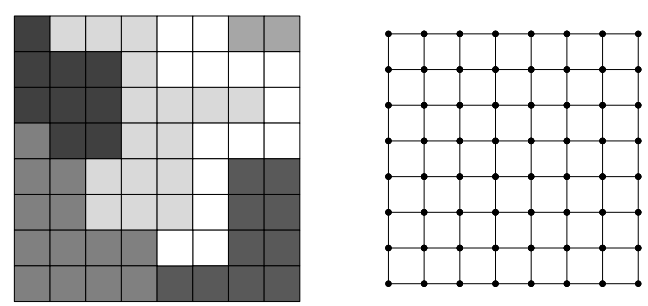

Figura 4.3 - Textura modelada como um PAG lattice 4-conectada: (a) cada pixel da imagem é um vértice no grafo; (b) uma aresta é adicionada entre dois vértices se estes representam pixeis 4 adjacentes na imagem original; (c) o peso definido pela diferença de intensidade do nível de cinza normalizado entre $[0,1]$.

Nessa configuração temos um grafo 4-regular, onde todos os vértices estão conectados a 4 vizinhos. Isso implica em um comportamento regular, que não apresenta propriedades relevantes para uma análise do grafo de forma direta. O mesmo é válido para análise hierárquica, por se tratar de um grafo regular, com conexões triviais via 4-adjacência, o cálculo da $L$-expantion seria igual para todas as imagens.

É necessário, portanto, transformar essa rede regular em uma rede que possua propriedades relevantes na discriminação de textura. Para isso inicialmente utilizamos a análise de subgrafos 
por limiarização, de forma a obter diversos subgrafos e desses extrair medidas. Para cada subgrafo obtido todas as medidas da Equação 2.3.27 são calculadas e concatenadas de modo a compor o vetor de características final.

A Tabela 4.1 apresenta um estudo via análise de subgrafos (limiares $T=[0.075,0.075, \ldots, 0.925]$ ) de modo a verificar qual função de peso possui melhor resposta ao modelo proposto. O número de descritores (ND) obtido após aplicação de redução de dimensionalidade por LDA e a taxa de acerto para 3 diferentes bases de dados são apresentados (para cada base o número de descritores pode variar um pouco, pois considera-se como descritores as $k$-variáveis canônicas que representam $99,99 \%$ da variância total explicada).

Tabela 4.1 - PAG lattice 4-conectada: Resultados obtidos para diferentes funções de peso $w_{i j}$, análise subgrafos.

\begin{tabular}{|c|c|c|c|c|}
\hline \multirow[b]{2}{*}{ Função de peso } & \multirow[b]{2}{*}{ ND } & \multicolumn{3}{|c|}{ Acerto (\%) } \\
\hline & & Brodatz & Outex & Vistex \\
\hline Equação 4.1 .4 & 16 & 2.83 & 3.56 & 4.35 \\
\hline Equação 4.1 .5 & 19 & 17.34 & 21.69 & 25.12 \\
\hline Equação 4.1 .6 & 19 & 18.58 & 21.84 & 25.58 \\
\hline
\end{tabular}

Verifica-se que, para função de peso de distância entre dois pixeis, os resultados são meramente aleatórios. Isso se deve ao fato de que todas as imagens irão gerar um modelo padrão, sem exceções (i.e. a distância entre pixeis é igual para todas as imagens, independente da textura ali presente). Já para as funções de peso dadas pela diferença de intensidade, e diferença de intensidade normalizada pela distância não houve diferenças estatísticas significantes, o que é de certa forma óbvio, visto que a distância que normaliza as diferenças de intensidade é única para todas as imagens (i.e. $r=1$ para adjacência 4-conectada).

A Tabela 4.2 apresenta os resultados para análise por subgrafos com diferentes conjuntos de limiares $(T)$ e função de peso da diferença de intensidade normalizada pela distância (Equação 4.1.6).

Tabela 4.2 - PAG lattice 4-conectada: Resultados obtidos para diferentes conjuntos de limiares, análise subgrafos.

\begin{tabular}{ccccc}
\hline & & \multicolumn{3}{c}{ Acerto (\%) } \\
\cline { 3 - 5 } $\boldsymbol{T}$ & ND & Brodatz & Outex & Vistex \\
\hline $0.075,0.025, \ldots, 0.925$ & 29 & 15.20 & 18.60 & 17.59 \\
$0.075,0.050, \ldots, 0.925$ & 25 & 14.13 & 20.81 & 21.06 \\
$0.075,0.075, \ldots, 0.925$ & 19 & $\mathbf{1 8 . 5 8}$ & $\mathbf{2 1 . 8 4}$ & $\mathbf{2 5 . 5 8}$ \\
$0.075,0.100, \ldots, 0.925$ & 13 & 12.22 & 19.41 & 16.20 \\
$0.500,0.025, \ldots, 0.925$ & 12 & 7.71 & 9.49 & 7.87 \\
$0.075,0.025, \ldots, 0.500$ & 19 & 17.00 & 22.13 & 24.07 \\
\hline
\end{tabular}

Verifica-se que as maiores taxas de acertos são alcançadas quando do uso de limiares com 
valores baixos, isso é, quando se mantêm da rede arestas que denotam as pequenas diferenças de intensidade entre os pixeis vizinhos. A utilização de um grande número de subgrafos (e.g. $T=[0.075,0.025, \ldots, 0.925])$, além de gerar vetores de características com tamanho excessivo, suscetíveis ao mal da dimensionalidade, também geram um decaimento na taxa de acerto.

A análise OPF é outra alternativa de análise que pode ser utilizadas em modelos PAG. A Tabela 4.3 apresenta resultado para tal análise com números diferentes conjuntos de sementes (S) e função de peso dada pela Equação 4.1.6. Cada conjunto de semente irá gerar um novo grafo do tipo floresta conectada de caminhos ótimos. Assim como na análise via subgrafos, para cada novo grafo as medidas da Equação 2.3.27 são calculadas e concatenadas.

Tabela 4.3 - PAG lattice 4-conectada: Resultados obtidos para diferentes quantidades de conjuntos de sementes, análise OPF.

\begin{tabular}{ccccc}
\hline & & \multicolumn{3}{c}{ Acerto (\%) } \\
\cline { 3 - 5 } $\boldsymbol{S}$ & ND & Brodatz & Outex & Vistex \\
\hline 1 & 6 & 5.57 & 8.53 & 6.48 \\
2 & 9 & 8.22 & 13.68 & 9.61 \\
3 & 16 & 7.94 & 13.97 & 10.53 \\
4 & 14 & 8.05 & 14.19 & 9.95 \\
5 & 22 & 10.75 & 17.06 & 14.35 \\
6 & 22 & 10.53 & 16.84 & 13.77 \\
7 & 23 & 11.54 & 18.75 & 15.28 \\
8 & 26 & 13.63 & 21.03 & 20.95 \\
9 & 25 & 13.34 & 19.56 & 19.79 \\
10 & 24 & 13.46 & 20.37 & 21.41 \\
\hline
\end{tabular}

Observamos que os resultados via análise OPF são inferiores à análise via subgrafos, sendo o melhor resultado obtido com limiares de $T=[0.075,0.075, \ldots, 0.925]$, que corresponde a 192 características no vetor original e 19 após redução de dimensionalidade. Porém ambas as análises alcançaram resultados extremamente baixos, de modo que nos leva a concluir que, de todas as características extraídas desse modelo, nenhuma é discriminante o suficiente para uma aplicação de reconhecimento de imagens.

\subsubsection{PAG lattice 8-conectada}

O segundo subcaso de PAG é quando temos um grafo do tipo PAG lattice 8-conectada. Nessa modelagem conectam-se todos os vértices se os pixeis que esses representem são 8adjacentes na imagem original (Figura 4.4). Assim como no caso apresentado acima, para cada aresta é associado um peso $w_{i j}$, sendo essa a diferença de intensidade dos mesmos normalizados. Um exemplo numérico dessa transformada pode ser vista na Figura 4.4). 

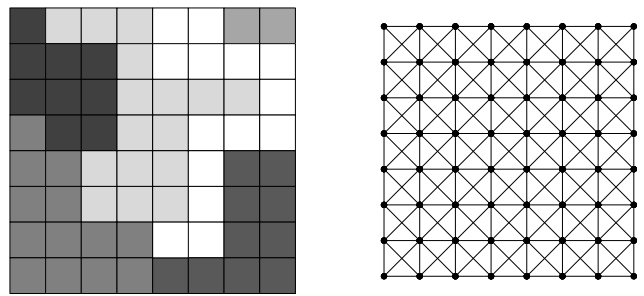

Figura 4.4 - Textura modelada como um PAG lattice 8-conectada: (a) cada pixel da imagem é um vértice no grafo; (b) uma aresta é adicionada entre dois vértices se estes representam pixeis 8 adjacentes na imagem original; (c) o peso definido pela diferença de intensidade do nível de cinza normalizado entre $[0,1]$.

A Tabela 4.4 apresenta os resultados para diferentes funções de peso das Equações 4.1.4. 4.1 .5 e 4.1 .6 com análise por subgrafos com $T=[0.075,0.075, \ldots, 0.500]$. Verifica-se que, assim como no PAG lattice 4-conectada a função de peso dada por simples distância entre dois pixeis é uma classificação completamente aleatória. O melhor resultado no entanto é obtido quando utilizada a função de peso como sendo a diferença de intensidade normalizada pela distância.

Tabela 4.4 - PAG lattice 8-conectada: Resultados obtidos para diferentes funções de peso $w_{i j}$, análise subgrafos.

\begin{tabular}{c|ccccc}
\hline & & \multicolumn{3}{c}{ Acerto (\%) } \\
\cline { 3 - 5 } Função de peso & ND & Brodatz & Outex & Vistex \\
\hline Equação & 4.1 .4 & 16 & 1.69 & 1.47 & 2.43 \\
Equação & 4.1 .5 & 20 & 68.75 & 42.94 & 68.98 \\
Equação & 4.1 .6 & 26 & 73.31 & 46.91 & 72.11 \\
\hline
\end{tabular}

A Tabela 4.5 apresenta os resultados via análise de subgrafos, utilizando como peso a diferença de intensidade normalizada pela distância.

Tabela 4.5 - PAG lattice 8-conectada: Resultados obtidos para diferentes conjuntos de limiares, análise subgrafos.

\begin{tabular}{ccccc}
\hline & & \multicolumn{3}{c}{ Acerto (\%) } \\
\cline { 3 - 5 } $\boldsymbol{T}$ & ND & Brodatz & Outex & Vistex \\
\hline $0.075,0.025, \ldots, 0.925$ & 49 & 72.80 & 47.35 & 71.41 \\
$0.075,0.050, \ldots, 0.925$ & 37 & 72.47 & 40.22 & 71.18 \\
$0.075,0.075, \ldots, 0.925$ & 30 & 68.64 & 31.69 & 68.40 \\
$0.075,0.100, \ldots, 0.925$ & 26 & 68.02 & 35.44 & 66.32 \\
$0.500,0.025, \ldots, 0.925$ & 37 & 62.73 & 43.68 & 56.94 \\
$0.075,0.025, \ldots, 0.500$ & 26 & $\mathbf{7 3 . 3 1}$ & $\mathbf{4 6 . 9 1}$ & $\mathbf{7 2 . 1 1}$ \\
\hline
\end{tabular}

Como na modelagem acima diversos valores de limiares foram utilizados, sendo o mais eficiente $T=[0.075,0.025, \ldots, 0.500]$. Observa-se um incremento considerável nos resultados se comparado com o modelo PAG lattice 4-conectada, isso é devido a melhor representação do grafo através de uma conexão mais densa. Adicionalmente a análise por subgrafos a Tabela 
4.6 apresenta um estudo via análise OPF para função de peso da Equação 4.1.6. Embora apresente resultados levemente superiores ao modelo PAG lattice 4-conectada, ainda assim análise OPF não se mostra adequada para esse tipo de modelo.

Tabela 4.6 - PAG lattice 8-conectada: Resultados obtidos para diferentes quantidades de conjuntos de sementes, análise OPF.

\begin{tabular}{ccccc}
\hline & & \multicolumn{3}{c}{ Acerto (\%) } \\
\cline { 3 - 5 } $\boldsymbol{S}$ & ND & Brodatz & Outex & Vistex \\
\hline 1 & 12 & 6.36 & 9.41 & 8.45 \\
2 & 12 & 7.94 & 12.94 & 13.89 \\
3 & 18 & 7.71 & 12.57 & 14.00 \\
4 & 21 & 10.75 & 18.16 & 17.94 \\
5 & 25 & 11.54 & 18.60 & 20.02 \\
6 & 22 & 13.29 & 19.34 & 22.69 \\
7 & 25 & 13.46 & 19.85 & 21.06 \\
8 & 29 & 17.06 & 21.69 & 25.23 \\
9 & 29 & 16.61 & 21.25 & 25.00 \\
10 & 28 & 16.95 & 22.13 & 23.96 \\
\hline
\end{tabular}

A Figura 4.5 apresenta um estudo em relação as características medidas para o melhor resultado desse modelo (análise por subgrafos, peso Equação 4.1.6e $T=[0.075,0.025, \ldots, 0.500]$ ). Podemos observar que a medida de grau máximo (6) é a que possui maior peso na composição da 1a e 2a variáveis canônicas. As variáveis canônicas são combinações lineares das variáveis originais de tal forma que não há correlação entre as mesmas (ver Anexo B.1). A 1a e 2a variáveis canônicas são ditas mais importantes pois 'explicam' a maior parte da variância total do sistema, de tal forma que, a 1a variável corresponde a $50 \% 91 \%$ e $76 \%$ da variância total explicada para as bases de Brodatz, Outex e Vistex respectivamente (Figura 4.6). Nesse sentido se pode afirmar que o grau máximo é uma medida bastante discriminativa entre classes. Outras medidas que compõe de forma significativa a 1a e 2a variável canônica são: densidade (1) e grau médio (2).

\subsubsection{PAG lattice $r$-conectada}

Como se pode observar acima a única diferença entre um PAG lattice 4-conectada e um PAG lattice 8-conectada é um parâmetro de raio $r$. Generalizando-se tal parâmetro podemos obter um grafo PAG lattice $r$-conectada para qualquer distância $r$ determinada pelo usuário. Um exemplo dessa transformada pode ser vista na Figura 4.7.

Um parâmetro chave nesse modelo é o raio $r$, onde diferentes configurações desses podem ocasionar diferentes resultados. A Tabela 4.7 apresenta os resultados para diferentes valores de $r$ por análise de subgrafos com $T=[0.075,0.025, \ldots, 0.0500]$. Nota-se um incremento 

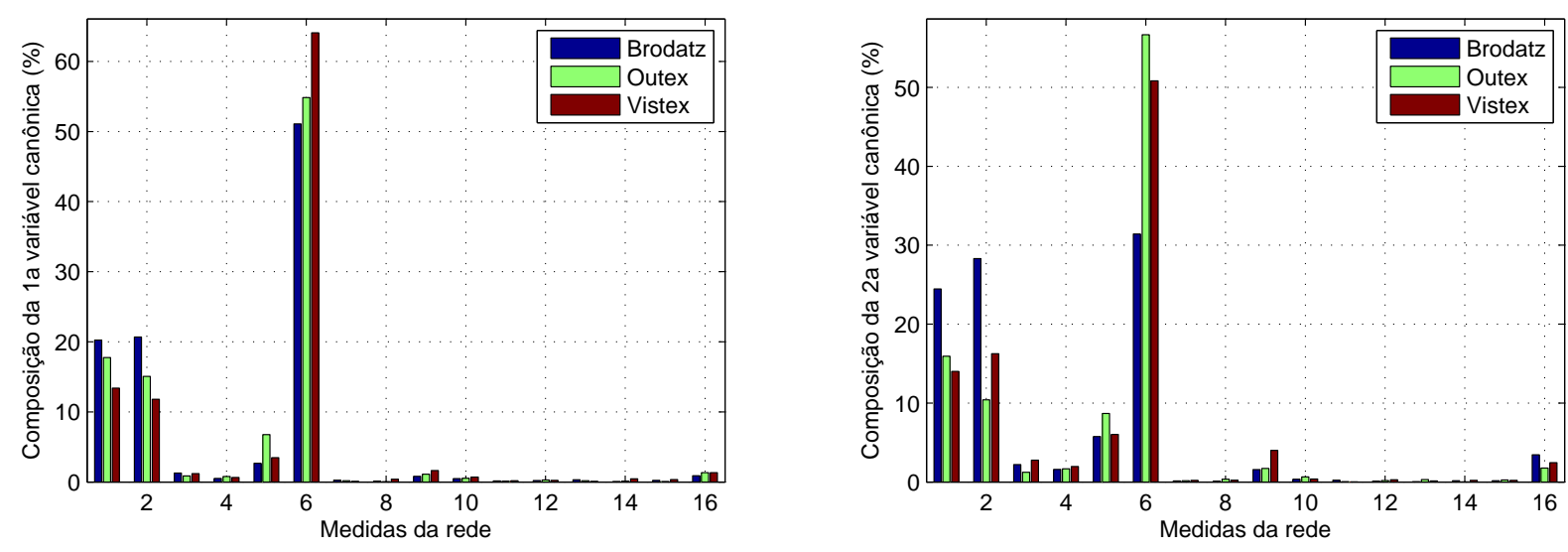

Figura 4.5 - Composição da 1a e 2a variável canônica, modelo PAG lattice 8-conectada.

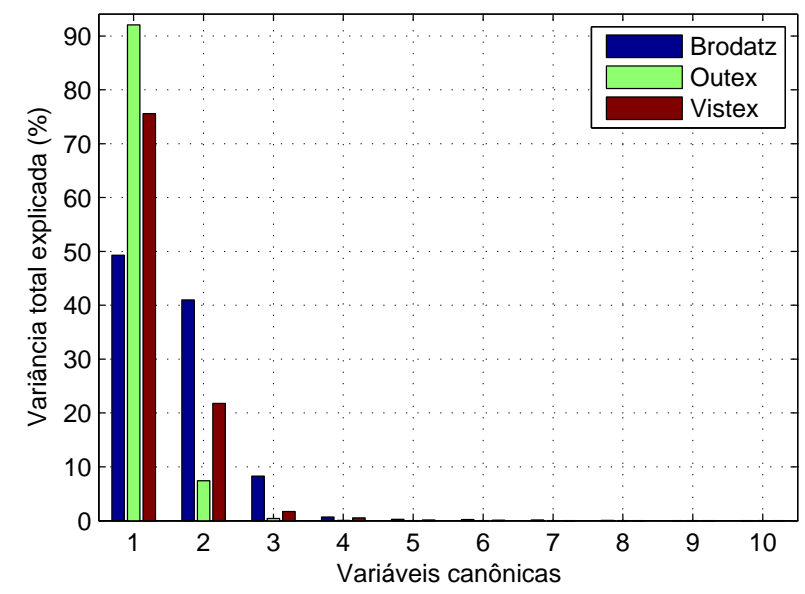

Figura 4.6 - Variância total explicada pelas 10 primeiras variáveis canônicas, modelo PAG lattice 8-conectada.

na performance quando incrementamos o raio de $r=2$ para $r=3$. No entanto para $r \geq 4$ notamos uma ligeira queda na qualidade do método. O que é de certa forma interessante, pois quanto menor o raio menos densa é a rede e, consequentemente, menor o custo computacional de tempo e espaço.

Tabela 4.7 - PAG lattice r-conectada: Resultados obtidos para diferentes valores de raio, análise subgrafos.

\begin{tabular}{cccc}
\hline & \multicolumn{3}{c}{ Acerto (\%) } \\
\cline { 2 - 4 } Raio & Brodatz & Outex & Vistex \\
\hline 2 & 89.64 & 78.01 & 89.93 \\
3 & 95.44 & 86.69 & 97.80 \\
4 & 94.31 & 85.15 & 95.25 \\
5 & 93.58 & 83.90 & 94.56 \\
\hline
\end{tabular}

Uma vez que um raio é utilizado para conexão esse deve possuir um fator normalizador que atenue a similaridade entre dois pixeis de mesma intensidade mas que estão distantes um do outro. Nesse sentido, e observando-se os resultados do modelo PAG lattice 8-conectada, optamos por utilizar exclusivamente a função de peso que considera a diferença de distância 

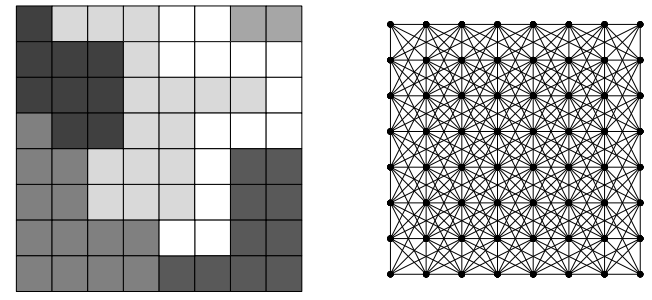

Figura 4.7 - Textura modelada como um PAG lattice r-conectada: (a) cada pixel da imagem é um vértice no grafo; (b) uma aresta é adicionada entre dois vértices se estes representam pixeis à uma distância $r(r=3$ para o exemplo acima); (c) o peso definido pela diferença de distância e intensidade do nível de cinza normalizado entre $[0,1]$.

e intensidade entre os pixeis (Equação 4.1.6) nesse modelo.

As Tabelas 4.8 e 4.9 apresentam as taxas de acerto para análise por subgrafos e OPF utilizando somente a função de peso da Equação 4.1.6 e $r=3$.

Tabela 4.8 - PAG lattice r-conectada: Resultados obtidos para diferentes conjuntos de limiares, análise subgrafos.

\begin{tabular}{ccccc}
\hline & & \multicolumn{3}{c}{ Acerto (\%) } \\
\cline { 3 - 5 } $\boldsymbol{T}$ & ND & Brodatz & Outex & Vistex \\
\hline $0.075,0.025, \ldots, 0.925$ & 27 & 93.36 & 83.90 & 95.95 \\
$0.075,0.050, \ldots, 0.925$ & 25 & 92.91 & 83.09 & 95.14 \\
$0.075,0.075, \ldots, 0.925$ & 22 & 90.54 & 81.69 & 92.71 \\
$0.075,0.100, \ldots, 0.925$ & 18 & 90.15 & 80.74 & 91.20 \\
$0.500,0.025, \ldots, 0.925$ & 25 & 66.84 & 44.49 & 68.98 \\
$0.075,0.025, \ldots, 0.500$ & 26 & $\mathbf{9 5 . 4 4}$ & $\mathbf{8 6 . 6 9}$ & $\mathbf{9 7 . 8 0}$ \\
\hline
\end{tabular}

Assim como no modelo PAG lattice 8-conectado é possível observar claramente que a maior parte das informações relevantes encontra-se nos primeiros subgrafos obtidos por baixos limiares, os quais preservam as informações de baixa frequência da imagem. Os conjuntos $T$ de 1 à 4, alteram o valor do incremento, diminuindo assim o número de características obtidas (i.e. menor número de subgrafos derivados). Observa-se que os resultados finais são aproximadamente preservados, havendo um pequeno declínio com intervalos de 0.100. Em relação aos modelos anteriores observa-se um grande incremento na taxa de acerto devido principalmente à análise de uma vizinhança maior. A análise via OPF por outro lado não demostra-se adequada para esse modelo.

A Figura 4.8 apresenta um estudo em relação as características extraídas desse modelo para composição do melhor resultado apresentado por análise de subgrafos com $r=3$. Podemos observar que, assim como no PAG lattice 8-conectada, a medida de grau máximo (6) é a característica mais importante na composição da 1a e 2a variáveis canônicas. As outras variáveis mais discriminativas são: densidade (1), grau médio (2), energia dos graus (3), entropia dos graus (4), contraste dos graus (5), entropia grau conjunto (9) e coeficiente de 
Tabela 4.9 - PAG lattice r-conectada: Resultados obtidos para diferentes quantidades de conjuntos de sementes, análise OPF.

\begin{tabular}{ccccc}
\hline & & \multicolumn{3}{c}{ Acerto (\%) } \\
\cline { 3 - 5 } $\boldsymbol{S}$ & ND & Brodatz & Outex & Vistex \\
\hline 1 & 9 & 10.02 & 11.76 & 12.62 \\
2 & 12 & 12.84 & 15.51 & 14.00 \\
3 & 18 & 12.33 & 15.15 & 16.20 \\
4 & 23 & 14.30 & 19.34 & 19.44 \\
5 & 28 & 15.20 & 19.78 & 21.30 \\
6 & 25 & 15.03 & 18.68 & 21.18 \\
7 & 27 & 16.22 & 21.47 & 21.76 \\
8 & 28 & 17.62 & 21.10 & 25.93 \\
9 & 29 & 16.84 & 21.10 & 25.00 \\
10 & 28 & 17.34 & 21.62 & 25.00 \\
\hline
\end{tabular}
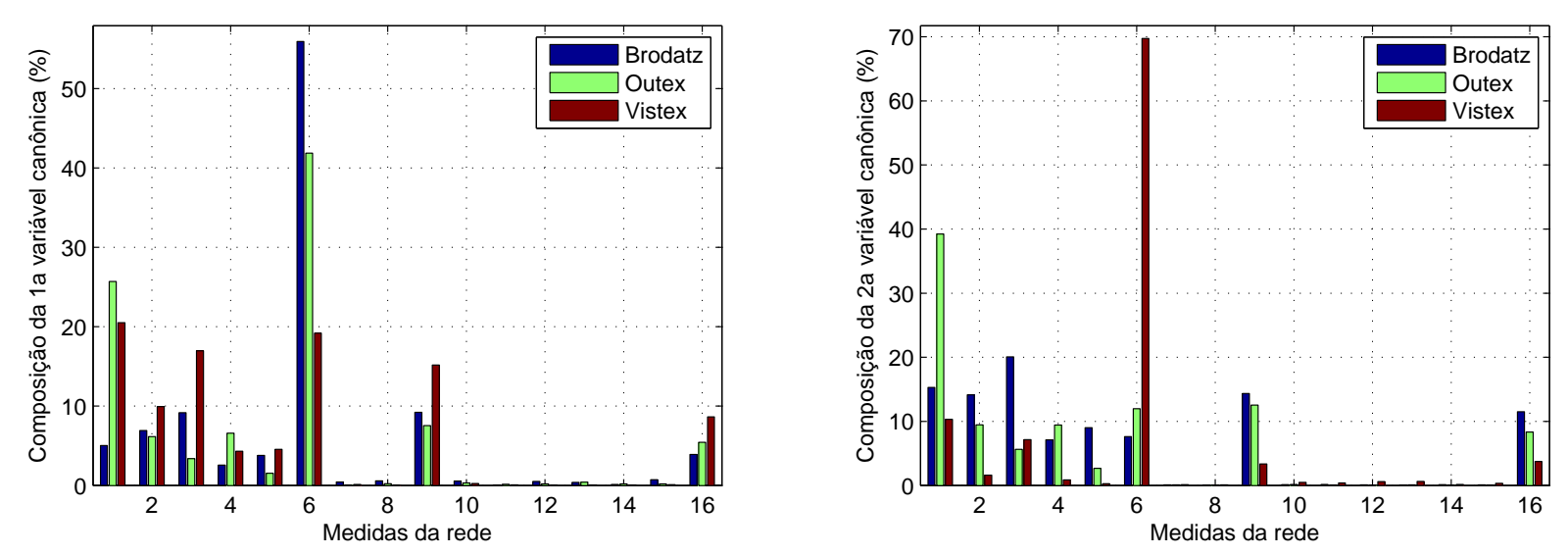

Figura 4.8 - Composição da 1a e 2a variável canônica, modelo PAG lattice r-conectada.

aglomeração (16).

As medidas baseadas em grau e conectividade explicam de forma indireta como está a distribuição dos níveis de cinza da imagem. O grau médio, por exemplo, indica que os vizinhos possuem uma diferença média de intensidade característica para cada classe em análise. 0 mesmo acontece com as medidas de dispersão (entropia), desordem (energia) e transição (contraste). A medida de densidade explica quantos vértices foram removidos do grafo a cada limiar, o que de maneira indireta também mede a variação de tons de cinza da imagem. A entropia de graus conjuntos indica de maneira indireta que há nas imagens regiões similares ou não. Caso uma região seja homogênea, em relação à distribuição de intensidades, há grande possibilidade dos vértices possuírem mesmo grau. Caso uma região seja bastante heterogênea, os limiares aplicados irão afetar de forma aleatória o grau, fator que influenciará nas medidas de grau conjunto. O coeficiente de aglomeração é outra medida que tende a variar conforme diferentes valores de limiares são utilizados (devido a remoção das arestas). 
A Figura 4.9 apresenta um estudo referente a variância total explicada pelas primeiras 10 variáveis canônicas. Observamos que, embora o conjunto de variáveis originais possua um número grande de características, é possível condensar eficientemente a informação via redução de dimensionalidade.

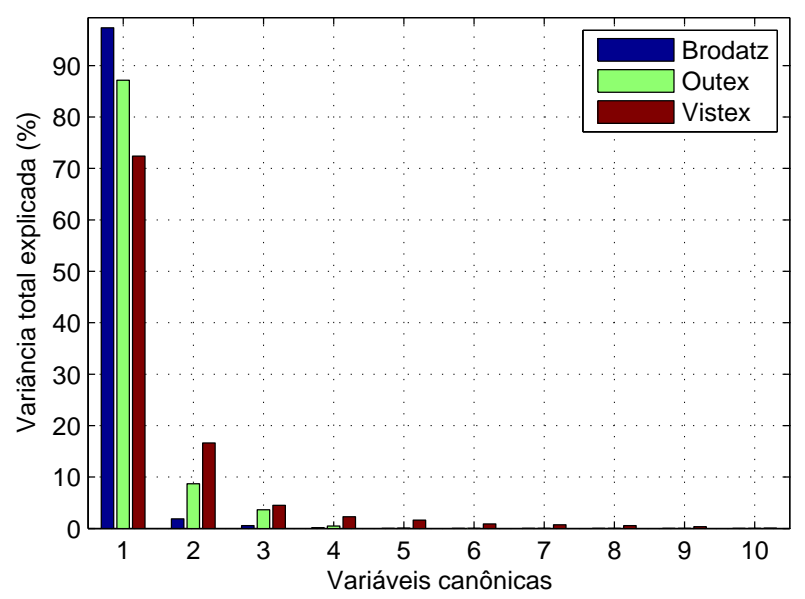

Figura 4.9 - Variância total explicada pelas 10 primeiras variáveis canônicas, modelo PAG lattice r-conectada.

Um modelo similar ao apresentado acima, desenvolvido de maneira independente e simultânea, foi proposto por Chalumeau et al. (8). O autor utiliza um modelo PAG lattice r-conectada, porém só considera a diferença de intensidade do nível de cinza como peso da aresta e utiliza apenas o grau médio e coeficiente de aglomeração como características. Os resultados acima demonstram que a adição de informação da distância entre pixeis geram melhores resultados. $\mathrm{O}$ autor também faz uso transformações hierárquicas precedido pela aplicação de limiar para analisar o modelo ao invés de análise de subgrafos como o aqui proposto.

Esse modelo PAG lattice r-conectada resultou em um artigo de conferência (13) e uma versão melhorada publicada na revista Information Science em 2013 (11). Nesses artigos estudos mais aprofundados a respeito dos parâmetros podem ser encontrados e analisados.

\subsubsection{PAG lattice completo}

Outro sub-caso interessante nesse tipo de modelagem é o grafo PAG lattice completo onde todos os vértices estão conectados com todos os outros, ou seja, o raio $r$ utilizado é o máximo permitido pela imagem. Um exemplo dessa transformada pode ser vista na Figura 4.10.

Esse tipo de modelagem no entanto apresenta um custo computacional muito elevado, não sendo viável uma implementação eficiente em termos de tempo computacional. Apresenta-se 

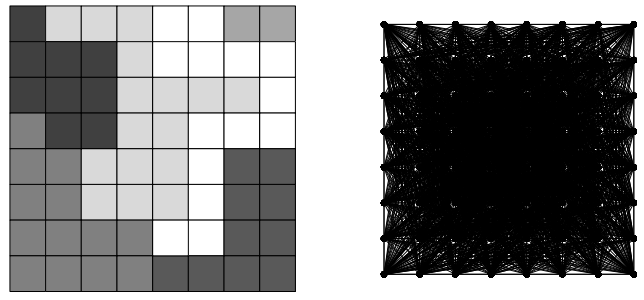

Figura 4.10 - Textura modelada como um PAG lattice completo: (a) cada pixel da imagem é um vértice no grafo; (b) uma aresta é adicionada entre todos os pares de vértices; (c) o peso definido pela diferença de distância e intensidade do nível de cinza normalizado entre $[0,1]$.

apenas os resultados para análise por subgrafos na Tabela 4.10. A análise OPF não é possível nesse modelo devido a representação inicial ser uma matriz completa.

Tabela 4.10 - PAG lattice completa: Resultados obtidos para diferentes conjuntos de limiares, análise subgrafos.

\begin{tabular}{ccccc}
\hline & & \multicolumn{3}{c}{ Acerto (\%) } \\
\cline { 3 - 5 } $\boldsymbol{T}$ & ND & Brodatz & Outex & Vistex \\
\hline $0.075,0.025, \ldots, 0.925$ & 40 & $\mathbf{5 3 . 4 3}$ & $\mathbf{2 9 . 0 4}$ & $\mathbf{5 5 . 3 2}$ \\
$0.075,0.050, \ldots, 0.925$ & 32 & 48.82 & 23.53 & 50.00 \\
$0.075,0.075, \ldots, 0.925$ & 26 & 42.51 & 19.56 & 42.94 \\
$0.075,0.100, \ldots, 0.925$ & 23 & 39.47 & 18.60 & 39.81 \\
$0.500,0.025, \ldots, 0.925$ & 15 & 26.52 & 12.28 & 24.19 \\
$0.075,0.025, \ldots, 0.500$ & 15 & 31.14 & 17.72 & 34.72 \\
\hline
\end{tabular}

Embora a análise da imagem seja feita de forma mais completa, os resultados não se mostraram satisfatórios. Isso se deve à quantidade de informações irrelevantes que são adicionadas à rede em detrimento exaltar as diferenças locais mais importantes. Percebe-se dessa forma que há um compromisso entre a análise local e global da textura. Do ponto de vista local, o modelo PAG lattice raio o faz quando mede as características de cada vértice (e.g. graus) considerando-se apenas a vizinhança a ele conectada por raio $r$, já as características globais fica por conta das medidas de média, dispersão, etc.. desses graus locais.

\subsubsection{PAG lattice k-vizinhos}

Outro sub-caso que pode ser explorado é o modelo PAG lattice do tipo k-vizinhos. Nesse modelo cada vértice é conectado a k-vizinhos mais próximo com base em alguma função de distância. De fato qualquer função de distância pode ser utilizada para tal modelo, caso a função seja a simples distância entre pixeis e $k=4$ o modelo se reduz a um PAG lattice 4conectada. Um exemplo desse modelo utilizando $k=1$ e uma função de distância da diferença de intensidade do nível de cinza pode ser vista na Figura 4.11.

O número $k$ de vizinhos é, portanto, chave nesse tipo de análise. Diferente dos modelos 

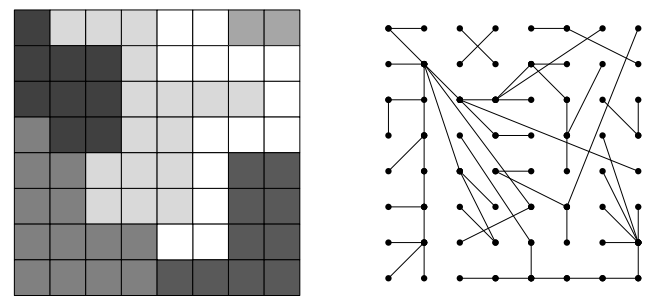

Figura 4.11 - Textura modelada como um PAG lattice k-vizinhos: (a) cada pixel da imagem é um vértice no grafo; (b) uma aresta é adicionada entre os dois vértices que possuírem a diferença $w_{i, j}$ mínima entre todas as possíveis combinações de $i$ e $j$; (c) o peso definido pela diferença de distância e intensidade do nível de cinza normalizado entre $[0,1]$.

anteriormente propostos, esse modelo de PAG lattice k-vizinhos não inicia como um grafo regular, de conexões triviais. Nesse sentido é possível extrair características diretamente do modelo sem a necessidade da análise de subgrafos. A Tabela 4.11 apresenta um estudo utilizando análise direta. Os resultados demostram que um número de 16 vizinhos é o ideal para se obter uma boa representatividade dos grafos, o que de certa forma faz o modelo se aproximar (devido ao número de conexões iniciais) a um PAG lattice r-conectado com $r=3$.

Tabela 4.11 - PAG lattice k-vizinhos: Resultados alcançados para diferentes valores de $k$, análise direta.

\begin{tabular}{ccccc}
\hline & & \multicolumn{3}{c}{ Acerto (\%) } \\
\cline { 3 - 5 } $\boldsymbol{k}$ & ND & Brodatz & Outex & Vistex \\
\hline 1 & 7 & 39.02 & 17.43 & 40.97 \\
2 & 6 & 40.48 & 19.93 & 43.17 \\
4 & 7 & 46.96 & 23.09 & 47.11 \\
8 & 9 & 47.13 & 21.69 & 48.03 \\
16 & 9 & 56.25 & 24.04 & 57.18 \\
32 & 8 & 50.28 & 27.57 & 52.55 \\
\hline
\end{tabular}

Também é possível obter os grafos hierárquicos eficientemente através do conceito de $L-$ expansion, bem como realizar análise via subgrafos e OPF. As Tabelas 4.12, 4.14 e 4.13 e apresentam os resultados para diferentes formas de análise.

Tabela 4.12 - PAG lattice k-vizinhos: Resultados alcançados para diferentes valores de $k$, análise hierárquica.

\begin{tabular}{ccccc}
\hline & & \multicolumn{3}{c}{ Acerto (\%) } \\
\cline { 3 - 5 } $\boldsymbol{L}$ & ND & Brodatz & Outex & Vistex \\
\hline 2 & 15 & 32.55 & 29.93 & 42.71 \\
3 & 23 & 44.93 & 22.57 & 44.44 \\
4 & 22 & 33.90 & 14.78 & 35.07 \\
\hline
\end{tabular}

Podemos observar que, embora possua menos características, a extração de medidas por análise direta apresenta resultados inferiores aos à análise por subgrafos. A Figura 4.12 apresenta um estudo em relação as características extraídas desse modelo para composição do melhor resultado apresentado por análise de subgrafos com $k=16$. Podemos observar que a 
Tabela 4.13 - PAG lattice k-vizinhos: Resultados obtidos para diferentes conjuntos de limiares, análise subgrafos.

\begin{tabular}{ccccc}
\hline & & \multicolumn{3}{c}{ Acerto (\%) } \\
\cline { 3 - 5 } $\boldsymbol{T}$ & ND & Brodatz & Outex & Vistex \\
\hline $0.075,0.025, \ldots, 0.925$ & 59 & 73.20 & 45.88 & 71.53 \\
$0.075,0.050, \ldots, 0.925$ & 51 & 72.35 & 40.81 & 71.18 \\
$0.075,0.075, \ldots, 0.925$ & 40 & 68.64 & 31.54 & 68.87 \\
$0.075,0.100, \ldots, 0.925$ & 36 & 67.74 & 34.71 & 66.32 \\
$0.500,0.025, \ldots, 0.925$ & 46 & 62.33 & 42.21 & 58.10 \\
$0.075,0.025, \ldots, 0.500$ & 41 & $\mathbf{7 0 . 2 1}$ & $\mathbf{4 6 . 4 7}$ & $\mathbf{7 3 . 1 5}$ \\
\hline
\end{tabular}

Tabela 4.14 - PAG lattice k-vizinhos: Resultados obtidos para diferentes quantidades de conjuntos de sementes, análise OPF.

\begin{tabular}{ccccc}
\hline & & \multicolumn{3}{c}{ Acerto (\%) } \\
\cline { 3 - 5 } $\boldsymbol{S}$ & ND & Brodatz & Outex & Vistex \\
\hline 1 & 7 & 18.52 & 6.25 & 13.31 \\
2 & 12 & 19.03 & 6.54 & 12.27 \\
3 & 12 & 18.86 & 7.72 & 13.08 \\
4 & 14 & 19.59 & 9.85 & 17.71 \\
5 & 15 & 18.92 & 10.15 & 18.29 \\
6 & 15 & 20.61 & 10.66 & 19.21 \\
7 & 18 & 23.82 & 12.79 & 20.14 \\
8 & 18 & 23.82 & 13.46 & 21.53 \\
9 & 23 & 27.48 & 13.24 & 25.23 \\
10 & 21 & 30.07 & 9.85 & 28.59 \\
\hline
\end{tabular}

medida de grau máximo (6) e diâmetro da rede (10) são as características mais importantes na composição da 1a e 2a variáveis canônicas. Outras medidas importantes são densidade (1), grau médio (2), energia dos graus (3), entropia dos graus (4), contraste dos graus (5), entropia grau conjunto (9) e coeficiente de aglomeração (16).

Interessante notar que o diâmetro da rede teve grande influência nas variáveis que mais contribuem para separação das classes. O diâmetro da rede, considerando sucessivos limiares, indica de forma indireta como valores similares de intensidade estão distribuídos na rede, fator que altera a excentricidade dos vértices e consequentemente o diâmetro da rede. A Figura 4.13 apresenta a variância total explicada pelas 10 primeiras variáveis canônicas.

\subsubsection{PAG lattice Small-World}

Os recentes interesses em se utilizar redes do tipo small world sugerem a inclusão desse modelo. O modelo PAG lattice small-world apresenta como característica a possibilidade de, a partir de um vértice qualquer, alcançar um outro com um pequeno número de passos. 

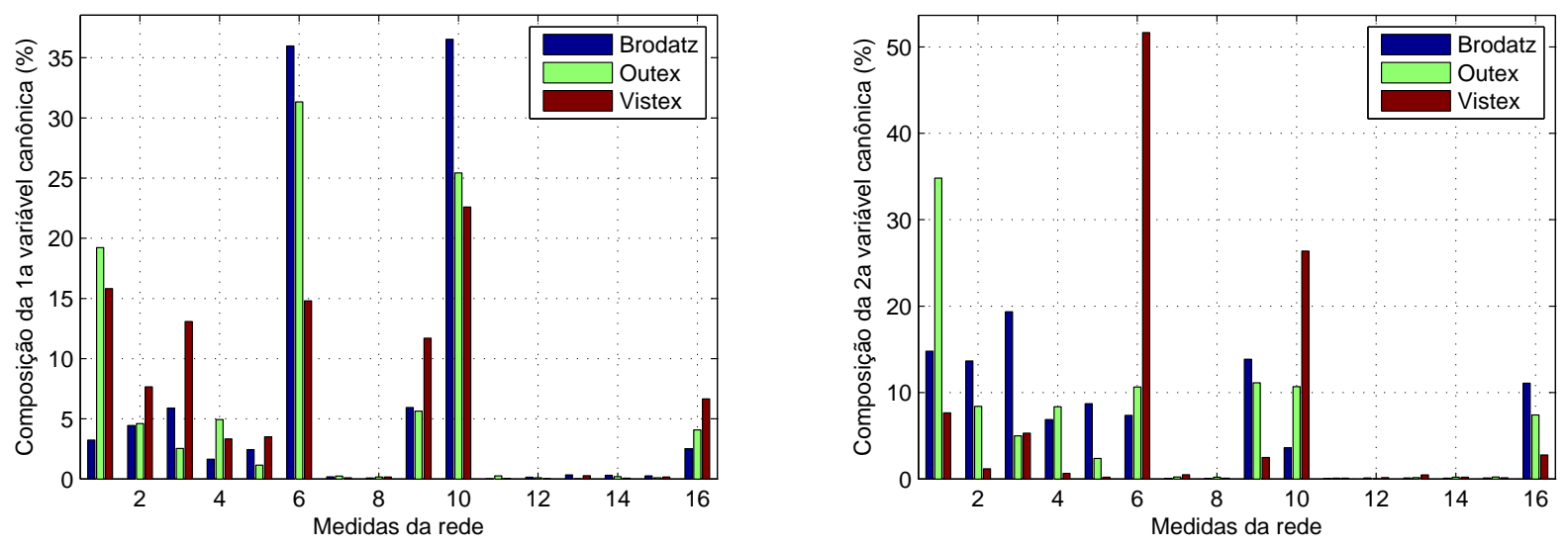

Figura 4.12 - Composição da 1a e 2a variável canônica, modelo PAG lattice k-vizinhos.

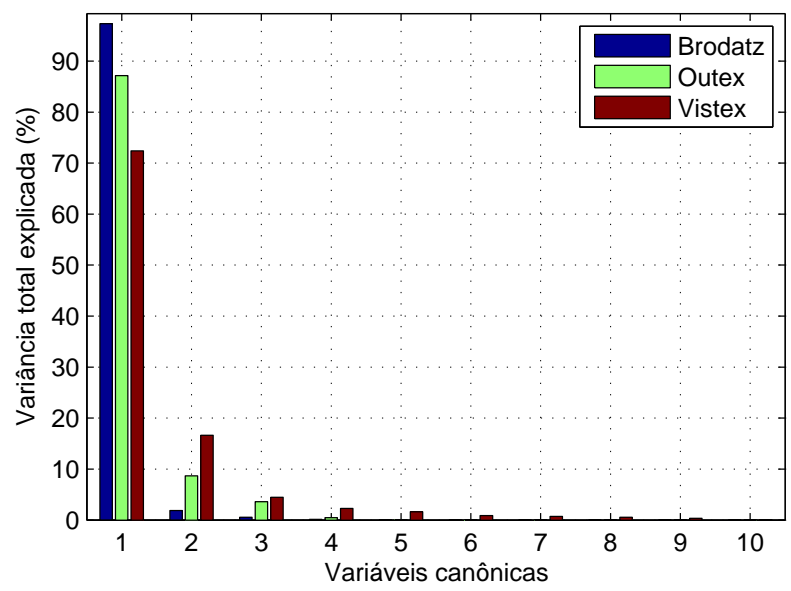

Figura 4.13 - Variância total explicada pelas 10 primeiras variáveis canônicas, modelo PAG lattice k-vizinhos.

Em redes complexas uma rede do tipo small-world refere-se a uma rede que apresenta duas propriedades: (1) mundo pequeno, i.e. todos os vértices podem ser alcançados por qualquer outro através de um número pequeno de arestas (caminho médio pequeno) e (2) apresenta um número alto de laços de tamanho três, i.e., se o vértice $i$ é conectado ao vértice $j$ e $k$, então há uma alta probabilidade dos vértices $j$ e $k$ também serem conectados (alto coeficiente de aglomeração).

Para construir uma rede pequeno mundo para análise de texturas utilizou-se o modelo de Watts e Strogatz (3): (1) inicia-se um grafo regular com $N$ vértices, cada um conectado a $\kappa$ vizinhos, onde $N>>\wedge>\ln (N)>>1$. Cada vértice então é randomicamente redirecionado com probabilidade $p$. Quando $p=0$ temos um grafo regular, para $p=1$ temos um grafo aleatório. Watts e Strogatz mostraram que, para um valor intermediário de $p$, temos a formação de uma rede com caminho médio pequeno e alto coeficiente de aglomeração. Um exemplo do resultado desse modelo pode ser visto na Figura 4.14).

A Tabela 4.15 apresenta o resultado para análise de subgrafos. Os resultados são bem 

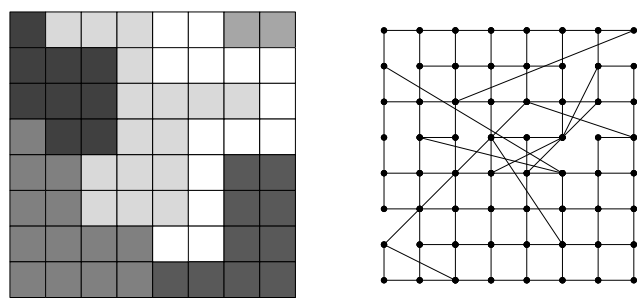

Figura 4.14 - Textura modelada como um PAG lattice small-world: (a) inicia-se uma grafo regular (PAG lattice 4-conectada); (b) cada aresta é redirecionada com probabilidade $p$; (c) o peso definido pela diferença de distância e intensidade do nível de cinza normalizado entre $[0,1]$.

inferiores aos obtidos pelo modelo PAG lattice k-vizinhos devido a esse modelo redirecionar arestas aleatoriamente sem nenhum critério. Utilizou-se nesse experimento probabilidade de $p=0.35$.

Tabela 4.15 - PAG lattice small-world: Resultados obtidos para diferentes conjuntos de limiares, análise subgrafos.

\begin{tabular}{ccccc}
\hline & & \multicolumn{3}{c}{ Acerto (\%) } \\
\cline { 3 - 5 } $\boldsymbol{T}$ & ND & Brodatz & Outex & Vistex \\
\hline $0.075,0.025, \ldots, 0.925$ & 24 & 25.23 & 14.78 & 23.26 \\
$0.075,0.050, \ldots, 0.925$ & 25 & 24.72 & 12.21 & 20.95 \\
$0.075,0.075, \ldots, 0.925$ & 17 & 23.09 & 10.15 & 20.60 \\
$0.075,0.100, \ldots, 0.925$ & 14 & 20.83 & 7.28 & 18.63 \\
$0.500,0.025, \ldots, 0.925$ & 16 & 14.64 & 5.66 & 12.50 \\
$0.075,0.025, \ldots, 0.500$ & 18 & 29.73 & 12.21 & 26.97 \\
\hline
\end{tabular}

A Tabela 4.16 apresenta uma análise via OPF. Embora não sejam resultados suficientemente bons destaque para um leve aumento na taxa de acerto da análise OPF se comparada com os modelos PAG anteriores. Isso talvez se deva a propriedade small-world criada no modelo, que possibilita a criação de florestas de caminhos ótimos que cobrem toda a rede com caminhos médios mais curtos.

Tabela 4.16 - PAG lattice small-world: Resultados obtidos para diferentes quantidades de conjuntos de sementes, análise OPF.

\begin{tabular}{ccccc}
\hline & & \multicolumn{3}{c}{ Acerto (\%) } \\
\cline { 3 - 5 } $\boldsymbol{S}$ & ND & Brodatz & Outex & Vistex \\
\hline 1 & 6 & 22.13 & 11.99 & 21.88 \\
2 & 11 & 26.35 & 11.10 & 29.05 \\
3 & 18 & 30.46 & 16.10 & 30.56 \\
4 & 20 & 37.61 & 14.12 & 37.27 \\
5 & 21 & 36.82 & 14.71 & 36.23 \\
6 & 31 & 37.84 & 22.79 & 40.86 \\
7 & 20 & 40.93 & 18.24 & 40.16 \\
8 & 20 & 40.48 & 18.97 & 40.39 \\
9 & 26 & 45.33 & 17.21 & 42.82 \\
10 & 24 & $\mathbf{4 5 . 0 5}$ & $\mathbf{1 7 . 6 5}$ & $\mathbf{4 4 . 5 6}$ \\
\hline
\end{tabular}


A Figura 4.15 e Figura 4.16 apresentam um estudo em relação as medidas de redes complexas extraídas do modelo. De forma interessante podemos notar que as medidas de distância geodésica média (11) e eficiência global (12), que são duas medidas relacionadas diretamente com o modelo small-world, tiveram grande importância na composição das primeiras variáveis canônicas.
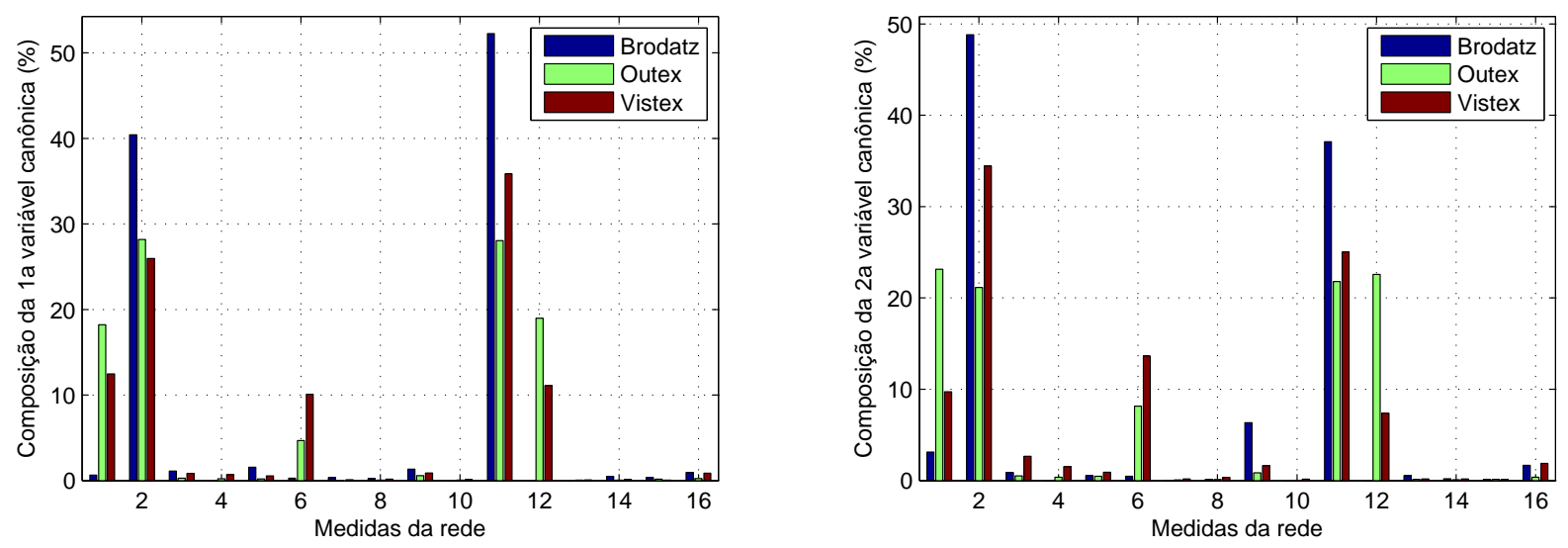

Figura 4.15 - Composição da 1a e 2a variável canônica, modelo PAG lattice small-world.

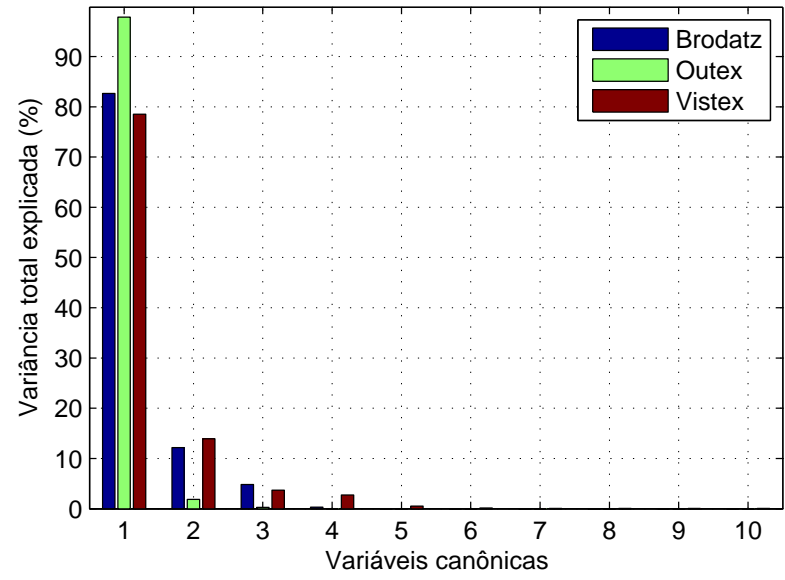

Figura 4.16 - Variância total explicada pelas 10 primeiras variáveis canônicas, modelo PAG lattice smallworld.

\subsection{CPAG - Grafo por adjacência de cor pixel}

Todos os modelos PAG anteriormente propostos são concebidos para análise de imagens em escala de cinza, ou seja, possuem apenas um canal de cores. As imagens coloridas por outro lado possuem 3 canais de cores (considerando-se o espaço de cores RGB), o que imediatamente nos leva a considerar um tipo de modelo especial para tal situação.

Nesse sentido a proposta é o grafo por adjacência de cor pixel, ou CPAG (do inglês color 
pixel adjacency graph). Nesse grafo cada pixel é representado por 3 vértices simultaneamente, ou seja, cada conjunto $S_{i}$ continua a representar um único pixel da imagem, porém a interseção de tais conjuntos não é um conjunto vazio. Nesse modelo conecta-se todos os vértices se os pixeis que esses representam são 18-adjacentes na imagem original (ou seja, considera-se como se cada canal de cores estivesse simplesmente empilhado um sobre o outro para cálculo da adjacência). Seguindo a regra geral temos:

- Quantidade de pixeis existentes em $S_{i}$ :

$$
\left|S_{i}\right|=1, \text { para todos } S_{i} \in C
$$

- Quantidade dos pixeis representados em $C$ :

$$
\bigcup_{S_{i} \in C} S_{i}=I
$$

- Relação entre cada subconjunto $S_{i}$ de $C$ :

$$
\bigcap_{S_{i} \in C} S_{i} \neq \oslash
$$

Para esse modelo o peso $w_{i j}$ é definido pela seguinte equação:

- Distância e diferença de intensidade normalizada entre dois pixeis $p\left(x_{i}, y_{j}\right)$ e $q\left(x_{i}, y_{j}\right)$ :

$$
w_{i j}=\frac{\sqrt{\left(x_{i}-x_{j}\right)^{2}+\left(y_{i}-y_{j}\right)^{2}}}{1.41}+\frac{p\left(x_{i}, y_{i}\right)-p\left(x_{j}, y_{j}\right)}{2 L}
$$

onde $p\left(x_{i}, y_{j}\right)$ e $q\left(x_{i}, y_{j}\right)$ denotam a intensidade do pixel para um determinado canal de cores nas coordenadas $(x, y), L$ é o valor máximo que uma cor pode assumir para o modelo RGB $(L=255)$ e 1.41 é o raio de conexão equivalente para vizinhança 18-adjacentes.

Como um mesmo pixel pode ser representado por 3 vértices distintos a aplicação da equação 4.2 .4 deve considerar qual o canal de cores está a ser conectado (i.e. valor de intensidade do pixel $p\left(x_{i}, y_{j}\right)$ depende do canal que esse vértice está representado). Nesse sentido em caso de conexão entre vértices que representam o mesmo pixel o valor de distância será nulo pois $\sqrt{\left(x_{i}-x_{j}\right)^{2}+\left(y_{i}-y_{j}\right)^{2}}=0$. Um exemplo de tal modelagem pode ser vista na Figura 4.17.

A Tabela 4.17 e 4.18 apresentam resultados para o modelo CPAG na análise de texturas coloridas no modelo RGB por análise de subgrafos e OPF. Assim como no modelo PAG as 

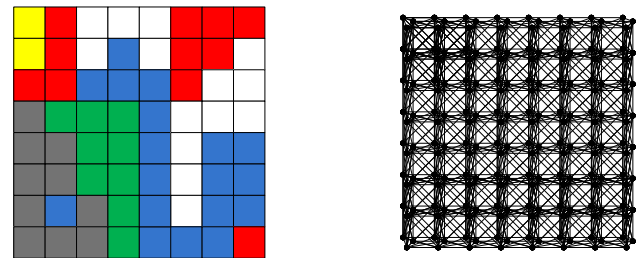

Figura 4.17 - Textura modelada como um CPAG: (a) cada pixel da imagem é representado por 3 vértices (RGB); (b) conecta-se todos os vértices se os pixeis que esses representem são 18-adjacentes na imagem original; (c) Distância e diferença de intensidade normalizada entre dois pixeis $p \mathrm{e}$ $q$.

análises direta e hierárquica não são adequadas, uma vez que a distribuição das arestas segue uma mesma regra de conexão para todas as imagens (i.e. grafo k-regular com distribuição de conexões triviais).

Tabela 4.17 - CPAG: Resultados obtidos para diferentes conjuntos de limiares, análise subgrafos.

\begin{tabular}{cccc}
\hline & & \multicolumn{2}{c}{ Acerto (\%) } \\
\cline { 3 - 4 } $\boldsymbol{T}$ & ND & Outex & Vistex \\
\hline $0.075,0.025, \ldots, 0.925$ & 28 & 38.68 & 70.14 \\
$0.075,0.050, \ldots, 0.925$ & 29 & 40.22 & 69.56 \\
$0.075,0.075, \ldots, 0.925$ & 30 & 40.74 & 69.21 \\
$0.075,0.100, \ldots, 0.925$ & 33 & 44.04 & 71.76 \\
$0.500,0.025, \ldots, 0.925$ & 29 & 28.82 & 59.61 \\
$0.075,0.025, \ldots, 0.500$ & 23 & 25.51 & 53.13 \\
\hline
\end{tabular}

Tabela 4.18 - CPAG: Resultados obtidos para diferentes quantidades de conjuntos de sementes, análise OPF.

\begin{tabular}{cccc}
\hline & & \multicolumn{2}{c}{ Acerto (\%) } \\
\cline { 3 - 4 } $\boldsymbol{S}$ & ND & Outex & Vistex \\
\hline 1 & 8 & 22.72 & 38.89 \\
2 & 10 & 27.21 & 40.63 \\
3 & 11 & 30.15 & 48.73 \\
4 & 11 & 31.25 & 54.28 \\
5 & 14 & 31.25 & 56.02 \\
6 & 13 & 34.78 & 61.81 \\
7 & 14 & 35.29 & 61.46 \\
8 & 15 & 36.54 & 66.55 \\
9 & 17 & 36.99 & 65.74 \\
10 & 19 & $\mathbf{4 2 . 2 8}$ & $\mathbf{7 4 . 3 1}$ \\
\hline
\end{tabular}

A Figura 4.18 apresenta um estudo em relação às medidas mais discriminativas desse modelo por análise OPF de 10 conjuntos de sementes. Observamos que as medidas de densidade (1), grau médio (2), energia dos graus (3), grau máximo (6) e grau conjunto médio (7) são as mais discriminativas para ambas as duas primeiras variáveis canônicas.

Um alto grau na análise análise por OPF indica a existência de vértices que conectam (i.e. são mais próximos) a diversos outros, formando hubs. A diversidade dos graus, medida pela 

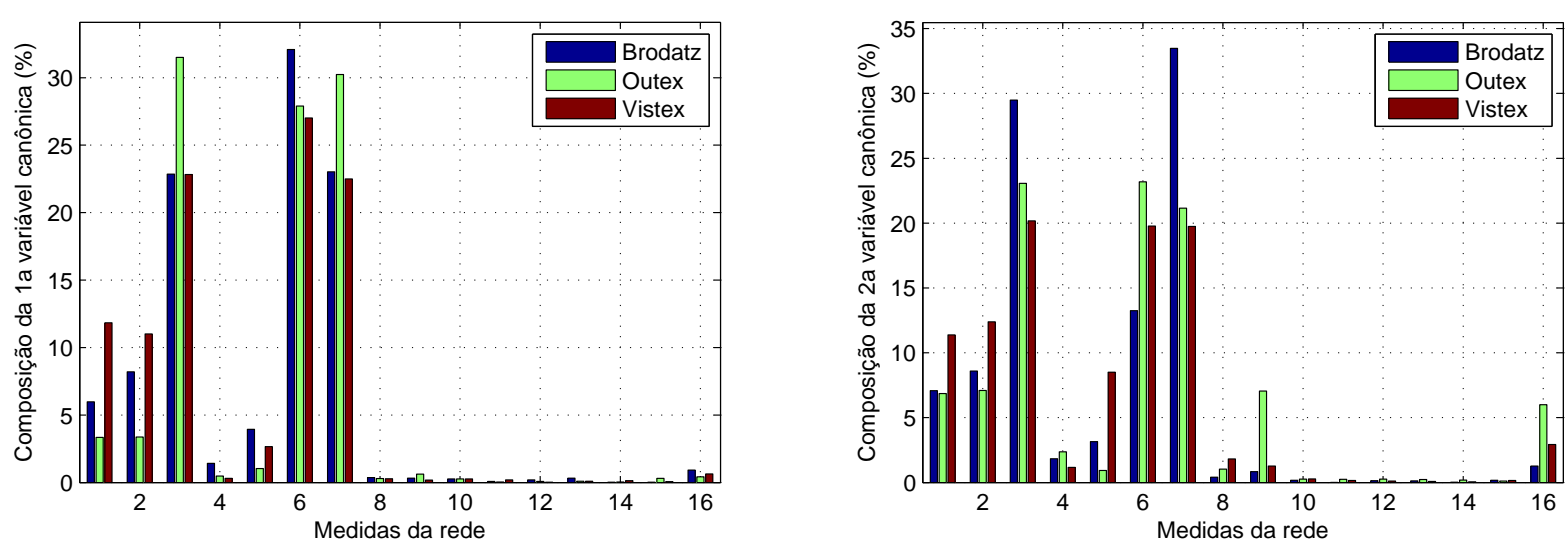

Figura 4.18 - Composição da 1a e 2a variável canônica, modelo CPAG.

média, energia, entropia e máximo, indica que há nas imagens vértices com comportamentos distintos de graus para diferentes classes. A Figura 4.19 apresenta a variância total explicada pelas primeiras variáveis canônicas.

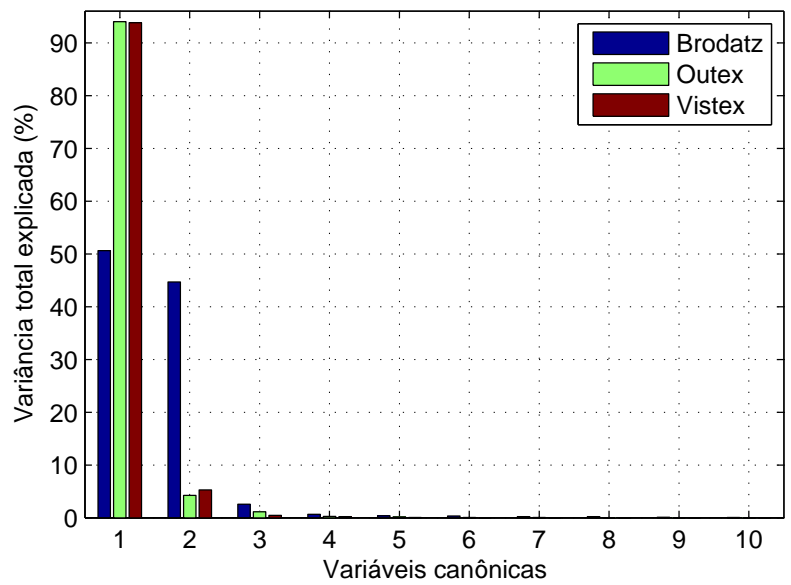

Figura 4.19 - Variância total explicada pelas 10 primeiras variáveis canônicas, modelo CPAG.

\subsection{MAG - Grafo por adjacência multiescala}

O grafo de adjacência multi-escala, ou MAG (do inglês multiscale adjacency graph), é um dos modelos que podem ser utilizados na modelagem de texturas. Esse modelo inicia de uma lattice regular onde cada pixel é representado por um vértice. Agrupamentos regulares de 4 pixeis são criados conectando-se uns aos outros os pixeis pertencentes ao grupo formado, gerando assim o primeiro nível hierárquico. No segundo nível hierárquico um vértice que representa cada um dos grupos de 4 pixeis é criado. Esse vértice é conectado aos 4 pixeis do primeiro nível por uma aresta e também é conectado a outros vértices de segundo nível vizinhos a ele. Os demais níveis hierárquicos seguem a mesma regra do segundo nível. Essa 
configuração leva a uma regra onde alguns dos conjuntos $S_{i}$ não contém nenhum pixel (e.g. vértices a partir do segundo nível hierárquico).

- Quantidade de pixeis existentes em $S_{i}$ :

$$
\left|S_{i}\right|=0, \text { para algum } S_{i} \in C
$$

- Quantidade dos pixeis representados em $C$ :

$$
\bigcup_{S_{i} \in C} S_{i}=I
$$

- Relação entre cada subconjunto $S_{i}$ de $C$ :

$$
\bigcap_{S_{i} \in C} S_{i}=\oslash
$$

Para esse modelo o peso $w_{i j}$ deve ser definido para arestas que conectam vértices em um mesmo nível e para arestas que conectam diferentes níveis hierárquicos. Por simplicidade consideramos a 'intensidade' do vértice de segundo nível como sendo a média da intensidade do grupo à que ele está conectado. Assim podemos definir uma função de peso geral sendo:

- Diferença de intensidade normalizada entre dois pixeis $p\left(x_{i}, y_{j}\right)$ e $q\left(x_{i}, y_{j}\right)$ ou vértices $i$ e $j$ :

$$
w_{i j}=\frac{p\left(x_{i}, y_{i}\right)-q\left(x_{j}, y_{j}\right)}{L}
$$

Tal representação assemelha-se ao método de wavelets (82), cuja uma representação multiescala é obtida através de filtros passa baixa. Nesse modelo porém as diversas escalas são conectadas entre si e analisadas em conjunto. A Figura 4.20 apresenta um esquema geral para melhor entendimento do modelo proposto.

Assim como no modelo PAG E CPAG, por possuir conexões regulares (i.e. definidas de forma igual para todas as imagens) a análise direta e hierárquica não são adequadas.

A Tabela 4.19 abaixo apresenta um estudo com relação ao número de níveis a serem empregados em análise de texturas. Resultados obtidos com análise de subgrafos com $T=$ $[0.075,0.075, \ldots, 0.925]$. Esse modelo de fato assemelha-se ao PAG lattice 4-conectada e os baixos resultados podem ser interpretados, assim como no lattice 4-conectada, ao baixo alcance das conexões entre os pixeis da imagem.

A Tabela 4.20 e 4.21 apresentam os resultados desse modelo com multi-escala 4 sob análise por subgrafos e OPF. Verifica-se que se retirados os baixos limiares há uma queda 

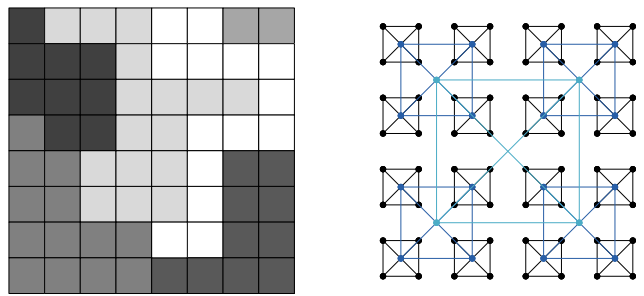

Figura 4.20 - Textura modelada como um MAG: (a) cada pixel é um vértice do grafo no primeiro nível hierárquico; (b) agrupamentos regulares de 4 vértices são criados e conectados uns aos outros; (c) o peso é definido como a diferença de intensidade normalizada entre os pixeis $p$ e $q$; (d) vértices extras são criados para representar cada um dos grupos do primeiro nível, o 'valor' do vértice definido como sendo uma média das intensidades do grupo que esse representa; (e) conectam-se esses vértices de segundo nível aos vértices do grupo de primeiro e também aos vértices de segundo nível vizinhos; (f) peso definido pela diferença intensidade entre vértices normalizada.

Tabela 4.19 - Resultados alcançados para diferentes níveis multiescala para o modelo MAG.

\begin{tabular}{ccccc}
\hline & & \multicolumn{3}{c}{ Acerto (\%) } \\
\cline { 3 - 5 } Multiescala & ND & Brodatz & Outex & Vistex \\
\hline 2 & 12 & 26.69 & 45.00 & 35.88 \\
3 & 15 & 30.12 & 48.24 & 38.08 \\
4 & 15 & 33.00 & 50.51 & 41.67 \\
8 & 15 & 30.74 & 48.31 & 39.70 \\
\hline
\end{tabular}

drástica nos resultados, como a função de peso é definida somente pela cor, percebe-se pela análise de subgrafos que as pequenas alterações dessa são mais informativas ou se fazem mais presentes nas diferentes imagens. A análise por OPF por outro lado apresenta resultados bem inferiores a análise por subgrafos.

Tabela 4.20 - MAG: Resultados obtidos para diferentes conjuntos de limiares, análise subgrafos.

\begin{tabular}{ccccc}
\hline & & \multicolumn{3}{c}{ Acerto (\%) } \\
\cline { 3 - 5 } $\boldsymbol{T}$ & ND & Brodatz & Outex & Vistex \\
\hline $0.075,0.025, \ldots, 0.925$ & 26 & 24.94 & 21.93 & 30.90 \\
$0.075,0.050, \ldots, 0.925$ & 19 & 30.29 & 28.49 & 38.66 \\
$0.075,0.075, \ldots, 0.925$ & 15 & $\mathbf{3 3 . 0 0}$ & $\mathbf{2 3 . 5 1}$ & $\mathbf{4 1 . 6 7}$ \\
$0.075,0.100, \ldots, 0.925$ & 16 & 31.93 & 27.28 & 39.24 \\
$0.500,0.025, \ldots, 0.925$ & 36 & 6.36 & 7.43 & 10.19 \\
$0.075,0.025, \ldots, 0.500$ & 20 & 31.70 & 27.63 & 37.96 \\
\hline
\end{tabular}

As Figuras 4.21 e 4.22 apresentam um estudo em relação às medidas mais discriminativas para o melhor resultado obtido para esse modelo (análise subgrafos). Observamos que as medidas de distância geodésica média (11) e eficiência global (12) prevalecem na formação da primeira variável canônica. O mesmo acontece para a segunda variável canônica, que adicionalmente é composta pela energia dos graus (3), entropia dos graus (4), contraste dos graus (5), grau máximo (6), energia grau conjunto (8) e entropia grau conjunto (9). 
Tabela 4.21 - MAG: Resultados obtidos para diferentes quantidades de conjuntos de sementes, análise OPF.

\begin{tabular}{ccccc}
\hline & & \multicolumn{3}{c}{ Acerto (\%) } \\
\cline { 3 - 5 } $\boldsymbol{S}$ & ND & Brodatz & Outex & Vistex \\
\hline 1 & 11 & 9.93 & 6.98 & 19.91 \\
2 & 14 & 13.60 & 3.94 & 23.96 \\
3 & 18 & 16.03 & 4.79 & 27.78 \\
4 & 17 & 16.76 & 4.90 & 27.20 \\
5 & 19 & 20.44 & 7.55 & 34.03 \\
6 & 20 & 19.71 & 8.33 & 34.84 \\
7 & 24 & 19.78 & 8.78 & 36.11 \\
8 & 23 & 19.49 & 11.99 & 22.80 \\
9 & 24 & 20.59 & 12.78 & 25.46 \\
10 & 27 & 20.74 & 13.34 & 27.08 \\
\hline
\end{tabular}
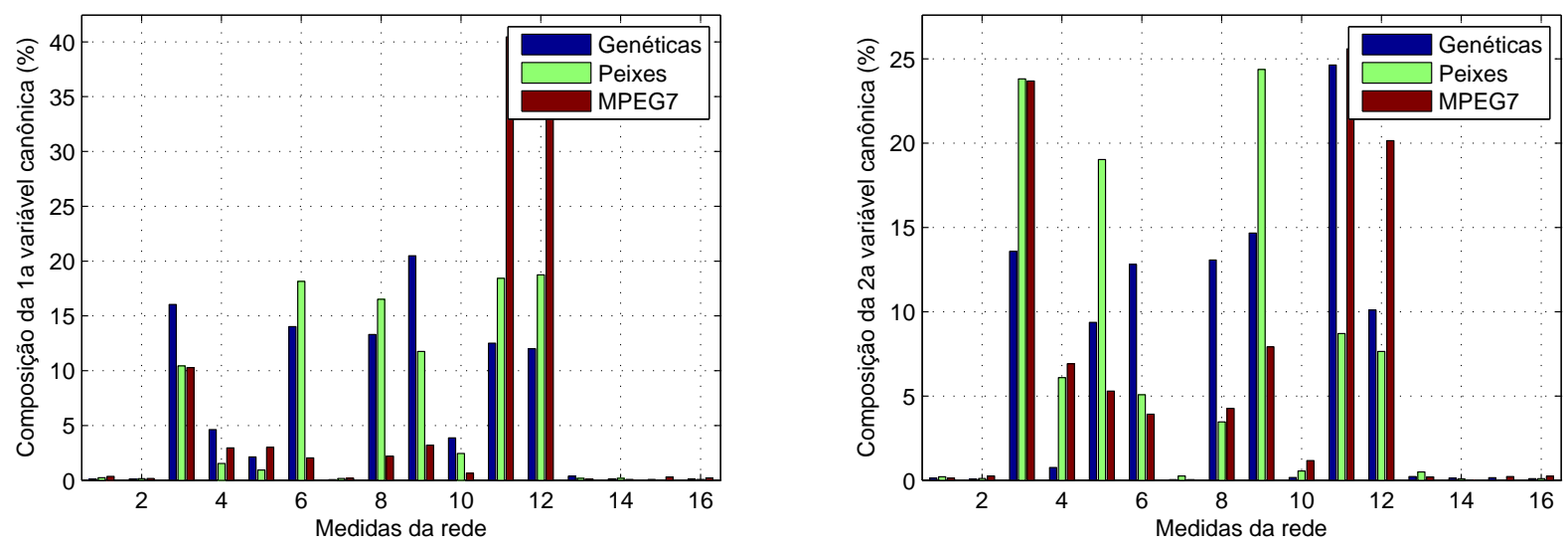

Figura 4.21 - Composição da 1a e 2a variável canônica, modelo MAG.

As medidas de distância geodésica média e eficiência global nesse modelo são bastante influenciadas por arestas de hierarquias superiores que por ventura venham a ser removidas por um limiar, uma vez que essas conectam grande parte do grafo e sua remoção tem grande impacto na conectividade total.

\subsection{RAG - Grafo por adjacência de regiões}

Um dos conceitos fundamentais de textura é que essa pode ser composta por primitivas chamadas de textons (83). Nesse sentido, ao invés de analisar as texturas a nível dos pixeis, podemos empregar uma operação de segmentação (pré-processamento) de forma a isolar tais primitivas e analisa-las sob um ponto de vista mais amplo. Tal modelagem é chamada na literatura de RAG (do inglês region adjacency graph), e é utilizada bastante em processos de segmentação de imagens. Todavia este mesmo processo de construção do grafo pode ser empregado aqui para posterior caracterização da rede. 


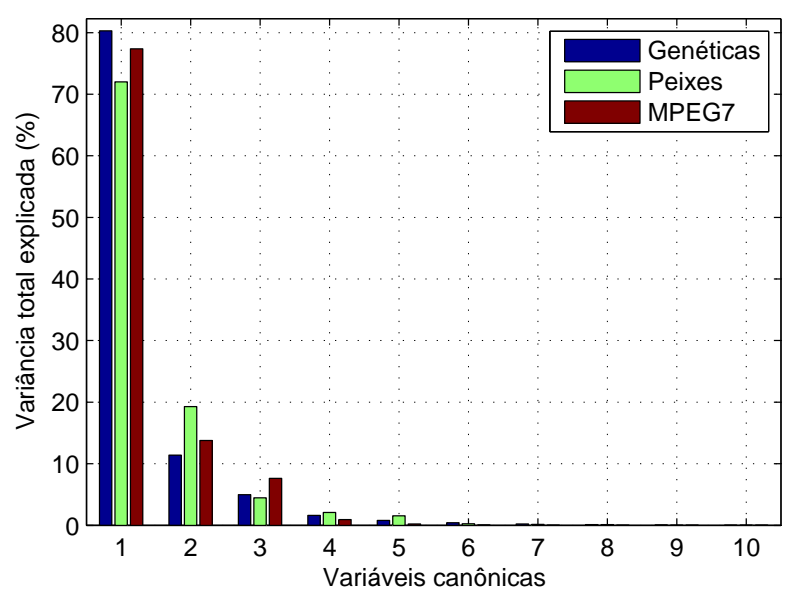

Figura 4.22 - Variância total explicada pelas 10 primeiras variáveis canônicas, modelo MAG.

A ideia do RAG é que cada região será representada por um vértice, e os dois vértices $i$ e $j$ serão conectados se as regiões que esses representem são adjacentes (i.e. compartilham borda em uma vizinhança do tipo 4 ou 8-conectada). Portanto para esse modelo necessariamente algum conjunto $S_{i}$ estará representando um conjunto de pixeis adjacentes. Seguindo a regra geral temos:

- Quantidade de pixeis existentes em $S_{i}$ :

$$
\left|S_{i}\right| \geq 1 \text {, para algum } S_{i} \in C
$$

- Relação dos pixeis em $S_{i}$ :

$$
\forall p_{i} \in S_{i} \exists p_{j} \in S_{i} \mid p_{i} \text { e } p_{j} \text { são adjacentes. }
$$

- Quantidade dos pixeis representados em $C$ :

$$
\bigcup_{S_{i} \in C} S_{i}=I
$$

- Relação entre cada subconjunto $S_{i}$ de $C$ :

$$
\bigcap_{S_{i} \in C} S_{i}=\oslash
$$

Podemos observar pelas equações acima que, matematicamente, a diferença básica entre um PAG em um RAG é a existência de pelo menos um vértice representando mais de um pixel. Embora os grafos por adjacência de pixel apresentem bons resultados, em alguns casos a complexidade de tais modelos é demasiadamente alta (e.g. um imagem de tamanho grande 
irá gerar grande número vértices e conexões, deixando a matriz de adjacência e os algoritmos de extração de características muito custosos no tempo e no espaço).

Algumas funções de peso básicas podem ser definidas para esse modelo, sendo elas:

- Distância entre o centro de massa de duas regiões $r\left(x_{i}, y_{i}\right)$ e $r\left(x_{j}, y_{j}\right)$ :

$$
w_{i j}=\sqrt{\left(x_{i}-x_{j}\right)^{2}+\left(y_{i}-y_{j}\right)^{2}}
$$

- Diferença de intensidade normalizada entre duas regiões $r\left(x_{i}, y_{i}\right)$ e $r\left(x_{j}, y_{j}\right)$ :

$$
w_{i j}=\frac{r\left(x_{i}, y_{i}\right)-r\left(x_{j}, y_{j}\right)}{L}
$$

- Distância e diferença de intensidade normalizada entre dois pixeis $r\left(x_{i}, y_{i}\right)$ e $r\left(x_{j}, y_{j}\right)$ :

$$
w_{i j}=\frac{\sqrt{\left(x_{i}-x_{j}\right)^{2}+\left(y_{i}-y_{j}\right)^{2}}}{2 \operatorname{dim}(I)}+\frac{r\left(x_{i}, y_{i}\right)-r\left(x_{j}, y_{j}\right)}{2 L}
$$

- Número de pixeis que compartilham borda entre as regiões $r\left(x_{i}, y_{i}\right)$ e $r\left(x_{j}, y_{j}\right)$ :

$$
w_{i j}=\sum_{p} 1 \text { se } \exists p \in S_{i} \text { 4-adjacente a } q \in S_{j}, i \neq j
$$

onde $r\left(x_{i}, y_{i}\right)$ e $r\left(x_{j}, y_{j}\right)$ representam a intensidade média da região com centro de massa nas coordenadas $(x, y), L$ é o número máximo de níveis de cinza na imagem e $\operatorname{dim}(I)$ a dimensão da imagem.

\subsubsection{RAG estático}

Um primeiro sub-caso de RAG é quando, após prévia segmentação, conecta-se todos os vértices se as regiões que esses representem são 4-adjacentes na imagem original. Para cada aresta um peso $w_{i j}$ é associado podendo essa ser definida pelas equações 4.4.5, 4.4.6, 4.4.7 e 4.4.8. Um exemplo desse modelo pode ser visto na Figura 4.23).

Para obtenção da imagem segmentada o algoritmo de Watershed proposto por Meyer e Beucher (84) foi utilizado. Baseado em morfologia matemática esse método utiliza os módulos dos gradientes como variações locais de intensidade luminosa da imagem, como uma topografia montanhosa que separa regiões. Une-se regiões aumentando a altura da água que cai na imagem. A modelagem RAG no entanto é independente do método de segmentação, podendo ser utilizado qualquer outro segmentador que obtenha bons resultados. A Figura 4.24 apresenta o resultado dessa segmentação e consequente modelagem modelagem. 

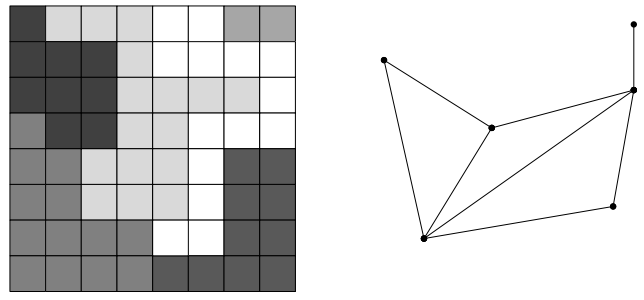

Figura 4.23 - Textura modelada como um RAG estático: (a) cada região da imagem é um vértice no grafo; (b) uma aresta é adicionada entre dois vértices se estes representam regiões 4-adjacentes na imagem; (c) o peso definido pela quantidade de vértices adjacentes entre as regiões.
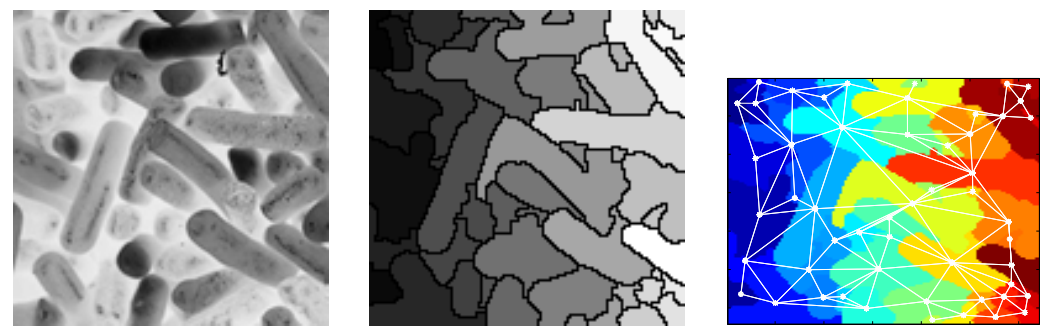

Figura 4.24 - Esquerda e centro: imagem original invertida e segmentação obtida. Direita: modelo RAG derivado dessa segmentação.

A Tabela 4.22 apresenta os resultados alcançados para análise direta considerando-se as 4 funções de peso listadas acima. Podemos observar que a maior taxa de discriminação é alcançada pela utilização da diferença de intensidade como peso (Equação 4.4.6).

Tabela 4.22 - RAG estático: Resultados obtidos para diferentes funções de peso, análise direta.

\begin{tabular}{cccccc}
\hline & & \multicolumn{3}{c}{ Acerto (\%) } \\
\cline { 4 - 6 } \multicolumn{1}{c}{ Peso } & ND & Brodatz & Outex & Vistex \\
\hline Equação & 4.4 .5 & 15 & 34.63 & 36.32 & 34.84 \\
Equação & 4.4 .6 & 12 & $\mathbf{5 0 . 5 6}$ & $\mathbf{5 1 . 4 7}$ & $\mathbf{5 2 . 7 8}$ \\
Equaçãon & 4.4 .7 & 14 & 44.99 & 44.19 & 42.71 \\
Equação & 4.4 .8 & 16 & 33.45 & 34.56 & 33.45 \\
\hline
\end{tabular}

As Tabelas 4.23, 4.24 e 4.25 apresentam os resultados para análise por subgrafos, hierárquica e OPF respectivamente. Para todas as análise a os pesos $w_{i j}$ foram definidos pela Equação 4.4.6. Na análise por subgrafos obtemos um resultado levemente superior, porém não adequado, quando da utilização de limiares maiores (menos subgrafos). A mesma tendência é observada na análise hierárquica e por OPF, ou seja, maior taxa de acerto se analisados um número menor de hierarquias ou conjunto de sementes.

A maior taxa de acerto é obtida por análise direta e função de peso da diferença de intensidade. As Figuras 4.25 e 4.26 e apresentam um estudo em relação as medidas da rede para esse resultado. Observamos que a variabilidade da primeira componente é explicada basicamente pelas medidas de distância geodésica média (11) e eficiência global (12), enquanto a segunda componente é explicada principalmente pelas medidas de grau conjunto médio (7) 
Tabela 4.23 - RAG estático: Resultados obtidos para diferentes conjuntos de limiares, análise subgrafos.

\begin{tabular}{ccccc}
\hline & & \multicolumn{3}{c}{ Acerto (\%) } \\
\cline { 3 - 5 } $\boldsymbol{T}$ & ND & Brodatz & Outex & Vistex \\
\hline $0.075,0.025, \ldots, 0.925$ & 33 & 33.84 & 26.10 & 25.00 \\
$0.075,0.050, \ldots, 0.925$ & 32 & 41.55 & 34.34 & 38.43 \\
$0.075,0.075, \ldots, 0.925$ & 26 & 46.45 & 37.79 & 40.97 \\
$0.075,0.100, \ldots, 0.925$ & 21 & 47.58 & 38.16 & 43.87 \\
$0.500,0.025, \ldots, 0.925$ & 26 & 27.14 & 19.85 & 24.31 \\
$0.075,0.025, \ldots, 0.500$ & 34 & 38.18 & 31.62 & 34.38 \\
\hline
\end{tabular}

Tabela 4.24 - RAG estático: Resultados obtidos para diferentes níveis hierárquicos, análise hierárquica.

\begin{tabular}{ccccc}
\hline & & \multicolumn{3}{c}{ Acerto (\%) } \\
\cline { 3 - 5 } $\boldsymbol{L}$ & ND & Brodatz & Outex & Vistex \\
\hline 2 & 7 & 42.06 & 46.25 & 39.24 \\
3 & 12 & 41.67 & 47.21 & 37.62 \\
4 & 17 & 40.93 & 47.87 & 36.92 \\
\hline
\end{tabular}

e energia grau conjunto (8). Caso uma classificação seja realizada utilizando essas 4 medidas será obtida uma taxa de acerto de $35.59 \% 42.35 \%$ e $42.48 \%$ para as Brodatz, Outex e Vistex respectivamente, ou seja, valores próximos ao melhor resultado obtido.

As medidas de distância geodésica média e eficiência global nesse modelo representam indiretamente a quantidade de regiões obtidas e o quão varia a intensidade média dessas regiões, que causa efeitos no peso e consequentemente na distância. Já as medidas de grau conjunto médio e energia do grau conjunto provavelmente quantificam a regularidade da distribuição das regiões na imagem, ou seja, uma segmentação regular tende a gerar vértices com mesmo número de vizinhos.
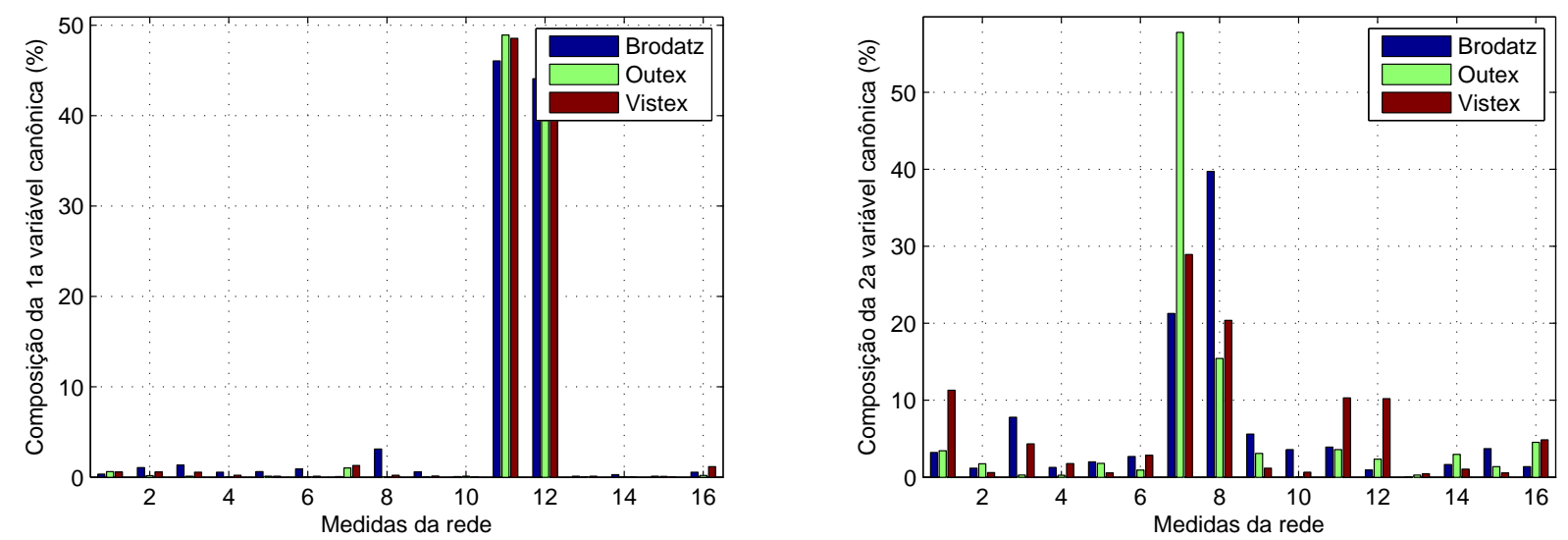

Figura 4.25 - Composição da 1a e 2a variável canônica, modelo RAG estático. 
Tabela 4.25 - RAG estático: Resultados obtidos para diferentes quantidades de conjuntos de sementes, análise OPF.

\begin{tabular}{ccccc}
\hline & & \multicolumn{3}{c}{ Acerto (\%) } \\
\cline { 3 - 5 } $\boldsymbol{S}$ & ND & Brodatz & Outex & Vistex \\
\hline 1 & 7 & 35.98 & 38.53 & 35.19 \\
2 & 11 & 32.77 & 39.19 & 35.65 \\
3 & 16 & 33.00 & 37.65 & 35.30 \\
4 & 20 & 34.12 & 36.76 & 35.65 \\
5 & 25 & 31.02 & 35.37 & 34.72 \\
6 & 26 & 31.02 & 34.63 & 33.91 \\
7 & 27 & 31.31 & 35.22 & 32.64 \\
8 & 31 & 31.02 & 32.57 & 31.02 \\
9 & 31 & 30.97 & 32.43 & 31.94 \\
10 & 33 & 28.89 & 33.31 & 30.56 \\
\hline
\end{tabular}

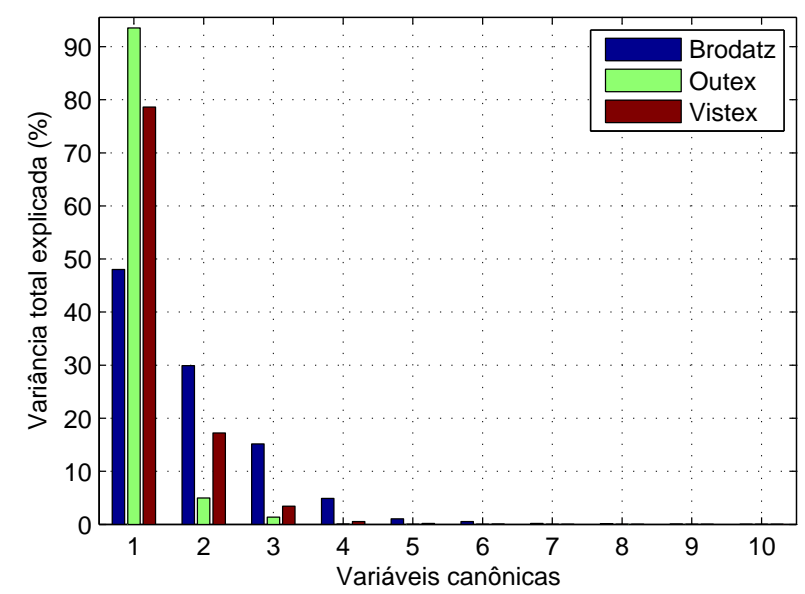

Figura 4.26 - Variância total explicada pelas 10 primeiras variáveis canônicas, modelo RAG estático.

\subsubsection{RAG dinâmico}

No modelo acima a análise é realizada por transformações diretas nos grafo obtido. No entanto é possível gerar diversos RAGs de uma mesma textura utilizando o próprio algoritmo de segmentação. Para tal faz-se necessário utilizar um algoritmo de segmentação que possibilite tal variabilidade, ou seja, aqueles possam obter uma hipersegmentação e a cada iteração ou mudança de parâmetros obtenha-se um resultado mais refinado. De fato muitos dos algoritmos de segmentação possuem tal propriedade.

É necessário, no entanto, garantir que o mesmo número de passos RAGs seja obtido em todas as imagens, a fim de obter o mesmo número de subgrafos e consequentemente de descritores. Nesse modelo 5 diferentes dilatações iniciais para o algoritmo de Watershed foram utilizados a fim de obter desde imagens hipersegmentadas, até um resultado mais refinado. É possível no entanto utilizar qualquer outro método de segmentação que obtenha em resultados 
diversos. A Figura 4.27 apresenta o resultado de tal alteração de parâmetros pra segmentação de uma imagem da base de dados Vistex.
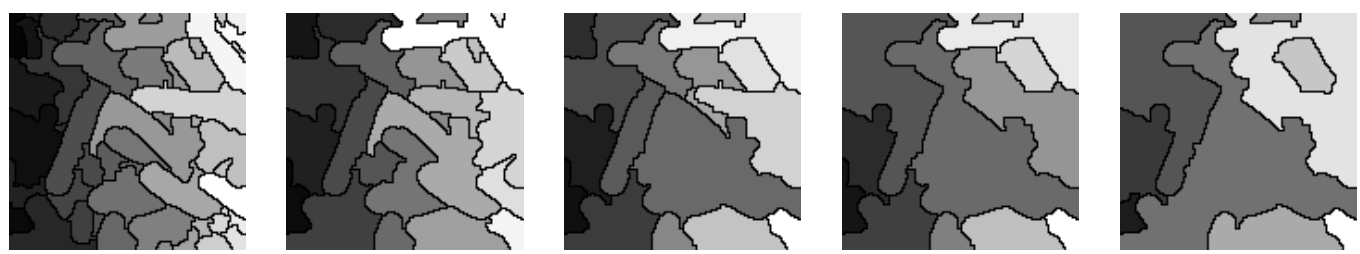

Figura 4.27 - Resultado segmentação por Watershed com diferentes parâmetros.

A Tabela 4.26 apresenta os resultados para tal método, considerando 5 diferentes segmentações (NS) para análise direta e função de peso dada pela Equaçãoeqt:rdifint.

Tabela 4.26 - RAG dinâmico: Resultados obtidos para diferentes segmentações, análise direta.

\begin{tabular}{ccccc}
\hline & & \multicolumn{3}{c}{ Acerto (\%) } \\
\cline { 3 - 5 } NS & ND & Brodatz & Outex & Vistex \\
\hline 2 & 17 & 64.53 & 61.76 & 65.86 \\
3 & 33 & 66.55 & 60.96 & 66.78 \\
4 & 34 & $\mathbf{6 5 . 4 8}$ & $\mathbf{6 1 . 0 3}$ & $\mathbf{6 7 . 5 9}$ \\
5 & 37 & 66.22 & 60.81 & 67.48 \\
\hline
\end{tabular}

Podemos observar um aumento na taxa de acerto se comparado com a abordagem estática. Tendo em vista que o processo de segmentação é complexo, esse irá gerar regiões diversas para cada parâmetro utilizado. As Figuras 4.28 e 4.29 apresentam um estudo em relação as medidas desse modelo. Verifica-se que a primeira variável canônica é bastante influenciada pela medida da distância geodésica média (11) e eficiência global (12), e a 2a componente pelas medidas de grau conjunto médio (7) e energia grau conjunto (8) assim como no RAG estático.
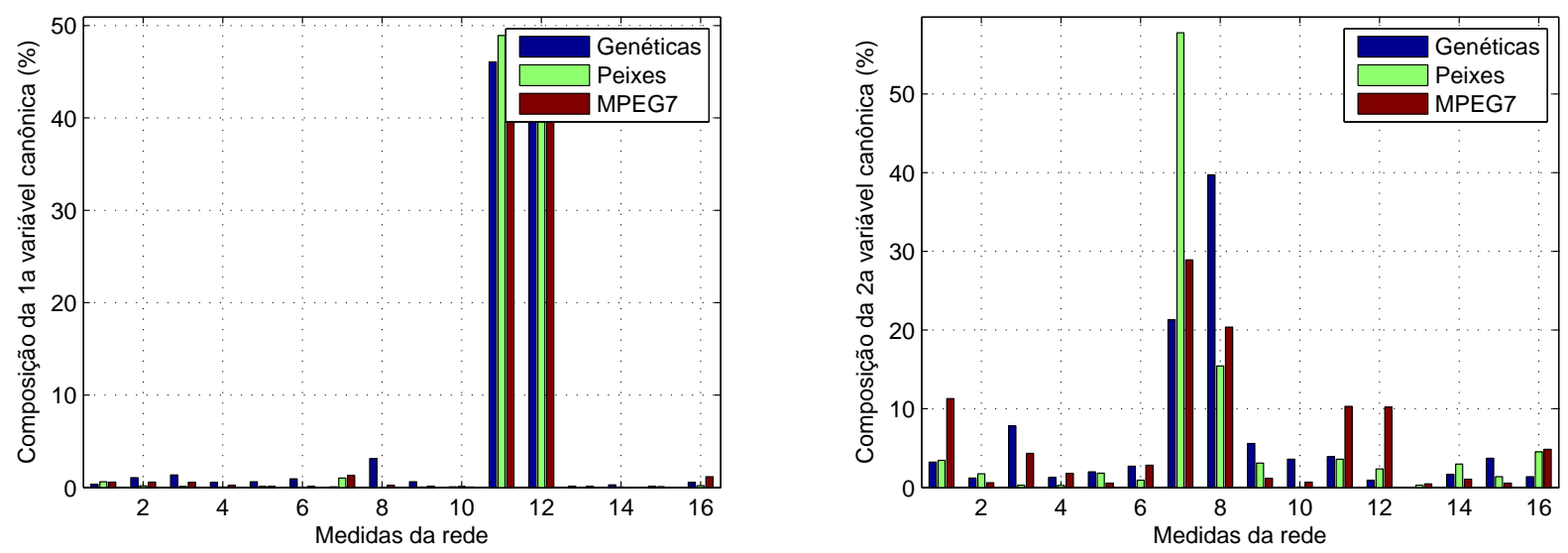

Figura 4.28 - Composição da 1a e 2a variável canônica, modelo RAG dinâmico. 


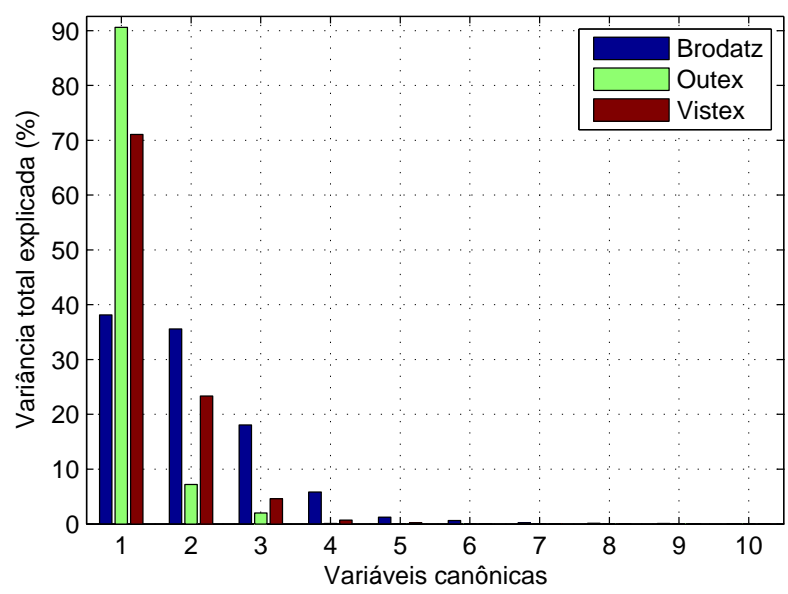

Figura 4.29 - Variância total explicada pelas 10 primeiras variáveis canônicas, modelo RAG dinâmico.

\subsection{CAG - Grafo por adjacência de cores}

De forma similar ao RAG apresentado acima, o grafo por adjacência de cores, ou CAG (do inglês color adjacency graph, é outra possível forma de se modelar uma imagem como um grafo. Quando disponíveis, o uso de informações cromáticas pode aumentar consideravelmente os resultados de processos de visão computacional, como a segmentação e a recuperação por conteúdo. A ideia do CAG é que cada cor ou tom de cinza presente do modelo de cores será representada por um vértice, e os dois vértices $i$ e $j$ serão conectados se as cores que esses representem existirem e forem adjacentes na imagem (i.e. para cada cor vizinha do tipo 4 ou 8adjacente, adiciona-se uma aresta entre os vértices que as representam). O número de vértices é, portanto, fixo e determinado pelo modelo de cores escolhido. Ou seja, algum conjunto $S_{i}$ pode não conter nenhum pixel da imagem e simultaneamente um ou mais conjuntos $S_{i}$ podem conter mais de um pixel, configurando um caso híbrido. Assim como no RAG algum conjunto $S_{i}$ estará representando um conjunto de pixeis, porém não há, necessariamente adjacência entre tais pixeis formadores desse conjunto $S_{i}$. Pela regra geral temos:

- Quantidade de pixeis existentes em $S_{i}$ :

$$
\begin{aligned}
& \left|S_{i}\right| \geq 1, \text { para algum } S_{i} \in C \\
& \left|S_{i}\right|=0, \text { para algum } S_{i} \in C
\end{aligned}
$$

- Relação dos pixeis em $S_{i}$ :

$$
\exists p \in S_{i} \text { e } \exists q \in S_{i} \mid p \text { e } q \text { não são adjacentes }
$$


- Quantidade dos pixeis representados em $C$ :

$$
\bigcup_{S_{i} \in C} S_{i}=I
$$

- Relação entre cada subconjunto $S_{i}$ de $C$ :

$$
\bigcap_{S_{i} \in C} S_{i}=\oslash
$$

Tal modelagem possui a mesma vantagem do RAG, ou seja, diminuição do número de vértices em comparação às modelagens do tipo PAG. Também podemos observar pelas equações acima que, matematicamente, a diferença básica entre um CAG em um RAG é a simples inexistência de uma restrição na relação dos pixeis do conjunto $S_{i}$.

Para esse modelo as funções de peso $w_{i j}$ podem ser definidas como:

- Existência ou não de adjacência entre as cores de $S_{i}$ e $S_{j}$ :

$$
w_{i j}=1 \text { se } \exists p \in S_{i} \text { 4-adjacente a } q \in S_{j}, i \neq j
$$

- Quantidade de adjacências entre as cores de $S_{i}$ e $S_{j}$ :

$$
w_{i j}=\sum_{p} 1 \text { se } \exists p \in S_{i} \text { 4-adjacente a } q \in S_{j}, i \neq j
$$

A modelagem do tipo CAG pode ser aplicada à uma diversidade grande de espaço de cores, inclusive na escala de cinza. Um exemplo desse caso pode ser visto na Figura 4.30
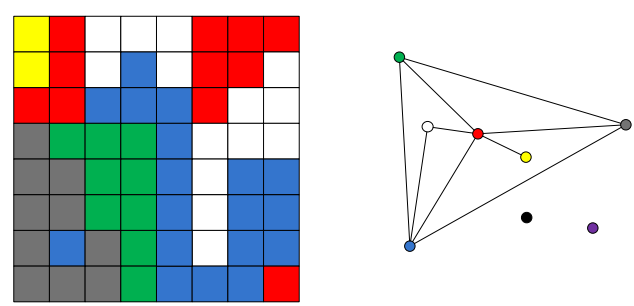

Figura 4.30 - Textura modelada como um CAG: (a) cada cor do modelo de cores corresponde a um vértice no grafo; (b) dois vértices $i$ e $j$ são conectados se as cores que esses representem são adjacentes na imagem; (c) o peso reflete a quantidade de ocorrências de adjacências das cores $S_{i}$ e $S_{j}$.

Adicionalmente uma quantização pode ser empregada preliminarmente com objetivo de diminuir a quantidade de cores na imagem e, consequente, o número de vértices no grafo. Utilizou-se aqui uma quantização uniforme, embora qualquer método possa ser empregado. Tal quantização também pode ser aplicada a outros espaços de cores. A Tabela 4.27]apresenta os resultados dessa modelagem para diferentes quantizações dos tons de cinza por análise direta 
e com função de peso da Equação 4.5.7. Podemos perceber que a utilização de quantizações não melhora os resultados para esse modelo. Para valores baixos (e.g. 4) muita informação a respeito da textura é perdida. Nesse modelo não há necessidade de normalização do grau uma vez que todas as imagens irão gerar um número igual de vértices.

Tabela 4.27 - CAG: Resultados obtidos para diferentes valores de pré-quantização, análise direta.

\begin{tabular}{ccccc}
\hline & & \multicolumn{3}{c}{ Acerto (\%) } \\
\cline { 3 - 5 } Quantização & ND & Brodatz & Outex & Vistex \\
\hline 8 & 9 & 40.43 & 29.85 & 55.09 \\
16 & 12 & 46.11 & 37.50 & 60.88 \\
32 & 10 & 51.24 & 48.16 & 65.74 \\
64 & 10 & 55.57 & 53.75 & 71.06 \\
128 & 6 & 59.57 & 59.12 & 71.06 \\
256 & 6 & $\mathbf{6 7 . 3 4}$ & $\mathbf{6 3 . 5 3}$ & $\mathbf{7 5 . 2 3}$ \\
\hline
\end{tabular}

As Tabelas 4.28, 4.29 e 4.30 apresentam os resultados para análise por subgrafos, hierárquica e OPF respectivamente. Observamos que a análise por subgrafos apresenta os melhores resultados quando se elimina os grafos que possuem arestas com grande peso. Adicionalmente essa análise alcança o melhor resultado para a base de dados Outex, contrariando os demais modelos até agora apresentados. Na análise hierárquica percebemos que a análise de grafos com $L>3$ não traz melhoras significativas, uma vez que o grafo torna-se extremamente denso. Ademais esse tipo de análise apresenta os melhores resultados para as bases de Brodatz e Vistex. Já a análise OPF possui um aumento considerável nos resultados quando se utiliza mais conjuntos de sementes para geração de florestas de caminhos ótimos diversas, ainda assim não apresentou-se superior à análise direta.

Para todas as análises a quantização de 256 níveis de cinza foi utilizada como parâmetro. Outros valores de quantização foram testados porém, assim como na análise direta, não apresentam melhoras no resultado final.

Tabela 4.28 - CAG: Resultados obtidos para diferentes conjuntos de limiares, análise subgrafos.

\begin{tabular}{ccccc}
\hline & & \multicolumn{3}{c}{ Acerto (\%) } \\
\cline { 3 - 5 } $\boldsymbol{T}$ & ND & Brodatz & Outex & Vistex \\
\hline $0.075,0.025, \ldots, 0.925$ & 44 & 23.76 & 44.78 & 28.01 \\
$0.075,0.050, \ldots, 0.925$ & 32 & 31.59 & 50.74 & 38.66 \\
$0.075,0.075, \ldots, 0.925$ & 25 & 34.91 & 50.66 & 41.09 \\
$0.075,0.100, \ldots, 0.925$ & 20 & 35.47 & 53.75 & 46.06 \\
$0.500,0.025, \ldots, 0.925$ & 38 & 6.93 & 18.24 & 8.45 \\
$0.075,0.025, \ldots, 0.500$ & 28 & 29.45 & 49.41 & 40.51 \\
\hline
\end{tabular}

Dentre as análises realizadas a forma direta é que obteve melhores resultados. As Figuras 4.31 e 4.32 apresentam um estudo em relação as medidas da rede para esse resultado 
Tabela 4.29 - CAG: Resultados obtidos para diferentes níveis hierárquicos, análise hierárquica.

\begin{tabular}{ccccc}
\hline & & \multicolumn{3}{c}{ Acerto (\%) } \\
\cline { 3 - 5 } $\boldsymbol{L}$ & ND & Brodatz & Outex & Vistex \\
\hline 2 & 5 & 61.66 & 44.19 & 74.54 \\
3 & 14 & 56.36 & 44.71 & 74.42 \\
4 & 14 & 54.67 & 40.81 & 70.49 \\
\hline
\end{tabular}

Tabela 4.30 - CAG: Resultados obtidos para diferentes quantidades de conjuntos de sementes, análise OPF.

\begin{tabular}{ccccc}
\hline & & \multicolumn{3}{c}{ Acerto (\%) } \\
\cline { 3 - 5 } $\boldsymbol{S}$ & ND & Brodatz & Outex & Vistex \\
\hline 1 & 7 & 21.57 & 20.37 & 40.86 \\
2 & 11 & 27.87 & 26.76 & 54.17 \\
3 & 19 & 37.27 & 28.97 & 59.95 \\
4 & 23 & 38.57 & 32.87 & 64.35 \\
5 & 25 & 40.65 & 36.47 & 66.44 \\
6 & 28 & 43.07 & 39.34 & 69.44 \\
7 & 30 & 47.58 & 39.26 & 69.91 \\
8 & 30 & 48.65 & 41.47 & 68.98 \\
9 & 31 & 48.76 & 40.88 & 70.37 \\
10 & 32 & 51.75 & 43.16 & 70.02 \\
\hline
\end{tabular}

(análise direta e quantização de 256 cores). Observamos que a variabilidade da primeira componente é explicada basicamente pela densidade (1) e grau médio do modelo (2), enquanto a segunda componente é explicada pelas medidas de densidade (1), grau médio (2), energia dos graus (3), entropia dos graus (4), contraste dos graus (5), grau máximo (6), energia grau conjunto (8), entropia grau conjunto (9), diâmetro da rede (10), eficiência global (12) e coeficiente de aglomeração (16). Caso um vetor de características seja composto por apenas essas variáveis a taxa de acerto seria de $66.44 \%, 63.46 \%$ e $75.69 \%$ para Brodatz, Outex e Vistex respectivamente, resultados esses extremamente próximos ao obtido pelo conjunto original de 16 características. Nesse modelo a densidade e grau médio da rede representam, de forma indireta, a quantidade de cores e sua distribuição espacial.

Na Tabela 4.31 apresenta os resultados quando da utilização de descritores fractais (Equação 2.3.28) para caracterizar a matriz de adjacência por análise direta. Para obtenção de tais resultados o método fractal foi aplicado diretamente na matriz de adjacência $A$ obtendo assim uma caracterização indireta da conectividade. Para tal utilizou-se como função de peso a simples existência ou não de adjacência de tons de cinza (Equação 4.5.6) uma vez que o fractal 2-dimensional não necessita da informações de peso da aresta. O raio de dilatação utilizado foi $r=9$, totalizando 36 características. Podemos observar um ganho significativo nos resultados alcançados em relação às medidas de grau acima apresentadas. Observamos também que uma quantização para 64 tons de cinza obtém melhores resultados, diferente no 

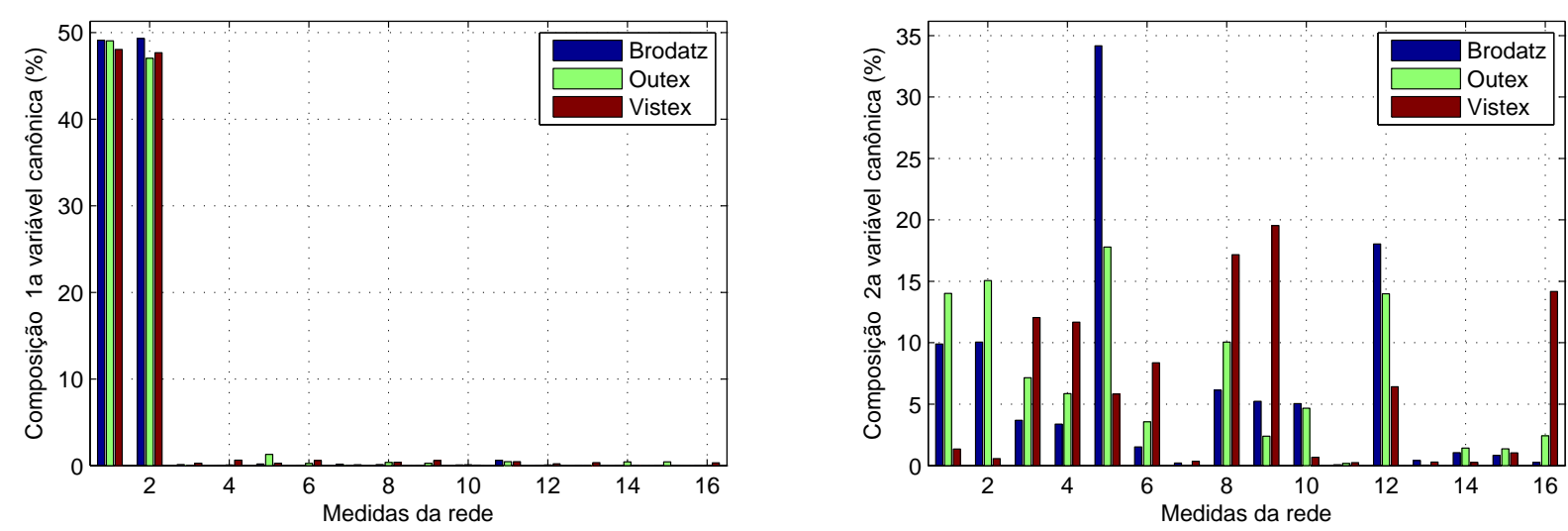

Figura 4.31 - Composição da 1a e 2a variável canônica, modelo CAG.

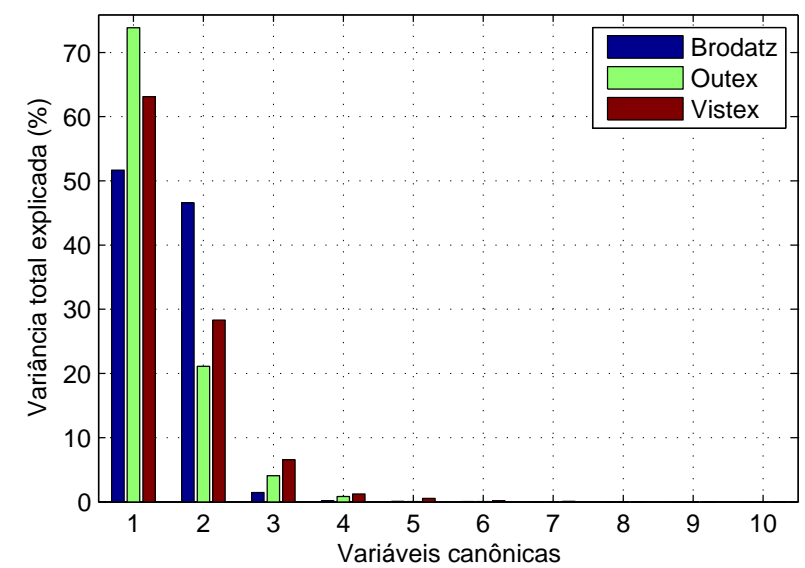

Figura 4.32 - Variância total explicada pelas 10 primeiras variáveis canônicas, modelo CAG.

que ocorre nas análises apresentadas acima.

Outro espaço de cores onde a modelagem do tipo CAG pode ser implementada é o RGB. O princípio é exatamente o mesmo utilizado na escala de cinza, bastando para isso que se utilize uma conversão das triplas RGB para índices (cores indexadas). O espaço de cores RGB (do inglês Red, Green and Blue) é um modelo aditivo no qual o vermelho, o verde e o azul (usados em modelos aditivos de luzes) são combinados de várias maneiras para reproduzir outras cores. Tal modelo é utilizado na reprodução de cores em dispositivos eletrônicos assim como na fotografia tradicional.

Embora o modelo RGB seja o mais comumente utilizado em processamento de imagens, a modelagem proposta pode ser aplicada a qualquer modelo. A Tabela 4.32 apresenta os resultados alcançados para o modelo RGB acima citado e mais 5 modelos de cores distintos utilizando análise direta do modelo obtido por descritores fractais. Os modelos de cores testados são:

1. CMYK: em contraposição ao RGB, as impressoras utilizam o modelo CMYK de cores 
Tabela 4.31 - CAG: Resultados obtidos para diferentes valores de pré-quantização, análise direta e caracterização por fractais.

\begin{tabular}{ccccc}
\hline & & \multicolumn{3}{c}{ Acerto (\%) } \\
\cline { 3 - 5 } Quantização & ND & Brodatz & Outex & Vistex \\
\hline 8 & 9 & 40.17 & 40.11 & 55.60 \\
16 & 10 & 70.00 & 61.42 & 75.15 \\
32 & 9 & 82.70 & 70.04 & 86.45 \\
64 & 12 & $\mathbf{8 4 . 3 2}$ & $\mathbf{7 9 . 4 2}$ & $\mathbf{9 1 . 4 6}$ \\
128 & 11 & 81.18 & 71.77 & 85.13 \\
256 & 13 & 69.10 & 60.91 & 73.63 \\
\hline
\end{tabular}

subtrativas (do inglês Cyan, Magenta, and Black). Tal sistema funciona devido à absorção de luz, pelo fato de que as cores que são vistas vêm da parte da luz que não é absorvida.

2. HSV: o modelo de matiz, saturação e valor, ou HSV (do inglês hue, saturation and value) é um espaço de cores que reorganiza a geometria do RGB, objetivando obter uma percepção das cores mais intuitiva que o cubo RGB. Nesse espaço de cores a matiz é a componente que seleciona a cor em uso, sendo controlada pela posição angular de um ponteiro. A saturação é a componente que determina a pureza da cor selecionada na matiz (todos os tons de cinza possuem saturação $=0$ e todos as matizes puras possuem saturação $=1$ ). O valor regula o brilho da cor determinada pela matiz e saturação. $A$ cor preta possui brilho zero e qualquer valor de matiz ou saturação. Valor $=1$ determina uma intensidade pura de matiz e saturação.

3. Lab: nenhum dos espaços de cor acima citados consegue reproduzir todas as cores existentes no espectro visível, porém o $L * a * b *$ é o que chega mais próximo disso. Também é o principal espaço de cor puramente matemático e, portanto independente de dispositivos. Fruto de pesquisas da Comissão Internacional em lluminação (Commission Internationale dEclairage), este espaço de cor trabalha com três canais diferentes. $\mathrm{O}$ canal $L$ (que varia de 0 -preto a 100-branco), que guarda as informações de luminosidade de uma cena, e os canais $a$ e $b$ comportam a informação de cor. Em a, valores positivos indicam magenta e negativos verde, enquanto em $b$, valores positivos indicam azul $e$ negativos amarelo.

4. IHLS: o modelo de matiz, luminância e saturação, ou IHLS (do inglês improved hue, luminance and saturation) é um espaço de cores perceptual que vem apresentando bons resultados em aplicações de reconhecimento de imagem (85, 86). Esse modelo é, basicamente, um melhoramento do modelo HLS que remove a dependência do brilho do canal de saturação. Assim como o RGB e o HSV esse modelo não é perceptualmente 
uniforme.

5. $I_{1} I_{2} I_{3}$ : este modelo de cores proposto por (87) é baseado na diferença dos canais RGB e também vem apresentado excelente resultados em aplicações de reconhecimento de imagens coloridas (88). Sua obtenção é bastante simples sendo um processo muito próximo ao modelo de oponência cromática mais amplamente difundido.

Tabela 4.32 - Resultados alcançados para diferentes espaços de cores e modelagem CAG e sua respectiva quantização ótima.

\begin{tabular}{cccc}
\hline & & \multicolumn{2}{c}{ Acerto (\%) } \\
\cline { 3 - 4 } Modelo de cores & Quantização & Outex & Vistex \\
\hline RGB & 96 & $\mathbf{8 7 . 5 0}$ & $\mathbf{9 1 . 0 4}$ \\
CMYK & 64 & 62.77 & 68.90 \\
HSV & 224 & 75.31 & 84.42 \\
Lab & 96 & 20.41 & 26.96 \\
IHLS & 16 & 82.94 & 87.20 \\
$I_{1} I_{2} I_{3}$ & 128 & 82.42 & 86.43 \\
\hline
\end{tabular}

Os resultados demostram que o espaço de cores RGB, embora mais simplificado, obtém os melhores resultados. Muito próximos a este temos os modelos IHLS e $I_{1} I_{2} I_{3}$ também apresentando resultados mais que satisfatórios. A Tabela 4.32 também demostra a quantização utilizada para se alcançar tais resultados, e nesse critério o modelo IHLS utiliza apenas 16 níveis de cores, fato que diminui o custo computacional envolvido nesse método.

\subsection{CHAG - Grafo por adjacência de cores do histograma}

Embora o CAG acima apresentado utilize a adjacência de cores (informação cromática) como princípio básico, sua estrutura é na verdade concebida para análise de texturas uma vez que utiliza informações das relações espaciais dos pixeis. Já o grafo por adjacência de cores do histograma, ou CHAG (do inglês color histogram adacency graph), utiliza apenas informação cromática da imagem para criar um modelo de rede. A ideia do CHAG é que cada cor presente na imagem seja representada por um vértice no espaço de cores RGB e que todos os vértices sejam conectados gerando inicialmente um grafo completo (repare que no CAG anteriormente proposto conectavam-se os vértices apenas se as cores que eles representavam fossem adjacentes na imagem). O peso nesse modelo é definido pela distância entre cores no modelo RGB normalizada pela diferença de quantidade de cores representadas pelos vértices $i$ e $j$. Esse processo pode ser melhor entendido como a criação de uma rede entre as bins do histograma 3D da imagem, ou seja, é uma forma indireta de se analisar o histograma. Assim 
como no RAG algum conjunto $S_{i}$ estará representando um conjunto de pixeis, porém não há, necessariamente, adjacência entre tais pixeis formadores desse conjunto $S_{i}$. Pela regra geral temos:

- Quantidade de pixeis existentes em $S_{i}$ :

$$
\left|S_{i}\right| \geq 1 \text {, para algum } S_{i} \in C
$$

- Relação dos pixeis em $S_{i}$ :

$$
\exists p \in S_{i} \text { e } \exists q \in S_{i} \mid p \text { e } q \text { não são adjacentes }
$$

- Quantidade dos pixeis representados em $C$ :

$$
\bigcup_{S_{i} \in C} S_{i}=I
$$

- Relação entre cada subconjunto $S_{i}$ de $C$ :

$$
\bigcap_{S_{i} \in C} S_{i}=\oslash
$$

Tal modelagem possui a mesma vantagem do RAG, ou seja, diminuição do número de vértices em comparação às modelagens do tipo PAG. Também podemos observar pelas equações acima que, matematicamente, a diferença básica entre um CAG ou CHAG em relação à um RAG é a simples inexistência de uma restrição na relação dos pixeis do conjunto $S_{i}$.

Para esse modelo as função de peso $w_{i j}$ utilizada é:

- Diferença da distância cromática normalizada pelo número de pixeis representados pelos conjuntos $S_{i}$ e $S_{j}$ :

$$
w_{i j}=\frac{\sqrt{\left(r\left(S_{i}\right)-r\left(S_{j}\right)\right)^{2}+\left(g\left(S_{i}\right)-g\left(S_{j}\right)\right)^{2}+\left(b\left(S_{i}\right)-b\left(S_{j}\right)\right)^{2}+\left(h\left(S_{i}\right)-h\left(S_{j}\right)\right)^{2}}}{255^{2}+255^{2}+255^{2}+\max _{i} h\left(S_{i}\right)^{2}}
$$

onde $r\left(S_{i}\right), g\left(S_{i}\right)$ e $b\left(S_{i}\right)$ correspondem aos valores cromáticos dos conjuntos $S_{i}$ e $h\left(S_{i}\right)$ à quantidade de pixeis que compõe o conjunto $S_{i}\left(h\left(S_{i}\right)=\left|S_{i}\right|\right)$. Um exemplo de tal modelagem pode ser vista na Figura 4.33 .

Tal modelo possui número variável de vértices, dependendo das cores que estão presentes na imagem. Assim como no CAG uma quantização pode ser empregada preliminarmente com 

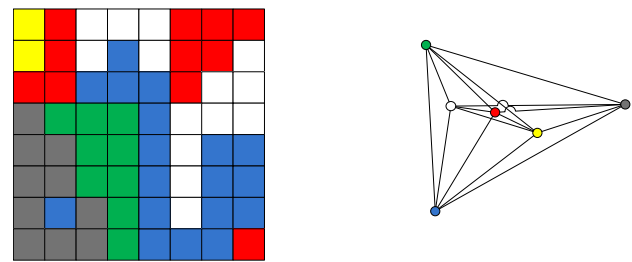

Figura 4.33 - Textura modelada como um CHAG: (a) cada cor presente na imagem é representada por um vértice no espaço de cores RGB; (b) todos os vértices são conectados gerando inicialmente um grafo completo; (c) o peso reflete a distância entre cores normalizada pela diferença da quantidade de cores representadas pelos vértices $i$ e $j$.

objetivo de diminuir a quantidade de cores na imagem e, consequente, o número de vértices no grafo. Nesse sentido a Tabela 4.33 apresenta os resultados para essa forma de modelagem considerando texturas coloridas no modelo RGB, e diferentes valores de quantização para análise por subgrafos com $T=0.075,0.075, \ldots, 0.925$. Observamos que não há diferença significativa para tais valores, sendo que a quantização de 512 cores obtém resultados ligeiramente superiores, porém uma quantização de 512 cores impede o uso de limiares muito baixo. Isso é devido ao fato de que algumas imagens geram modelos não discriminativos se considerados uma baixa quantidade de cores.

Tabela 4.33 - CHAG: Resultados obtidos para diferentes valores de pré-quantização, análise por subgrafos.

\begin{tabular}{cccc}
\hline & & \multicolumn{2}{c}{ Acerto (\%) } \\
\cline { 3 - 4 } Quantização & ND & Outex & Vistex \\
\hline 512 & 19 & $\mathbf{5 3 . 0 1}$ & $\mathbf{8 0 . 2 1}$ \\
1024 & 12 & 48.53 & 75.12 \\
2048 & 17 & 57.43 & 76.85 \\
4096 & 17 & 53.31 & 78.24 \\
\hline
\end{tabular}

A Tabela 4.34 apresenta um estudo em relação aos parâmetros da análise por subgrafos para o modelo CHAG com quantização de 4096 cores. A análise por subgrafos é empregada uma vez que as análises direta, hierárquica e OPF não são adequadas para análise de grafos completos. Observamos que os limiares de $T=0.075,0.075, \ldots, 0.925$ é melhor configuração de limiares encontrada. Não há grandes diferenças entre subgrafos com limiares baixos e altos.

Tabela 4.34 - CHAG: Resultados obtidos para diferentes conjuntos de limiares, análise subgrafos.

\begin{tabular}{cccc}
\hline & & \multicolumn{2}{c}{ Acerto $(\%)$} \\
\cline { 3 - 4 } $\boldsymbol{T}$ & ND & Outex & Vistex \\
\hline $0.075,0.025, \ldots, 0.925$ & 23 & 52.79 & 72.92 \\
$0.075,0.050, \ldots, 0.925$ & 21 & 53.53 & 75.35 \\
$0.075,0.075, \ldots, 0.925$ & 17 & 53.31 & 78.24 \\
$0.075,0.100, \ldots, 0.925$ & 17 & 50.15 & 75.93 \\
$0.500,0.025, \ldots, 0.925$ & 18 & 36.99 & 66.09 \\
$0.075,0.025, \ldots, 0.500$ & 20 & 53.16 & 71.06 \\
\hline
\end{tabular}


As Figuras 4.34 e 4.35 apresenta um estudo em relação as medidas extraídas da rede para o melhor resultado obtido acima (quantização de 512 e $T=0.025,0.075, \ldots, 0.925$ ). Podemos observar que a variabilidade da primeira e segunda variáveis canônicas são explicadas, em sua maior parte, pelas características de densidade (1), grau médio (2), contraste da distribuição dos graus (5), grau máximo (6) e distância geodésica média (11).
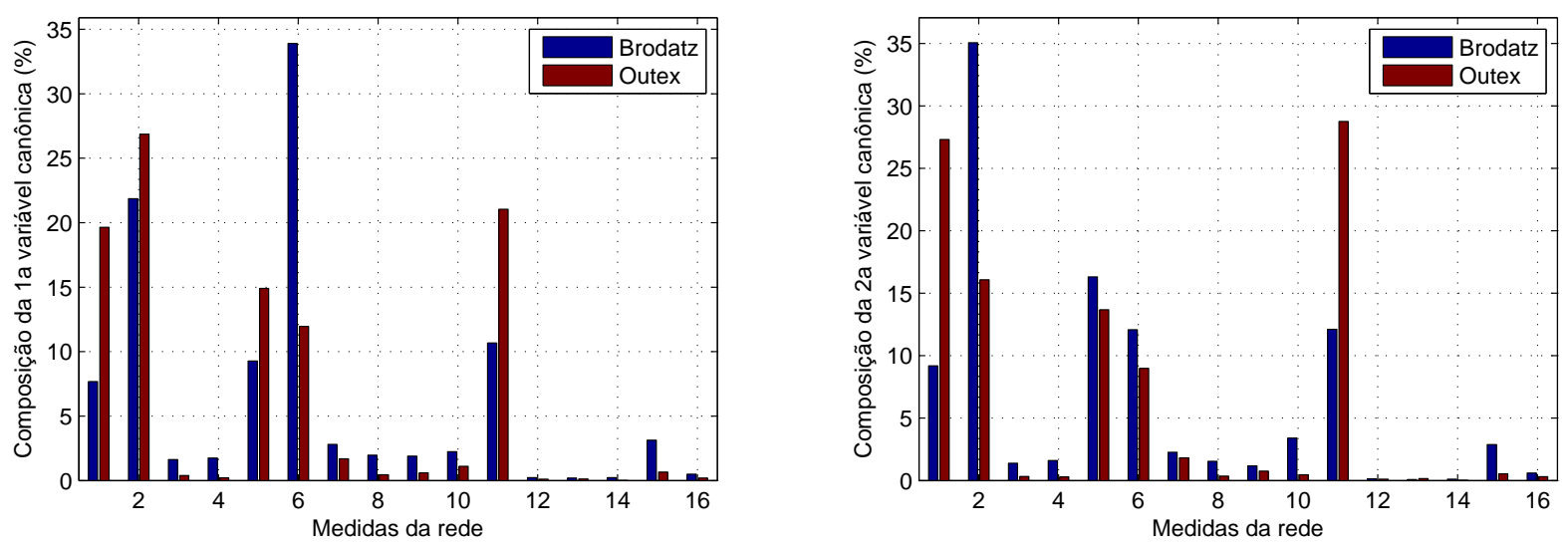

Figura 4.34 - Composição da 1a e 2a variável canônica, modelo CHAG.

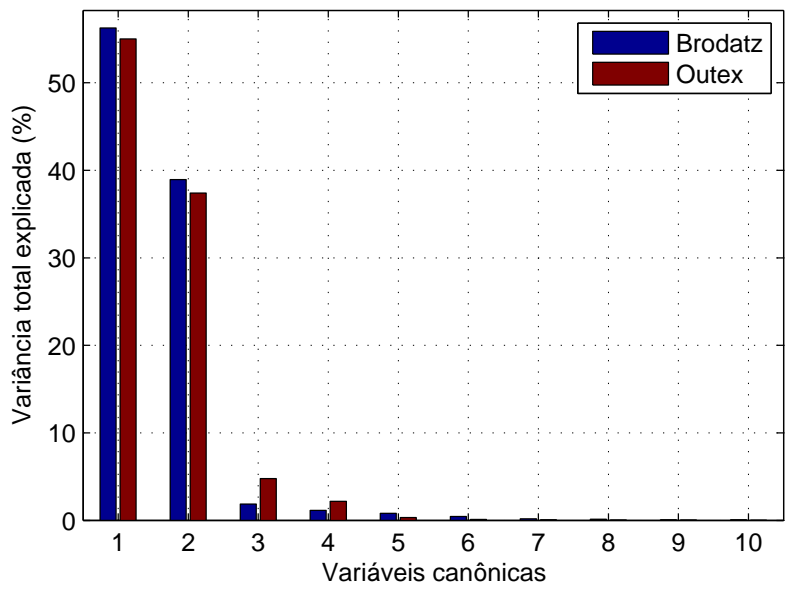

Figura 4.35 - Variância total explicada pelas 10 primeiras variáveis canônicas, modelo CHAG.

Realizando-se uma classificação com apenas essas 5 medidas obtemos uma taxa de acerto de $44.85 \%$ para base Outex e 71.99 para a base Vistex, resultado que confirma que essas medidas são as mais discriminativas para esse modelo.

Tal modelagem poderia alcançar melhores taxas de acerto caso algumas classes de imagens não gerassem grafos semelhantes a outras classes. Com o advento da quantização as imagens que não possuem grande quantidade de cores tendem a gerar um número pequeno de vértices, independentemente qual seja a cor predominante dessa. Porém, considerando-se o fato de que o modelo CHAG não possui informação nenhuma a respeito da distribuição espacial, pode-se considerar que tais taxas de acerto são satisfatórias. 


\section{7 aPAG - Grafo por adjacência de alguns pixeis}

As modelagens acima mencionadas utilizam todos os pixeis da imagem, direta ou indiretamente, na composição dos vértices do grafo. No entanto é possível selecionar apenas alguns pixeis e realizar uma modelagem restrita a esses.

A utilização de apenas uma parcela dos pixeis é algo muito comum em aplicações de processamento de imagens e visão computacional. Essas aplicações fazem uso de uma variedade de informações pré-processadas da imagem original tais como bordas, esqueletos, pontos de interesse, contorno, etc. Há vários métodos de se obter tais pontos (inclusive alguns baseados em grafos), e todos são dependentes da aplicação desejada.

Embora haja alguns métodos baseados em grafos voltados para a extração/detecção dos pontos de interesse (ver Seção 3.2, e.g. detecção de borda), não há na literatura recente métodos que utilizam grafos na análise/reconhecimento de tais pontos. A modelagem aqui proposta tem exatamente esse objetivo, de analisar os pontos de interesse previamente obtidos. O primeiro e mais direto exemplo é quando modelamos apenas alguns pixeis de uma imagem como um grafo. Aqui chamado de aPAG, em alusão ao PAG já citado, exceto pela quantidade de pixeis representados no grafo, cada pixel (e.g. contorno de um objeto) é representado como um vértice na rede.

- Quantidade de pixeis existentes em $S_{i}$ :

$$
\left|S_{i}\right|=1, \text { para todo } S_{i} \in C
$$

- Quantidade dos pixeis representados no grafo:

$$
\bigcup_{S_{i} \in C} S_{i} \neq I
$$

- Relação entre cada subconjunto $S_{i}$ de $C$ :

$$
\bigcap_{S_{i} \in C} S_{i}=\oslash
$$

Como apenas alguns pixeis são utilizados nessa modelagem é necessário, antes de se analisar o grafo, normalizar o grau de cada vértice $k_{i}$ pelo número total de nós do grafo. Essa normalização é necessária a fim de reduzir a influência do tamanho da rede obtida nas medidas de grau e conectividade, visto que não há garantias da quantidade de vértices gerados para diferentes imagens. 


$$
\forall k_{i}=\frac{k_{i}}{n}
$$

Para o presente modelo podemos definir a seguinte função de distância:

- Distância normalizada entre dois pixeis $p\left(x_{i}, y_{j}\right)$ e $q\left(x_{i}, y_{j}\right)$ :

$$
w_{i j}=\frac{\sqrt{\left(x_{i}-x_{j}\right)^{2}+\left(y_{i}-y_{j}\right)^{2}}}{\max _{w_{i j}}}
$$

\subsection{1 aPAG completo contorno}

A modelagem aPAG acima proposta pode ser aplicada a uma grande variedade de problemas. O primeiro e mais direto é mostrado na imagem 4.36 onde apenas os pixeis do contorno de um objeto são utilizados na modelagem do grafo (i.e. cada conjunto $S_{i}$ representa um único pixel do contorno do objeto). Nesse sub-caso o modelo aPAG completo contorno é um grafo do tipo completo (todos os vértices conectam-se com todos os outros) e para cada aresta um peso $w_{i j}$ é associado.
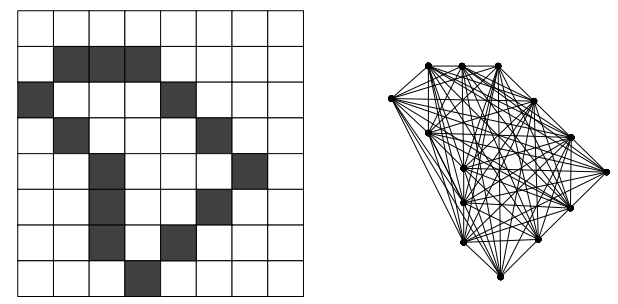

Figura 4.36 - Contorno modelado como um aPAG completo contorno: (a) cada ponto do contorno imagem é um vértice no grafo; (b) uma aresta é adicionada entre todos os pares de vértices; (c) o peso reflete a distância euclidiana normalizada entre os pontos $p$ e $q$.

Nesta configuração inicial temos um grafo completo, onde todos os vértices estão conectados a todos os outros e os pesos normalizados no intervalo de $[0,1]$. O que implica em um comportamento regular, uma vez que todos os vértices tem o mesmo número de ligações. Esse modelo possui importantes características desejadas em aplicações de análise de imagens, são elas:

Invariância a rotação e escala: a normalização da matriz $W$ no intervalo $[0,1]$ garante a propriedade de invariância à escala e rotação. Considerando imagens em diferentes escalas, essa normalização fixa a aresta com maior peso (i.e. maior distância euclidiana entre dois vértices) em 1. No mesmo sentido as arestas restantes são normalizadas adquirindo um peso proporcional ao tamanho da forma. Essa propriedade pode ser melhor entendida observando-se a Figura 4.37 . 
Considerando imagens em diferentes rotações, a maior aresta é preservada, independentemente da direção em que esta se encontra. A normalização assegura as mesmas propriedades para o restante das arestas. Apenas um pequeno erro, derivado do cálculo da distância Euclidiana, é adicionado ao conjunto de pesos $W$. A Figura 4.38 representa essa propriedade.

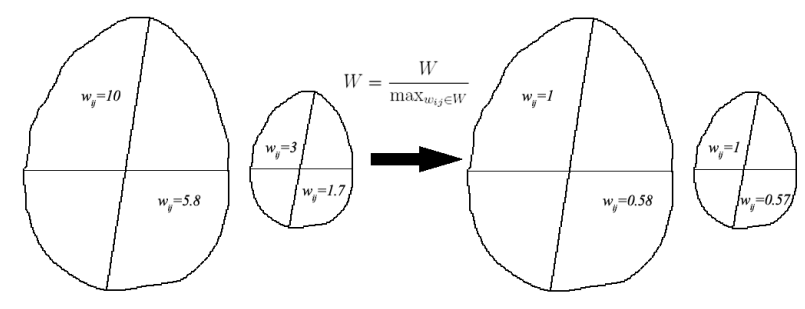

Figura 4.37 - Propriedade de invariância à escala.

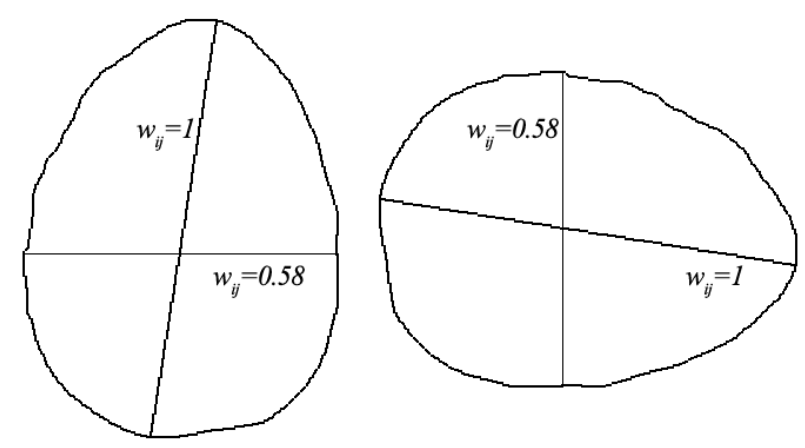

Figura 4.38 - Propriedade de invariância à rotação.

Ainda no sentido de manter a característica de invariância à escala é necessário verificar que imagens de diferentes tamanhos possuem diferentes números de pontos em seu contorno. Uma vez que $|S|=|V|$, como mostrado anteriormente, dois contornos similares $S_{A}=\left[p_{1}, p_{2}, \ldots, p_{N}\right]$ e $S_{B}=\left[p_{1}, p_{2}, \ldots, p_{M}\right]$, com $(N \neq M)$, produzem diferentes redes $\left(G_{A} \neq G_{B}\right)$ (i.e. redes com diferentes números de vértices). Dessa forma o cálculo do grau $k_{i}$ é diretamente afetado por $N$. A solução é normalizar os graus $k_{i}$ com respeito ao tamanho da rede modelada $N$. A Figura demonstra os efeitos dessa normalização.

Podemos observar na Figura $4.39 \mathrm{a}$ o grau $k_{i}$ de todos os nós da rede e sua respectivo grau médio para uma mesma imagem em duas diferentes escalas. Na Figura 4.39p, após realizada a normalização, observamos que os graus médios convergem para um valor aproximado.

Tolerância a ruído: durante a aquisição ou qualquer outro processo pequenos erros e variação podem aparecer no contorno. Essa forma de modelagem do contorno é robusta até determinado nível de ruído, caso medidas como média dos graus sejam consideradas na análise. A média tem a propriedade de incorporar e dissolver os ruídos que apresentem-se em determinados locais da forma. 


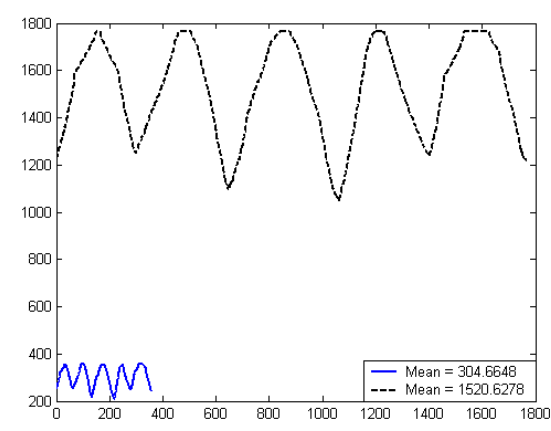

(a)

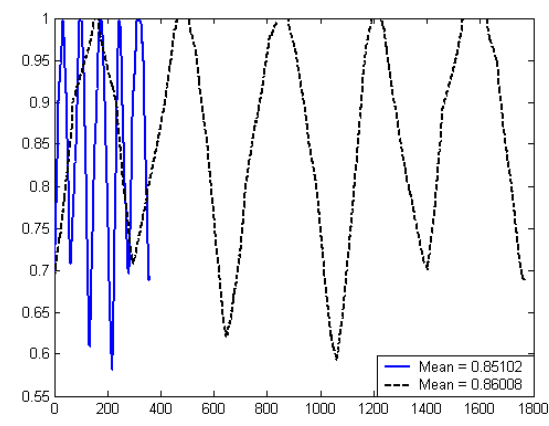

(b)

Figura 4.39 - Grau médio calculado para uma mesma imagem em duas diferentes escalas. (a) médias discrepantes antes da normalização; (b) médias aproximadas após normalização. Adaptado de (14).

Robustez: a modelagem proposta não possui nenhuma informação sobre a sequencia ou localização espacial dos pontos do contorno. Dessa forma apenas a lista das coordenadas dos pontos é suficiente na derivação do modelo, não sendo necessário extrair os pontos sequencialmente. Isso implica que contornos parciais ou com pequenas falhas podem ser utilizados de igual forma no método proposto, o que torna robusto a tais problemas frequentemente encontrados.

Tendo o contorno modelado como uma rede complexa algumas propriedade precisam ser quantificadas. Como já mencionado, nesta configuração inicial temos um grafo completo. No entanto uma rede regular não apresenta qualquer propriedade relevante para análise direta ou hierárquica. A análise por OPF também não é adequada pois não há 'correspondência' entre os vértices de diferentes imagens (e.g. dada que uma semente será colocada no pixel $i$ não há garantias de que o mesmo pixel estará representado no modelo para outra imagem).

Dessa forma optou-se então pela análise de subgrafos obtidos por um conjunto de limiares $T$. Para cada subgrafo obtido o conjunto de características da Equação 2.3.27 é calculado e concatenado com os demais.

Verificou-se que, independentemente do intervalo de limiares utilizados, o método continua apresentando bons resultados, ou seja, $O$ conjunto de limiares $T$ utilizados tem baixa influência no resultado final, diferentemente dos modelos PAG. Para comprovar tal afirmação diferentes valores de limiares foram utilizados e são apresentados na Tabela 4.35.

Verifica-se um bom compromisso entre número de subgrafos gerados e acurácia obtida quando se utiliza 12 valores de limiares $T=[0.075,0.075, \ldots, 0.925]$, que nesse caso resulta em 25 descritores pós redução de dimensionalidade LDA. A Figura 4.40 apresenta um estudo em relação as medidas calculadas sobre esse modelo e a Figura 4.41 apresenta a variância 
Tabela 4.35 - aPAG completo contorno: Resultados obtidos para diferentes conjuntos de limiares, análise subgrafos.

\begin{tabular}{ccccc}
\hline & & \multicolumn{3}{c}{ Acerto (\%) } \\
\cline { 3 - 5 } $\boldsymbol{T}$ & ND & Genéricas & Peixes & MPEG7 \\
\hline $0.075,0.025, \ldots, 0.925$ & 27 & 94.95 & 99.01 & 75.50 \\
$0.075,0.050, \ldots, 0.925$ & 29 & 94.95 & 99.07 & 76.93 \\
$0.075,0.075, \ldots, 0.925$ & 25 & $\mathbf{9 5 . 9 6}$ & $\mathbf{9 9 . 3 5}$ & $\mathbf{7 7 . 6 4}$ \\
$0.075,0.100, \ldots, 0.925$ & 21 & 92.93 & 98.44 & 76.21 \\
$0.500,0.025, \ldots, 0.925$ & 18 & 90.91 & 97.19 & 71.93 \\
$0.075,0.025, \ldots, 0.500$ & 20 & 95.96 & 98.10 & 76.64 \\
\hline
\end{tabular}

total explicada pelas 10 primeiras variáveis canônicas.
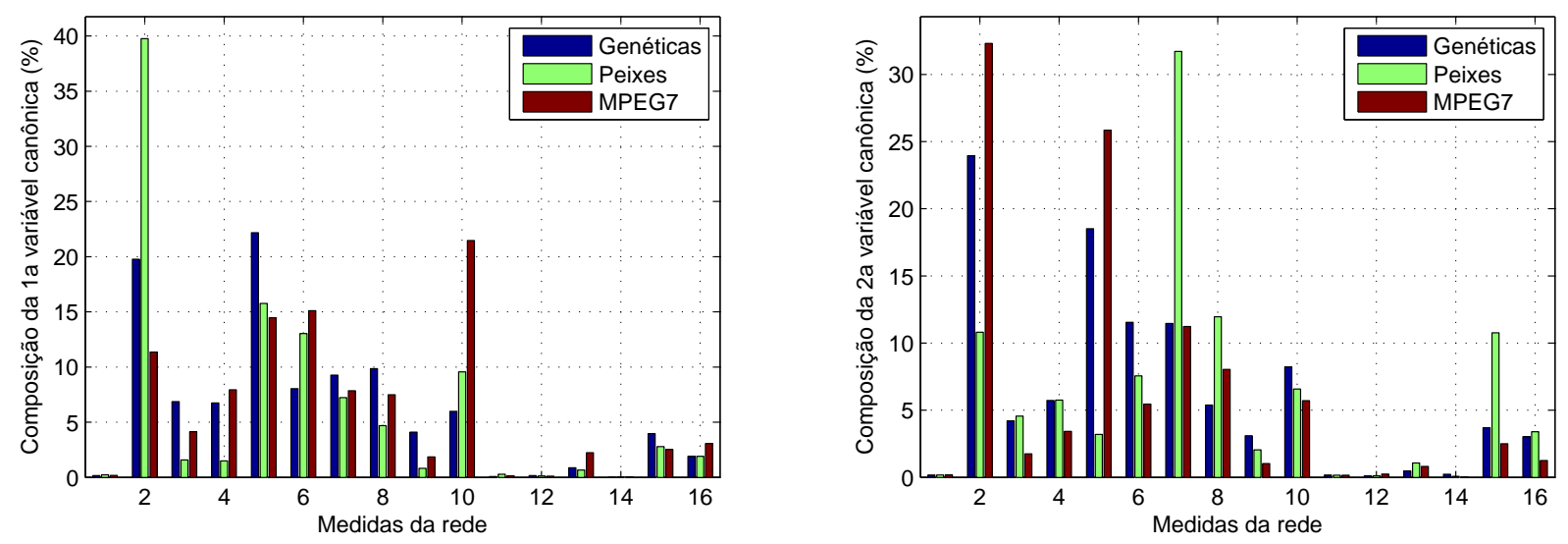

Figura 4.40 - Composição da 1a e 2a variável canônica, modelo aPAG completo contorno.

Observamos que para esse modelo as características de grau médio (2), energia dos graus (3), entropia dos graus (4), contraste dos graus (5), grau máximo (6), grau conjunto médio (7), energia grau conjunto (8), entropia grau conjunto (9), diâmetro da rede (10), centralidade máxima (15) e coeficiente de aglomeração (16) são as características mais discriminativas. Nesse tipo de modelo os vértices com maior grau encontram-se localizados em regiões de alta curvatura, logo medidas que descrevam essa distribuição dos graus dos vértices são as mais interessantes e discriminativas pois caracterizam mudanças bruscas na forma. Um grau conjunto alto, por outro lado, é encontrado em regiões com curvaturas semelhantes, pois os vértices que participam de um segmento semelhante (e.g. reta) tendem a ter o mesmo número de vizinhos a uma determinada distância. Essa medida de grau conjunto portanto caracteriza de forma indireta os segmentos semelhantes.

Esse modelo resultou em um artigo publicado na revista Pattern Recognition (14) onde um estudo mais aprofundado a respeito do modelo e das medidas pode ser obtido. 


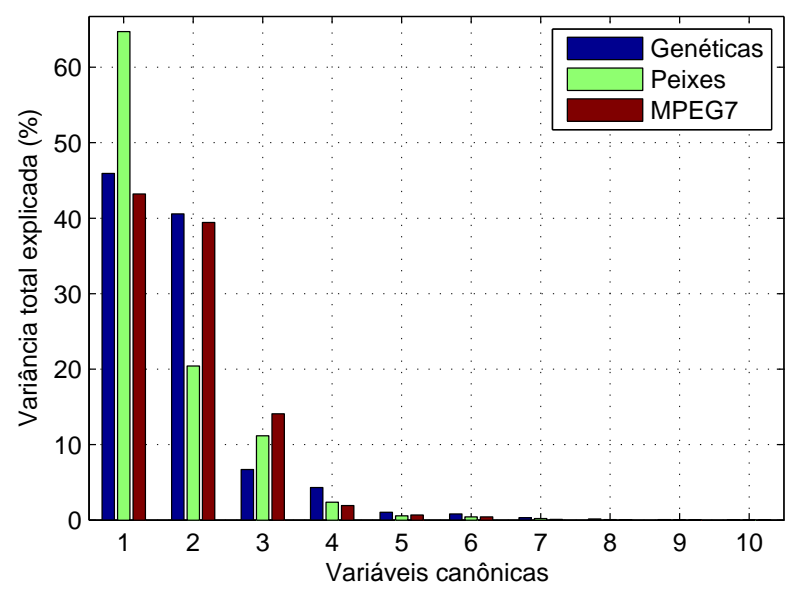

Figura 4.41 - Variância total explicada pelas 10 primeiras variáveis canônicas, modelo aPAG completo contorno.

\subsection{2 aPAG completo esqueleto}

Outro problema comum em processamento de imagens e visão computacional onde a modelagem aPAG pode ser utilizada é no reconhecimento de formas através do esqueleto da mesma. Nesse modelo cada conjunto $S_{i}$ é composto por um pixel de um esqueleto de uma forma. Um exemplo de esqueleto modelado como um aPAG completo pode ser visto na Figura 4.42 .
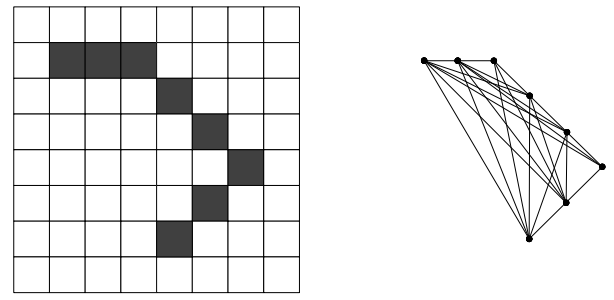

Figura 4.42 - Esqueleto modelado como um aPAG completo esqueleto: (a) cada ponto do esqueleto é um vértice no grafo; (b) uma aresta é adicionada entre todos os pares de vértices; (c) o peso reflete a distância euclidiana normalizada entre os pixeis $p$ e $q$.

$\mathrm{Na}$ literatura há muitas formas de se obter o esqueleto de um objeto. Utilizamos aqui um algorítimo baseado na transformada da distância (89), porém poderia ser utilizado qualquer outro método, mais detalhes no Anexo A.3.

Assim como na análise do contorno essa configuração inicial compreende um grafo completo, ou seja, não possui características relevantes para classificação. Dessa forma a caracterização dá-se pela análise de subgrafos.

A Tabela 4.36 apresenta uma avaliação dos intervalos de limiares testados. Para as bases de dados testadas verificou-se que, a utilização de um valor inicial de limiar $t$ alto, auxilia o processo de reconhecimento. Um possível motivo desse comportamento é que, na esquele- 
tonização espaço-escala, as ramificações geradas pelos diversos pontos de extremidade são, sob um aspecto local, semelhantes para diversas imagens (as arestas geradas entre os vértices dessas ramificações possuem um peso baixo após normalizados). Assim, a não utilização de limiar com valores baixos tende a eliminar esse aspecto local das ramificações, enfatizando as diferenças entre os diversos segmentos gerados. Nessa mesma linha é interessante notar também que a base de dados de peixes possui resultados discrepantes ao exposto acima. Isso se deve ao fato de que as formas de peixes são bem similares umas as outras, gerando pontos de extremidade em locais similares. Segundo esse raciocínio as diferenças encontram-se justamente nas diferenças de ângulos das ramificações.

Tabela 4.36 - aPAG completo esqueleto: Resultados obtidos para diferentes conjuntos de limiares, análise subgrafos.

\begin{tabular}{ccccc}
\hline & & \multicolumn{3}{c}{ Acerto (\%) } \\
\cline { 3 - 5 } $\boldsymbol{T}$ & ND & Genéricas & Peixes & MPEG7 \\
\hline $0.075,0.025, \ldots, 0.925$ & 25 & 58.59 & 39.28 & 57.00 \\
$0.075,0.050, \ldots, 0.925$ & 21 & 60.61 & 39.25 & 57.29 \\
$0.075,0.075, \ldots, 0.925$ & 19 & 62.63 & 39.71 & 57.86 \\
$0.075,0.100, \ldots, 0.925$ & 19 & 65.66 & 40.71 & 58.57 \\
$0.500,0.025, \ldots, 0.925$ & 21 & $\mathbf{7 5 . 7 6}$ & $\mathbf{4 2 . 5 3}$ & $\mathbf{6 2 . 8 6}$ \\
$0.075,0.025, \ldots, 0.500$ & 20 & 38.38 & 30.19 & 42.71 \\
\hline
\end{tabular}

As Figuras 4.43 e 4.44 fazem um estudo em relação as características obtidas por esse modelo. Podemos observar que o grau conjunto médio (7), energia grau conjunto (8) e distância geodésica média (11) são as medidas que mais contribuem para a composição da 1a e 2a variável canônica, embora essa variem fortemente entre as bases de dados. As medidas referentes a distribuição de graus conjuntos caracterizam, para o caso de esqueletos, o quão longas ou curtas são os segmentos de reta do esqueleto.
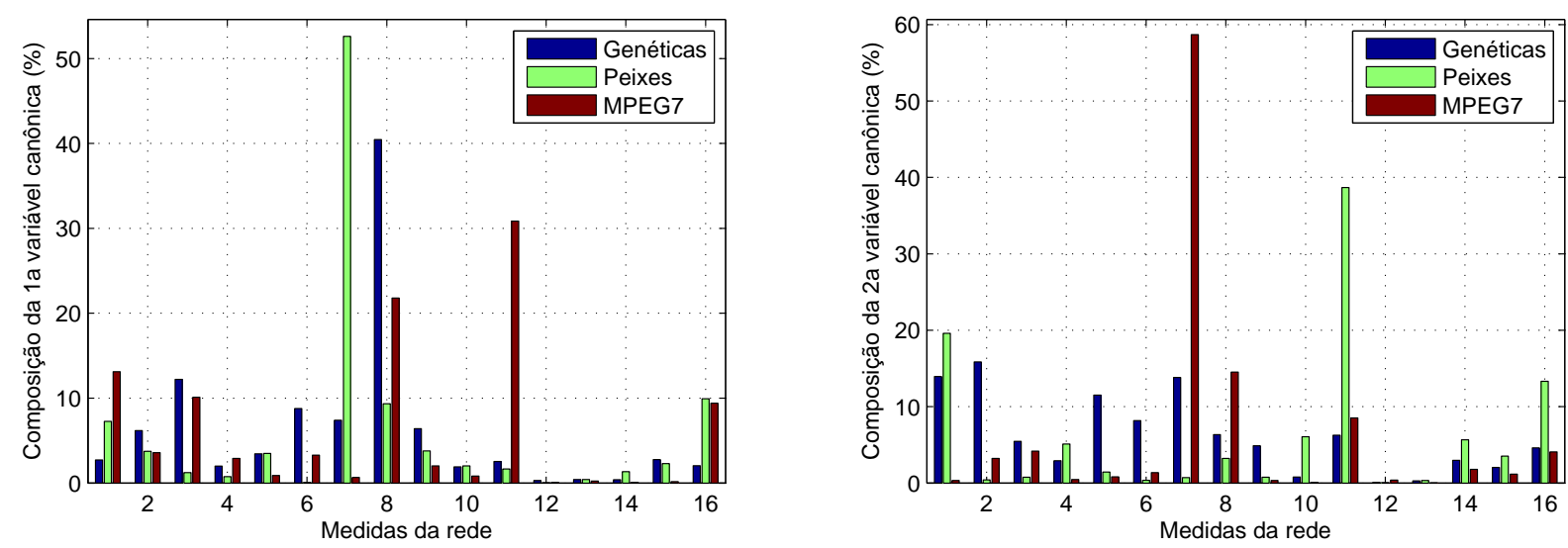

Figura 4.43 - Composição da 1a e 2a variável canônica, modelo aPAG completo esqueleto. 


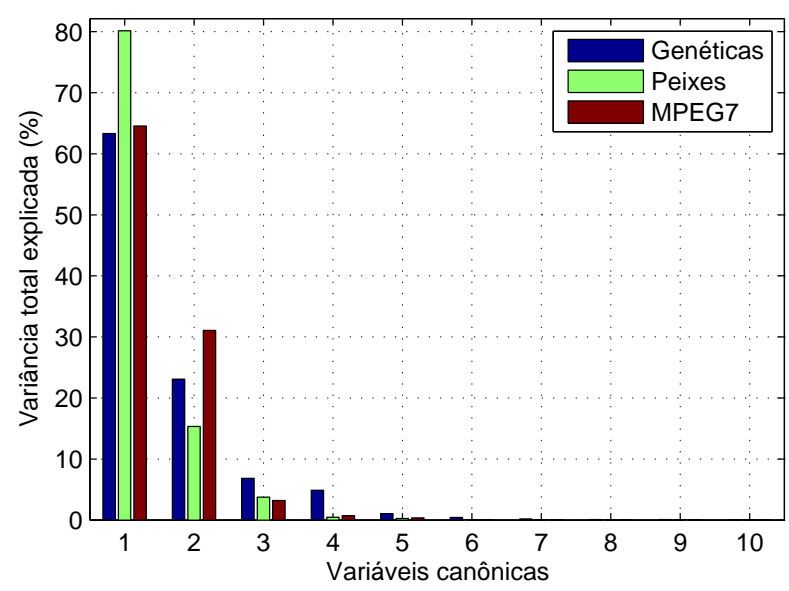

Figura 4.44 - Variância total explicada pelas 10 primeiras variáveis canônicas, modelo aPAG completo esqueleto.

\subsection{3 aPAG completo textura}

Uma forma de se analisar texturas utilizando modelos aPAG é modelando-se um conjunto de pixeis representativos da textura como grafos individuais. A esse modelo chamamos de aPAG completo textura pois os conjuntos $S_{i}$ é formado por apenas alguns pixeis da textura em análise. Nesse sentido um ou mais conjunto de pixeis podem ser escolhidas para compor a análise da imagem podendo, para cada conjunto, ser realizada uma análise individual (processo semelhante ao RAG dinâmico).

A determinação de tais conjuntos nesse caso é parâmetro chave nesse modelo. Optou-se nesse modelo determinar tais conjuntos como sendo compostos por todos os pixeis de uma determinada cor (i.e. o conjunto $C$ é formado por todos os pixeis de uma determinada cor e, cada conjunto $S_{i}$ representa um pixel desse conjunto). Seria esse um processo equivalente a segmentar a imagem (por cores) e modelar os pixeis de uma única região como um aPAG. A Figura 4.45 apresenta um exemplo de tal modelo.
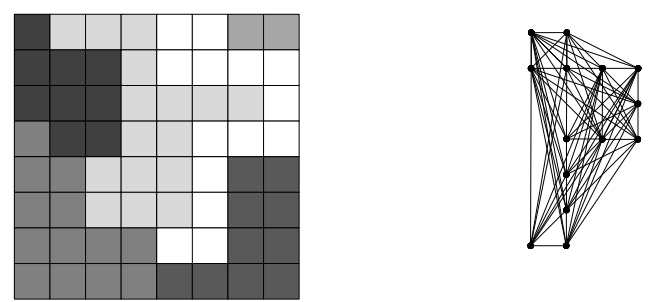

Figura 4.45 - Textura modelada como um aPAG completo textura (a) cada pixel de um conjunto de pixeis da imagem é um vértice no grafo; (b) uma aresta é adicionada entre todos os pares de vértices; (c) o peso definido pela diferença de distância normalizado entre $[0,1]$.

Para análise de textura optamos por utilizar diferentes conjuntos de pixeis, gerando diversidade de grafos. Cada grafo é então analisado utilizando análise de subgrafos. Uma 
quantização de 8 níveis de cores foi empregada, obtendo assim 8 grafos. A Tabela 4.37 apresenta os resultado para diferentes conjuntos de limiares.

Tabela 4.37 - aPAG completo textura: Resultados obtidos para diferentes conjuntos de limiares, análise subgrafos.

\begin{tabular}{ccccc}
\hline & & \multicolumn{3}{c}{ Acerto (\%) } \\
\cline { 3 - 5 } $\boldsymbol{T}$ & ND & Genéricas & Peixes & MPEG7 \\
\hline $0.075,0.025, \ldots, 0.925$ & 30 & 12.08 & 7.54 & 10.08 \\
$0.075,0.050, \ldots, 0.925$ & 29 & 11.86 & 8.76 & 9.66 \\
$0.075,0.075, \ldots, 0.925$ & 30 & $\mathbf{1 2 . 4 5}$ & $\mathbf{0 8 . 1 5}$ & $\mathbf{1 0 . 3 1}$ \\
$0.075,0.100, \ldots, 0.925$ & 25 & 12.31 & 8.21 & 7.13 \\
$0.500,0.025, \ldots, 0.925$ & 26 & 8.75 & 4.47 & 6.97 \\
$0.075,0.025, \ldots, 0.500$ & 24 & 12.87 & 6.68 & 9.28 \\
\hline
\end{tabular}

A intenção era analisar, de forma indireta, como tais cores/níveis de cinza encontram-se distribuídos na imagem. Os resultados no entanto demonstram que tal abordagem não é efetiva. Isso se deve ao fato de que para duas imagens de uma mesma classe de textura as cores não se distribuem de forma organizada, o que leva a uma análise imprecisa dos objetos.

\subsection{4 aPAG interno}

Em se estando trabalhando com contornos de um objeto um sub-caso possível é quando conecta-se um vértice ao outro se, e somente se, a aresta criada está inserida totalmente no interior do objeto em análise. Chamamos esse modelo de aPAG interno onde cada conjunto $S_{i}$ representa um único pixel do contorno do objeto, alterando-se aqui a regra básica de conexão em relação ao modelo aPAG completo contorno. Um exemplo de tal modelagem pode ser visto na Figura 4.46 .
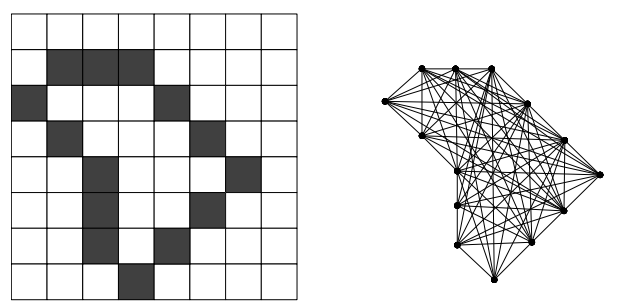

Figura 4.46 - Contorno modelado como um aPAG interno: (a) cada ponto do contorno imagem é um vértice no grafo; (b) todos os vértices $i$ e $j$ são conectados se, e somente se a aresta criada está inserida totalmente no interior do objeto em análise; (c) o peso reflete a distância euclidiana normalizada entre os pixeis $p$ e $q$.

Em tal modelagem segmentos côncavos da imagem irão influenciar a criação de aresta que passem por tal. O resultado é uma variação natural no número de arestas inicial do grafo.

Podemos perceber uma grande diferença nesse modelo aPAG interno para o aPAG completo, especialmente no que diz respeito à configuração inicial da rede. Ao se iniciar com um 
grafo não-completo, é possível se analisar a rede obtida extraindo características diretamente do modelo inicial, sem a necessidade de obter subgrafos (embora esse procedimento possa enriquecer a análise). Nesse sentido a análise direta apresenta resultados de 50.51\% 53.83\% e $42.71 \%$ para as bases de Genéricas, Peixes e MPEG7 respectivamente. Podemos perceber que, mesmo que seja possível extrair características diretamente da configuração inicial, esse método não é suficiente para uma boa caracterização dos contornos. As análise hierárquica e OPF não são realizaveis nesse modelo por se tratar de um grafo inicial completo.

Nesse sentido a Tabela 4.38 mostra o resultado para análise por subgrafos. O conjunto de limiares $T=[0.075,0.075, \ldots, 0.925]$, totalizando 12 subgrafos, foi o que obteve os melhores resultados dos conjuntos analisados (o mesmo conjunto utilizado para modelo aPAG completo).

Tabela 4.38 - aPAG interno: Resultados obtidos para diferentes conjuntos de limiares, análise subgrafos.

\begin{tabular}{ccccc}
\hline & & \multicolumn{3}{c}{ Acerto (\%) } \\
\cline { 3 - 5 } $\boldsymbol{T}$ & ND & Genéricas & Peixes & MPEG7 \\
\hline $0.075,0.025, \ldots, 0.925$ & 28 & 93.94 & 96.01 & 69.86 \\
$0.075,0.050, \ldots, 0.925$ & 27 & 94.95 & 97.46 & 71.29 \\
$0.075,0.075, \ldots, 0.925$ & 25 & $\mathbf{9 6 . 9 7}$ & $\mathbf{9 8 . 3 7}$ & $\mathbf{7 8 . 4 3}$ \\
$0.075,0.100, \ldots, 0.925$ & 21 & 94.95 & 96.28 & 71.36 \\
$0.500,0.025, \ldots, 0.925$ & 22 & 90.91 & 95.55 & 65.64 \\
$0.075,0.025, \ldots, 0.500$ & 21 & 91.92 & 95.74 & 71.21 \\
\hline
\end{tabular}

Também há de se considerar diferentes comportamentos para algumas medidas de rede. As medidas de densidade (1), grau médio (2), contraste dos graus (5), grau máximo (6), grau conjunto médio (7), energia grau conjunto (8), diâmetro da rede (10) e centralidade média (14) compõem a maior parte da 1a variável canônica. A 2a variável canônica é composta por densidade (1), grau médio (2), contraste dos graus (5), grau máximo (6), grau conjunto médio (7), energia grau conjunto (8), diâmetro da rede (10), centralidade média (14) e centralidade máxima (15). Especificamente nessa modelagem a medida de centralidade é bem interessante uma vez que os vértices de grande curvatura, localizados em regiões côncavas da imagem, tenderão a possuírem um alto grau e, consequentemente, terão uma medida de centralidade mais elevada. A Figura 4.47 apresenta o estudo de tais medidas por análise de subgrafos com $T=[0.075,0.075, \ldots, 0.925]$ e a Figura 4.48 apresenta a variância total explicada pelas 10 primeiras variáveis canônicas.

\subsection{5 aPAG externo}

O oposto do aPAG interno apresentado acima também é possível. Na modelagem aPAG externo conecta-se um vértice ao outro se, e somente se, a aresta criada está totalmente fora 

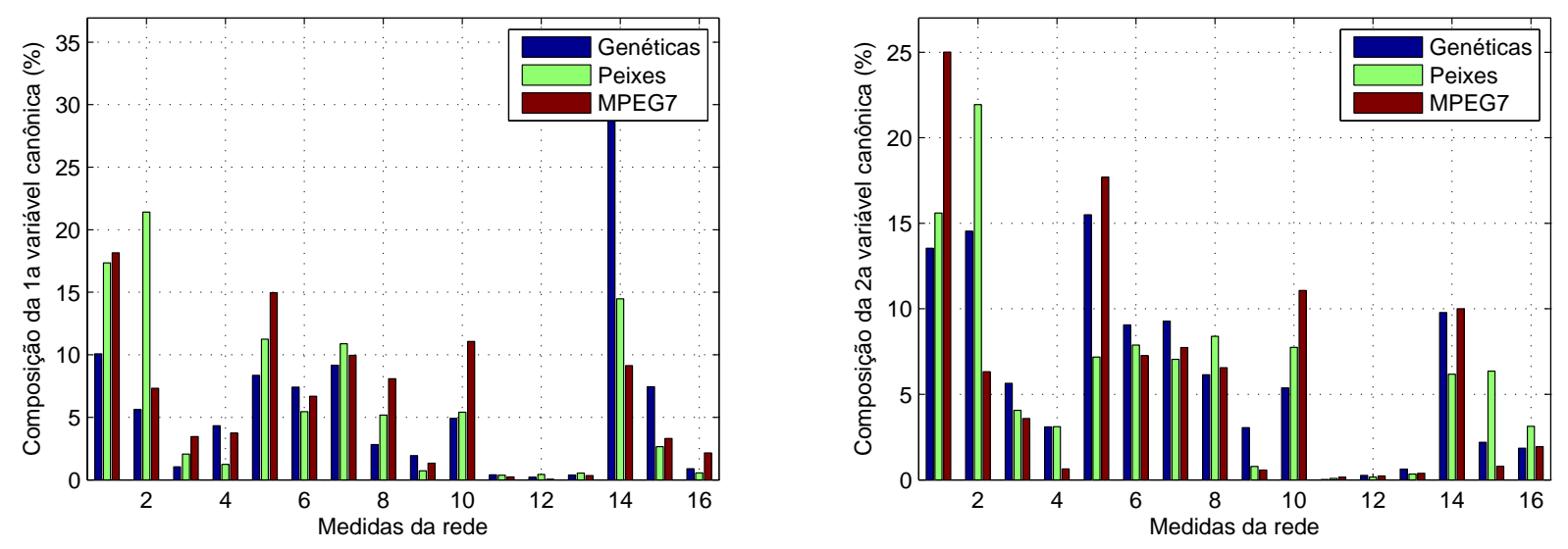

Figura 4.47 - Composição da 1a e 2a variável canônica, modelo aPAG interno.

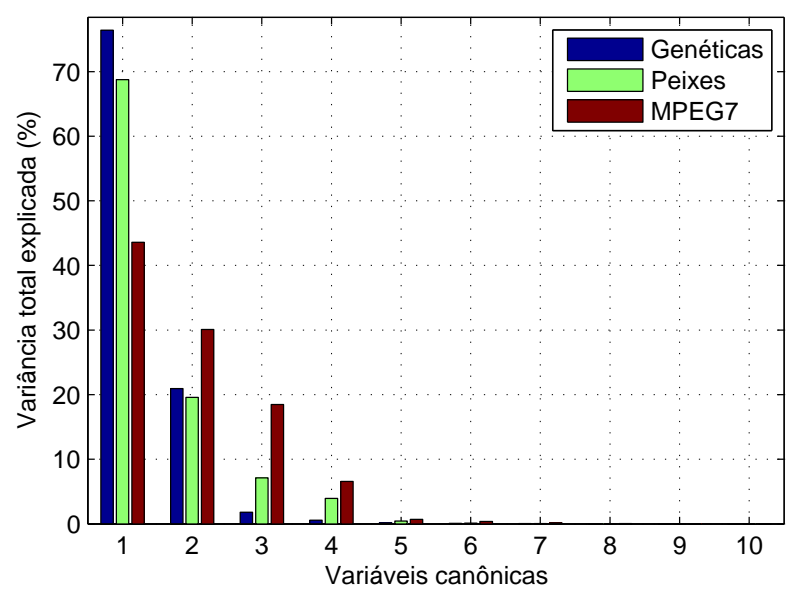

Figura 4.48 - Variância total explicada pelas 10 primeiras variáveis canônicas, modelo aPAG interno.

no interior do objeto em análise. Aqui os segmentos convexos da imagem irão inibir a criação de arestas no grafo, fazendo com que o grafo inicial não seja completo como o primeiro caso apresentado. Um exemplo de tal modelagem pode ser visto na imagem 4.49 .

Assim como o aPAG interno, o modelo aPAG externo apresenta melhores resultados quando da análise por sub-grafos obtidos pelo conjunto de limiares $T=[0.075,0.075, \ldots, 0.925]$, totalizando 12 subgrafos. A Tabela 4.39 apresenta os resultados para tal análise.

As Figuras 4.50 e 4.51 apresentam um estudo referente as medidas extraídas do modelo aPAG externo para análise por subgrafos (melhor resultado da tabela acima). A 1a e 2a variáveis canônicas são compostas basicamente pelas medidas de densidade (1), grau médio (2), energia dos graus (3), entropia dos graus (4), contraste dos graus (5), grau máximo (6), entropia grau conjunto (9), diâmetro da rede (10), centralidade média (14) centralidade máxima (15) e coeficiente de aglomeração (16). Observa-se que, assim como no modelo aPAG interno, as medidas de centralidade tem uma considerável importância na composição das primeiras variáveis canônicas. 

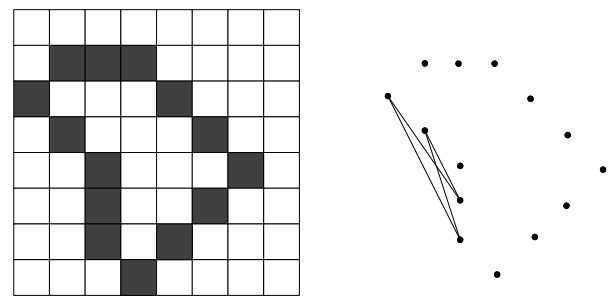

Figura 4.49 - Contorno modelado como um aPAG externo: (a) cada ponto do contorno imagem é um vértice no grafo; (b) todos os vértices $i$ e $j$ são conectados se, e somente se a aresta criada está totalmente fora no interior do objeto em análise; (c) o peso reflete a distância euclidiana normalizada entre os pixeis $p$ e $q$.

Tabela 4.39 - aPAG externo: Resultados obtidos para diferentes conjuntos de limiares, análise subgrafos.

\begin{tabular}{ccccc}
\hline & & \multicolumn{3}{c}{ Acerto (\%) } \\
\cline { 3 - 5 } $\boldsymbol{T}$ & ND & Genéricas & Peixes & MPEG7 \\
\hline $0.075,0.025, \ldots, 0.925$ & 23 & 72.73 & 54.65 & 43.00 \\
$0.075,0.050, \ldots, 0.925$ & 23 & 73.74 & 55.38 & 44.29 \\
$0.075,0.075, \ldots, 0.925$ & 21 & $\mathbf{7 5 . 7 6}$ & $\mathbf{5 5 . 4 7}$ & $\mathbf{4 5 . 0 0}$ \\
$0.075,0.100, \ldots, 0.925$ & 18 & 73.74 & 55.56 & 44.43 \\
$0.500,0.025, \ldots, 0.925$ & 20 & 69.70 & 52.84 & 41.50 \\
$0.075,0.025, \ldots, 0.500$ & 18 & 66.67 & 54.54 & 42.79 \\
\hline
\end{tabular}
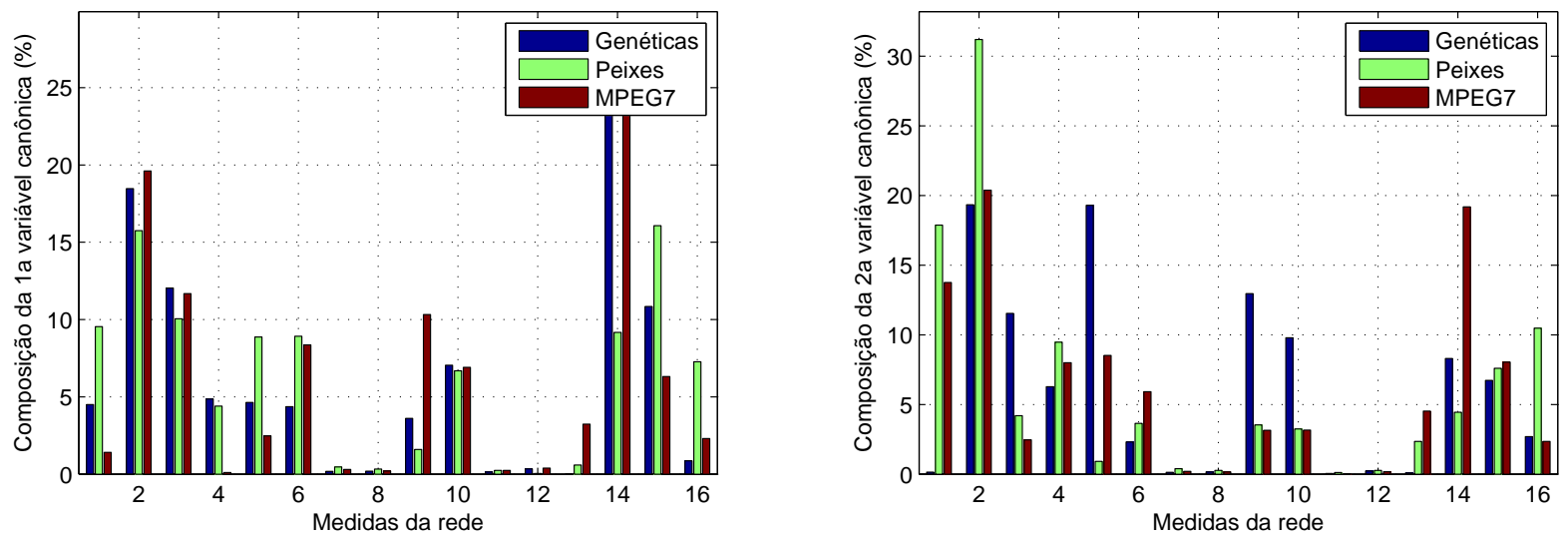

Figura 4.50 - Composição da 1a e 2a variável canônica, modelo aPAG externo.

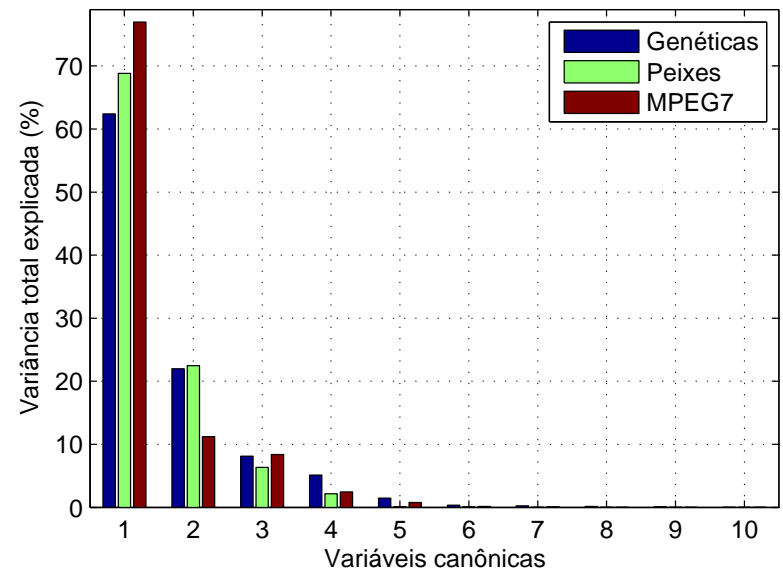

Figura 4.51 - Variância total explicada pelas 10 primeiras variáveis canônicas, modelo aPAG externo. 


\section{CAPÍTULO 5}

\section{Resumo dos resultados e avaliação}

Essa seção tem por objetivo fazer uma análise geral dos métodos propostos em relação aos métodos tradicionais e métodos estado da arte. Essa avaliação é realizada sobre 4 diferentes problemas da área de visão computacional, análise de textura, contorno, cor e esqueletos.

A avaliação aqui emprega os métodos propostos utilizando a melhor configuração de parâmetros observada na seção anterior. A classificação e avaliação se dá pelos métodos de LDA+Bayes e LDA+Knn com métricas de desempenho definidos no anexo $B$.

\subsection{Análise de textura}

Os resultados obtidos pelos métodos de análise de textura propostos são comparados com outras descritores de textura bem conhecidos na literatura. São eles:

- Características de primeira ordem (90): Características de média, variância, curtose, energia e entropia são calculadas a partir do histograma da imagem, totalizando 5 características.

- Descritores de Fourier (91): A transformada de Fourier é aplicada na textura e a energia de 64 coeficientes é utilizada para formar o vetor de características. Para isso o espectro bi-dimensional é dividido em 64 setores compostos por 8 distâncias radiais e 8 ângulos. Cada característica corresponde à soma do valor absoluto de cada setor.

- Filtros de Gabor (92-95): O filtro de Gabor 2-d é basicamente uma gaussiana bidimensional modulada com um senoide orientada com determinada frequência e direção. O processo consiste em convoluir uma imagem com um conjunto de filtros que apresentam diversas escalas e rotações. Um total de 64 filtros (8 rotações e 8 escalas), com frequência inferior e superior de 0.01 e 0.4 respectivamente, é utilizado. A energia das 
respostas de cada filtro compõe o vetor de características. A definição dos parâmetros individuais de cada filtro segue a metodologia proposta por (92).

- Matrizes de coocorrência (GLCM) (83): É, basicamente, a distribuição conjunta entre pares de pixeis em uma determinada distância e direção. Distâncias de 1 e 2 pixeis, com ângulos de $-45^{\circ},-90^{\circ}, 45^{\circ}$ e $90^{\circ}$ são usadas. Medidas de contraste, correlação, energia e homogeneidade são então extraídas de cada matriz resultante, totalizando 32 características. A versão não simétrica é adotada nos experimentos.

- Transformada discreta do cosseno (DCT) (96): Um conjunto de mascaras de $3 \times 3$ é gerada a partir de 3 vetores bases $U_{1}=1,1,1^{T}, U_{2}=1,0,-1^{T}$, e $U_{3}=1,-2,1^{T}$. Nove mascaras são geradas a partir desses vetores e a máscara passa baixa resultante é excluída. A variância das respostas dos filtros compõe o vetor de características.

- Matriz de diferenças (GLDM) (97, 98): É baseado na probabilidade de dois pixeis terem o mesmo valor absoluto (nível de cinza) quando separados por uma distância $d$. Nos experimentos considerou-se as distâncias $(0, d),(-d, d),(d, 0)$, e $(-d,-d)$ com 3 diferentes valores de $d(1,2$ e 5$)$. Cinco medidas (contraste, segundo momento angular, entropia, médias e momento de diferença inversa) são calculados para cada matriz obtida, resultando em 60 características.

- Descritores de wavelets (82, 99-101): A decomposição 2D wavelet em 4 níveis é utilizada (daubechies 4). A energia, entropia e média dos detalhes horizontais, verticais e diagonais são calculadas, compondo assim um vetor de características de 36 elementos.

- Padrões binários locais completos (Complete Local Binary Pattern (CLBP)) (102): É uma alteração do tradicional LBP (103, 104). Utiliza a diferença local dos sinais para compor os operadores CLBP_C, CLBP_S e CLBP_M. Esses 3 operadores podem ser combinados de diferentes formas. Aqui histogramas 3D são utilizados para tal. Os outros parâmetros utilizados são radius $=2$, neighborhood $=16$ com padrões invariantes a rotação $U \leq 2$, totalizando 648 característica. O mesmo classificador proposto pelos autores é empregado.

- Padrões binários locais com variância (Local Binary Pattern Variance (LBPV)) (105): É outra variação do tradicional LBP (103) que utiliza a variação local como característica extra. Os parâmetros utilizados foram radius $=3$, neighborhood $=24$, totalizando 555 características. Esses são, segundo o autor do trabalho, os melhores parâmetros para a base de dados Outex. O classificador baseado em global matching com 2 orientações, proposto pelo autor é utilizado nos experimentos. 
- Padrões ternários locais (Local Ternary Pattern (LTP)) (106): É outra extensão do LBP original LBP (103) na qual o operador utiliza um código de 3 , ao invés de 2 valores para caracterizar os pixeis vizinhos. Como sugerido pelos autores do trabalho utilizou-se threshold de 0.1 , com radius $=2$, neighborhood $=8$, totalizando 32769 características. O classificador baseado em distância proposto pelos autores também é utilizado.

A Tabela 5.1 apresenta os resultados dos métodos propostos com demais métodos tradicionais em análise de texturas. Podemos observar que o método PAG lattice $r$-conectada apresenta os melhores resultados para as bases de dados Brodatz e Outex e o segundo melhor resultado, por margem mínima, para a base de dados Vistex, perdendo apenas para o método CLBP. Esses excelentes resultados, especialmente para o modelo aPAG completo textura, demonstram que a análise de textura, via redes complexas, é uma alternativa viável a outros métodos da literatura.

Tabela 5.1 - Comparação do método com diversos descritores de textura. Alta discriminação obtida para todas as bases de dados.

\begin{tabular}{|c|c|c|c|c|c|c|c|}
\hline \multirow[b]{3}{*}{ Método } & \multirow[b]{3}{*}{ ND } & \multicolumn{6}{|c|}{ Acerto (\%) e Desvio padrão } \\
\hline & & \multicolumn{2}{|c|}{ Brodatz } & \multicolumn{2}{|c|}{ Outex } & \multicolumn{2}{|c|}{ Vistex } \\
\hline & & BAYES & KNN & BAYES & KNN & BAYES & KNN \\
\hline PAG lattice 4 & 19 & $18.58( \pm 1.45)$ & $17.48( \pm 2.76)$ & $21.84( \pm 1.85)$ & $19.64( \pm 1.77)$ & $25.58( \pm 1.85)$ & $22.36( \pm 3.70)$ \\
\hline PAG lattice 8 & 26 & $73.31( \pm 1.41)$ & $68.00( \pm 3.40)$ & $46.91( \pm 1.29)$ & $43.72( \pm 2.57)$ & $72.11( \pm 1.65)$ & $67.38( \pm 4.53)$ \\
\hline PAG lattice raio & 26 & $95.44( \pm 1.85)$ & $92.47( \pm 2.76)$ & $\mathbf{8 6 . 6 9}( \pm 1.84)$ & $79.12( \pm 3.16)$ & $97.80( \pm 2.00)$ & $93.24( \pm 3.80)$ \\
\hline PAG lattice completo & 40 & $53.43( \pm 2.14)$ & $46.12( \pm 2.34)$ & $29.04( \pm 1.65)$ & $22.30( \pm 1.67)$ & $55.32( \pm 2.22)$ & $51.02( \pm 2.56)$ \\
\hline PAG lattice k-vizinhos & 41 & $70.21( \pm 1.74)$ & $63.80( \pm 2.79)$ & $46.47( \pm 1.44)$ & $40.87( \pm 3.15)$ & $73.15( \pm 1.71)$ & $69.46( \pm 4.61)$ \\
\hline PAG lattice small-world & 24 & $45.05( \pm 3.04)$ & $42.73( \pm 2.93)$ & $17.65( \pm 1.71)$ & $15.02( \pm 3.45)$ & $44.56( \pm 1.86)$ & $40.01( \pm 4.71)$ \\
\hline MAG & 15 & $33.00( \pm 2.46)$ & $28.61( \pm 2.14)$ & $23.51( \pm 1.97)$ & $19.85( \pm 2.30)$ & $41.67( \pm 1.44)$ & $31.53( \pm 3.01)$ \\
\hline RAG estático & 12 & $50.56( \pm 1.75)$ & $44.47( \pm 3.06)$ & $51.47( \pm 1.56)$ & $47.72( \pm 3.65)$ & $52.78( \pm 1.48)$ & $49.80( \pm 4.89)$ \\
\hline RAG dinâmico & 34 & $65.48( \pm 1.61)$ & $54.16( \pm 3.14)$ & $61.03( \pm 2.60)$ & $57.41( \pm 3.65)$ & $67.59( \pm 1.10)$ & $61.33( \pm 4.61)$ \\
\hline CAG & 12 & $84.32( \pm 2.46)$ & $79.05( \pm 3.04)$ & $79.42( \pm 1.33)$ & $68.61( \pm 2.87)$ & $91.46( \pm 2.44)$ & $88.86( \pm 2.78)$ \\
\hline aPAG completo textura & 30 & $12.45( \pm 0.87)$ & $07.09( \pm 1.53)$ & $08.15( \pm 1.79)$ & $11.01( \pm 2.53)$ & $10.31( \pm 1.53)$ & $07.08( \pm 2.27)$ \\
\hline Primeira ordem & 6 & $41.89( \pm 1.48)$ & $44.16( \pm 2.90)$ & $55.37( \pm 1.66)$ & $63.03( \pm 3.55)$ & $56.71( \pm 2.10)$ & $62.23( \pm 4.86)$ \\
\hline Fourier & 13 & $84.57( \pm 1.87)$ & $78.09( \pm 2.32)$ & $83.90( \pm 2.49)$ & $78.76( \pm 2.65)$ & $92.13( \pm 0.87)$ & $89.17( \pm 2.93)$ \\
\hline Gabor & 24 & $83.22( \pm 2.12)$ & $82.94( \pm 2.05)$ & $80.51( \pm 1.82)$ & $79.90( \pm 2.84)$ & $91.32( \pm 3.05)$ & $90.31( \pm 3.05)$ \\
\hline GLCM & 14 & $90.65( \pm 1.47)$ & $82.87( \pm 2.12)$ & $83.53( \pm 2.15)$ & $78.10( \pm 3.12)$ & $94.33( \pm 1.55)$ & $92.18( \pm 3.21)$ \\
\hline DCT & 6 & $79.73( \pm 1.17)$ & $77.79( \pm 2.51)$ & $70.74( \pm 1.36)$ & $72.77( \pm 2.68)$ & $79.63( \pm 1.64)$ & $79.73( \pm 4.14)$ \\
\hline GLDM & 15 & $94.26( \pm 0.86)$ & $91.21( \pm 1.99)$ & $86.62( \pm 1.99)$ & $78.99( \pm 2.90)$ & $96.41( \pm 0.73)$ & $\mathbf{9 3 . 5 9}( \pm 3.93)$ \\
\hline Wavelets & 11 & $85.42( \pm 1.94)$ & $81.18( \pm 3.06)$ & $78.46( \pm 3.01)$ & $71.34( \pm 3.58)$ & $89.81( \pm 1.43)$ & $84.40( \pm 3.88)$ \\
\hline CLBP & & $95.32( \pm 2.15)$ & & $85.80( \pm 2.40)$ & & $98.03( \pm 2.19)$ & \\
\hline LBPV & & $86.26( \pm 2.33)$ & & $75.66( \pm 2.42)$ & & $88.65( \pm 2.11)$ & \\
\hline LTP & & $88.04( \pm 1.71)$ & & $79.16( \pm 2.00)$ & & $91.56( \pm 2.65)$ & \\
\hline
\end{tabular}

No geral a base de dados Vistex é a mais fácil de ser reconhecida, seguida pela Brodatz. A Outex apresenta em média um decaimento de $10 \%$ em relação as duas anteriores. De fato a base de dados Outex possui texturas com composições e variações de intensidade bem semelhantes em algumas classes, o que explica tal resultado. Para os métodos da literatura destaque para GLDM e os baseados em LBP. O GLDM é um método extremamente simples, porém pouco conhecido e utilizado na literatura. Já os métodos baseados em LBP apresentados acima utilizam o próprio classificador sugerido pelos autores (não sendo portanto apresentado resultados na coluna do Knn). Caso uma classificação via LDA+Bayes fosse realizada com tais métodos os resultados seriam inferiores, por esse motivo optou-se por apresentar o método proposto pelos autores em seu inteiro teor, para uma melhor comparação. 
Embora o método de classificação por LDA+Knn possua boa capacidade de generalização, sua acurácia para os métodos baseados em teoria das redes complexas apresentam-se inferiores ao classificador LDA+bayes. Para ambos utilizou-se a redução de dimensionalidade via LDA através de combinações lineares de características. Essas as novas características apresentam a propriedade de não serem correlacionadas entre si, o que talvez explica os melhores resultados alcançados pelo classificador Bayesiano. Adicionalmente essa redução de dimensionalidade evita o mau da dimensionalidade, caso o conjunto de características original possua um grande número de variáveis.

No geral os dois classificadores, LDA+Bayes e LDA+Knn são bem comportados. Isso é devido a natureza determinística de ambos, ou seja, caso a mesma entrada seja fornecida k-vezes, a mesma saída será obtida k-vezes. O desvio padrão obtido pelas 10 repetições é resultado da variação das amostras que compõe cada um dos 10 -folds utilizados no treinamento/classificação. Observamos um desvio padrão levemente superior para o classificador Knn na maioria dos métodos, porém nada fora do aceitável.

Considerando-se apenas os métodos propostos o modelo PAG lattice r-conectada é seguramente bem superior aos demais. Outro que obtive bons resultado é o modelo CAG. O modelo CAG alcança bons resultados devido à utilização de medidas fractais. Os demais métodos não apresentam-se adequados para análise de texturas.

Em relação aos modelos adotados é importante observar que deve haver uma relação de equivalência entre modelos obtidos por diferentes imagens. Ou seja, o número de pixeis representados por um modelo deve ser igual para todas as imagens. O único modelo que não satisfaz tal restrição é o aPAG, onde o conjunto de pixeis que serão incluídos no grafo é variável e dependente do problema/imagem apresentados. Nesse sentido o modelo aPAG necessita de uma normalização das medidas em relação ao número de vértices representados no modelo (e.g. grau normalizado) para que as características sejam invariantes à escala.

Ainda nessa linha os modelos RAG E CHAG (ver análise de cor) também geram representações com número variável de vértices, todavia nesses casos todos os pixeis da imagem estão representados no conjunto $C$. Essa variação do número de vértices acaba sendo uma característica de tais modelos, que representa o número de regiões e número de cores respectivamente. Já no modelo CAG e MAG o número de vértices é fixo e dependente do número de cores e/ou escalas, que obrigatoriamente será igual para todas as imagens da base. Dessa forma esses modelos não necessitam de nenhum tipo de normalização em relação aos vértices.

Por outro lado os pesos $w_{i j}$ adotados nas arestas dos modelos necessitam de atenção especial, especialmente quando analisados via análise por subgrafos. Sendo a análise de subgrafos 
baseada em limiares, é necessário garantir que cada limiar gere efeitos correspondentes para todas as imagens. Logo se deve ter cuidado ao normalizar tal informação.

Das formas de análise propostas a análise por subgrafos é seguramente a mais genérica, podendo essa ser utilizada em todos os modelos propostos. De forma geral percebemos que a utilização de um número excessivo ou reduzido de limiares não alcança os melhores resultados, sendo o conjunto de 12 limiares dados por $T=[0.075,0.075, \ldots, 0.925]$ o melhor em muitos modelos. Obviamente tais limiares são fortemente dependentes da forma de normalização das arestas. Os modelos PAG, por exemplo, apresentam uma concentração de informação nos primeiros limiares, uma vez que normalmente não há grandes diferenças de intensidade em imagens de textura, nesse sentido o conjunto $T=[0.075,0.075, \ldots, 0.925]$ é melhor para alguns subcasos de PAG.

A análise direta, por outro lado, só é adequada em grafos cujas distribuições das conexões não sejam triviais, ou seja, modelos CAG, RAG, aPAG interno e aPAG externo. Esse tipo de análise obteve o melhor resultado no modelo RAG. As mesmas restrições são observadas na análise hierárquica, ou seja, só é possível realiza-la efetivamente em modelos com conexões não regulares (casos de CAG e RAG). Isso é devido ao fato de que as medidas de redes complexas aqui apresentadas são concebidas exclusivamente para grafos binários não direcionados. Ambas as formas de análise podem vir a ser úteis se as medidas de redes forem modificadas no sentido de consideraram grafos com peso (e.g. força média/grau médio).

A análise OPF tem como principal restrição a necessidade de uma 'correspondência' entre os vértices de diferentes modelos, ou seja, é necessário garantir que o vértice $v_{i}$ represente uma mesma propriedade (pixel ou conjunto de pixeis) em diferentes imagens. Tal premissa não é satisfeita nos modelos aPAG, pois não há garantias que um mesmo pixel de diferentes imagens esteja presente no modelo. Caso esse tipo de análise seja realizada nesses modelos há a possibilidade de se obter florestas de caminhos ótimos totalmente diversas para imagens extremamente semelhantes, justamente o contrário do objetivo desejado. Obviamente heurísticas podem ser desenvolvidas para sanar tal problema. A escolha das sementes como sendo os $n$ pontos de maior curvatura dos objetos é um exemplo de heurística que pode ser testada em trabalhos futuros.

Dentre as análises propostas seguramente a análise direta é a que obtém um número menor de características originais. De modo geral as outras análises tendem a gerar um número grande de características. Todavia, como demonstrado pelos gráficos de variância total explicada de cada método, tais características podem ser resumidas em um número pequeno de variáveis canônicas. O número de variáveis canônicas que representam 99.99\% 
da variância total explicada gira em torno de 9 à 30, dependendo da forma de análise. Esse número pode ser considerado adequado se comparado com o número de características dos demais métodos.

Devido a toda essa variabilidade de modelos, funções de peso e formas de análise não é possível afirmar que uma medida, ou conjunto de medidas estatísticas, sejam mais discriminativas. Tal análise deve ser feita para cada modelo/função de peso/forma de análise individualmente. A medida de densidade, por exemplo, pode indicar características da imagem distintas em análises diretas ou por OPF. É importante considerar nesse ponto que todas as características estudadas obtiveram uma determinada importância para algum modelo.

Para o melhor método proposto, o PAG lattice $r$-conectada, observamos que as características que medem o grau e conectividade tiveram grande destaque na composição das primeiras variáveis canônicas. Nesse sentido o artigo publicado na Information Science (14) apresenta tal modelo utilizando apenas esse conjunto de medidas para caracterização das texturas.

Em relação as características de complexidade essa obteve grande sucesso na caracterização de modelos do tipo CAG. Esse tipo de modelo possui as duas propriedades necessárias para o uso adequado de tal medida: (1) não ser um grafo trivial, que para o modelo CAG é facilmente observável pela complexa relação de adjacência definida pelas cores adjacentes da imagem e (2) possuir uma relação de ordem no grafo, que no CAG é dada pela simples ordem das cores em algum modelo de cores. Dessa forma é possível aplicar essa medida à matriz de adjacência da rede, de forma a mensurar indiretamente a complexidade em termos de sua conectividade.

Para modelos os PAG, por exemplo, a relação da adjacência do modelo é igual para todas as imagens analisadas, ou seja, a relação de adjacência é definida exclusivamente pelo raio de conexão, não sendo afetada por nenhuma outra propriedade indireta da imagem. O modelo PAG é caracterizado exclusivamente por medidas de peso das arestas e não pela complexidade da distribuição dessas. Nesse sentido não é adequado utilizar a medida de complexidade na matriz de adjacência, pois a mesma possui um comportamento trivial k-regular. A mesma problemática aplica-se aos modelos CPAG, MAG, CHAG e aPAG.

Já para os modelos RAG não é possível a utilização das medidas de complexidade na matriz de adjacência uma vez que essa não apresenta ordem de nós definida. Ou seja, é impossível determinar se o nó 1 de duas diferentes imagens representam a mesma região, até porque o número de regiões é variável entre as imagens. O mesmo ocorre com os modelos CHAG e aPAG. 


\subsection{Análise de cor}

A análise de cor para esse trabalho compreende os métodos que empregam informações cromáticas (RGB) na geração do modelo, ou seja, não há conversão das imagens para escala de cinza como nos métodos de textura acima listados. São 3 os métodos de redes complexas propostos com tal característica, CPAG, CHAG e CAG. A Tabela 5.2 apresenta os resultados obtidos para ambos os métodos para análise via LDA+Bayes e LDA+Knn:

Tabela 5.2 - Comparação do método com diversos descritores de textura. Alta discriminação obtida para todas as bases de dados.

\begin{tabular}{ccccccc}
\hline & & \multicolumn{3}{c}{ Acerto (\%) e Desvio padrão } \\
\cline { 3 - 4 } \cline { 5 - 6 } Método & ND & BAYES & KNN & & \multicolumn{2}{c}{ Vistex } \\
\cline { 3 - 4 } \cline { 5 - 7 } CPAG & 19 & $42.28( \pm 1.42)$ & $37.43( \pm 2.12)$ & & $74.31( \pm 1.82)$ & $69.24( \pm 3.09)$ \\
CHAG & 19 & $53.01( \pm 2.31)$ & $48.76( \pm 2.97)$ & & $80.21( \pm 1.83)$ & $74.02( \pm 2.46)$ \\
CAG & 16 & $\mathbf{8 7 . 5 0}( \pm 2.02)$ & $\mathbf{8 3 . 5 6}( \pm 2.76)$ & & $\mathbf{9 1 . 0 4}( \pm 2.37)$ & $\mathbf{8 8 . 9 4}( \pm 3.11)$ \\
\hline
\end{tabular}

A análise sobre as duas bases de dados cromáticas mostra que os melhores resultados são obtidos utilizando o modelo CAG para modelo de cores RGB e medidas de fractais. Os modelos CPAG e CAG fazem uso da relação de adjacência, seja na determinação do peso ou da conectividade. Nesse sentido destaque deve ser dado ao modelo CHAG que obteve um boa taxa de acerto, especialmente na base Vistex, uma vez que tal modelo não considera as relações espaciais dos pixeis. Observa-se novamente que a classificação por LDA+Knn é inferior à classificação por LDA+Bayes e também apresenta um desvio padrão levemente superior.

\subsection{Análise de forma}

Assim como na análise de textura, os métodos propostos para análise de forma são comparados com outros métodos da literatura, são eles:

- Descritores de Fourier (107, 108): Os descritores de Fourier são compostos pelas 20 coeficientes mais significantes da transformada de Fourier.

- Momentos de Zernike (109): Cada imagem é representada por um vetor de características contendo as 20 magnitudes mais importantes de um conjunto de momentos complexos ortogonais (ordem $n=0,1, \ldots, 7$ ).

- Curvatura (110): A curvatura representa cada contorno como uma curva onde seus máximos mínimos locais correspondem às mudanças de direção no contorno forma. 
- Dimensão Fractal Multi-escala (89, 111): Esse método permite representar uma forma através de uma curva que descreve como a complexidade do objeto se altera em diferentes escalas. Para tal os 50 pontos mais significativos da curva foram utilizados para compor o vetor de características.

A Tabela 5.3 apresenta os resultados para as melhores configurações dos métodos propostos. Observamos que, comparativamente com os métodos da literatura, os métodos de análise de contornos baseados em redes complexas apresentam uma ótima capacidade de reconhecimento. O método aPAG interno foi o que obteve melhores resultados nas bases Genéricas e MPEG7, enquanto o método aPAG completo apresentou melhores resultados para a base de dados de Peixes. A base de dados de peixes é a mais facilmente classificada. Um artigo apresentando os resultados do método aPAG interno estão publicados na revista Pattern Recognition (14).

Tabela 5.3 - Resultados alcançados por diversos métodos de análise de formas em 3 bases de dados.

\begin{tabular}{|c|c|c|c|c|c|c|c|}
\hline \multirow[b]{3}{*}{ Método } & \multirow[b]{3}{*}{ ND } & \multicolumn{6}{|c|}{ Acerto (\%) e Desvio padrão } \\
\hline & & \multicolumn{2}{|c|}{ Genéricas } & \multicolumn{2}{|c|}{ Peixes } & \multicolumn{2}{|c|}{ MPEG7 } \\
\hline & & BAYES & KNN & BAYES & KNN & BAYES & KNN \\
\hline aPAG completo & 25 & $95.96( \pm 2.44)$ & $89.55( \pm 3.04)$ & $\mathbf{9 9 . 3 5}( \pm 2.84)$ & $93.45( \pm 2.93)$ & $77.64( \pm 3.12)$ & $75.56( \pm 3.35)$ \\
\hline aPAG interno & 25 & $\mathbf{9 6 . 9 7}( \pm 2.57)$ & $89.28( \pm 2.51)$ & $98.37( \pm 3.01)$ & $93.01( \pm 2.56)$ & $\mathbf{7 8 . 4 3}( \pm 3.09)$ & $74.49( \pm 3.00)$ \\
\hline aPAG externo & 21 & $75.76( \pm 2.14)$ & $69.02( \pm 2.71)$ & $55.47( \pm 3.02)$ & $50.85( \pm 2.30)$ & $45.00( \pm 2.51)$ & $40.24( \pm 2.84)$ \\
\hline Descritores de Fourier & 11 & $83.84( \pm 3.21)$ & $78.20( \pm 2.77)$ & $99.07( \pm 2.45)$ & $93.21( \pm 2.82)$ & $75.08( \pm 1.52)$ & $69.06( \pm 2.45)$ \\
\hline Momentos de Zernike & 9 & $91.92( \pm 2.45)$ & $88.42( \pm 3.10)$ & $12.23( \pm 3.15)$ & $10.55( \pm 4.04)$ & $23.87( \pm 2.33)$ & $20.52( \pm 3.03)$ \\
\hline Curvatura & 12 & $76.77( \pm 2.21)$ & $74.24( \pm 1.87)$ & $97.55( \pm 2.18)$ & $92.85( \pm 2.31)$ & $65.12( \pm 2.67)$ & $61.02( \pm 2.45)$ \\
\hline Dimensão Fractal Multi escala & 17 & $87.88( \pm 2.36)$ & $85.02( \pm 2.59)$ & $37.32( \pm 2.76)$ & $35.34( \pm 1.98)$ & $69.31( \pm 2.98)$ & $64.64( \pm 2.31)$ \\
\hline
\end{tabular}

É importante notar que as bases de dados possuem diferentes variações em sua estrutura, tais como oclusão, articulações, partes ausentes e diversas outras deformações. O método proposto mostrou-se eficaz mesmo nessas situações. Nesse sentido, além da comparação direta com outros métodos o estudo das propriedades de invariância à rotação, escala, robustez e tolerância a ruídos podem ser realizados.

Rotação e escala: em relação à propriedade de invariância à escala e rotação a base de dados de Peixes pode ser um bom parâmetro, pois esse contém diferentes manifestações de escala e rotação de um mesmo contorno. Nesse sentido o modelo aPAG externo não apresentam bons resultados. O mesmo ocorre com os métodos de momentos de Zernique e dimensão fractal multi-escala. Segundo Torres et al. (111) a dimensão fractal multi-escala não é totalmente independente de escala, por isso a baixa taxa de acerto. Já os momentos de Zernike falham em distinguir entre objetos que são muito similares (112).

Robustez à ruídos: a Tabela 5.4 apresenta os resultados da intolerância a ruído somente para classificação via LDA+Bayes. É importante enfatizar que nenhum processamento adicional é utilizado nos métodos propostos, e mesmo assim esses obtém bons resultados para todos 
os níveis de ruídos testados. A curvatura, por exemplo, utiliza-se de filtros passa baixa que atenuam o ruído presente na forma. Podemos perceber uma queda substancial nos resultados do método que utiliza modelagem interna e externa. Acredita-se que é devido a quantidade de arestas côncavas e convexas falsas que são adicionadas à imagem. Como são diversos níveis de ruído não há um padrão em tal alteração.

Tabela 5.4 - Resultados para bases de dados com diferentes níveis de ruído.

\begin{tabular}{ccccc}
\hline & & \multicolumn{3}{c}{ Acerto (\%) } \\
\cline { 3 - 5 } $\boldsymbol{T}$ & ND & Genéricas & Peixes & MPEG7 \\
\hline aPAG completo contorno & 25 & $\mathbf{9 2 . 7 4}$ & $\mathbf{9 6 . 8 5}$ & $\mathbf{7 4 . 3 5}$ \\
aPAG interno & 25 & 35.75 & 35.16 & 41.67 \\
aPAG externo & 21 & 23.93 & 41.33 & 11.53 \\
Descritores de Fourier & 11 & 82.88 & 95.08 & 71.81 \\
Momentos de Zernike & 9 & 89.67 & 10.01 & 22.57 \\
Curvatura & 12 & 75.68 & 96.15 & 63.89 \\
Dimensão Fractal Multi escala & 17 & 83.11 & 36.41 & 67.90 \\
\hline
\end{tabular}

Robustez à contornos parciais I: a última característica que precisa ser avaliada é a robustez do método. Essa propriedade é caracterizada pela capacidade do método reconhecer uma forma incompleta, ou seja, com segmentos ausentes ou impossíveis de serem capturados. A Figura 5.1 mostra a taxa de acerto dos vários métodos para os diferentes níveis de degradação para a base de dados Genérica. Os resultados mostram uma grande robustez do método proposto quando comparado aos demais métodos.

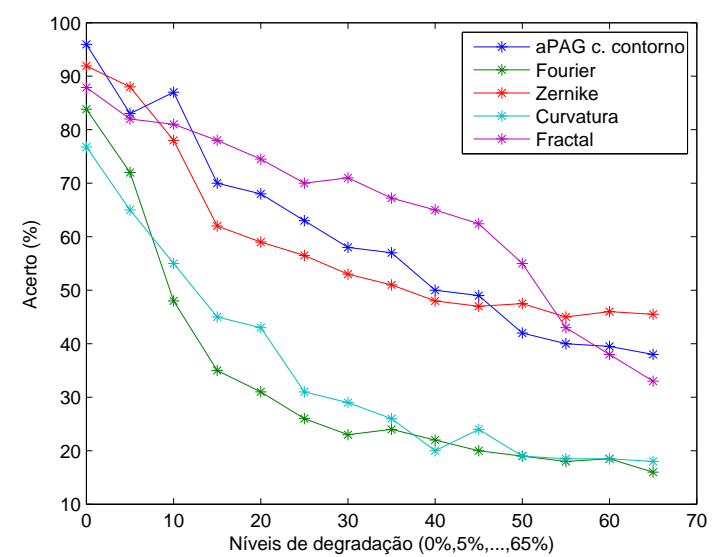

Figura 5.1 - Robustez dos métodos em formas incompletas.

As modelagens do tipo aPAG interno, externo e esqueleto não são apresentados devido à impossibilidade de se determinar, sem uso de nenhuma heurística especial, a delimitação do objeto nesses contornos parciais. Já o método de modelagem aPAG completo, além da 
capacidade de trabalhar com contornos degradados e não contínuos, o método também é independente do ponto inicial.

Robustez à contornos parciais II: um segundo experimento de robustez é realizado para avaliar a tolerância à degradação em formas com degradação randômica (i.e. pontos de diferentes locais do contorno são excluídos). A Figura 5.2 apresenta os resultados desse experimento para a base de dados Genérica.

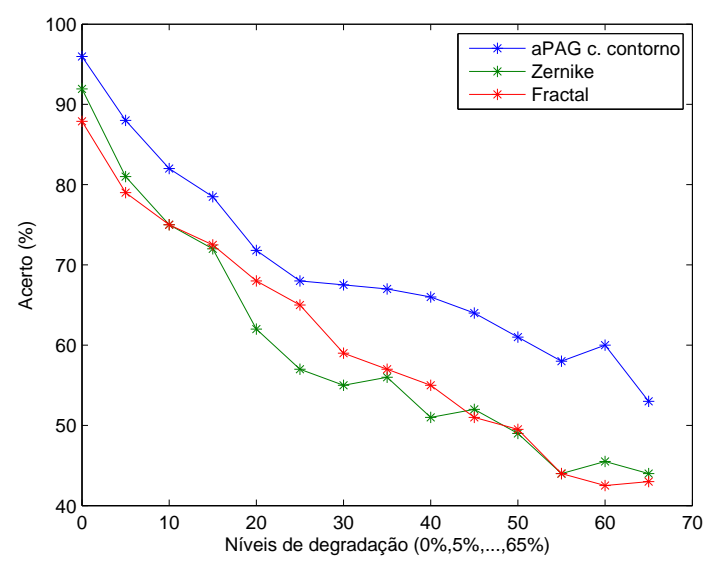

Figura 5.2 - Robustez dos métodos em formas degradadas randomicamente.

Assim como na análise anterior aqui não se apresenta métodos de redes complexas baseados em modelagem por esqueleto, modelagem interna e externa. Também os métodos de curvatura e descritores de Fourier são suprimidos, uma vez que os mesmos necessitam do contorno contínuo para sua análise. No geral os resultados apresentados podem ser considerados excelentes. O método aPAG completo contorno apresenta-se robusto a ruído, degradação, é invariante a rotação e escala, características desejáveis para muitas aplicações de processamento de imagens. Esse mesmo método também possui a característica de não necessitar da informação de ordem dos pontos do contorno para realizar a análise (os métodos de Fourier e curvatura, por exemplo, necessitam obrigatoriamente da informação de sequencia para que possam ser utilizados).

\subsection{Análise de esqueletos}

Os resultados do método de análise de esqueleto proposto, aPAG esqueleto, é comparado com outros métodos de análise de esqueleto da literatura (Tabela 5.5), são eles:

- Skeleton Paths (78): Esse método usa o caminho mínimo entre cada par de end points 
para descrever o esqueleto. Cada caminho mínimo é então descrito por $M$ equidistantes pontos do esqueleto. Para cada ponto é associado um raio de alcance máximo.

- Shape axis trees (113): No método de SA-trees a linha mediana(esqueleto) do objeto é tomada como base para a construção de um grafo-árvore onde as bifurcações da linha mediana principal são representadas por vértices e estes conectados aos segmentos subsequentes. Um algoritmo de busca gulosa via programação dinâmica é então empregado para realizar a comparação de entre um par de grafos. Embora o custo computacional seja extremamente elevado o fato das shape axis possuírem poucos vértices tornam esse método viável computacionalmente.

Tabela 5.5 - Resultados alcançados por diversos métodos de análise de esqueletos em 3 bases de dados.

\begin{tabular}{|c|c|c|c|c|c|c|c|}
\hline \multirow[b]{3}{*}{ Método } & \multirow[b]{3}{*}{ ND } & \multicolumn{6}{|c|}{ Acerto (\%) e Desvio padrão } \\
\hline & & \multicolumn{2}{|c|}{ Genéricas } & \multicolumn{2}{|c|}{ Peixes } & \multicolumn{2}{|c|}{ MPEG7 } \\
\hline & & BAYES & KNN & BAYES & KNN & BAYES & KNN \\
\hline aPAG esqueleto & 21 & $75.76( \pm 3.12)$ & $71.42( \pm 3.00)$ & $42.53( \pm 3.03)$ & $38.47( \pm 3.11)$ & $62.86( \pm 2.35)$ & $59.02( \pm 2.66)$ \\
\hline Eskeleton paths & & $\mathbf{9 2 . 4 5}( \pm 1.87)$ & & $\mathbf{8 8 . 2 1}( \pm 1.56)$ & & $70.22( \pm 2.70)$ & \\
\hline SA-trees & & $85.12( \pm 1.76)$ & & $81.40( \pm 2.97)$ & & $65.83( \pm 2.38)$ & \\
\hline
\end{tabular}

Podemos observar que o método de análise de esqueletos proposto, embora consiga um bom resultado na base de dados Genérica, é bem inferior aos métodos da literatura. Para as 3 bases de dados o melhor resultado é alcançado pelo método de Eskeleton paths, sendo a base de dados Genérica a mais fácil de se classificar. Os resultados para ambos os métodos de comparação Eskeleton paths e SA-trees são obtidos via classificador de correspondência de grafos, por esse motivo o número de características e o resultado para classificador Knn não são apresentados na tabela acima.

\subsection{Análise dos modelos via correspondência inexata de grafos}

As aplicações de análise de textura, contorno, esqueletos e cor aqui propostas pretendem reconhecer uma imagem comparando-a com um padrão/classe já conhecido (classificação multiclasses). Considerando os modelos de grafos propostos, essa tarefa de reconhecimento de imagens pode ser entendida como o problema de identificar se um grafo é similar ao outro. Tal problema é conhecido na teoria dos grafos como correspondência inexata de grafos (114).

Embora o foco deste trabalho seja a utilização de medidas estatísticas de redes complexas para análise e classificação dos modelos propostos, é inevitável e apropriado que uma classificação multiclasses seja realizada utilizando correspondência inexata como forma de se avaliar os modelos. É nesse ponto que há uma diferenciação clara entre os métodos baseados 
em teoria das redes complexas propostos (imagem $\rightarrow$ grafo $\rightarrow$ medidas estatísticas) e métodos baseados em teoria dos grafos (imagem $\rightarrow$ grafo $\rightarrow$ método de teoria de grafos). Esse tipo de classificação via correspondência inexata de grafos pode alcançar uma solução razoável ao sistema de forma totalmente diferente à proposta.

Derivado do problema clássico de correspondência exata entre grafos (problema de decisão no qual deseja-se saber se dois grafos são equivalentes (ou isoformos)), a correspondência inexata é um problema de otimização que tem como objetivo encontrar uma melhor forma de casar dois grafos, que não necessariamente são equivalentes. Nesse sentido vários algoritmos foram propostos para a resolução do problema de correspondência inexata de grafos. Devido a sua complexidade, a obtenção de soluções ótimas pode ser difícil para um tempo computacional viável.

Por esse motivo tem se intensificado o estudo de algoritmos heurísticos, os quais, pela utilização de informações características do problema estudado, são capazes de gerar soluções aproximadas de boa qualidade e baixo esforço computacional. Podemos citar algoritmos genéticos (115), graph edit distance (66, 116).

\subsubsection{Métodos de comparação}

Alguns modelos propostos, especialmente aqueles que possuem um baixo número de vértices, permitem a utilização de soluções heurísticas para o problema de correspondência inexata de grafos. Tal metodologia é utilizada em substituição às etapas de extração de características e classificação das redes complexas (RC). Nesse sentido consideramos 2 métodos de correspondência inexata que são utilizados em outros trabalhos de análise de contornos/esqueletos. São eles:

- Algoritmos genéticos (AG) (115): Esse método utiliza uma busca via otimização por algoritmos genéticos. A ideia geral do algoritmo genético é manter uma população de soluções alternativas enquanto otimiza iterativamente os indivíduos que obtém um melhor resultado. Tal otimização ocorre através de operações crossover/seleção e remoção/adição de arestas/vértices a cada ciclo evolutivo. Utiliza-se a distância de Hamming como medida de fitness. A classificação se dará pela observância do menor erro de fitness obtido após 1000 iterações da amostra para todo o conjunto de testes.

- Graph edit distance (GED) (66, 116): Um grafo pode ser transformado por uma sequência finita de operações. O método mais comum é baseado em subsequentes remoções e adições de arestas e/ou vértices onde cada um dessas operações possui 
custo associado. A imagem em análise será classificada à classe da imagem cujo o custo seja o menor dentre todos os custos para todas as outras imagens.

Nesse sentido os modelos aPAG completo contorno, aPAG interno, aPAG externo e aPAG esqueleto são avaliados pelos métodos de correspondência inexata de ambos trabalhos. A Tabela 5.6 apresenta um resultado comparativo entre os os métodos que usam a correspondência inexata de grafos em substituição ao processo aqui proposto (extração de características/classificação).

Tabela 5.6 - Resultados alcançados por diversos métodos de análise de formas em 3 bases de dados.

\begin{tabular}{|c|c|c|c|c|c|c|c|c|c|}
\hline \multirow[b]{3}{*}{ Método } & \multicolumn{9}{|c|}{ Acerto (\%) } \\
\hline & \multicolumn{3}{|c|}{ Genéricas } & \multicolumn{3}{|c|}{ Peixes } & \multicolumn{3}{|c|}{ MPEG7 } \\
\hline & RC & AG & GED & RC & AG & GED & RC & AG & GED \\
\hline aPAG completo contorno & 95.96 & 3.03 & 2.02 & 99.35 & 0.09 & 0.11 & 77.64 & 0.21 & 0.36 \\
\hline aPAG interno & 96.97 & 8.08 & 3.03 & 98.37 & 0.74 & 0.55 & 78.43 & 2.29 & 1.57 \\
\hline aPAG externo & 75.76 & 10.10 & 3.03 & 55.47 & 0.68 & 0.64 & 45.00 & 1.93 & 2.00 \\
\hline aPAG esqueleto & 75.76 & 7.07 & 1.01 & 42.53 & 0.68 & 0.75 & 62.86 & 2.71 & 2.14 \\
\hline
\end{tabular}

Podemos concluir pelos resultados alcançados que, a correspondência inexata não é adequada para análise e classificação dos modelos propostos. Isso se deve pela grande semelhança entre os grafos obtidos, a citar o modelo de aPAG completo e aPAG esqueleto, que geram em seu modelo inicial um grafo completo, onde a diferença será apenas o número de nós e o peso das arestas. Como o problema de correspondência inexata baseia-se basicamente em custos para adições e remoções de arestas/vértices, a maioria dos grafos será muito semelhante entre si.

Importante observar que os trabalhos citados de correspondência inexata (66, 115, 116) não são ruins, pois utilizou-se aqui apenas o algoritmo de correspondência inexata por eles propostos, e não a totalidade do processo descrito nos artigos. A única conclusão passível de ser realizada é que correspondência inexata não é adequada para os modelos aqui propostos. Nesse sentido entende-se que uma modelagem diferente deva ser utilizada quando se deseja fazer uso de correspondência inexata de grafos. A citar observamos os resultados do método de SA-tress da Tabela 5.3, método que faz uso de correspondência inexata para classificação, este utiliza uma modelagem de esqueletos diferente daquelas aqui propostas. Digno de comentário é o alto custo computacional do cálculo da correspondência inexata, especialmente quando o modelo possui vários vértices, o que torna a abordagem baseada em extração de características aqui proposta ainda mais interessante. 


\subsection{Análise de tempo de execução}

A Tabela 5.7 apresenta o tempo médio de execução dos métodos propostos e dos métodos da literatura para cada imagem. Foi considerada nessa análise a melhor configuração de cada método e apenas a etapa de extração de característica e/ou modelagem. O tempo de todos os métodos foram obtidos com implementação em MATLAB 7.12 e processador Intel Core i7 Q720@1.60GHz.

Tabela 5.7 - Tempo de execução dos métodos propostos.

\begin{tabular}{|c|c|c|c|c|c|}
\hline Método & Característica & Tempo(s) & Método & Característica & Tempo(s) \\
\hline PAG lattice 4 & Textura & 0.46 & CPAG & Cor & 1.03 \\
\hline PAG lattice 8 & Textura & 0.62 & $\mathrm{CHAG}$ & Cor & 0.25 \\
\hline PAG lattice raio & Textura & 0.78 & CAG & Cor & 1.38 \\
\hline PAG lattice completo & Textura & 8.81 & & & \\
\hline PAG lattice k-vizinhos & Textura & 0.42 & aPAG completo contorno & Contorno & 0.12 \\
\hline PAG lattice small-world & Textura & 0.35 & aPAG interno & Contorno & 0.55 \\
\hline MAG & Textura & 0.41 & aPAG externo & Contorno & 0.53 \\
\hline RAG estático & Textura & 0.62 & Descritores de Fourier & Contorno & 0.41 \\
\hline RAG dinâmico & Textura & 0.95 & Momentos de Zernike & Contorno & 0.33 \\
\hline CAG & Textura & 1.15 & Curvatura & Contorno & 0.45 \\
\hline aPAG completo textura & Textura & 2.45 & Dimensão Fractal Multi escala & Contorno & 0.62 \\
\hline Primeira ordem & Textura & 0.24 & & & \\
\hline Fourier & Textura & 0.65 & aPAG completo esqueleto & Esqueletos & 0.15 \\
\hline Gabor & Textura & 0.67 & Esqueleton paths Esqueletos & Esqueletos & 0.15 \\
\hline GLCM & Textura & 0.29 & SA-trees Esqueletos & Esqueletos & 0.21 \\
\hline DCT & Textura & 0.66 & & & \\
\hline GLDM & Textura & 0.54 & & & \\
\hline Wavelets & Textura & 0.74 & & & \\
\hline CLBP & Textura & 1.25 & & & \\
\hline LBPV & Textura & 0.37 & & & \\
\hline LTP & Textura & 0.05 & & & \\
\hline
\end{tabular}

Para textura o método mais rápido na etapa de extração de características é o LTP, porém esse método demanda um maior tempo maior na etapa de classificação pois não utiliza os classificadores aqui propostos. O pior resultado refere-se ao método de PAG lattice completo, resultado já esperado devido ao alto custo do método. O método CAG também obteve um alto tempo de execução devido à caracterização por fractal.

É importante lembrar que os tempos obtidos podem sofrer alterações drásticas caso o tamanho da imagem seja alterado (nesse estudo considerou-se apenas imagens de 128×128). Os métodos PAG, por exemplo, terão custos bastante elevados em caso de imagens de tamanho maior.

Já para análise de contornos o aPAG completo contorno apresenta os melhores resultados. O modelo aPAG interno, apesar de sua similaridade com aPAG completo contorno, tem o custo bem elevado pois necessita de verificações de retas internas.

Para análise de cor o modelo CHAG apresentou-se como mais eficiente e para esqueletos o método aPAG completo esqueleto tem desempenho equivalente aos métodos da literatura. 


\section{CAPÍTULO 6}

\section{Classificação de espécies vegetais}

\section{baseada em análise foliar}

A taxonomia vegetal é a ciência na qual cada planta deve ser corretamente atribuída a uma série descendente de plantas correlacionadas. Alguns estudos estimam que há 298.000 espécies na flora mundial, das quais apenas 215.644 estão catalogadas e nomeadas pelos taxonomistas (117). Essa imensa variedade de espécies e suas incontáveis características taxonômicas tornam a pesquisa em taxonomia vegetal uma difícil tarefa. Para qualquer pesquisador é impossível saber mais do que uma pequena parte das espécies nomeadas. Essa situação revela a necessidade de sistemas e ferramentas capazes de auxiliar nas tarefas taxonômicas. Alguns novos métodos de taxonomia, tais como quimiotaxonomia, citotaxionomia, cladística, etc, vem se tornando populares, no entanto esses métodos possuem custos elevados, são extremamente complicados, demorados e podem ser utilizados apenas por especialistas (118).

Apesar da existência dessas novas ferramentas a morfologia tradicional continua a ser amplamente utilizada. O processo manual de taxonomia e identificação de plantas com morfologia é basicamente feito por meio de herbários (119), onde as características morfológicas e anatômicas de órgãos vegetativos e reprodutivos de diferentes espécies podem ser estudadas e analisadas por observação (120), sendo sua identificação realizada através de comparação com espécimes previamente catalogadas (121) e pela utilização de algumas características chaves (122). A precisão ou sucesso na identificação depende basicamente da experiência e do conhecimento do especialista. Esse método tradicional de discriminação é baseado em estudos morfológicos e, por vez, depende de uma avaliação visual subjetiva, levando assim a falhas na detecção de diferenças muito pequenas e específicas, como aquelas que ocorrem entre plantas de espécies muito semelhantes.

Para essa atividade de catalogação, que é essencial para qualquer outro estudo ecológico, botânico ou taxonômico, é necessário recolher e secar um ramo da planta, montar um voucher, e compara-lo com outros vouchers em herbários $(123,124)$. Um dos grandes problemas nesse 
processo é a que as flores e frutas, principais fontes utilizadas para o diagnóstico não estão disponíveis para estudos em todo o ano, mas apenas em certos períodos, o que causa uma dificuldade natural nesse processo de identificação (125). Em contrapartida o exame das folhas, quase sempre disponíveis, não é suficiente para um diagnóstico em nível de espécie, nos melhores casos pode levar a uma redução drástica no número de espécies que precisam ser consideradas (126).

Com o recente desenvolvimento da computação, estatística e outros métodos numéricos, a morfometria automatizada (definida como a análise quantitativa da forma biológica) vem se tornando mais popular e precisa. Nesse contexto a classificação de plantas automatizada usando dispositivos ópticos (scanners ou câmeras digitais), vem se tornando um método promissor no sentido de auxiliar os taxonomistas. Tal abordagem é simples, barata, rápida e possui ainda a vantagem de preservar importantes características da folha que seriam perdidas no processo de desidratação, tais como cor, textura e brilho.

Nesse sentido esforços vem sendo realizados desde os anos 70 para desenvolver métodos automatizados para reconhecer e classificar plantas. Os trabalhos (127-130) são os primeiros que tentam utilizar a morfologia e anatomia foliar como característica taxonômica para tal e, desde então, muitos outros estudos tem sido documentados (131). Outra razão para o interesse especial em folhas, além da alta disponibilidade no campo, é a velocidade e facilidade com que esse item taxonômico pode ser analisado com dispositivos ópticos, devido a sua natureza bidimensional.

A seguir apresenta-se uma breve descrição das principais abordagens utilizadas na análise automatizada de folhas, as dificuldades envolvidas e os desafios ainda abertos nesse campo de pesquisa.

\subsection{Morfologia foliar}

Em biologia a morfologia é definida como estudo da forma de um organismo, ou de parte dele. Isso inclui aspectos de aparência exterior de superfície adaxial e/ou abaxial bem como a forma e estrutura de suas partes internas, como órgãos (Figura 6.1).

Ambos os tipos de imagens apresentam um desafio natural inerente ao problema de classificação: a grande a similaridade entre folhas de diferentes espécies e a dissimilaridade entre foIhas dentro de uma mesma espécie. Essa variação pode ocorrer em todos os níveis hierárquicos: dentro e entre árvores, populações e grupos taxonômicos. Alguns exemplos dessa variabilidade são: 


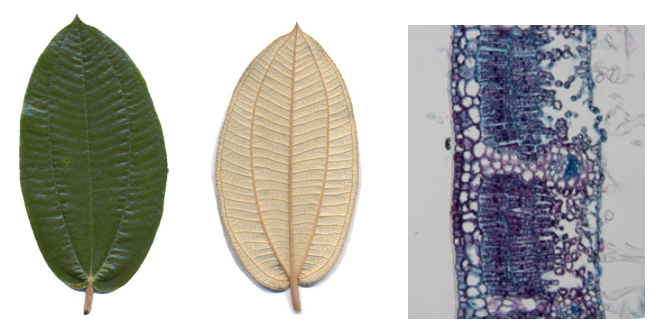

Figura 6.1 - Esquerda e centro: Superfícies adaxial e adaxial adquirida por um scanner óptico de uma folha de Micônia albicans. Direita: Imagem de corte transversal adquirida por microscópio digital de uma folha de Ochnatia polymorpha.

- Variação de cor entre folhas de mesma espécie ou até mesma planta, indo do branco ao vermelho. Um exemplo simples é mostrado na Figura 6.2 .

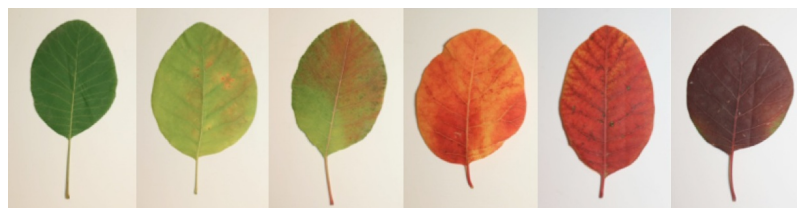

Figura 6.2 - Variação da cor em uma folha de Cotinus coggygria (132).

- A variação de textura pode ocorrer entre folhas ou até mesmo dentro de uma mesma folha. Não são raros os casos onde a textura da base da folha, próximo ao pecíolo, difere bastante da textura de seu ápice. Também há folhas com diversas cores em sua superfície, o que acarreta em diferentes percepções dependendo da região a ser estudada (Figura 6.3).
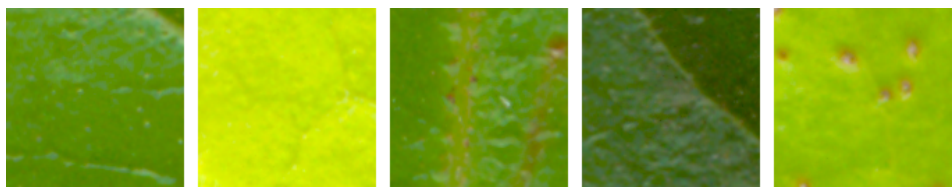

Figura 6.3 - Variação na textura de uma folha de Miconia langsdorfii.

- Variação do formato geral da folha (Figura 6.4), tamanho (Figura 6.5), margem (Figura 6.6), número e posição dos leaflets (Figura 6.7 e 6.8) ou no número de lobos (Figura 6.9).

- Acredita-se que diferentes padrões de venação também podem ocorrer sob determinadas circunstâncias, porem não há estudos científicos que comprovem tal suposição.

Entre as razões que podem causar essa dissimilaridade entre folhas, algumas são de origem natural e outras ocasionadas no momento da aquisição das imagens. Dentre as razões naturais que causam essa variabilidade as mais comuns são: 


\section{0}

Figura 6.4 - Variação do formato geral de uma folha de Corylus avellana (132).

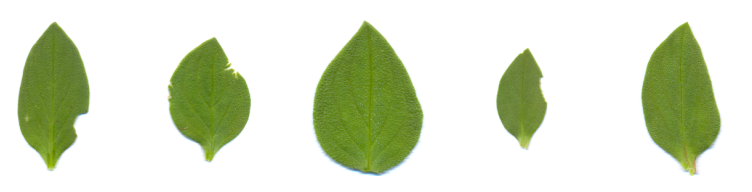

Figura 6.5 - Variação de tamanho de uma folha de Sophora japonica.

- Folhas coletadas em diferentes épocas do ano pode ocasionar alterações de cor, formato e textura (133). Obviamente essa dificuldade pode ser amenizada com a coleta em uma mesma época. Porém, como o objetivo principal de tais sistemas automatizados utilizando folhas é justamente evitar a dificuldade de se encontrar flores e frutos disponíveis, essa dificuldade deve ser superada nos sistemas automatizados.

- Folhas coletadas em diferentes locais da planta. Algumas podem ficar mais ou menos expostas ao sol, enquanto outras podem apresentar-se estágios de crescimento diferentes como parte do padrão de desenvolvimento natural (134, 135). Mancuso e Mancuso et al. (136, 137) sugerem coletar as folhas entre o 7th e 11th nós da planta, visando assim garantir a uniformidade de aparência e exposição solar. Porém não é em todas as espécies que esses nós são visíveis ou acessíveis, dificultando assim esse processo de padronização. Recomenda-se coletar folhas com seu estágio vegetativo completo, sem indícios de início de morte foliar.

- Presença de manchas causadas por fungos, doenças ou lesões. Assim como no item acima recomenda-se priorizar a coleta de folhas saudáveis, a fim de evitar eventuais dificuldades adicionais nos sistemas automatizados.

- Diferentes condições ambientais durante o desenvolvimento podem induzir um diferenças marcantes no fenótipo foliar (heterofilia) (138).
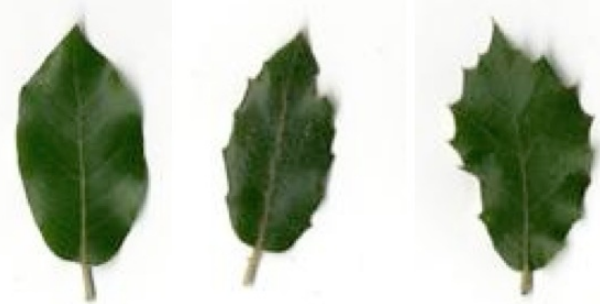

Figura 6.6 - Variação na margem de uma folha de Quercus ilex (132). 


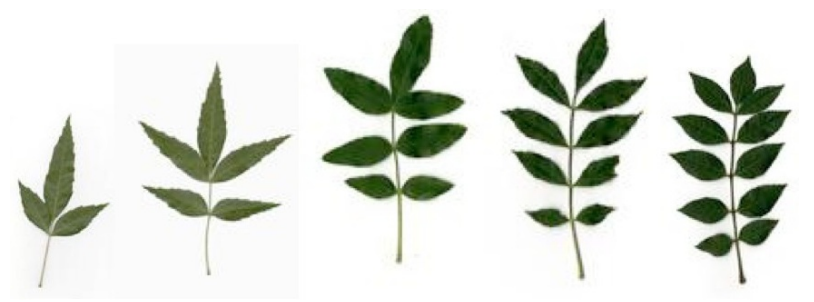

Figura 6.7 - Variação no número de leaflets de uma folha de Fraxinus angustifolia (132).

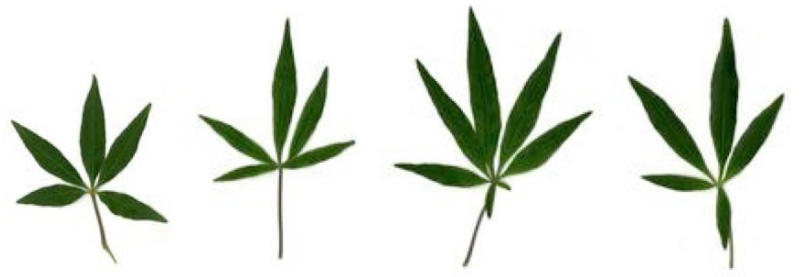

Figura 6.8 - Variação na posição dos leaflets de uma folha de Vitex agnus-castus (132).

Além das razões naturais elencadas acima que são causa da diversidade foliar temos as razões artificiais, ou seja, ocasionadas pelo homem no momento da aquisição/digitalização. Isso ocorre principalmente devido à inexistência de um padrão de aquisição comum para os diversos sistemas ópticos. Embora pareça simples (i.e. maioria das folhas são planares e, consequentemente, fáceis de serem coletadas com um scanner ou câmera digital), a aquisição de tais imagens não é uma tarefa trivial. Dentre os vários motivos que podem criar artefatos nas imagens temos:

- Sobreposições entre partes adjacentes ou rígidas das folhas são muitas vezes inevitáveis e podem criar grandes diferenças entre os contornos de folhas inicialmente semelhantes.

- A presença de sombras causadas por partes rígidas ou não planares das folhas pode fazer com que a percepção da textura seja alterada.

- A coleta de forma equivocada de folhas simples, sendo que na realidade tratam-se de leflets de folhas compostas. Isso obviamente ocasiona alterações drásticas no formato foliar.

- A retirada do pecíolo da folha que, assim como o que ocorre acima, também causa

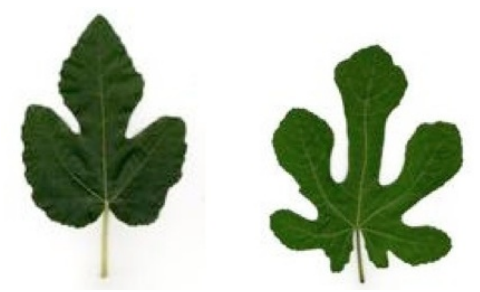

Figura 6.9 - Variação no número de lobos de uma folha de Ficus carica (132). 
alterações no formato foliar. Preservar o pecíolo é um procedimento simples que auxilia a análise da forma foliar.

- A aquisição da imagem de forma não orientada, ou seja, posicionada verticalmente ao longo do eixo natural principal. Embora alguns métodos computacionais sejam invariantes à rotações, muitos não trabalham bem com esse tipo de variação.

- Aquisição das imagens com diferentes resoluções e em diferentes escalas. Tal falta de padronização pode prejudicar ainda mais a percepção de textura foliar, que já é alterada por diversas variações naturais.

- A não utilização de um fundo uniforme pode dificultar o processo de separação da folha e sua posterior análise. Recomenda-se utilizar um background comum, branco ou preto, assim como controlar ao máximo a iluminação utilizada.

- A utilização de diferentes marcas/modelos de equipamentos pode acarretar em distorções de alto nível no formato, cor e textura foliar, pois cada equipamento possui uma determinada regulagem. Para contornar tal dificuldade sugere-se a utilização de um padrão de controle, do tipo IT8 target, para possibilitar correções posteriores de cor (139).

- A desidratação durante o transporte foliar pode alterar as características taxonômicas das folhas. Caso haja necessidade de transporte das folhas até outro local (i.e. para utilizar um scanner ou microscópio) recomenda-se utilizar sacos plásticos e adquirir as imagens preferencialmente no mesmo dia da coleta.

Também não há um consenso sobre a melhor forma de aquisição a ser utilizada. Atualmente são utilizados 3 tipos principais de equipamentos de aquisição, câmeras fotográficas, scanners de mesa e/ou microscópios digitais:

1. As câmeras fotográficas tem a vantagem de serem extremamente portáteis, rápidas, fáceis de utilizar e baratas, porém possuem resoluções limitadas podendo gerar artefatos como variação de luminosidade, cor ou distorções ópticas. Pode conter mais ou menos sombras, uma vez que não há nenhum tipo de prensa para fixar a folha.

2. Os scanners, apesar de não serem ainda equipamentos de alta mobilidade (i.e. como as câmeras digitais), tem algumas vantagens bem interessantes. As mais importantes são a alta resolução, que possibilita a análise de texturas com alto grau de detalhes e a existência de um background e iluminação comum, o que facilita o processamento da imagem e diminui a variação de iluminação. Outra possibilidade é a de se controlar com 
exatidão a resolução utilizada na captura, algo que só é possível com as câmeras digitais se utilizados equipamentos extras de fixação. A utilização de scanners de mesa também diminui a ocorrência de sombras, uma vez que as folhas são prensadas entre o vidro e a tampa do scanner. Enquanto não há estudos sobre a melhor resolução a ser utilizada da captação das imagens nós sugerimos a utilização de 1200dpi como resolução padrão, uma vez que nesse tamanhos de imagem é possível realizar análises de forma, venação, cor e textura simultaneamente.

3. Os microscópios digitais possuem a clara desvantagem de serem muito pouco portáteis e difíceis de se manusear, necessitando de treinamento especial para tal. Também necessitam de um tempo de aquisição bem maior que os utilizados para as câmeras digitais e scanners. Porém podem revelar detalhes da imagem únicos e especiais. Não possuem problemas com iluminação.

\subsection{Caracteres taxonômicos}

Atualmente a análise automatizada de folhas pode ser realizada estudando-se 4 diferentes características foliares da superfície: forma, venação, cor e textura. Na sequência apresenta-se os principais trabalhos e métodos desenvolvidos para cada uma dessas possíveis abordagens.

\subsubsection{Forma}

A forma é o caractere taxonômico mais utilizada na análise foliar manual e automatizada. Também chamado de morfometria, refere-se à análise quantitativa de seu tamanho e formato. Os vários métodos que têm sido desenvolvidos para tal podem ser categorizados em 3 diferentes abordagens: morfometria tradicional, morfometria utilizando landmarks e morfometria baseada em contornos.

A morfometria tradicional analisa, basicamente, comprimento, largura, ângulos, áreas e proporções geométricas. Em geral os métodos de morfometria tradicional são medidas relacionadas à tamanho e com direta interpretação biológica. Uma desvantagem é que essas medidas muitas vezes são correlacionadas e, como resultado, há poucas variáveis independentes. Outro problema é que tais medidas podem não ser adequadas quando utilizadas em objetos sujeitos a variação de tamanho e orientação.

A morfometria por landmarks é baseada em informações espaciais contidas nas próprias folhas. Por exemplo, a interseções entre as nervuras da folha podem ser consideradas como 
marcos (landmarks) e medidas podem ser extraídas considerando tais landmarks. Alternativamente também é possível definir-se pseudolandmarks, ou seja, especificando uma posição na estrutura em relação há outros landmarks conhecidos. Esse tipo de morfometria possui a vantagem de que suas medidas podem ser facilmente conceitualizadas biologicamente. A principal dificuldade, por outro lado, é a existência de poucos landmarks, especialmente em folhas não lobadas (140).

Métodos de morfometria que utilizam todo o contorno da forma são mais recentes e utilizados somente em análises automatizadas. Tal abordagem representa um objeto como uma curva fechada e a análise é realizada tentando-se ajustar uma função matemática a esses pontos. A vantagem é que esse tipo de abordagem realiza uma análise mais geral da folha e, como consequência, não apresenta uma interpretação biológica direta.

As 3 diferentes abordagens no entanto não são mutualmente exclusivas e podem ser facilmente combinadas com objetivo de melhorar os sistemas de reconhecimento foliar.

O trabalho de Meltzer el al. (127) em 1967 foi o primeiro a utilizar um sistema automatizado baseado em contorno (i.e. transformada de Walsh) no estudo sistemático de duas espécies. Mais tarde, em 1971 Fox e Brazee (130) utilizaria a mesma metodologia para classificar e separar 4 diferentes espécies. Ainda no mesmo ano Dale et al. (129) utiliza-se de morfometria tradicional automatizada para estudar variações de forma dentro de uma mesma espécie.

Kincaid e Schneider (141) em 1983 foi o primeiro a utilizar a transformada de Fourier para quantificar uma forma foliar. Embora esse trabalho não realize classificação foliar, ele provê diretrizes para determinar se as folhas tem formas estatisticamente diferentes. Embora existam trabalhos que correlacionam os coeficientes de Fourier com características biológicas, tal método foi e ainda é criticado até hoje (142) devido à sua dificuldade de interpretação biológica. Rohlf e Archie (143) por outro lado argumentam que tal interpretabilidade não é necessariamente uma desvantagem.

De fato os trabalhos (130, 144-146) são os primeiros dedicados especificamente à classificação de espécies utilizando análise de forma foliar. No entanto esses trabalhos utilizam um pequeno número de espécies, o que obviamente facilita a obtenção de bons resultados.

Desde então diversos outros métodos tem sido propostos. Utilizando características de morfometria tradicional e landmarks (146-148), teoria dos fractais (140, 149, 150), descritores de Fourier (126, 144, 151, 152), eigenshape (153), curvature scale space (CSS) (154), momentos de Zernike (118), chain-code (135, 144, 152), angle-code (155, 156), supervised isomap (157), locally linear embedding (158, 159), algorítimos genéticos (160) e métodos de 
matching (160-163) são apenas alguns exemplos.

São referências obrigatórias para desenvolvimento de trabalhos nessa área os trabalhos (140, 144, 150, 164) pois resumem e comparam alguns métodos de análise de formas. Além da classificação foliar os trabalhos (126, 149, 165, 166) também constroem e comparam os dendrogramas obtidos por classificação automatizada com algumas taxonômicas existentes.

Todo esse desenvolvimento leva alguns autores à propor a criação de herbários digitais (167, 168) e à utilização de sistemas móveis de análise. Tal iniciativa demostra amadurecimento dessa área de pesquisa e real necessidade de pessoas especializadas para tal.

\subsubsection{Cor}

$\mathrm{Na}$ taxonomia as cores são um caractere biológico muito importante quando se analisa as flores, frutos e sementes. Porém para a taxonomia foliar tal caractere não é comumente utilizado. A explicação disso se deve talvez à grande variabilidade de tons verdes encontradas em uma única planta, o que torna esse tipo de informação pouco confiável. É verdade que algumas espécies possuem um coloração bem destacada (e.g. folhas vermelhas e marrons), no entanto apenas tal informação não é suficiente para determinar sua espécie.

Essa problemática reflete também nos poucos trabalhos de classificação automatizados utilizando cores, sendo que apenas Kadir et al. (169) explorou tal caractere taxonômico. Tal trabalho no entanto utiliza características da forma, venação e textura em conjunto com a cor, o que levanta dúvidas sobre a eficácia isolada desse caractere na classificação foliar.

A cor, no entanto, contribui significativamente para a formação da percepção da textura foliar, um caractere taxonômico de maior importância e mais estável. Há, inclusive, trabalhos que utilizam as informações de cor para melhor caracterizar a textura, casos de (136, 170).

\subsubsection{Textura}

É de consenso geral que as características da epiderme foliar podem ser muito úteis no estudo das relações entre grupos taxonômicos (171). Como exemplo podemos citar o trabalho de Erxu et al. (171) e Dean e Ashton (172)), que fazem uso de tais características, extraídas manualmente, para classificar 54 espécies de Camellia.

Como já foi discutido anteriormente, a análise manual da morfologia da epiderme foliar pode não ser efetiva, podendo ocasionar dúvidas quando se possui espécies com morfologia similar (e.g. espécies do mesmo gênero ou família). Dessa forma os métodos automatizados 
de análise de textura podem trazer novas informações ao biólogo/taxonomista (23).

Durante as últimas décadas os métodos de análise de textura evoluíram muito e vem sendo utilizados em uma grande variedade de imagens e problemas. No entanto, para a classificação automática de folhas essa é uma abordagem que vem ganhando popularidade apenas nos últimos 10 anos. Esse incremento no interesse da utilização da textura para classificação foliar deve-se muito provavelmente à melhor qualidade, facilidade de aquisição, utilização e preço reduzido dos equipamentos de captura de imagens.

O trabalho de Shearer (170) é um dos poucos com mais de 10 anos. Nesse trabalho o autor utiliza as matrizes de coocorrência (83), um método chave e bastante conhecido em análise de texturas. Apenas mais recentemente, no século $\mathrm{XXI}$, com melhores equipamentos de aquisição surgiram diversos outros trabalhos que utilizam a textura como informação para classificação foliar. Em 2002 Mancuso (136) utilizou fractais sobre os 3 canais de cor da imagem para caracterização de diferentes cultivares de Vitis vinifera. Os autores tiveram o cuidado de coletar as folhas entre o 7th e 11th nós da planta, visando assim garantir a uniformidade de aparência e exposição solar. Outra constatação de (136) é que, embora algumas folhas originem-se de diferentes regiões da Itália, o método fractal não mostrou um diferença significativa entre as folhas de diferentes regiões. No entanto tal suposição necessita de mais pesquisas para ser comprovada, uma vez que tal plasticidade pode ser mais evidente quando se utiliza outra resolução/método ou até quando compararmos outras regiões.

A grande inovação, no entanto, está na utilização de scanners (300dpi de resolução), ou invés de fotografias, para aquisição das imagens. Esse tipo de equipamento permite um controle maior da resolução, cor e iluminação das imagens devido a não sofrer influências do ambiente.

Em 2008/09, Casanova et al. e Casanova (173, 174) utilizaram os filtros de Gabor (92) para identificação foliar. Em sequência, outros trabalhos dos mesmos autores, (23, 68), utilizam dimensão fractal volumétrica. Nesses trabalhos a resolução utilizada foi de $1200 \mathrm{dpi}$, possibilitando assim extrair várias amostras de textura de toda a folha e após calcular uma média das mesmas. Segundo os autores isso diminui a variabilidade e melhora o resultado final.

Outra característica importante na análise da textura foliar é a presença de texturas distintas na epiderme abaxial e adaxial. Segundo Ramos e Fernández (175) a epiderme abaxial é mais discriminativa que a adaxial, uma vez que apresenta estômatos e outras estruturas mais visíveis. Outra contribuição importante deste trabalho é a investigação da textura foliar com resolução microscópica (200x de aumento). Nessa resolução as microestruturas foliares (e.g. 
estômatos) ficam bem visíveis, diferentemente dos outros trabalhos que utilizam scanners para captura, onde se possui resolução limitada.

A resolução e/ou taxa de aumento utilizada para aquisição das imagens é portanto um fator chave nesse tipo de análise foliar por textura. Enquanto alguns autores utilizam-se de imagens microscópicas (e.g. (175)) adquiridas com utilização de microscópios eletrônicos, outros optam por utilizar imagens de scanners em alta resolução (e.g. (23, 174, 176)) ou baixas resoluções (e.g. (136, 169, 177, 178)). Embora se suponha que as imagens microscópicas sejam mais úteis na determinação das espécies (i.e. pois pode-se perceber mais detalhes na imagem), tal equipamento para aquisição desse tipo de imagem é de difícil manuseio e transporte, ao passo que fotografias ou mesmo um scanner de mesa são ferramentas fáceis de se transportar e utilizar.

Destaque especial deve ser dado ao trabalho de Rossatto et al. (176) que obteve $100 \%$ de acurácia em ambas as epidermes abaxial e adaxial. A utilização da textura neste estudo mostrou-se muito mais efetiva que a utilização de outros métodos baseados na cor, contorno e/ou métodos híbridos, contestando assim as afirmações de alguns autores (e.g. (154, 179, 180)) que a cor ou textura não são bons caracteres taxonômicos. Também há de se salientar que é o único trabalho a estudar uma única família de plantas (e.g. Melastomataceae), o que torna a tarefa ainda mais complexa, pois, segundo Mendonça et al (181) os gêneros estudados possuem morfologia foliar bastante similar.

\subsubsection{Venação}

Embora a venação por si só não seja um critério seguro para classificação foliar, esta continua sendo uma das características mais salientes e estudadas por Hickey (182) e utilizadas na catalogação foliar.

Tanto é verdade que diversos estudos revelam propriedades surpreendentes deste caractere taxonômico. Segundo Bohn et al. (183), por exemplo, os ângulos entre as veias são bem definidos e estão diretamente relacionados ao tamanho do segmento. Além de descobrir tais propriedades o autor deste trabalho utiliza-as para criar um modelo matemático baseado em fractais para modelar a venação foliar.

No entanto, para um sistema automatizado, a grande dificuldade encontrada é a extração da venação para posterior caracterização. Em Nam et al. (184), por exemplo, essa extração é realizada manualmente e a venação é então caracterizada por um grafo. Um sistema de recuperação de imagens por conteúdo é composto utilizando uma distância de similaridade 
e uma versão melhorada do método de polígonos de perímetro mínimo ou MPP (do inglês minimum perimeter polygons) para o contorno e venação. Assim também ocorre nos trabalhos (179, 185).

Já em Plotze et al. (89) a venação foi extraída utilizando-se de filtros, morfologia matemática e algoritmos de esqueletonização. A caracterização da venação e do contorno é então realizada utilizando um método baseado em fractal alcançando acurácia de 100\%. Interessante notar que (183) utiliza fractais para gerar venação, e a mesma teoria é utilizada em (89) para caracterização desse caractere taxonômico. Outro ponto interessante desse artigo é a possibilidade de se descobrir a árvore taxonômica (dendograma) das espécies através da análise fractal do contorno e venação. Tal capacidade demostra que tal metodologia automatizada é condizente com o já realizado manualmente.

A exemplo do realizado por (89) o trabalho de Fu e Chi (186) explora unicamente uma forma efetiva de se extrair a venação foliar. Os autores utilizam limiares e redes neurais artificiais para completar essa tarefa e (152) faz uso de tal técnica em seu trabalho. Embora existam tais métodos, não há um algoritmo genérico suficientemente bom que tenha bom desempenho nos mais diferentes casos. O trabalho de Gouveia et al. (187), por exemplo, utiliza altas resoluções e um aparato especial de aquisição (i.e. lâmpadas incandescentes violetas e uma câmera de aquisição negra) para ressaltar a venação foliar. No entanto seu sistema ainda precisa de uma correção manual da venação para funcionar corretamente. Já Bruno et al. e Plotze e Bruno (188, 189) optaram por utilizar uma clarificação química nas folhas antes da aquisição da imagem por um scanner. Após utilização de vários filtros e posterior caracterização por fractais os autores conseguem alcançar bons resultados (ver Figura 6.10).

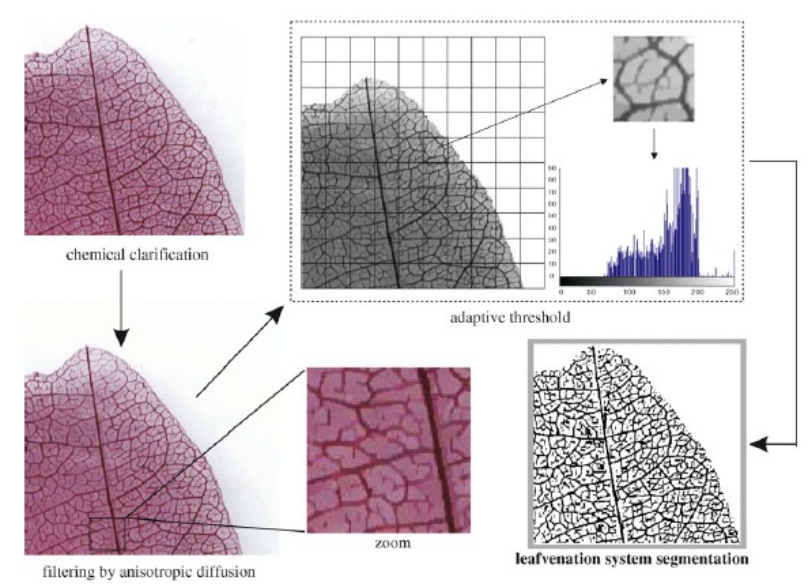

Figura 6.10 - Clarificação e processo de filtragem de venação utilizados em (188).

Outra possibilidade explorada por Park et al. (179, 185) é a criação de sistemas onde as 
folhas são classificadas pelo tipo de venação dado por Hickey (182). Tal informação poderia então ser posteriormente utilizada para classificação foliar, tal como é feito em (190). Porém nesse último as informações sobre a venação são inseridas pelo manualmente pelo usuário no sistema de reconhecimento.

Embora talvez apenas a venação seja suficiente para categorização de poucas espécies a quase totalidade dos trabalhos aqui apresentados à utilizam em conjunto com informações da forma foliar nos métodos. A exceção é o trabalho de (189) que utiliza apenas medidas biométricas para caracterizar a venação.

\subsubsection{Cortes seccionais}

Os 4 caracteres morfológicos apresentados acima também podem ser empregados, além da superfície foliar, às imagens de cortes seccionais. As características da epiderme (Figura 6.11) também tem sido consideradas de grande valia no estudo das relações entre espécies (171). (171), por exemplo, usa tais características observadas no corte transversal da folha para classificar entre 54 espécies de Camellia. O corte transversal da folha permite a visualização dos diferentes tipos de estômatos e tricomas, formato celular, presença ou não de cutícula e/ou hipoderme, estrutura de secreção entre outras coisas (191).

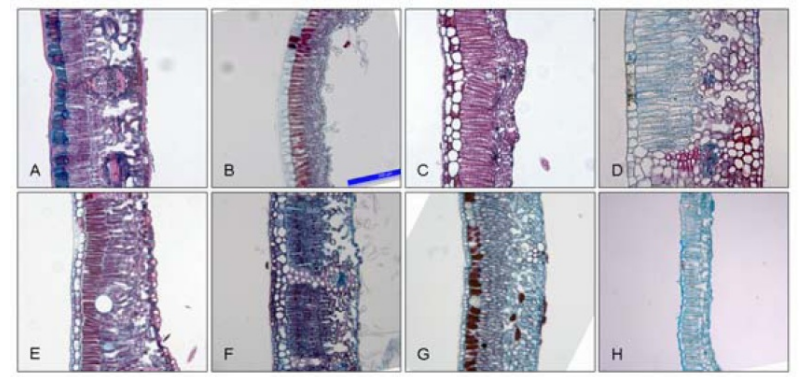

Figura 6.11 - Epiderme foliar de 8 diferentes espécies (192).

Embora essa seja uma abordagem bastante utilizada em sistemática, apenas 2 trabalhos utilizam tal caractere taxonômico em sistemas automatizados de reconhecimento. Talvez isso se deva ao fato de que essa abordagem demanda uma preparação das amostras mais apurada, uma vez que as imagens das amostras precisam ser desidratadas, clarificadas e obtidas através de microscópios digitais (192). Isso obviamente inviabiliza a utilização desse caractere taxonômico em um sistema remoto de reconhecimento ou em locais onde tal equipamento não esteja disponível.

Outra dificuldade envolvida é a segmentação/separação das estruturas. Visualmente não há grandes dificuldades em tal processo, no entanto computacionalmente ainda há desafios 
devido ao fato de que cada folha possui uma estrutura diferenciada (e.g. não havendo, por exemplo, cutícula em algumas espécies). Isso dificulta a criação de regras automatizadas de segmentação, necessitando de um nível maior de inteligência do sistema para tratar tal problema. Em Backes et al. (192), por exemplo, a segmentação é realizada utilizando-se o algoritmo de Mumford-Shah, no entanto os autores tratam a hipoderme e a epiderme como uma só estrutura, uma vez que a primeira não está presente em todas as espécies estudadas. Em trabalho complementar Sá Júnior (193) os autores adicionam um módulo de seleção de atributos ao sistema, alcançando assim ainda melhores resultados. Em ambos os trabalhos os autores utilizam características de textura e forma para caracterizar o corte histológico.

\subsection{Avaliação}

Percebe-se pelo exposto que o problema de identificação vegetal por análise foliar automatizada é um grande desafio na área de visão computacional. A grande variabilidade intra-espécies e a similaridade inter-espécies vem tornando esse problema fonte de estudos de diversos pesquisadores.

Nesse sentido nada mais justo que avaliar os métodos aqui propostos utilizando tal problema. Para isso a base de dados do ImageCLEF 2012 (194) foi selecionada. O ImageCLEF é um congresso que proporciona um fórum para os pesquisadores que trabalham com métodos de análise de imagem e inteligência artificial. Desde o ano de 2011 um novo desafio foi proposto: a identificação de espécies através da análise de imagem foliar. Como dito anteriormente, nosso grupo já vem trabalhando nesse tipo de problema há mais de uma década, e nesse sentido seria mais que conveniente aceitar o desafio.

A base de dados PI@antLeaves (132) é composta por 11572 imagens de 126 espécies foi criada pelo projeto francês PI@ntNet (INRIA, CIRAD, Telabotanica). Dessa base original 2 espécies foram suprimidas nesse estudo por conterem apenas 1 amostra cada, totalizando assim 11570 imagens de 124 espécies. As imagens apresentam-se de 3 diferentes formas: (1) Scan: 6630 imagens coletadas com utilização de scanner (orientadas e com luminosidade controlada); (2) Scan-like: 2726 imagens coletadas com uma câmera fotográfica (orientadas porém com variações de iluminação, distorções e sombras); (3) Free natural photos: 2214 imagens obtidas também com auxilio de uma câmera fotográfica, porém diretamente da planta/árvore (apresenta fundo não uniforme, problemas com rotação, escala entre outros). Para o terceiro tipo de imagem uma pré-segmentação manual foi realizada de forma a isolar a folha do fundo da imagem (16, 17). Adicionalmente cada imagem contém um arquivo xml associado contendo diversas informações sobre a planta. A Tabela 6.1 apresenta a relação das espécies 
contidas na base de dados e o número de folhas por espécie (NF).

Tabela 6.1 - Base de dados foliar: relação das espécies e número de folhas por espécie

\begin{tabular}{|c|c|c|c|c|c|}
\hline Espécie & NF & Espécie & NF & Espécie & NF \\
\hline Viburnum opulus & 68 & Crataegus monogyna & 166 & Rhamnus cathartica & 43 \\
\hline Platanus $\times$ hispanica & 150 & Morus nigra & 7 & Ulmus minor & 367 \\
\hline Paliurus spina-christi & 73 & Prunus serotina & 24 & Buxus sempervirens & 297 \\
\hline Ilex aquifolium & 125 & Fraxinus angustifolia & 147 & Arbutus unedo & 147 \\
\hline Ginkgo biloba & 160 & Pistacia terebinthus & 116 & Celtis australis & 236 \\
\hline Quercus rubra & 26 & Olea europaea & 270 & Fagus sylvatica & 80 \\
\hline Fraxinus ornus & 77 & Quercus coccifera & 76 & Mespilus germanica & 47 \\
\hline Daphne cneorum & 157 & Populus alba & 157 & Acer monspessulanum & 174 \\
\hline Alnus cordata & 73 & Buddleja davidii & 122 & Syringa vulgaris & 104 \\
\hline Euphorbia characias & 205 & Frangula dodonei & 13 & Cercis siliquastrum & 228 \\
\hline Robinia pseudoacacia & 146 & Juglans nigra & 55 & Diospyros kaki & 135 \\
\hline Vitex agnus-castus & 127 & Acer opalus & 60 & Liriodendron tulipifera & 46 \\
\hline Quercus petraea & 78 & Ficus carica & 124 & Hedera helix & 243 \\
\hline Cotinus coggygria & 170 & Pittosporum tobira & 244 & Laburnum anagyroides & 53 \\
\hline Pistacia lentiscus & 188 & Acer pseudoplatanus & 37 & Phillyrea angustifolia & 335 \\
\hline Quercus pubescens & 132 & Pittosporum tenuifolium & 104 & Populus nigra & 215 \\
\hline Nerium oleander & 209 & Photinia serrulata & 65 & Quercus ilex & 287 \\
\hline Magnolia grandiflora & 111 & Corylus avellana & 196 & Viburnum lantana & 36 \\
\hline Prunus laurocerasus & 82 & Laurus nobilis & 144 & Prunus padus & 8 \\
\hline Cornus mas & 71 & Eriobotrya japonica & 99 & Aesculus hippocastanum & 89 \\
\hline Viburnum tinus & 253 & Rhus coriaria & 179 & Populus tremula & 81 \\
\hline Crataegus azarolus & 81 & Ligustrum vulgare & 47 & Acer campestre & 183 \\
\hline Broussonetia papyrifera & 130 & Cornus sanguinea & 69 & Tilia cordata & 35 \\
\hline Morus alba & 81 & Ruscus aculeatus & 241 & Castanea sativa & 105 \\
\hline Acer negundo & 97 & Capparis spinosa & 59 & Acer platanoides & 91 \\
\hline Carpinus betulus & 104 & Sorbus aria & 29 & Sorbus domestica & 41 \\
\hline Juniperus oxycedrus & 164 & Sophora japonica & 68 & Prunus dulcis & 40 \\
\hline Rhus typhina & 63 & Gleditsia triacanthos & 73 & Punica granatum & 134 \\
\hline Liquidambar styraciflua & 45 & Rhamnus alaternus & 116 & Melia azedarach & 49 \\
\hline Prunus spinosa & 22 & Ailanthus altissima & 90 & Prunus serrulata & 6 \\
\hline Salix alba & 14 & Acer saccharinum & 24 & Albizia julibrissin & 77 \\
\hline Quercus palustris & 32 & Elaeagnus angustifolia & 11 & Alnus glutinosa & 52 \\
\hline Betula pendula & 107 & Sambucus nigra & 52 & Sorbus torminalis & 38 \\
\hline Crataegus laevigata & 17 & Juglans regia & 53 & Prunus avium & 70 \\
\hline Euonymus europaeus & 31 & Sorbus latifolia & 12 & Koelreuteria paniculata & 18 \\
\hline Quercus cerris & 32 & Tilia platyphyllos & 28 & Fraxinus excelsior & 35 \\
\hline Sorbus intermedia & 24 & Quercus robur & 35 & Betula utilis var. jacquemontii & 26 \\
\hline Colutea arborescens & 14 & Sorbus aucuparia & 4 & Betula pubescens & 16 \\
\hline Malus sylvestris & 25 & Ostrya carpinifolia & 13 & Cerasus mahaleb & 55 \\
\hline Populus trichocarpa & 4 & Salix caprea & 28 & Salix cinerea & 3 \\
\hline Ulmus laevis & 13 & Tilia $x$ europaea & 2 & Salix fragilis & 3 \\
\hline Pyrus nivalis & 2 & Xanthium strumarium & 1 & Euonymus latifolius & 1 \\
\hline
\end{tabular}

Os 4 diferentes caracteres morfológicos são extraídos sobre essa base de dados, a saber:

1. Forma: A extração da forma foliar dá-se por simples limiarização para eliminar o fundo e posterior utilização do algoritmo do ceguinho (110).

2. Textura: 30 amostras de textura de tamanho $128 \times 128$ são extraídas, sem sobreposição, da superfície foliar. Caso a folha seja de tamanho muito reduzido admite-se sobreposição. As características de textura são então extraídas de cada amostra de textura, sendo que uma média do 30 vetores de características é obtida para cada folha (processo similar ao utilizado em (176)).

3. Cor: A coloração foliar é analisada através do mesmo processo para análise de textura, ou seja, com média de 30 amostras de textura extraídas por folha. 
4. Venação: Como já comentado a extração da venação foliar exige processos químicos não disponíveis nessa base de dados. A venação foliar é então aproximada através da extração esqueletos espaço-escala (ver notas no Anexo A.3).

A identificação foliar é realizada utilizando-se o classificador LDA+Bayes com validação cruzada 10-fold (detalhes podem ser consultados no Anexo B). Incluem-se, para efeitos comparativos, alguns trabalhos concebidos especificamente para de analise foliar.

\subsection{Resultados e discussão}

Como já mencionado, a morfometria automatizada de folhas pode ser realizada estudandose 4 diferentes características foliares: forma, venação, cor e textura. A Tabela 6.2 apresenta os resultados dos métodos propostos para cada um desses caracteres individualmente.

Tabela 6.2 - Resultados obtidos para os diversos métodos propostos e da literatura nos diferentes caracteres morfológicos em análise foliar.

\begin{tabular}{ccc}
\hline Método & Carácter Morfológico & Acerto (\%) e $\boldsymbol{K}$ \\
\hline PAG lattice 4 & Textura & $22.86(0.2224)$ \\
PAG lattice 8 & Textura & $31.42(0.3091)$ \\
PAG lattice raio & Textura & $36.68(0.3610)$ \\
PAG lattice completo & Textura & $15.68(0.1485)$ \\
PAG lattice k-vizinhos & Textura & $15.69(0.1501)$ \\
PAG lattice small-world & Textura & $12.05(0.1123)$ \\
PAG lattice cor & Textura & $09.47(0.0842)$ \\
CPAG & Textura & $25.48(0.2486)$ \\
MAG & Textura & $18.42(0.1777)$ \\
RAG estático & Textura & $20.89(0.2028)$ \\
RAG dinâmico & Textura & $13.31(0.1276)$ \\
CAG & Textura & $32.49(0.3195)$ \\
CAG multiescala & Textura & $27.73(0.2720)$ \\
aPAG completo & Textura & $05.82(0.0502)$ \\
Filtros de Gabor (174) & Textura & $\mathbf{3 8 . 6 2}(0.3793)$ \\
Dimensão Fractal Volumétrica (23) & Textura & $37.43(0.3672)$ \\
\hline aPAG completo & Contorno & $28.92(0.2822)$ \\
aPAG interno & Contorno & $\mathbf{3 1 . 1 2}(0.3047)$ \\
aPAG externo & Contorno & $20.65(0.2005)$ \\
Descritores de Fourier (141) & Contorno & $26.03(0.2551)$ \\
Matching AG (160) & Contorno & $30.40(0.2988)$ \\
Curvatura (154) & Contorno & $28.80(0.2848)$ \\
\hline CHAG & Cor & $\mathbf{0 4 . 8 0}(0.0412)$ \\
\hline aPAG completo & Venação & $21.05(0.2058)$ \\
Dimensão Fractal (89) & Venação & $\mathbf{2 3 . 6 9 ( 0 . 2 2 9 9 )}$ \\
\hline
\end{tabular}

Observamos que, dentre os caracteres morfológicos analisados, o contorno e a textura são sem dúvida os mais discriminativos. Para a textura, embora os métodos propostos não apresentem os melhores resultados (i.e. os método de (23) e (174) apresentam taxa ligeiramente 
superior) os bons resultados, especialmente do modelo PAG lattice raio e CAG corroboram a eficácia do uso de redes complexas em problemas de naturezas diferentes.

Já os métodos para análise de contorno, aPAG completo e aPAG interno, apresentam resultados acima dos concorrentes, mostrando a eficácia do método mesmo em diferentes bases de dados.

O caractere de cor, todavia, não apresenta boa discriminação. Como já comentado a cor, pura e simplesmente, é uma característica morfológica muito dependente de ambiente, iluminação e outros fatores. Não é portanto adequado análise foliar baseada nesse caractere morfológico apenas.

Sabe-se que as nervuras são um caractere morfológico muito poderoso. Todavia os resultados alcançados são apenas intermediários. Isso se deve ao fato de que as nervuras são inferidas artificialmente através do processo de esqueletonização, cujo qual o resultado meramente se aproxima das nervuras foliares reais. Embora esse seja um processo válido, o desenvolvimento de uma metodologia de extração automatizada das nervuras reais pode incrementar substancialmente os resultados desse caractere morfológico.

Os resultados demostram que isoladamente nenhum dos 4 caracteres morfológicos é suficientemente discriminativo para gerar um sistema de reconhecimento eficaz. Há de se salientar no entanto que a sinergia entre os métodos pode ser uma boa saída para auferir bons resultados de classificação foliar. Nesse sentido optamos por combinar os métodos de análise de textura (PAG lattice raio e CAG), forma (aPAG interno) e venação (aPAG completo) para obter um resultado superior. O vetor de características final fica composto por 183 medidas, o que não chega a ser um problema na classificação, pois a análise canônica realiza uma redução de dimensionalidade antes da aplicação do classificador Bayesiano.

Tal sinergia eleva a taxa de acerto para $76.03 \%$ com indice kappa de 0.7571 na classificação vegetal por análise foliar. Ou seja, em $76.03 \%$ das consultas o sistema é capaz de responder com exatidão a classe a qual pertence determinada folha. Adicionalmente a tal resultado a Figura 6.12 apresenta a curva de acerto incremental quando considera-se não apenas a primeira classe com maior probabilidade na análise Bayesiana. Observamos nessa figura que, observando as 2 classes com maior probabilidade a posteriori, encontraremos com $84.45 \%$ de confiança a espécie correta da folha submetida à classificação. De forma análoga a espécie correta encontra-se com $95.57 \%$ de confiança entre as 10 primeiras classes mais prováveis.

Tais resultados demonstram o potencial da sinergia dos caracteres morfológicos na classificação foliar. O alto índice kappa, que traduz o ganho de precisão relativo a uma distribuição aleatória dos indivíduos pelas classes, também corrobora tal metodologia demostrando que a 


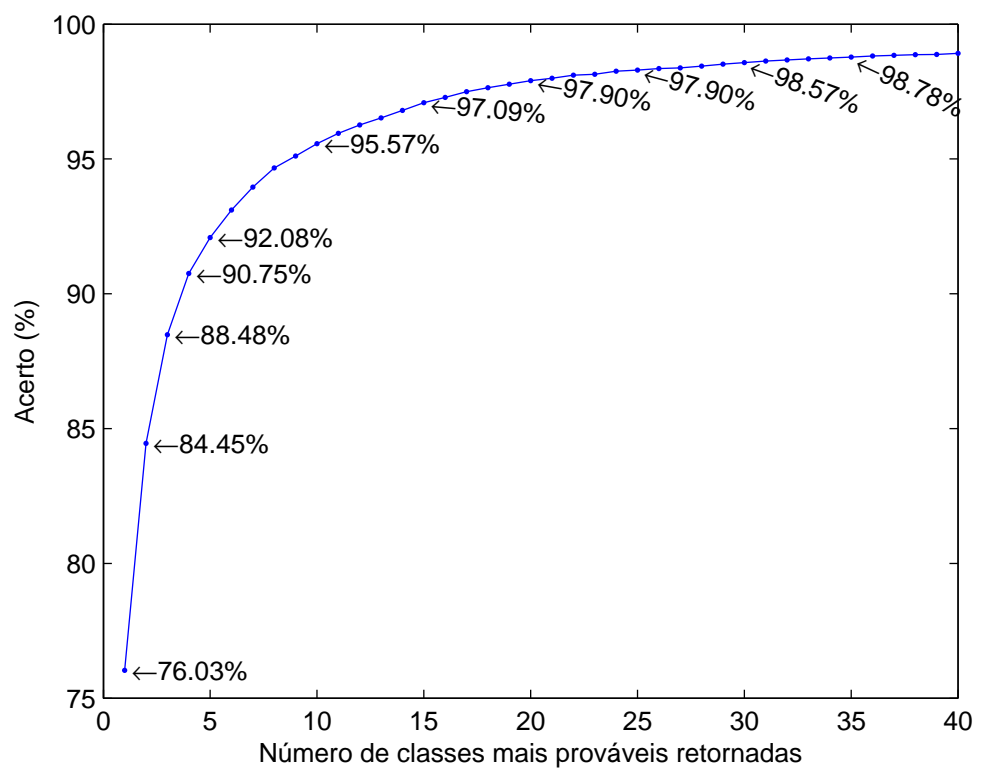

Figura 6.12 - Acerto para diferentes números de folhas retornadas na consulta.

análise foliar automatiza é uma técnica robusta no sentido de classificar bem todas as classes em análise. Nesse sentido a Figura 6.13 apresenta a matriz de confusão para o resultado de $76.03 \%$ de acerto, demostrando que em geral não há espécies difíceis de serem classificadas, excetuando-se espécies com baixa amostragem na base de dados.

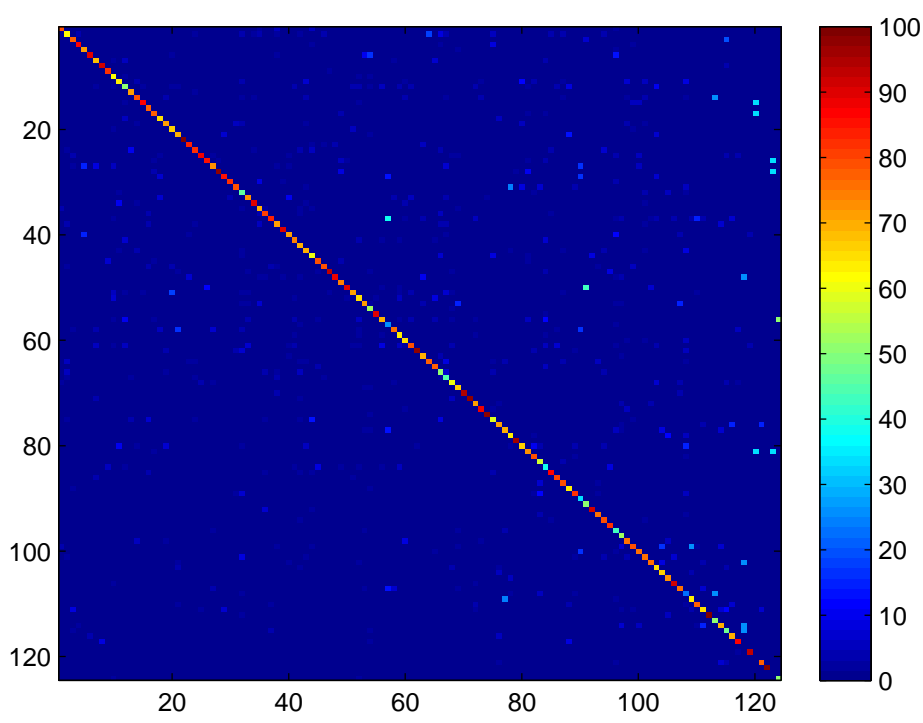

Figura 6.13 - Matriz de confusão para as 124 espécies

Embora uma taxa de acerto de $76.03 \%$ possa ser considerada adequada para um sistema automatizado, acreditamos que a metodologia de análise foliar aqui proposta possa alcançar melhores resultados caso a base de dados/método de aquisição fosse mais padronizado. Pode- 
se perceber na base de dados foliar que todas as razões artificiais de diversidade foliar estão presentes nas imagens, desde simples sobreposições até alterações drásticas de resolução e escala.

Para demostrar tal dificuldade do sistema as Figuras 6.14 à 6.25 apresentam diversas consultas a base da dados. Nesse sistema de recuperação de imagens baseado em conteúdo 9 folhas mais próximas à folha de consulta são retornadas para análise pelo biólogo/taxonomista.

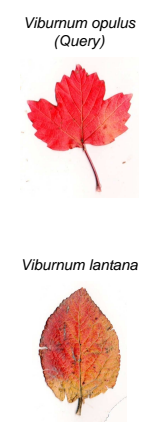

DS: 2.717

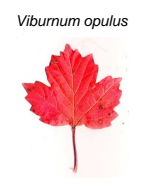

DS: 1.5985
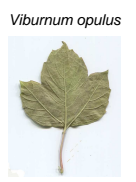

DS: 2.7315

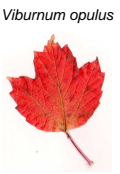

DS: 1.971
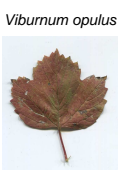

DS: 2.9172

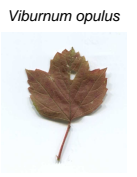

Viburnum opulus

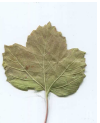

DS: 2.9965

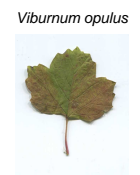

DS: 2.7025

Viburnum opulus

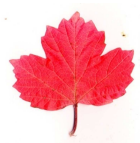

DS: 3.1047

Figura 6.14 - Ranking das imagens recuperadas para consulta de Viburnum opulus (68 imagens na base).

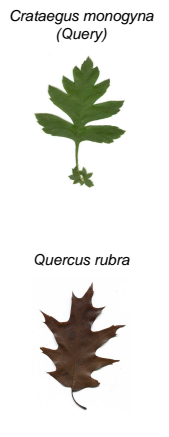

DS: 2.5594

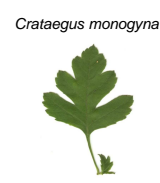

DS: 1.8522

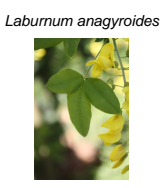

DS: 2.5968

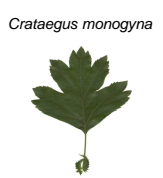

DS: 2.2108 Acer campestre

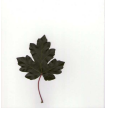

DS: 2.5982

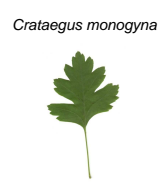

DS: 2.2887

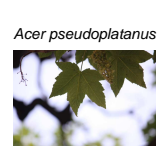

DS: 2.6227

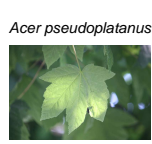

DS: 2.5481

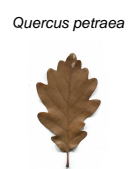

DS: 2.6362

Figura 6.15 - Ranking das imagens recuperadas para consulta de Crataegus monogyna (166 imagens na base).
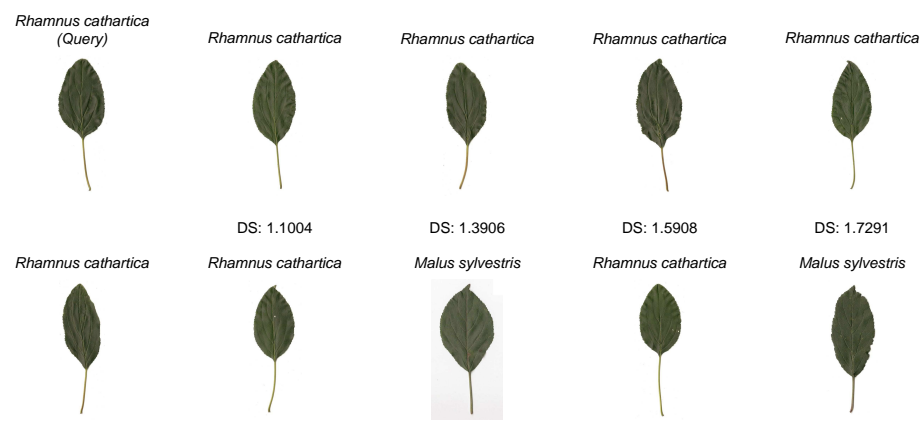

DS: 1.1004

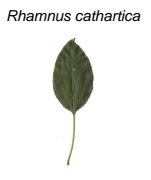

DS: 1.7991

DS: 2.2395

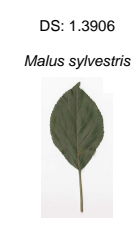

DS: 2.2443

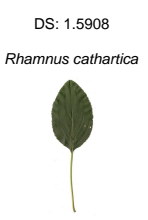

DS: 2.2956

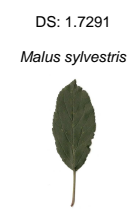

DS: 2.3175

Figura 6.16 - Ranking das imagens recuperadas para consulta de Rhamnus cathartica (43 imagens na base).

Embora os valores de dissimilaridade (DS) não variem muito, as primeiras 6 consultas (Viburnum opulus, Crataegus monogyna, Rhamnus cathartica, Platanus x hispanica, Morus 


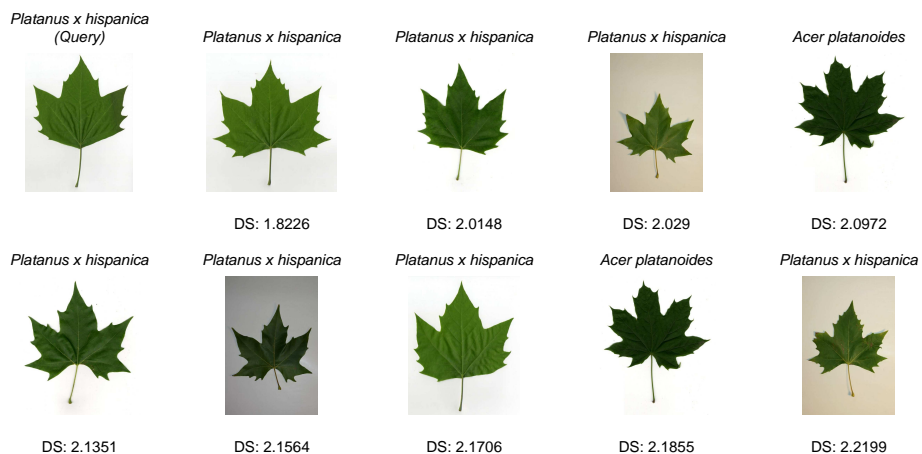

Figura 6.17 - Ranking das imagens recuperadas para consulta de Platanus x hispanica (150 imagens na base).

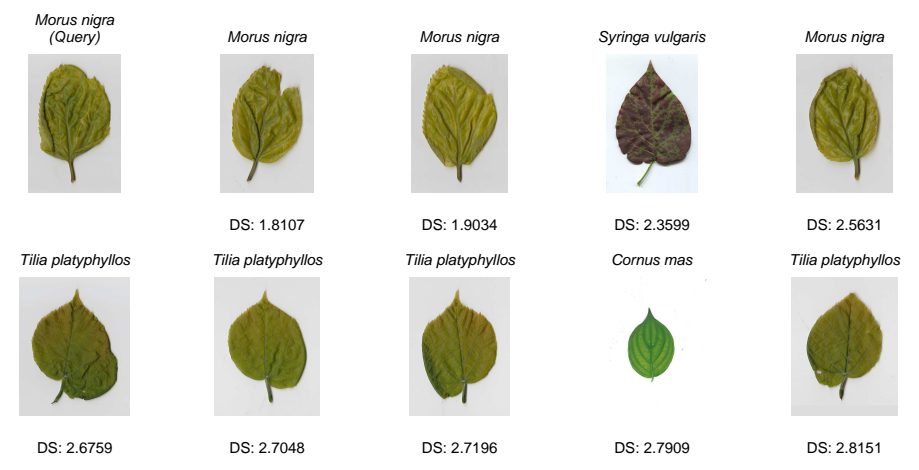

Figura 6.18 - Ranking das imagens recuperadas para consulta de Morus nigra (7 imagens na base).

nigra, Ginkgo biloba) aparentam ser relativamente fáceis se comparadas com as 6 últimas (Fraxinus ornus, Mespilus germanica, Pittosporum tobira, Diospyros kaki, Cercis siliquastrum, Quercus pubescens), uma vez que essas retornam um número menor de folhas da mesma espécie na consulta. As principais dificuldades são observadas quando se faz necessário um préprocessamento (segmentação) das folhas de consulta, o que muitas vezes resulta em qualidade final duvidosa em relação a diversos aspectos (e.g. folhas compostas tratadas como simples, sobreposição, escala, etc.).

A Figura 6.26 apresenta de forma resumida as curvas de precisão/revocação (mais detalhes
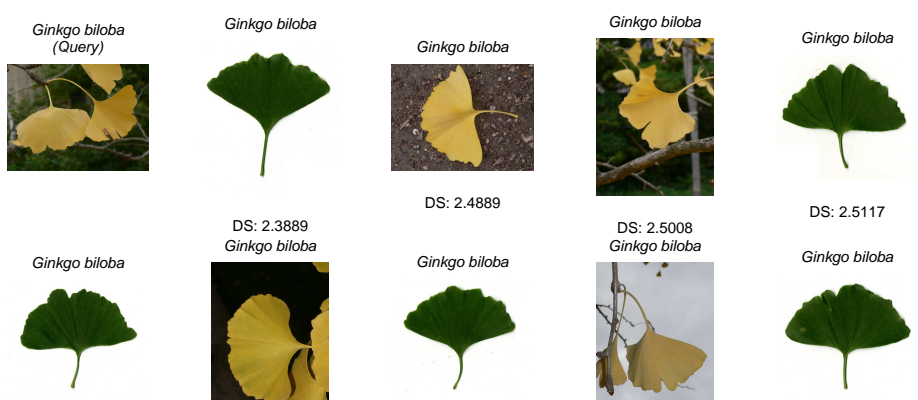

DS: 2.5576

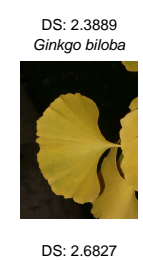

$$
\text { DS: } 2.4889
$$

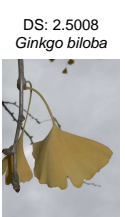

DS: 2.5117

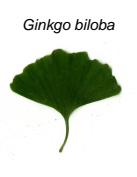

DS: 2.6908

DS: 2.6947

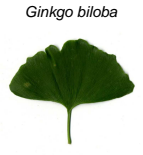

DS: 2.6967

Figura 6.19 - Ranking das imagens recuperadas para consulta de Ginkgo biloba (160 imagens na base). 


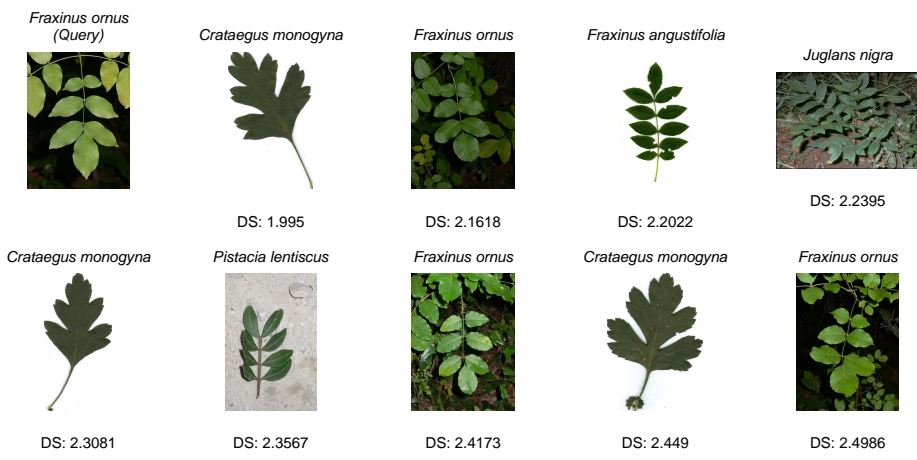

Figura 6.20 - Ranking das imagens recuperadas para consulta de Fraxinus ornus (77 imagens na base).
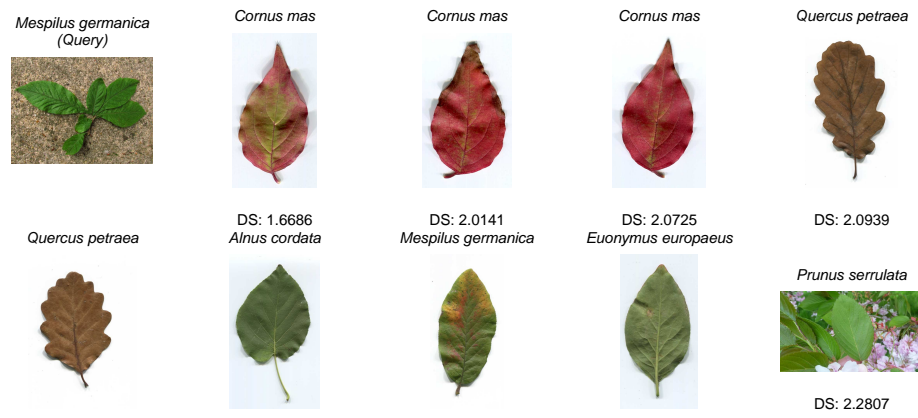

DS: 2.0939

DS: 2.2025

DS: 2.2283

DS: 2.2332

DS: 2.2724

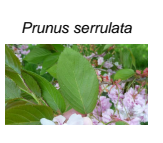

DS: 2.2807

Figura 6.21 - Ranking das imagens recuperadas para consulta de Mespilus germanica (47 imagens na base).
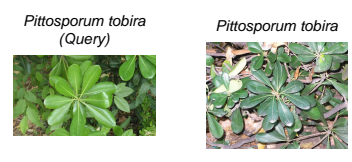

DS: 2.0828

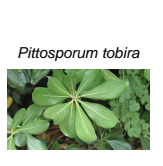

DS: 2.3549

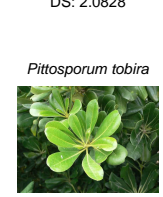

DS: 2.3571
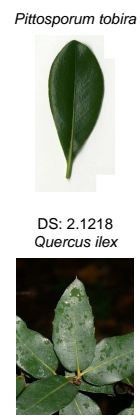

DS: 2.3597

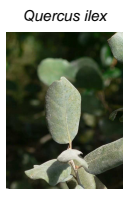

DS: 2.192
Quercus ilex

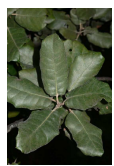

DS: 2.3743

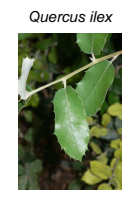

DS: 2.2342
Pittosporum tobira

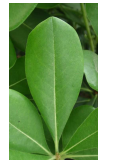

DS: 2.4032

Figura 6.22 - Ranking das imagens recuperadas para consulta de Pittosporum tobira (244 imagens na base).
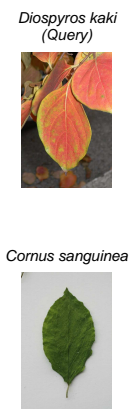

DS: 1.8005

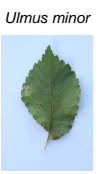

DS: 1.7084

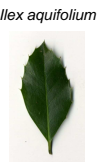

DS: 1.8352

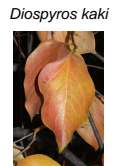

DS: 1.7272

Broussonetia papyrifera

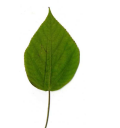

DS: 1.8468

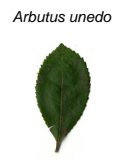

DS: 1.7362

Quercus ilex

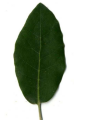

DS: 1.8537

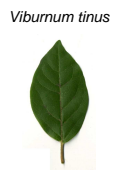

DS: 1.7915 Ilex aquifolium

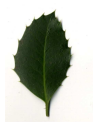

DS: 1.8537

Figura 6.23 - Ranking das imagens recuperadas para consulta de Diospyros kaki (135 imagens na base). 

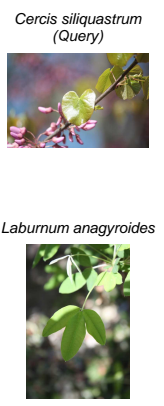

DS: 3.2546

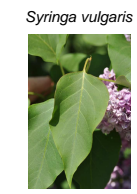

DS: 2.2369

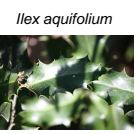

DS: 3.2763

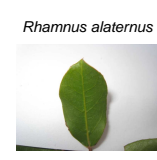

DS: 2.4392

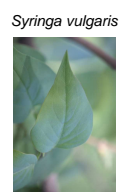

DS: 3.3461

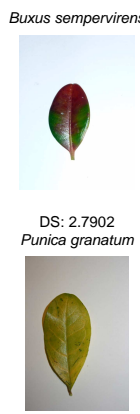

DS: 3.3465

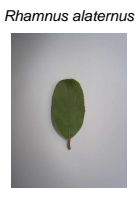

DS: 2.9815

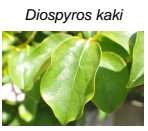

DS: 3.3765

Figura 6.24 - Ranking das imagens recuperadas para consulta de Cercis siliquastrum (228 imagens na base).
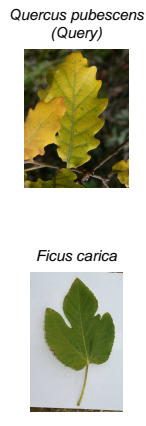

DS: 2.0599

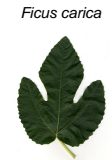

DS: 1.8161

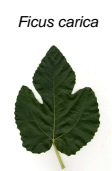

DS: 2.0606

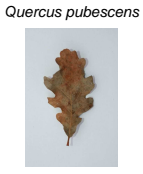

DS: 1.9695

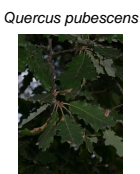

DS: 2.1195

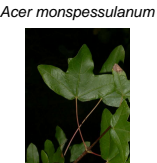

DS: 1.9861

Ficus carica

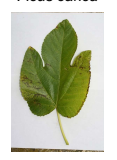

DS: 2.2121

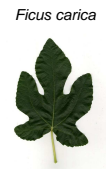

DS: 1.9981

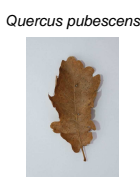

DS: 2.2338

Figura 6.25 - Ranking das imagens recuperadas para consulta de Quercus pubescens (123 imagens na base).

no Anexo B.4) para as 12 consultas citadas acima citadas. A precisão mede a fração de folhas relevantes recuperadas (folhas da mesma espécie da consulta) pelo número de folhas recuperadas e a revocação mede a fração de folhas relevantes pelo total de folhas relevantes existentes na base de dados. Nessa análise novamente as espécies Viburnum opulus, Rhamnus cathartica, Platanus x hispanica, Morus nigra, Ginkgo biloba obtém os melhores resultados pois apresentam curvas com tendência de precisão superior. A exceção fica por conta da Crataegus monogyna.

É importante observar que o método de redes complexas pode ser empregado em análise de imagens de diferentes formas, bastando para isso alterar a forma de modelagem/processamento/medidas. No caso de análise foliar todos os caracteres morfológicos são analisados via redes complexas. Obviamente os resultados não são ótimos em todos os possíveis cenários, porém indica uma flexibilidade inerente a esses métodos que pode vir a ser melhor explorada em futuras pesquisas.

Do ponto de vista biológico consideramos que esse estudo pode gerar uma ferramenta de auxilio muito importante para biólogos e taxonomistas. Acredita-se que em um futuro próximo tais profissionais terão a disposição um software para computadores e/ou dispositivos móveis que utiliza a metodologia de identificação aqui proposta. Nesse sentido a análise 

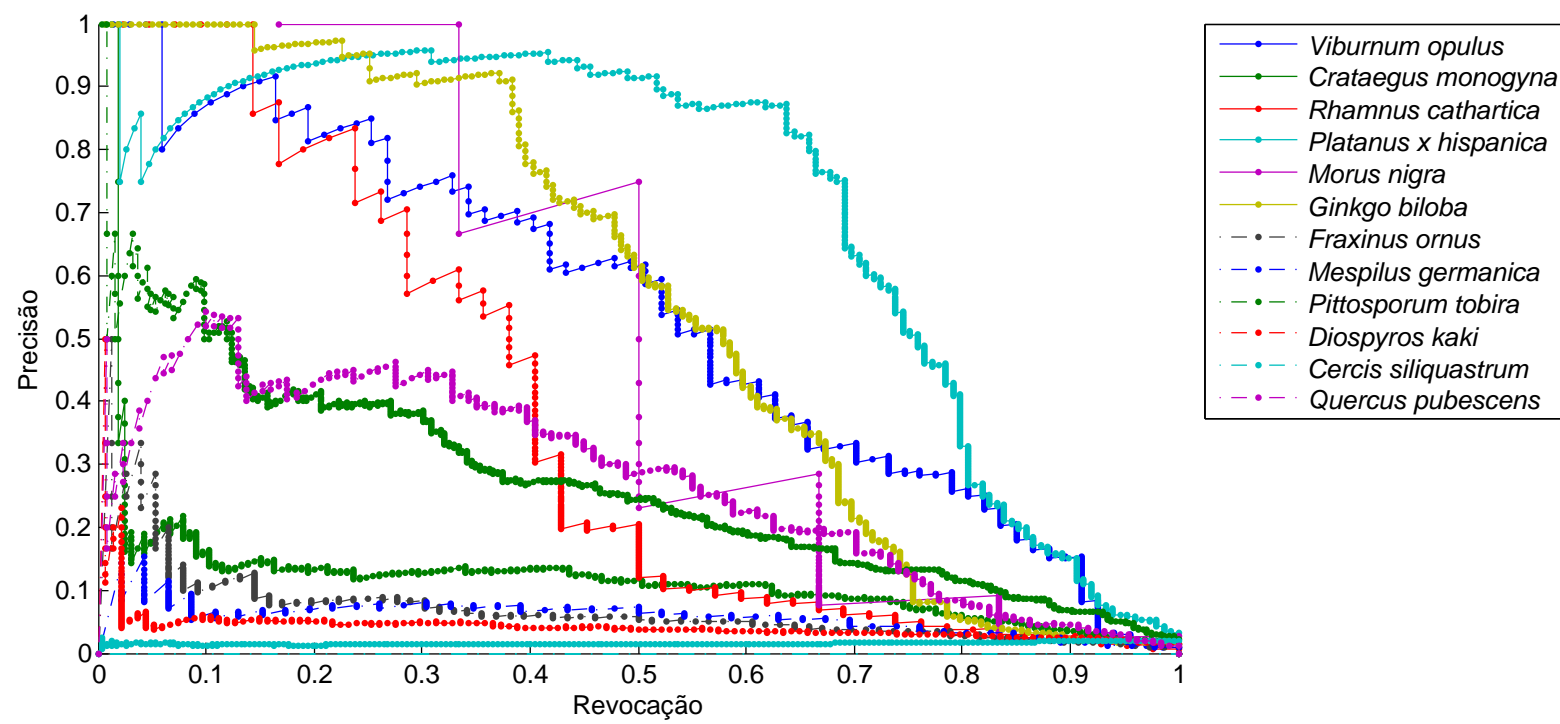

Figura 6.26 - Curvas de precisão/revocação para as 12 consultas realizadas

automatizada das folhas irá disponibilizar de forma rápida e eficiente uma lista com as mais prováveis espécies, gerando economia de tempo e esforços na identificação foliar, especialmente quando em campo. 


\section{CAPÍTULO 7}

\section{Conclusão}

Esse trabalho apresentou uma nova área de aplicação da teoria das redes complexas até então pouco explorada, a análise de imagens. Essa teoria tem emergido nos últimos anos e vem sendo utilizadas em larga escala na análise de outros problemas do mundo real, porém em análise de imagens sua aplicabilidade ainda é reduzida. Este trabalho traz justamente algumas propostas de como aplicar essa teoria na solução de problemas de visão computacional. Foram exploradas diferentes formas de modelagem, bem como a análise da aplicabilidade de tais modelos em problemas específicos tais como análise de textura, contorno, cor e esqueletos.

Em análise de textura o destaque principal fica por conta dos métodos de PAG lattice completo e CAG que apresentam resultados superiores à métodos tradicionais nessa área. Tais métodos culminaram em artigos em grandes revistas da área de visão computacional tais como Information Science (11), Journal of Physics (12) e Lecture Notes in Computer Science (13), gerando conhecimento e alternativas às soluções hoje conhecidas.

Além da análise de textura acima citada, a análise de contornos é outra área da visão computacional que pode se beneficiar dos métodos baseados na teoria das redes complexas. Nesse sentido o método de aPAG completo e aPAG interno obtiveram excelentes resultados, sendo o aPAG completo já publicado na Pattern Recognition (14).

A análise de esqueletos é outra área com resultados interessantes. Além de toda análise aqui realizada, um artigo curto derivado desse trabalho foi publicado no Journal of Physics (15), demostrando grande viabilidade do emprego das redes complexas em análise de imagens.

Essa variedade de aplicações é possível devido as diferentes formas de se modelar imagens como grafos aqui apresentadas. Embora alguns dos modelos listados já tenham sido empregados em métodos de processamento de imagens via grafos (e.g. segmentação), aqui se utiliza tais modelos em um contexto totalmente diferente: o das redes complexas (i.e. utilização de métodos estatísticos para se caracterizar a estrutura e conexões da rede). Os resultados demonstram que se tais modelos fossem empregados no contexto de grafos para classificar 
imagens (via correspondência inexata), esses não seriam adequados.

Nesse sentido a teoria das redes complexas apresenta diversas medidas estatísticas que podem ser utilizadas na análise dos modelos, e consequentemente das imagens. Na maioria dos casos observou-se que, dentre as medidas testadas, as melhores medidas são as mais usuais como grau médio, densidade e grau máximo. Fato esse interessante se considerarmos a complexidade da tarefa de classificação. Além das medidas clássicas, uma nova medida baseada na análise fractal é apresentada com resultados bastante interessantes e inicialmente explorada no artigo (12).

No aspecto biológico esse trabalho apresenta uma ferramenta de auxilio a um grande problema da biologia: a identificação vegetal via análise foliar. Utilizando os métodos propostos é possível disponibilizar ao biólogo/taxonomista um conjunto de prováveis espécies para a folha sob investigação. A precisão de tal sistema (probabilidade de que a espécie correta esteja entre as 10 primeiras espécies sugeridas) é de $95.57 \%$, um ótimo resultado considerando-se a baixa qualidade das imagens das folhas em análise. Adicionalmente verificou-se que a análise de um único caractere taxonômico, seja ele textura, forma, cor ou venação, não é suficiente para alcançar tais resultados. Essa precisão só é possível com a sinergia obtida da união desses caracteres taxonômicos.

\subsection{Trabalhos futuros}

Esse trabalho apresenta uma visão geral e diversas sugestões de como analisar imagens via teoria das redes complexas. Por se tratar de um trabalho amplo, no sentido de que explora diversos modelos e diversas aplicações (e.g. textura, contorno, etc.), existem diversos trabalhos futuros que podem ser desenvolvidos.

Em relação aos métodos aqui apresentados uma investigação mais criteriosa de outras formas de modelagem podem ser derivadas da taxonomia geral apresentada. Procurou-se nesse trabalho explorar modelos com diferentes características, cobrindo o máximo possível as possibilidades existentes, porém muitos outros podem ser empregados em análise de imagens. O objetivo geral aqui é apresentar algumas possibilidades de modelos para que outros estudos possam ser derivados desse. Ainda em relação aos modelos outras funções de peso podem ser investigadas e implementadas.

No que diz respeito a utilização de outras formas de análise, idealmente os modelos devem possibilitar a análise direta, ou seja, sem transformações adicionais no grafo. Caso isso não seja possível é necessário empregar outras formas de análise como a de subgrafos, hierárquica 
e OPF aqui apresentadas. Nesse sentido outros métodos de se transformar os grafos podem ser pesquisados. Um exemplo seria utiliza uma transformação do tipo árvore geradora mínima.

A utilização de outras medidas de redes complexas, bem como a investigação de seus efeitos em cada modelo, é algo passível de diversos estudos. Um entendimento mais criterioso de qual tipo de informação uma determinada medida está obtendo da imagem, pode dar diversas pistas da melhor forma de análise a ser empregada. Melhores resultados em análise de imagens e uma compreensão mais adequada do comportamento do problema podem ser obtidas nesse sentido.

\subsection{Principais contribuições e publicações}

A utilização da teoria das redes complexas em análise de imagens e a aplicação de tais métodos na identificação vegetal denota uma multidisciplinaridade natural ao projeto. Como resultado dessa multidisciplinaridade diversas contribuições desse trabalho podem ser assim resumidas:

- Utilização de redes complexas em análise de imagens;

- Desenvolvimento de métodos de análise de textura, cor, contorno e esqueletos;

- Proposta de taxonomia das diversas formas de se modelar uma imagem como grafo;

- Estudo e proposta de solução para um problema prático da biologia: a identificação vegetal;

Tais contribuições resultaram em diversos artigos nas áreas de biologia, física e computação, que estão publicados, submetidos ou em fase de redação, são eles:

- CASANOVA, D.; FLORINDO, J. B.; GONÇALVES, W. N.; BRUNO, O. M. IFSC/USP at imageCLEF 2012: plant identication task. In: CONFERENCE AND LABS OF THE EVAlUATION FORUM (CLEF), 4., 2012, Rome. Proceedings... Rome: CLEF, 2012.

- CASANOVA, D.; FLORINDO, J. B.; BRUNO, O. M. IFSC/USP at imageCLEF 2011: plant identication task. In: CONFERENCE AND LABS OF THE EVALUATION FORUM (CLEF), 3., 2011, Amsterdam. Proceedings... Amsterdam: CLEF, 2011.

- BACKES, A. R.; CASANOVA, D.; BRUNO, O. M. Texture analysis and classification: a complex network-based approach. Information Science, v. 219, p. 168-180, 2013. 
- BACKES, A. R.; CASANOVA, D.; BRUNO, O. M. A complex network-based approach for boundary shape analysis. Pattern Recognition, v. 42, n. 1, p. 54-67, 2009.

- BACKES, A. R.; CASANOVA, D.; BRUNO O. M. A Complex Network-Based Approach for Texture Analysis. In: IBEROAMERICAN CONGRESS ON PATTERN RECOGNITION (CIARP), 15., 2010. Heidelberg. Proceedings... Heidelberg: Springer, 2010. p. 354-361. (Lecture notes in computer science, v. 6419)

- ROSSATTO, D. R.; CASANOVA, D.; KOLB, R. M.; BRUNO, O. M. Fractal analysis of leaf-texture properties as a tool for taxonomic and identification purposes: a case study with species from Neotropical Melastomataceae (Miconieae tribe) Plant Systematics and Evolution, v. 291, n. 1-2, p, 103-116, 2010.

- CASANOVA, D.; BACKES, A. R.; BRUNO, O. M. Pattern recognition tool based on complex network-based approach. Journal of Physics: conference series, v. 410, p. 012048, 2013.

- CASANOVA, D.; BACKES, A. R.; BRUNO, O. M. Fractal measures of complex networks applied to texture analysis. Journal of Physics: conference series, v. 410, p. 012091, 2013.

- CASANOVA, D.; ROSSATTO, D. R.; FAlVO, M.; KOlB, R.; BRUNO, O. M. Plant taxonomy based on automated leaf analysis: a review. Plant Systematics and Evolution, 2013. (Redação)

- CASANOVA, D.; VIANA M.; BACKES, A. R.; NASSIF, B.; CESAR JR., R. M.; BRUNO, O. M.; COSTA, L. F. Graph and complex networks in image analysis and computer vision. ACM Computing Surveys, 2013. (Redação).

- CASANOVA, D.; GABRIEL, J. C.; BRUNO, O. M. Intestinal parasite identification by complex network analysis. Machine Vision and Applications, 2013. (Redação).

- CASANOVA, D.; SILVA, N. R.; BRUNO, O. M. Betweenness measure effects on image shape analysis. In: INTERNATIONAL CONFERENCE ON COMPUTER ANALYSIS OF IMAGES AND PATTERNS, 2013. (Redação).

- BACKES, A. R.; CASANOVA, D.; BRUNO, O. M. Color texture analysis based on fractal descriptors. Pattern Recognition, v. 45, n. 5, p. 1984-1992, 2012.

- CASANOVA D.; FLORINDO J. B.; BRUNO, O. M. Measuring color and spacial affnity between pixels using fractals. International Journal of Computer Vision, 2013. (Submetido). 
- MACHADO B. B.; CASANOVA D.; GONÇALVES W. N.; BRUNO, O. M. Partial differential equations and fractal analysis to plant leaf identification. Journal of Physics: conference series, v. 410, p. 012066, 2012.

- CASANOVA, D.; BRUNO, O. M. RGB color distribution analysis using volumetric fractal dimension. In: INTERNATIONAL CONFERENCE ON IMAGE AND SIGNAL PROCESSING (ICISP), 5., 2012, Heidelberg. Proceedings... Heidelberg: Springer, 2012. p. 343-351. (Lecture notes in computer science, v. 7340).

- BACKES, A. R.; CASANOVA, D.; BRUNO, O. M. Identificação de plantas por análise de textura foliar. Learning and Nonlinear Models, v. 9, p. 84-90, 2011.

- CASANOVA D.; BRUNO, O. M. Plant leaf identification using Gabor wavelets. International Journal of Imaging Systems and Technology, v. 19, p. 236-243, 2009.

- BACKES, A. R.; CASANOVA, D.; BRUNO, O. M. Plant leaf identifications based on volumetric fractal dimension. International Journal of Pattern Recognition and Artificial Intelligence, v. 23, p. 1145-1160, 2009.

- CASANOVA, D.; FALVO, M.; BRUNO, O. M. Influência na padronização do sistema de cor RGB nos métodos de visão computacional. In: WORKSHOP DE VISÃO COMPUTACIONAL (WVC), 7., 2011, Curitiba. Anais ... Curitiba: UFPR, 2011. p. 167-172.

- BACKES, A. R.; CASANOVA, D.; BRUNO, O. M. Identificação de plantas por análise de textura foliar. In: WORKSHOP DE VISÃO COMPUTACIONAL (WVC), 6., 2010, Presidente Prudente. Anais... Presidente Prudente: UNESP/FCT, 2010. P. 19-24.

- CASANOVA D.; BACKES, A. R. , BRUNO, O. M. Measurements of color texture on plant leaf identification. In: INTERNATIONAL SYMPOSIUM ON MATHEMATICAL AND COMPUTATIONAL BIOLOGY (BIOMAT), 8., 2008, Campos do Jordão. Proceedings... Campos do Jordão: BIOMAT, 2008. v. 2. p. 23-45. 


\section{REFERÊNCIAS}

1 ERDÖS, P.; RÉNYI, A. On the evolution of random graphs. Publication of the Mathematical Institute of the Hungarian Academy of Sciences, v. 5, p. 17-61, 1960.

2 MILGRAM, S. The small world problem. Psychology Today, v. 1, n. 1, p. 60-67, 1967.

3 WATTS, D. J.; STROGATZ, S. H. Collective dynamics of 'small-world' networks. Nature, London, v. 393, n. 6684, p. 440-442, 1998.

4 BARABÁSI, A. L.; ALBERT, R. Emergence of scaling in random networks. Science, Washington, v. 286, n. 5439, p. 509-512, 1999.

5 COSTA, L. F.; RODRIGUES, F. A.; TRAVIESO, G.; VILLAS BOAS, P. R. Characterization of complex networks: a survey of measurements. Advances in Physics, London, v. 56, n. 1, p. 167-242, 2007.

6 COSTA, L. F.; OLIVEIRA JUNIOR., O. N.; TRAVIESO, G.; RODRIGUES, F. A.; VILLAS BOAS, P. R.; ANTIQUEIRA, L.; VIANA, M. P.; ROCHA, L. E. C. Analyzing and modeling real-world phenomena with complex networks: a survey of applications. Advances in Physics, London, v. 60, n. 3, p. 329-412, 2008.

7 COSTA, L. F. Complex networks, simple vision. 2004. Disponível em: $<$ http://arxiv.org/pdf/cond-mat/0403346v1.pdf>. Acesso em: 16 abr. 2013.

8 CHALUMEAU, T.; COSTA, L. F.; LALIGANT, O.; MERIAUDEAU, F. Complex networks: application for texture characterization and classification. Electronic Letters on Computer Vision and Image Analysis, v. 7, n. 3, p. 93-100, 2008.

9 CHALUMEAU, T.; COSTA, L. F.; LALIGANT, O.; MERIAUDEAU, F. Optimized texture classification by using hierarchical complex network measurements. In: CONFERENCE ON MACHINE VISION APPLICATIONS IN INDUSTRIAL INSPECTION (SPIE), 14., 2006, San Jose. Proceedings... San Jose: SPIE, 2006. p. 238-245. DOI:10.1117/12.655592.

10 CHALUMEAU, T.; COSTA, L. F.; LALIGANT, O.; MERIAUDEAU, F. Texture discrimination using hierarchical complex networks. In: INTERNATIONAL CONFERENCE ON SIGNAL 
IMAGE TECHNOLOGY AND INTERNET BASED SYSTEMS (SITIS), 2., 2006, Hammamet. Proceedings... Hammamet: Springer, 2006. p. 543-550. DOI:10.1007/978-0-387-72500-0_9.

11 BACKES, A. R.; CASANOVA, D.; BRUNO, O. M. Texture analysis and classification: a complex network-based approach. Information Sciences, v. 219, p. 168-180, 2013.

12 CASANOVA, D.; BACKES, A. R.; BRUNO, O. M. Fractal measures of complex networks applied to texture analysis. Journal of Physics: conference series, v. 410, n. 1, p. 012091 , 2013.

13 BACKES, A. R.; CASANOVA, D.; BRUNO, O. M. A complex network-based approach for texture analysis. In: IBEROAMERICAN CONGRESS ON PATTERN RECOGNITION (CIARP), 15., 2010, São Paulo. Proceedings... São Paulo: Springer, 2010. p. 354-361. DOI:10.1007/10.1007/978-3-642-16687-7_48.

14 BACKES, A. R.; CASANOVA, D.; BRUNO, O. M. A complex network-based approach for boundary shape analysis. Pattern Recognition, v. 42, n. 1, p. 54-67, 2009.

15 CASANOVA, D.; BACKES, A. R.; BRUNO, O. M. Pattern recognition tool based on complex network-based approach. Journal of Physics: conference series, v. 410, n. 1, p. 012048, 2013.

16 CASANOVA, D.; FLORINDO, J. B.; BRUNO, O. M. IFSC/USP at imageCLEF 2011: plant identication task. In: CONFERENCE AND LABS OF THE EVALUATION FORUM (CLEF), 3., 2011, Amsterdam. Proceedings... Amsterdam: CLEF, 2011.

17 CASANOVA, D.; FLORINDO, J. B.; GONÇALVES, W. N.; BRUNO, O. M. IFSC/USP at imageCLEF 2012: plant identication task. In: CONFERENCE AND LABS OF THE EVALUATION FORUM (CLEF), 4., 2012, Rome. Proceedings... Rome: CLEF, 2012.

18 BIGGS, E.; LLOYD, K.; WILSON, R. Graph theory, 1736-1936. Oxford: Oxford University Press, 1986.

19 EULER, L. Solutio problematis ad geometriam situs pertinentis. Commentarii Academiae Scientiarum Petropolitanae, v. 8, p. 128-140, 1736.

20 RODRIGUES, F. A. Caracterização, classficação e análise de redes complexas. 2007. 175 p. Tese (Doutorado) - Institudo de Física de São Carlos, Universidade de São Paulo, São Carlos, 2007.

21 RAPOPORT, A. Contribution to the theory of random and biased nets. Bulletin of Mathematical Biology, v. 19, p. 257-277, 1957.

22 BACKES, A. R. Implementação e comparação de métodos de estimativa da dimensão fractal e sua aplicação à análise e processamento de imagens. 2006. 107 p. Dissertação 
(Mestrado) - Instituto de Ciências Matemáticas e da Computação, Universidade de São Paulo, São Carlos, 2006.

23 BACKES, A. R.; CASANOVA, D.; BRUNO, O. M. Plant leaf identification based on volumetric fractal dimension. International Journal of Pattern Recognition and Artificial Intelligence, v. 23, n. 6, p. 1145-1160, 2009.

24 BACKES, A. R.; CASANOVA, D.; BRUNO, O. M. Color texture analysis based on fractal descriptors. Pattern Recognition, v. 45, n. 5, p. 1984-1992, 2012.

25 FALCÃO, A. X.; STOLFI, J.; LOTUFO, R. A. The image foresting transform: theory, algorithms, and applications. IEEE Transactions on Pattern Analysis and Machine Intelligence, v. 26, n. 1, p. $19-29,2004$.

26 MORRIS, O. J.; DE J. LEE, M.; CONSTANTINIDES, A. G. Graph theory for image analysis: an approach based on the shortest spanning tree. IEEE Proceedings, v. 133, n. 2, p. 146-152, 1986.

$27 \mathrm{XU}, \mathrm{Y}$.; UBERBACHER, E. 2d image segmentation using minimum spanning trees. Image and Vision Computing, v. 15, n. 1, p. 47-57, 1997.

28 VLACHOS, T.; CONSTANTINIDES, A. Graph-theoretical approach to colour picture segmentation and contour classification. IEEE Proceedings I Communications, Speech and Vision, v. 140, n. 1, p. 36-45, 1993.

29 JAGANNATHAN, A.; MILLER, E. L. A graph-theoretic approach to multiscale texture segmentation. In: INTERNATIONAL CONFERENCE ON IMAGE PROCESSING (ICIP), 2002, New York. Proceedings... New York: IEEE, $2002 . \quad$ p. 777-780. DOI:10.1109/ICIP.2002.1040066.

30 HAXHIMUSA, Y.; KROPATSCH, W. G. Hierarchy of partitions with dual graph contraction. In: SYMPOSIUM OF THE GERMAN ASSOCIATION FOR PATTERN RECOGNITION (DAGM), 25., 2003, Magdeburg. Proceedings... Magdeburg: Springer, 2003. p. 338-345. DOI:10.1007/978-3-540-45243-0_44.

31 SHU, Y.; BILODEAU, G.-A.; CHERIET, F. Segmentation of laparoscopic images: Integrating graph-based segmentation and multistage region merging. In: CONFERENCE ON COMPUTER AND ROBOT VISION (CRV), 2., 2005, Montreal. Proceedings... Montreal: IEEE, 2005. p. 429-436. DOI:10.1109/CRV.2005.74.

32 WU, Z.; LEAHY, R. Image segmentation via edge contour finding: a graph theoretic approach. In: CONFERENCE ON COMPUTER VISION AND PATTERN RECOGNITION (CVPR), 1992, Champaign. Proceedings... Champaign: IEEE, 1992. p. 613-619. DOI:10.1109/CVPR.1992.223127. 
33 WU, Z.; LEAHY, R. M. An optimal graph theoretic approach to data clustering: theory and its application to image segmentation. IEEE Transactions on Pattern Analysis and Machine Intelligence, v. 15, n. 11, p. 1101-1113, 1993.

34 GOMORY, R. E.; HU, T. C. Multi-terminal network flow. Journal of the Society for Industrial and Applied Mathematics, v. 9, n. 4, p. 551-570, 1961.

35 GOMORY, R. E.; HU, T. C. Synthesis of a communication network. Journal of the Society for Industrial and Applied Mathematics, v. 12, n. 2, p. 348-369, 1964.

$36 \mathrm{WU}, \mathrm{Z}$.; LEAHY, R. Tissue classification in $\mathrm{mr}$ images using hierarchical segmentation. In: NUCLEAR SCIENCE SYMPOSIUM (NSS), 1990, Arlington. Proceedings... Arlington: IEEE, 1990. p. 1410-1414. DOI:10.1109/NSSMIC.1990.693573.

37 COX, I. J.; RAO, S. B.; ZHONG, Y. Ratio regions: A technique for image segmentation. In: INTERNATIONAL CONFERENCE ON PATTERN RECOGNITION (ICPR), 13., 1996, Vienna. Proceedings... Vienna: IEEE, 1996. p. 557-564. DOI:10.1109/ICPR.1996.546886.

38 SARKAR, S.; SOUNDARARAJAN, P. Supervised learning of large perceptual organization: Graph spectral partitioning and learning automata. IEEE Transactions on Pattern Analysis and Machine Intelligence, v. 22, n. 5, p. 504-525, 2000.

39 BOYKOV, Y.; KOLMOGOROV, V. An experimental comparison of min-cut/max-flow algorithms for energy minimization in vision. IEEE Transactions on Pattern Analysis and Machine Intelligence, v. 26, n. 9, p. 1124-1137, 2004.

40 JERMYN, I.; ISHIKAWA, H. Globally optimal regions and boundaries as minimum ratio weight cycles. IEEE Transactions on Pattern Analysis and Machine Intelligence, v. 23, n. 10, p. 1075-1088, 2001.

41 COUR, T.; BÉNÉZIT, F.; SHI, J. Spectral segmentation with multiscale graph decomposition. In: CONFERENCE ON COMPUTER VISION AND PATTERN RECOGNITION (CVPR), 2005, Philadelphia. Proceedings... Philadelphia: IEEE, 2005. p. 1124-1131. DOI:10.1109/CVPR.2005.332.

42 FELZENSZWALB, P. F.; HUTTENLOCHER, D. P. Efficient graph-based image segmentation. International Journal of Computer Vision, v. 59, n. 2, p. 167-181, 2004.

43 SUMENGEN, B.; MANJUNATH, B. Graph partitioning active contours (gpac) for image segmentation. IEEE Transactions on Pattern Analysis and Machine Intelligence, v. 28, n. 4, p. 509-521, 2006.

$44 \mathrm{SHI}$, J.; MALIK, J. Normalized cuts and image segmentation. IEEE Transactions on Pattern Analysis and Machine Intelligence, v. 22, n. 8, p. 888-905, 2000. 
45 SCANLON, J.; DEO, N. Graph-theoretic algorithms for image segmentation. In: INTERNATIONAL SYMPOSIUM ON CIRCUITS AND SYSTEMS (ISCAS), 1999, Orlando. Proceedings... Orlando: IEEE, 1999. p. 141-144. DOI:10.1109/ISCAS.1999.780115.

46 SHARON, E.; BRANDT, A.; BASRI, R. Fast multiscale image segmentation. In: CONFERENCE ON COMPUTER VISION AND PATTERN RECOGNITION (CVPR), 2000, Los Alamitos. Proceedings... Los Alamitos: IEEE, 2000. p. 1070-1077. DOI:10.1109/CVPR.2000.855801.

47 YU, S. X.; SHI, J. Multiclass spectral clustering. In: INTERNATIONAL CONFERENCE ON COMPUTER VISION (ICCV), 9., 2003, Nice. Proceedings... Nice: IEEE, 2003. p. 313-319. DOI:10.1109/ICCV.2003.1238361.

48 FOWLKES, C.; BELONGIE, S.; CHUNG, F. R. K.; MALIK, J. Spectral grouping using the nyström method. IEEE Transactions on Pattern Analysis and Machine Intelligence, v. 26, n. 2, p. 214-225, 2004.

49 BERGO, F. P. G.; FALCÃO, A. X.; MIRANDA, P. A. V.; ROCHA, L. M. Automatic image segmentation by tree pruning. Journal of Mathematical Imaging and Vision, v. 29, n. 2, p. 141-162, 2007.

50 MiRANDA, P. A. V.; FAlCÃO, A. X.; ROCHA, A.; BERGO, F. P. G. Object delineation by $\kappa$-connected components. Journal on Advances in Signal Processing, v. 2008, 2008.

51 BOYKOV, Y.; JOLLY, M.-P. Interactive graph cuts for optimal boundary and region segmentation of objects in N-D images. In: INTERNATIONAL CONFERENCE ON COMPUTER VISION (ICCV), 8., 2001, Vancouver. Proceedings... Vancouver: IEEE, 2001. p. 105-112. DOI:10.1109/ICCV.2001.937505.

52 JACQUOT, J. Z. Graph cuts segmentation with geometric shape priors for medical images. In: SYMPOSIUM ON IMAGE ANALYSIS AND INTERPRETATION (SSIAI), 2008, Santa Fe. Proceedings... Santa Fe: IEEE, 2008. p. 109-112. DOI:10.1109/SSIAI.2008.4512297.

53 KIM, J.-S.; HONG, K.-S. Color-texture segmentation using unsupervised graph cuts. Pattern Recognition, v. 42, n. 5, p. 735-750, 2009.

54 CORRIGAN, D.; HARTE, N.; KOKARAM, A. C. Automated segmentation of torn frames using the graph cuts technique. In: INTERNATIONAL CONFERENCE ON IMAGE PROCESSING (ICIP), 2007, San Antonio. Proceedings... San Antonio: IEEE, 2007. p. 557-560. DOI:10.1109/ICIP.2007.4379015.

55 GRECU, H.; LAMBERT, P. Simplification of color image segmentation using a fuzzy attributed graph. In: INTERNATIONAL CONFERENCE ON IMAGE PROCESSING (ICIP), 2000, Vancouver. Proceedings... Vancouver: IEEE, 2000. p. 525-528. DOI:10.1109/ICIP.2000.901011. 
56 QIAN, Y. Image interpretation with fuzzy-graph based genetic algorithm. In: INTERNATIONAL CONFERENCE ON IMAGE PROCESSING (ICIP), 1999, Kobe. Proceedings... Kobe: IEEE, 1999. p. 545-549. DOI:10.1109/ICIP.1999.821688.

57 PARKER, B. Three-dimensional medical image segmentation using a graph-theoretic energy-minimisation approach. In: PAN-SYDNEY AREA WORKSHOP ON VISUAL INFORMATION PROCESSING (VIP), 1., 2001, Sydney. Proceedings... Sydney: ACS, 2001. p. 47-50. DOI:10.1.1.18.9211.

58 HARCHAOUI, Z.; BACH, F. Image classification with segmentation graph kernels. In: CONFERENCE ON COMPUTER VISION AND PATTERN RECOGNITION (CVPR), 2007, Minneapolis. Proceedings... Minneapolis: IEEE, $2007 . \quad$ p. 1-8. DOI:10.1109/CVPR.2007.383049.

59 BACKES, A. R.; MARTINEZ, A. S.; BRUNO, O. M. Texture analysis using graphs generated by deterministic partially self-avoiding walks. Pattern Recognition, v. 44, n. 8, p. 1684 - 1689, 2011.

60 SUK, M.; SONG, O. Curvilinear feature extraction using minimum spanning trees. Computer Vision, Graphics, and Image Processing, v. 26, n. 3, p. $400-411,1984$.

61 FERRARI, V.; TUYTELAARS, T.; GOOL, L. V. Object detection by contour segment networks. In: EUROPEAN CONFERENCE ON COMPUTER VISION (ECCV), 9., 2006, Graz. Proceedings... Graz: Springer, 2006. p. 14-28. DOI:10.1007/11744078_2.

62 AUWATANAMONGKOL, S. Inexact graph matching using a genetic algorithm for image recognition. Pattern Recognition Letters, v. 28, n. 12, p. 1428-1437, 2007.

63 LABELLE, L.; LAUZON, D.; KONRAD, J.; DUBOIS, E. Arithmetic coding of a lossless contour based representation of label images. In: INTERNATIONAL CONFERENCE ON IMAGE PROCESSING (ICIP), 1998, Chicago. Proceedings... Chicago: IEEE, 1998. p. 261265. DOI:10.1109/ICIP.1998.723469.

64 BATTIATO, S.; GALLO, G.; IMPOCO, G.; STANCO, F. An efficient re-indexing algorithm for color-mapped images. IEEE Transactions on Image Processing, v. 13, n. 11, p. 1419-1423, 2004.

65 ZHAO, H.; KONG, M.; LUO, B. Shape representation based on polar-graph spectra. In: INTERNATIONAL CONFERENCE ON INTELLIGENT COMPUTING (ICIC), 2., 2006, Kunming. Proceedings... Kunming: Springer, 2006. p. 900-905. DOI:10.1007/978-3-54037258-5_111.

66 TANG, J.; ZHANG, C.; LUO, B. Shape representation and distance measure based on relational graph. In: INTERNATIONAL CONFERENCE ON HYBRID INTELLIGENT SYSTEMS (HIS), 6., 2006, Rio de Janeiro. Proceedings... Rio de Janeiro: IEEE, 2006. p. 20-20. DOI:10.1109/HIS.2006.264903. 
67 YIN, P.-Y. A discrete particle swarm algorithm for optimal polygonal approximation of digital curves. Journal of Visual Communication and Image Representation, v. 15, n. 2, p. $241-260,2004$.

68 BACKES, A. R.; BRUNO, O. M. A graph-based approach for shape skeleton analysis. In: INTERNATIONAL CONFERENCE ON IMAGE ANALYSIS AND PROCESSING (ICIAP), 15., 2009, Vietri sul Mare. Proceedings... Vietri sul Mare: Springer, 2009. p. 731-738. DOI:10.1007/978-3-642-04146-4_78.

69 BACKES, A. R.; BRUNO, O. M. Shape skeleton classification using graph and multiscale fractal dimension. In: INTERNATIONAL CONFERENCE ON IMAGE AND SIGNAL PROCESSING (ICISP), 4., 2010, Trois-Rivières. Proceedings... Trois-Rivières: Springer, 2010. p. 448-455. DOI:10.1007/978-3-642-13681-8_52.

70 PAVLIDIS, T.; SAKODA, W. J.; SHI, H. Matching graph embeddings for shape analysis. In: INTERNATIONAL CONFERENCE ON DOCUMENT ANALYSIS AND RECOGNITION (ICDAR), 3., 1995, Montreal. Proceedings... Montreal: IEEE, 1995. p. 729-733. DOI:10.1109/ICDAR.1995.602006.

71 HE, L.; HAN, C. Y.; EVERDING, B.; WEE, W. G. Graph matching for object recognition and recovery. Pattern Recognition, v. 37, n. 7, p. 1557-1560, 2004.

72 LAM, L.; SUEN, C. Y. Automatic comparison of skeletons by shape matching methods. International Journal of Pattern Recognition and Artificial Intelligence, v. 7, n. 5, p. 12711286, 1993.

73 BUNKE, H.; ALLERMANN, G. Inexact graph matching for structural pattern recognition. Pattern Recognition Letters, v. 1, n. 4, p. 245-253, 1983.

74 ARRIVAULT, D.; RICHARD, N.; FERNANDEZ-MALOIGNE, C.; BOUYER, P. Collaboration between statistical and structural approaches for old handwritten characters recognition. In: INTERNATIONAL WORKSHOP ON GRAPH-BASED REPRESENTATIONS IN PATTERN RECOGNITION (GBRPR), 5., 2005, Poitiers. Proceedings... Poitiers: Springer, 2005. p. 291-300. DOI:10.1007/978-3-540-31988-7_28.

75 DI RUBERTO, C. Recognition of shapes by attributed skeletal graphs. Pattern Recognition, v. 37, n. 1, p. 21-31, 2004.

76 YANG, X.; BAI, X.; YU, D.; LATECKI, L. J. Shape classification based on skeleton path similarity. In: INTERNATIONAL WORKSHOP ON ENERGY MINIMIZATION METHODS IN COMPUTER VISION AND PATTERN RECOGNITION (EMMCVPR), 6., 2007, Ezhou. Proceedings... Ezhou: Springer, 2007. p. 375-386. DOI:10.1007/978-3-540-74198-5_29.

77 BAI, X.; YANG, X.; YU, D.; LATECKI, L. J. Skeleton-based shape classification using path similarity. International Journal of Pattern Recognition and Artificial Intelligence, v. 22, n. 4, p. 733-746, 2008. 
$78 \mathrm{BAI}, \mathrm{X}$; LATECKI, L. J. Path similarity skeleton graph matching. IEEE Transactions on Pattern Analysis and Machine Intelligence, v. 30, n. 7, p. 1282-1292, 2008.

79 SIDDIQI, K.; SHOKOUFANDEH, A.; DICKINSON, S. J.; ZUCKER, S. W. Shock graphs and shape matching. International Journal of Computer Vision, v. 35, n. 1, p. 13-32, 1999.

80 MATAS, J.; MARIK, R.; KITTLER, J. On representation and matching of multicoloured objects. In: INTERNATIONAL CONFERENCE ON COMPUTER VISION (ICCV), 5., 1995, Cambridge. Proceedings... Cambridge: IEEE, 1995. p. 726-732. DOI:10.1109/ICCV.1995.466866.

81 PARK, I.; YUN, I.; LEE, S. Color image retrieval using hybrid graph representation. Image and Vision Computing, v. 17, n. 7, p. 465-474, 1999.

82 RANDEN, T.; HUS $\varnothing \mathrm{Y}$, J. H. Filtering for texture classification: a comparative study. IEEE Transactions on Pattern Analysis and Machine Intelligence, v. 21, n. 4, p. 291-310, 1999.

83 HARALICK, R. M. Statistical and structural approaches to texture. Proceedings of IEEE, v. 67, n. 5, p. 786-804, 1979.

84 MEYER, F.; BEUCHER, S. Morphological segmentation. Journal of Visual Communication and Image Representation, v. 1, n. 1, p. 21-46, 1990.

85 QAZI, I.-U.-H.; ALATA, O.; BURIE, J.-C.; MOUSSA, A.; FERNANDEZ-MALOIGNE, C. Choice of a pertinent color space for color texture characterization using parametric spectral analysis. Pattern Recognition, v. 44, n. 1, p. 16-31, 2011.

86 QAZI, I.-U.-H.; ALATA, O.; BURIE, J.-C.; FERNANDEZ-MALOIGNE, C. Color spectral analysis for spatial structure characterization of textures in IHLS color space. Pattern Recognition, v. 43, n. 3, p. 663-675, 2010.

87 OHTA, Y.; KANADE, T.; SAKAI, T. Color information for region segmentation. Computer Vision, Graphics, and Image Processing, v. 13, p. 222-241, 1980.

88 MAENPAA, T.; PIETIKAINEN, M. Classification with color and texture: jointly or separately? Pattern Recognition, v. 37, n. 8, p. 1629-1640, Aug. 2004.

89 PLOTZE, R. O.; FALVO, M.; PÁDUA, J. G.; BERNACCI, L. C.; VIEIRA, M. L. C.; OLIVEIRA, G. C. X.; BRUNO, O. M. Leaf shape analysis using the multiscale Minkowski fractal dimension, a new morphometric method: a study with Passiflora (Passifloraceae). Canadian Journal of Botany, v. 83, n. 3, p. 287-301, 2005.

90 MATERKA, A.; STRZELECKI, M. Texture analysis methods, a review. Brussels: University of Lodz, 1998. Technical report, COST B11. DOI:10.1.1.97.4968. 
91 AZENCOTT, R.; WANG, J.-P.; YOUNES, L. Texture classification using windowed Fourier filters. IEEE Transactions on Pattern Analysis and Machine Intelligence, v. 19, n. 2, p. 148153, 1997.

92 MANJUNATH, B. S.; MA, W.-Y. Texture features for browsing and retrieval of image data. IEEE Transactions on Pattern Analysis and Machine Intelligence, v. 18, n. 8, p. 837-842, 1996.

93 JAIN, A. K.; FARROKHNIA, F. Unsupervised texture segmentation using Gabor filters. Pattern Recognition, v. 24, n. 12, p. 1167-1186, 1991.

94 DAUGMAN, J.; DOWNING, C. Gabor wavelets for statistical pattern recognition. In: ARBIB, M. A. (Ed.) The handbook of brain theory and neural networks. Cambridge: MIT Press, 1995. p. 414-419.

95 IDRISSA, M.; ACHEROY, M. Texture classification using Gabor filters. Pattern Recognition Letters, v. 23, n. 9, p. 1095-1102, 2002.

96 NG, I.; TAN, T.; KITTLER, J. On local linear transform and Gabor filter representation of texture. In: INTERNATIONAL CONFERENCE ON PATTERN RECOGNITION (ICPR), 11., 1992, The Hague. Proceedings... The Hague: IEEE, 1992. p. 627-631. DOI:10.1109/ICPR.1992.202065.

97 WESZKA, J. S.; DYER, C. R.; ROSENFELD, A. A comparative study of texture measures for terrain classification. IEEE Transactions on Systems, Man, and Cybernetics, v. 6, n. 4, p. 269-285, 1976.

98 KIM, J.-K.; PARK, H. W. Statistical textural features for detection of microcalcificationsin digitized mammograms. IEEE Transactions on Medical Imaging, v. 18, n. 3, p. 231-238, 1999.

99 DAUBECHIES, I. Ten lectures on wavelets. Philadelphia: Society for Industrial and Applied Mathematics, 1992.

100 CHANG, T.; KUO, C.-C. Texture analysis and classification with tree-structure wavelet transform. IEEE Transactions on Image Processing, v. 2, n. 4, p. 429-441, 1993.

101 JIN, X.; GUPTA, S.; MUKHERJEE, K.; RAY, A. Wavelet-based feature extraction using probabilistic finite state automata for pattern classification. Pattern Recognition, v. 44, n. 7 , p. 1343-1356, 2011.

102 GUO, Z.; ZHANG, L.; ZHANG, D. A completed modeling of local binary pattern operator for texture classification. IEEE Transactions on Image Processing, v. 19, n. 6, p. 1657-1663, 2010. 
103 OJALA, T.; PIETIKÄINEN, M.; MÄENPÄÄ, T. Multiresolution gray-scale and rotation invariant texture classification with local binary patterns. IEEE Transactions on Pattern Analysis and Machine Intelligence, v. 24, n. 7, p. 971-987, 2002.

104 ZHOU, H.; WANG, R.; WANG, C. A novel extended local-binary-pattern operator for texture analysis. Information Sciences, v. 178, n. 22, p. 4314-4325, 2008.

105 GUO, Z.; ZHANG, L.; ZHANG, D. Rotation invariant texture classification using lbp variance (lbpv) with global matching. Pattern Recognition, v. 43, n. 3, p. 706-719, 2010.

106 TAN, X.; TRIGGS, B. Enhanced local texture feature sets for face recognition under difficult lighting conditions. IEEE Transactions on Image Processing, v. 19, n. 6, p. 1635 -1650 , june 2010 .

107 GONZALEZ, R. C.; WOODS, R. E. Digital image processing. Reading: Addison-Wesley, 1992.

108 OSOWSKI, S.; NGHIA, D. D. Fourier and wavelet descriptors for shape recognition using neural networks - a comparative study. Pattern Recognition, v. 35, n. 9, p. 1949-1957, 2002.

109 ZHENJIANG, M. Zernike moment-based image shape analysis and its application. Pattern Recognition Letters, v. 21, n. 2, p. 169-177, 2000.

110 COSTA, L. F.; CESAR, R. M. Shape analysis and classification: theory and practice. Boca Raton: CRC Press, 2000.

111 TORRES, R. S.; FALCÃO, A.; COSTA, L. F. A graph-based approach for multiscale shape analysis. Pattern Recognition, v. 37, n. 6, p. 1163-1174, 2003.

112 MOKHTARIAN, F.; BOBER, M. Curvature scale space representation: theory, applications, and MPEG-7 standardization. New York: Kluwer, 2003.

113 GEIGER, D.; LIU, T.-L.; KOHN, R. V. Representation and self-similarity of shapes. IEEE Transactions on Pattern Analysis and Machine Intelligence, v. 25, n. 1, p. 86-99, 2003.

114 FREIRE, A. S. Correspondência inexata entre grafos. 2008. 138 p. Dissertação (Mestrado) - Instituto de Matemática e Estatística, Universidade de São Paulo, São Paulo, 2008.

115 CROSS, A. D. J.; WILSON, R. C.; HANCOCK, E. R. Inexact graph matching using genetic search. Pattern Recognition, v. 30, n. 6, p. 953-970, 1997.

$116 \mathrm{GAO}, \mathrm{X}$; XIAO, B.; TAO, D.; LI, X. A survey of graph edit distance. Pattern Analysis and Applications, v. 13, n. 1, p. 113-129, 2010. 
117 MORA, C.; TITTENSOR, D. P.; ADL, S.; SIMPSON, A. G. B.; WORM, B. How many species are there on earth and in the ocean? PLoS Biology, v. 9, n. 8, p. e1001127+, 2011.

118 WANG, X.-F.; HUANG, D.-S.; DUA, J.-X.; XU, H.; HEUTTE, L. Classification of plant leaf images with complicated background. Applied Mathematics and Computation, v. 205, n. 2, p. $916-926,2008$.

119 BRIDSON, D.; FORMAN, L. The herbarium handbook. Kew: Royal Botanic Gardens, Kew, 1998.

120 LEENHOUTS, P. W. A guide to the practice of herbarium taxonomy. Utrecht: International Bureau for Plant Taxonomy and Nomenclature of the International Association for Plant Taxonomy, 1968.

121 DEWOLF, G. Notes on making an herbarium. Arnoldia, v. 28, n. 8, p. 69-111, 1968.

122 DALLWITZ, M. J. A flexible computer program for generating diagnostic keys. Systematic Zoology, v. 26, n. 1, p. 50-57, 1974.

123 PANKHURST, R. J. Biological identification. Baltimore: University Park Press, 1978.

124 HOLGREN, P. K.; HOLGREN, N. Plant specialists index. Königstein: Koeltz Scientific Books, 1992.

125 ASH, A.; ELLIS, B.; HICKEY, L. J.; JOHNSON, K.; WILF, P. Manual of leaf architecture - morphological description and categorization of dicotyledonous and net-veined monocotyledonous angiosperms by leaf architecture. Washington D. C.: Smithsonian Institution, 1999.

126 MORACZEWSKI, I. R. Analyzing leaf margins with the use of a shape feature description language. Canadian Journal of Botany, v. 76, n. 3, p. 552-560, 1998.

127 MELTZER, B.; SEARLE, N. H.; BROWN, R. Numerical specification of biological form. Nature, London, v. 216, n. 10, p. 32-36, 1967.

128 BLACKITH, R. E.; REYMENT, R. A. Multivariate morphometrics. New York: Academic Press, 1971.

129 DALE, M. B.; GROVES, R. H.; HULL, V. J.; O'CALLAGHAN, J. F. A new method for describing leaf shape. New Phytologist, v. 70, n. 2, p. 437-442, 1971.

130 FOX, R. D.; BRAZEE, R. D. Numerical methods of describing leaf shapes. Journal of Agricultural Engineering Research, v. 16, n. 4, p. 353-363, 1971. 
131 SLAUGHTER, D. C.; GILES, D. K.; DOWNEY, D. Autonomous robotic weed control systems: a review. Computers and Electronics in Agriculture, v. 61, n. 1, p. 63-78, 2008.

132 GOËAU, H.; BONNET, P.; JOLY, A.; BOUJEMAA, N.; BARTHELEMY, D.; MOLINO, J.-F.; BIRNBAUM, P.; MOUYSSET, E.; PICARD, M. The clef 2011 plant images classification task. In: INTERNATIONAL CONFERENCE OF THE CROSS-LANGUAGE EVALUATION FORUM (CLEF), 3., 2011, Amsterdam. Proceedings... Amsterdam: CLEF, 2011.

133 BLUE, M. P.; JENSEN, R. J. Positional and seasonal variation in oak (quercus; fagaceae) leaf morphology. American Journal of Botany, v. 75, n. 7, p. 939-947, 1988.

$134 \mathrm{WU}, \mathrm{H}$. Allometrical growth of the quantitative characters of plants I. measurement of leaf size and shape. Botanical Bulletin of Academia Sinica, v. 35, n. 3, p. 115-124, 1994.

135 CAMARGO NETO, J.; MEYER, G. E.; JONES, D. D.; SAMAL, A. K. Plant species identification using elliptic Fourier leaf shape analysis. Computers and Electronics in Agriculture, v. 50, n. 2, p. 121-134, 2006.

136 MANCUSO, S. Discrimination of grapevine (Vitis vinifera I.) leaf shape by fractal spectrum. Vitis, v. 41, n. 3, p. 137-142, 2002.

137 MANCUSO, S.; PISANI, P. L.; BANDINELLI, R.; RINALDELLI, E. Application of an artificial neural network (ann) for the identification of grapevine genotypes. Vitis, v. 37, n. 1 , p. 27-32, 1998.

138 SAWADA, S. Time of determination and variation within and between plants in leaf shape of soybean. Japanese Journal of Crop Science, v. 61, n. 1, p. 96-100, 1992.

139 CASANOVA, D.; FALVO, M.; BRUNO, O. M. Influência da padronização do sistema de cor RGB nos métodos de visão computacional. In: WORKSHOP DE VISÃO COMPUTACIONAL (WVC), 7., 2011, Curitiba. Anais... Curitiba: UFP, 2011. p. 167-172.

140 MCLELLAN, T.; ENDLER, J. A. The relative success of some methods for measuring and describing the shape of complex objects. Systematic Biology, v. 47, n. 2, p. 264-281, 1998.

141 KINCAID, D. T.; SCHNEIDER, R. B. Quantification of leaf shape with a microcomputer and Fourier transform. Canadian Journal of Botany, v. 61, n. 9, p. 2333-2342, 1983.

142 BOOKSTEIN, F. L.; STRAUSS, R. E.; HUMPHRIES, J. M.; CHERNOFF, B.; ELDER, R. L.; SMITH, G. R. A comment upon the uses of Fourier methods in systematics. Systematic Zoology, v. 27, n. 1, p. 85-92, 1982. 
143 ROHLF, F. J.; ARCHIE, J. W. A comparison of Fourier methods for the description of wing shape in mosquitoes (Diptera: Culicidae). Systematic Zoology, v. 33, n. 3, p. 302-317, 1984.

144 WHITE, R. J.; PRENTICE, H. C.; VERWIJST, T. Automated image acquisition and morphometric description. Canadian Journal of Botany, v. 66, n. 3, p. 450-459, 1988.

145 GUYER, D. E.; MILES, G. E.; SCHREIBER, M. M.; MITCHELL, O. R.; VANDERBILT, V. C. Machine vision and image processing for plant identification. Transactions of the American Society of Agricultural Engineers, v. 29, n. 1, p. 1500-1507, 1986.

146 WEST, J. G.; NOBLE, I. R. Analyses of digitised leaf images of the dodonaea viscosa complex in australia. Taxon, v. 33, n. 4, p. 595-613, 1984.

147 IM, C.; NISHIDA, H.; KUNII, T. L. A hierarchical method of recognizing plant species by leaf shapes. In: WORKSHOP ON MACHINE VISION APPLICATIONS (MVA), 1., 1998, Chiba. Proceedings... Chiba: MVA, 1998. p. 158-161.

148 IM, C.; NISHIDA, H.; KUNII, T. L. Recognizing plant species by leaf shapes - a case study of the acer family. In: INTERNATIONAL CONFERENCE ON PATTERN RECOGNITION (ICPR), 14., 1998, Brisbane. Proceedings... Brisbane: IEEE, 1998. p. 1171-1173. DOI:10.1109/ICPR.1998.711904.

149 BORKOWSKI, W. Fractal dimension based features are useful descriptors of leaf complexity and shape. Canadian Journal of Forest Research, v. 29, n. 9, p. 1301-1310, 1999.

150 MORACZEWSKI, I. R.; BORKOWSKI, W. Analyzing leaf shapes with the use of fractal measures and a shape feature description language. In: NATIONAL CONFERENCE ON APPLICATIONS OF MATHEMATICS IN BIOLOGY AND MEDICINE (AMBM), 3., 1997, Madralin. Proceedings... Madralin: AMBM, 1997. p. 50-55.

151 BORKOWSKI, W.; KOSTRZYNSKA, L. Specialized measures of leaf outlines and hierarchical perceptrons in an automatic identification of plants. International Journal of Modern Physics C, v. 15, n. 8, p. 1171-1186, 2004.

152 FU, H.; CHI, Z.; FENG, D.; SONG, J. Machine learning techniques for ontology-based leaf classification. In: INTERNATIONAL CONFERENCE ON AUTOMATION, ROBOTICS AND COMPUTER VISION (ICARCV), 8., 2004, Kunming. Proceedings... Kunming: Springer, 2004. p. 681-686. DOI:10.1109/ICARCV.2004.1468909.

153 ROHLF, F. J.; BOOKSTEIN, F. L. Michigan morphometrics workshop. Ann Arbor: University of Michigan Museum of Zoology, 1990. 
154 ABBASI, S.; MOKHTARIAN, F.; KITTLER, J. V. Reliable classification of chrysanthemum leaves through curvature scale space. In: INTERNATIONAL CONFERENCE ON SCALESPACE THEORY IN COMPUTER VISION (SSTCV), 1., 1997, Utrecht. Proceedings... Utrecht: Springer, 1997. p. 284-295. DOI:10.1007/3-540-63167-4_58.

155 WANG, Z.; CHI, Z.; FENG, D. Fuzzy integral for leaf image retrieval. In: INTERNATIONAL CONFERENCE ON FUZZY SYSTEMS (FUZZ-IEEE), 1., 2002, Honolulu. Proceedings... Honolulu: IEEE, 2000. p. 372-377. DOI:10.1109/FUZZ.2002.1005019.

156 WANG, Z.; CHI, Z.; FENG, D. Shape based leaf image retrieval. IEEE Proceedings Vision, Image \& Signal Processing, v. 150, n. 1, p. 34-43, 2003.

157 DU, M.; ZHANG, S.; WANG, H. Supervised isomap for plant leaf image classification. In: INTERNATIONAL CONFERENCE ON INTELLIGENT COMPUTING (ICIC), 5., 2009, Ulsan. Proceedings... Ulsan: Springer, 2009. p. 627-634. DOI:10.1007/978-3-642-04020-7_67.

158 LIU, J.; ZHANG, S.; LIU, J. A method of plant leaf recognition based on locally linear embedding and moving center hypersphere classifier. In: INTERNATIONAL CONFERENCE ON INTELLIGENT COMPUTING (ICIC), 5., 2009, Ulsan. Proceedings... Ulsan: Springer, 2009. p. 645-651. DOI:10.1007/978-3-642-04020-7_69.

159 ZHANG, S.; CHAU, K.-W. Dimension reduction using semi-supervised locally linear embedding for plant leaf classification. In: INTERNATIONAL CONFERENCE ON INTELLIGENT COMPUTING (ICIC), 5., 2009, Ulsan. Proceedings... Ulsan: Springer, 2009. p. 948-955. DOI:10.1007/978-3-642-04070-2_100.

160 DU, J.-X.; WANG, X.-F.; ; GU, X. Shape matching and recognition base on genetic algorithm and application to plant species identification. In: INTERNATIONAL CONFERENCE ON INTELLIGENT COMPUTING (ICIC), 1., 2005, Hefei. Proceedings... Hefei: Springer, 2005. p. 282-290. DOI:10.1007/11538059_30.

161 WANG, D.-L.; ZHANG, X.-M.; LIU, Y.-Q. Recognition system of leaf images based on neuronal network. Journal of Forestry Research, v. 17, n. 3, p. 243-246, 2006.

162 FELZENSZWALB, P. F.; SCHWARTZ, J. D. Hierarchical matching of deformable shapes. In: CONFERENCE ON COMPUTER VISION AND PATTERN RECOGNITION (CVPR), 2007, Minneapolis. Proceedings... Minneapolis: IEEE, 2007. p. 1-8. DOI:10.1109/CVPR.2007.383018.

163 LING, H.; JACOBS, D. W. Shape classification using the inner-distance. IEEE Transactions on Pattern Analysis and Machine Intelligence, v. 29, n. 2, p. 286-299, 2007.

164 HEARN, D. J. Shape analysis for the automated identification of plants from images of leaves. Taxon, v. 58, n. 3, p. 934-954, 2009. 
165 MANCUSO, S. Elliptic Fourier analysis (EFA) and artificial neural networks (ANNs) for the identification of grapevine (Vitis vinifera L.) genotypes. Vitis, v. 38, n. 2, p. 73-77, 1999.

166 MANCUSO, S.; FERRINI, F.; NICESE, F. P. Chestnut (Castanea sativa mill.) genotype identification: an artificial neural network approach. Journal of Horticultural Science \& Biotechnology, v. 74, n. 1, p. 777-784, 1999.

167 AGARWAL, G.; BELHUMEUR, P.; FEINER, S.; JACOBS, D.; KRESS, W. J.; RAMAMOORTHI, R.; BOURG, N. A.; DIXIT, N.; LING, H.; MAHAJAN, D.; RUSSELL, R.; SHIRDHONKAR, S.; SUNKAVALLI, K.; WHITE, S. First steps toward an electronic field guide for plants. Taxon, v. 55, n. 3, p. 597-610, 2006.

168 BELHUMEUR, P. N.; CHEN, D.; FEINER, S.; JACOBS, D. W.; KRESS, W. J.; LING, H.; LOPEZ, I.; RAMAMOORTHI, R.; SHEOREY, S.; WHITE, S.; ZHANG, L. Searching the world's herbaria: a system for visual identification of plant species. In: EUROPEAN CONFERENCE ON COMPUTER VISION (ECCV), 10., 2008, Marseille. Proceedings... Marseille: Springer, 2008. p. 116-129. DOI:10.1007/978-3-540-88693-8_9.

169 KADIR, A.; NUGROHO, L. E.; SUSANTO, A.; SANTOSA, P. I. Leaf classification using shape, color, and texture features. International Journal of Computer Trends and Technology, v. 1, n. 3, p. 225-230, 2011.

170 SHEARER, S. A.; HOLMES, R. G. Plant identification using color co-occurrence matrices. Transactions of the American Society of Agricultural Engineers, v. 33, n. 6, p. 2037-2044, 1990.

171 ERXU, P.; QIUFA, P.; HONGFEI, L.; JINGBO, S.; YUEQIANG, D.; FEILAI, H.; HUI, H. Leaf morphology and anatomy of camellia section camellia (theaceae). Botanical Journal of the Linnean Society, v. 159, n. 3, p. 456-476, 2009.

172 DEAN, M.; ASHTON, P. A. Leaf surfaces as a taxonomic tool: the case of Carex section Phacocystis (Cyperaceae) in the British Isles. Plant Systematics and Evolution, v. 237, n. 1, p. $97-105,2008$.

173 CASANOVA, D.; BACKES, A. R.; BRUNO, O. M. Measurements of color texture on plant leaf identification. In: INTERNATIONAL SYMPOSIUM ON MATHEMATICAL AND COMPUTATIONAL BIOLOGY (BIOMAT), 8., 2008, Campos do Jordão. Proceedings... Campos do Jordão: IEEE, 2008. p. 23-45.

174 CASANOVA, D.; SÁ JUNIOR, J. J. M.; BRUNO, O. M. Plant leaf identification using Gabor wavelets. International Journal of Imaging Systems and Technology, v. 19, n. 3, p. 236-243, 2009.

175 RAMOS, E.; FERNÁNDEZ, D. S. Classification of leaf epidermis microphotographs using texture features. Ecological Informatics, v. 4, n. 3, p. 177-181, 2009. 
176 ROSSATTO, D. R.; CASANOVA, D.; KOLB, R. M.; BRUNO, O. M. Fractal analysis of leaf-texture properties as a tool for taxonomic and identification purposes: a case study with species from neotropical Melastomataceae (Miconieae tribe). Plant Systematics and Evolution, v. 291, n. 1, p. 103-116, 2010.

177 HUSSEIN, A.; MASHOHOR, S.; SARIPAN, M. A texture-based approach for content based image retrieval system for plant leaves images. In: INTERNATIONAL COLLOQUIUM ON SIGNAL PROCESSING AND ITS APPLICATIONS (CSPA), 7., 2011, Serdang. Proceedings... Serdang: IEEE, 2011. p. 11-14. DOI:10.1109/CSPA.2011.5759833.

178 BEGHIN, T.; COPE, J. S.; REMAGNINO, P.; BARMAN, S. Shape and texture based plant leaf classification. In: INTERNATIONAL CONFERENCE ADVANCED CONCEPTS FOR INTELLIGENT VISION SYSTEMS (ACIVS), 12., 2010, Sydney. Proceedings... Sydney: Springer, 2010. p. 345-353. DOI:10.1007/978-3-642-17691-3_32.

179 PARK, J.-K.; HWANG, E.; NAM, Y. A venation-based leaf image classification scheme. In: ASIA CONFERENCE ON INFORMATION RETRIEVAL TECHNOLOGY (AIRS), 3., 2006, Singapore. Proceedings... Singapore: Springer, 2006. p. 416-428. DOI:10.1007/11880592_32.

180 NAM, Y.; HWANG, E. A shape-based retrieval scheme for leaf images. In: PACIFIC-RIM CONFERENCE ON MULTIMEDIA (PCM), 6., 2005, Jeju Island. Proceedings... Jeju Island: Springer, 2005. p. 876-887. DOI:10.1007/11581772_77.

181 MENDONÇA, R. C.; FELFILI, J. M.; WALTER, B. M. T.; SILVA-JUNIOR, M. C.; REZENDE, A. V.; FILGUEIRAS, T. S.; NOGUEIRA, P. E.; FAGG, C. W. Flora vascular do bioma cerrado: checklist com 12.356 espécies. In: SANO, S. M.; ALMEIDA, S. P.; RIBEIRO, J. F. (Eds.) Cerrado: ambiente e flora. Brasília: Embrapa Cerrados, 2008. p. 421-1279.

182 HICKEY, L. J. Classification of the architecture of dicotyledons leaves. American Journal of Botany, v. 60, n. 1, p. 17-33, 1973.

183 BOHN, S.; ANDREOTTI, B.; DOUADY, S.; MUNZINGER, J.; COUDER, Y. Constitutive property of the local organization of leaf venation networks. Physical Review E, v. 65, n. 6, p. 061914-1-061914-12, 2002.

184 NAM, Y.; HWANG, E.; KIM, D. CLOVER: a mobile content-based leaf image retrieval system. In: INTERNATIONAL CONFERENCE ON ASIAN DIGITAL LIBRARIES (ICADL), 8., 2005, Bangkok. Proceedings... Bangkok: Springer, 2005. p. 139-148. DOI:10.1007/11599517_16.

185 PARK, J.; HWANG, E.; NAM, Y. Utilizing venation features for efficient leaf image retrieval. Journal of Systems and Software, v. 81, n. 1, p. 71-82, 2008.

$186 \mathrm{FU}, \mathrm{H}$.; $\mathrm{CHI}, \mathrm{Z}$. Combined thresholding and neural network approach for vein pattern extraction from leaf images. IEEE Proceedings Vision, Image \& Signal Processing, v. 153, n. 6, p. 881-892, 2006. 
187 GOUVEIA, F.; FILIPE, V.; REIS, M.; COUTO, C.; BULAS-CRUZ, J. Biometry: the characterization of chestnut-tree leaves using computer vision. In: INTERNATIONAL SOCIETY FOR INDUSTRIAL ECOLOGY (ISIE), 1997, Guimaraes. Proceedings... Guimaraes: IEEE, 1997. p. 757-760. DOI:10.1109/ISIE.1997.648634.

188 BRUNO, O. M.; PLOTZE, R. O.; FALVO, M.; CASTRO, M. Fractal dimension applied to plant identification. Information Sciences, v. 178, n. 12, p. 2722-2733, 2008.

189 PLOTZE, R. O.; BRUNO, O. M. Automatic leaf structure biometry: computer vision techniques and their applications in plant taxonomy. International Journal of Pattern Recognition and Artificial Intelligence, v. 23, n. 2, p. 247-262, 2009.

190 CHENG, S.-C.; JHOU, J.-J.; LIOU, B.-H. Pda plant search system based on the characteristics of leaves using fuzzy function. In: INTERNATIONAL CONFERENCE ON INDUSTRIAL, ENGINEERING, AND OTHER APPLICATIONS OF APPLIED INTELLIGENT SYSTEMS (AIE), 20., 2007, Kyoto. Proceedings... Kyoto: Springer, 2007. p. 834-844. DOI:10.1007/978-3-540-73325-6_83.

191 METCALFE, C.; CHALK, L. Anatomy of dicotyledons. Oxford: Oxford University Press, 1979.

192 BACKES, A. R.; SÁ JUNIOR, J. J. M.; KOLB, R. M.; BRUNO, O. M. Plant species identification using multi-scale fractal dimension applied to images of adaxial surface epidermis. In: INTERNATIONAL CONFERENCE ON COMPUTER ANALYSIS OF IMAGES AND PATTERNS (CAIP), 13., 2009, Münster. Proceedings... Münster: Springer, 2009. p. 680-688. DOI:10.1007/978-3-642-03767-2_83.

193 SÁ JUNIOR, J. J. M.; BACKES, A. R.; ROSSATTO, D. R.; KOLB, R. M.; BRUNO, $O$. M. Measuring and analyzing color and texture information in anatomical leaf cross sections: an approach using computer vision to aid plant species identification. Botany, v. 89, n. 7, p. 467-479, 2011.

194 GOËAU, H.; BONNET, P.; JOLY, A.; YAHIAOUI, I.; BARTHELEMY, D.; BOUJEMAA, N.; MOLINO, J. F. The imageclef 2012 plant image identification task. In: INTERNATIONAL CONFERENCE OF THE CROSS-LANGUAGE EVALUATION FORUM (CLEF), 4., 2012, Rome. Proceedings... Rome: CLEF, 2012.

195 BRODATZ, P. Textures: a photographic album for artists and designers. New York: Dover Publications, 1966.

196 VISION texture database. 2009.2 Disponível em: $<$ http://vismod.media.mit.edu/vismod/imagery/VisionTexture/vistex.html>. Acesso em: 18 abr. 2013.

197 OJALA, T.; MÄENPÄÄ, T.; PIETIKÄINEN, M.; VIERTOLA, J.; KYLLÖNEN, J.; HUOVINEN, S. Outex: new framework for empirical evaluation of texture analysis algorithms. 
In: INTERNATIONAL CONFERENCE ON PATTERN RECOGNITION (ICPR), 16., 2002, Quebec. Proceedings... Quebec: IEEE, 2002. p. 701-706. DOI:10.1109/ICPR.2002.1044854.

198 SEBASTIAN, T. B.; KLEIN, P. N.; KIMIA, B. B. Recognition of shapes by editing their shock graphs. IEEE Transactions on Pattern Analysis and Machine Intelligence, v. 26, n. 5, p. 550-571, 2004.

199 FISH database. 2003. Disponível em: <http://www.ee.surrey.ac.uk/CVSSP/demos/css /demo.html>. Acesso em: 18 abr. 2013.

200 LATECKI, L. J.; LAKÄMPER, R.; ECKHARDT, U. Shape descriptors for non-rigid shapes with a single closed contour. In: CONFERENCE ON COMPUTER VISION AND PATTERN RECOGNITION (CVPR), 2000, Los Alamitos. Proceedings... Los Alamitos: IEEE, 2000. p. 1424-1429. DOI:10.1109/CVPR.2000.855850.

201 WANG, J.; BAI, X.; YOU, X.; LIU, W.; LATECKI, L. J. Shape matching and classification using height functions. Pattern Recognition Letters, v. 33, n. 2, p. 134-143, 2012.

202 CORREA, D. C.; SAITO, J. H.; COSTA, L. F. Musical genres: beating to the rhythms of different drums. New Journal of Physics, v. 12, n. 5, p. 053030, 2010.

203 COVER, T. M.; HART, P. E. Nearest neighbor pattern classification. IEEE Transactions in Information Theory, v. 13, n. 1, p. 21-27, 1967.

204 CONGALTON, R. G.; GREEN, K. Assessing the accuracy of remotely sensed data: principles and practices. Berkeley: CRC Press, 2008. 


\section{APÊNDICE $A$}

\section{Bases de dados}

\section{A.1 Bases de dados de textura}

Para avaliar os métodos propostos de análise de textura, 3 diferentes bases de dados de textura foram utilizadas:

- Brodatz (195): Trata-se de base de dados composta por 1776 texturas divididas em 111 classes. Cada imagem tem dimensão de $128 \times 128$ pixeis com 256 níveis de cinza (Figura A.1).

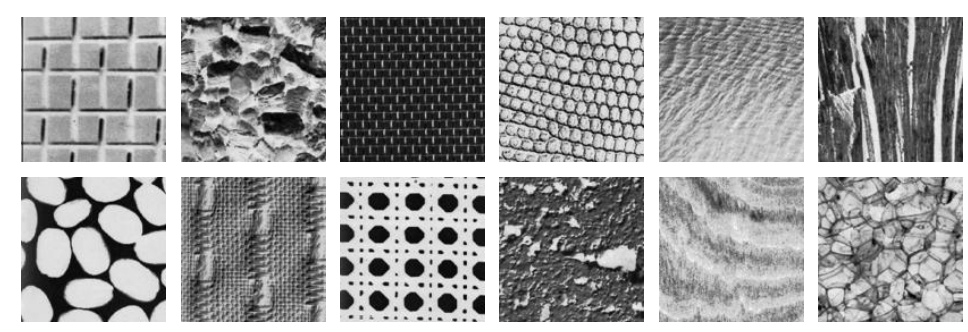

Figura A.1 - Exemplos de textura da base de dados Brodatz.

- VisTex (196): A base de dados The Vision Texture (VisTex) é mantida pelo grupo de Vision and Modelling do MIT Media Lab. A base de dados possui texturas do mundo real em condições reais (variação de luz, perspectiva, etc.). Cada uma das 54 classes possui 16 imagens de $128 \times 128$, totalizando 864 imagens (Figura A.2).

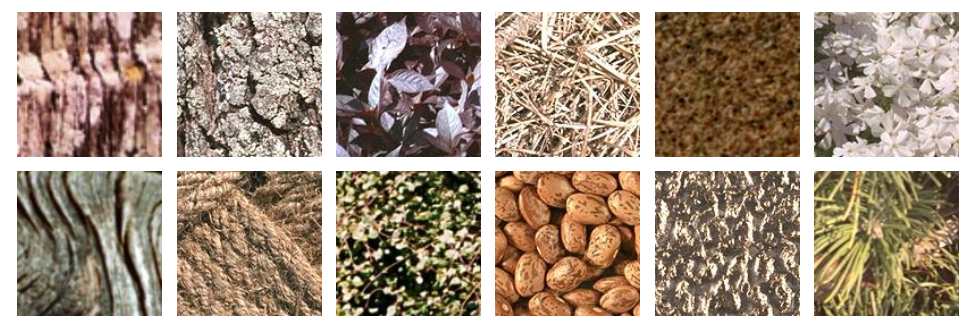

Figura A.2 - Exemplos de textura da base de dados Vistex. 
- Outex (197): Essa base de dados inclui uma coleção de cenas naturais. A base é composta por 1360 imagens (Outex_TC_00013) de $128 \times 128$, num total de 68 classes (20 por classe) (Figura A.3).
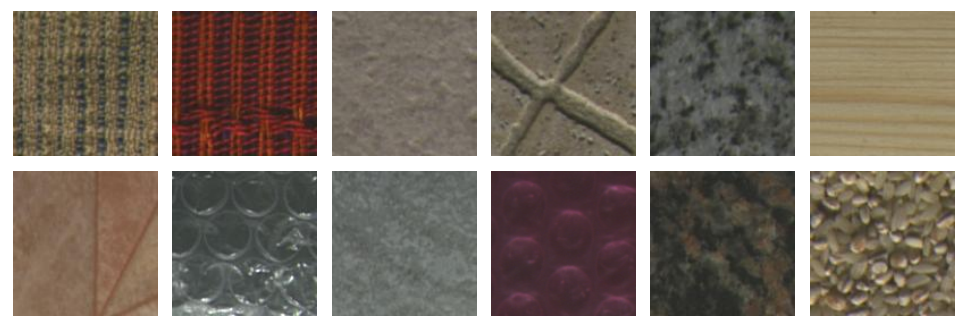

Figura A.3 - Exemplos de textura da base de dados Outex.

Das 3 bases de dados acima citadas 2 delas são compostas por imagens coloridas (Vistex, Outex) e uma por imagens em nível de cinza (Brodatz). No entanto alguns métodos propostos são concebidos para análise de texturas exclusivamente em níveis de cinza. Nesses casos uma versão em tons de cinza das 2 bases coloridas é obtida eliminando-se os canais de matiz e saturação e preservando o valor da luminância.

\section{A.2 Bases de dados de forma}

Para avaliar a qualidade dos métodos propostos 3 diferentes bases de formas serão utilizadas:

- Formas genéricas (198): com variação estrutural, é composta por 99 amostras, onde cada classe contém 11 imagens com variações na estrutura da forma, totalizando 9 classes (Figura A.4).

- Formas de peixes (199): utilizadas para avaliar as propriedades de invariância de rotação e escala. Essa base é composta por 10 diferentes manifestações (5 rotações e 5 escalas)

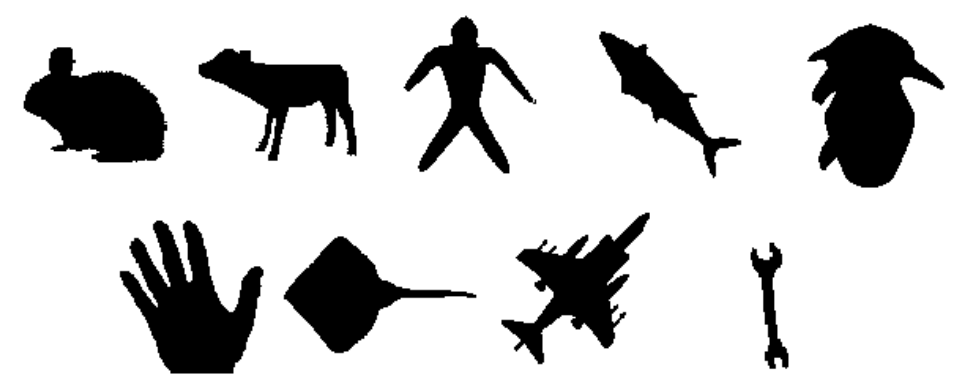

Figura A.4 - Exemplos de formas da base de dados Genérica. 
de cada um dos 1100 peixes. Dessa forma a base totaliza 11000 contornos agrupados em 1100 classes com 10 amostras cada. A Figura A.5 apresenta alguns exemplos dessa base.

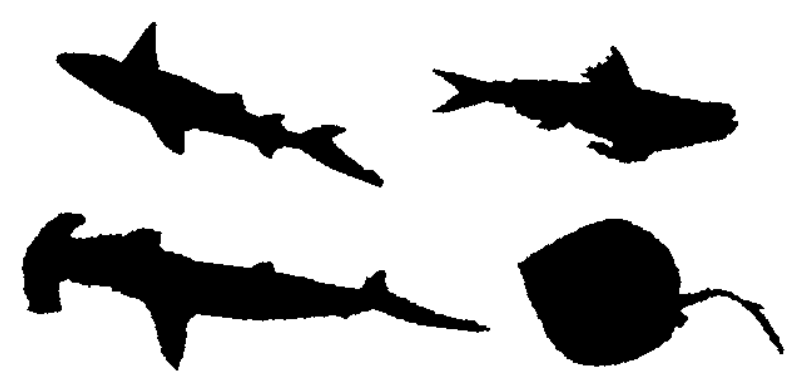

Figura A.5 - Exemplos de formas da base de dados Peixes.

- MPEG-7 (200): base composta por 1400 contornos de 70 classes (20 amostras cada). Trata-se de uma base de dados já amplamente difundida e utilizada para comparação de métodos de análise de contorno (201). Possui diferentes manifestações de escala, rotação e deformações para um mesmo objeto. A Figura A.6 Apresenta alguns exemplos dessa base.

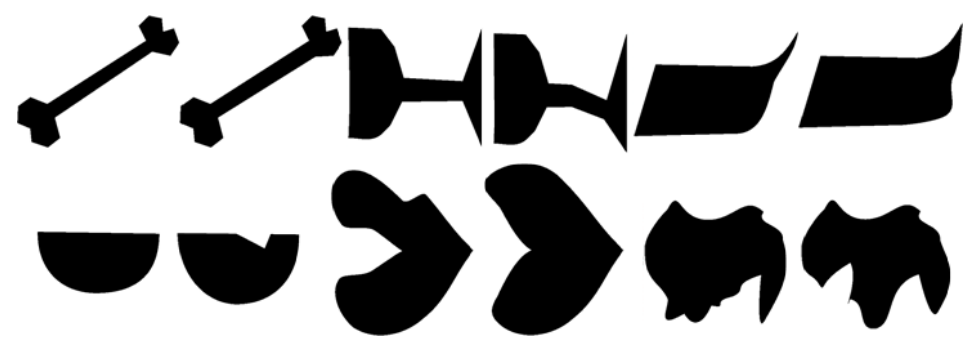

Figura A.6 - Exemplos de formas da base de dados MPEG-7.

A extração da forma/objeto de cada imagem dá-se por simples aplicação de uma operação de limiarização para eliminar o fundo e posterior utilização do algoritmo do ceguinho (110).

\section{A.2.1 Tolerância ruído}

Para avaliar a tolerância a ruído 4 diferentes níveis de ruídos foram empregados em cada base de dados, gerando 4 diferentes manifestações da forma. O ruído é uniformemente gerado no intervalo $[-n \ldots n]$, onde $n$ é a intensidade do ruído, e aplicado às coordenadas $x$ e $y$. Exemplos de folhas com ruído são apresentadas na Figura A.7. 


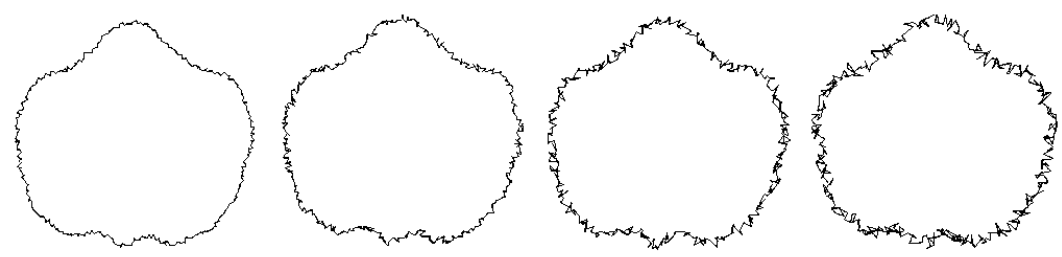

Figura A.7 - Exemplos de forma com ruído.

\section{A.2.2 Robustez à contornos parciais I}

É desejável que os métodos de análise de foram sejam capaz de trabalhar com contornos onde uma parte do mesmo esteja faltando ou indisponível. Para verificar essa propriedade 13 níveis de degradação $(5 \%, 10 \% \ldots 65 \%)$ são aplicados a cada amostra. Nesse primeiro experimento essa degradação é aplicada de forma contínua, de forma que a extração sequencial dos pontos do contorno ainda é possível de ser realizada. A Figura A.8 mostra exemplos dessa degradação. Uma base de dados nova é obtida para cada nível de degradação.
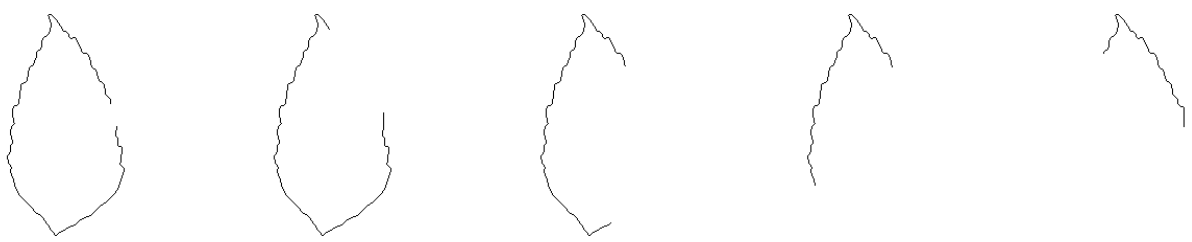

Figura A.8 - Exemplos de degradação contínua aplicada às formas de folhas

\section{A.2.3 Robustez à contornos parciais II}

Similarmente ao realizado acima, esse experimento utiliza 13 níveis de degradação $(5 \%, 10 \%$...65\%), porém esta é aplicada randomicamente ao contorno original. Por essa razão não é possível extrair os pontos do contorno sequencialmente. A Figura A.9 apresenta exemplos desse processo. Uma base de dados nova é gerada para cada nível de degradação.
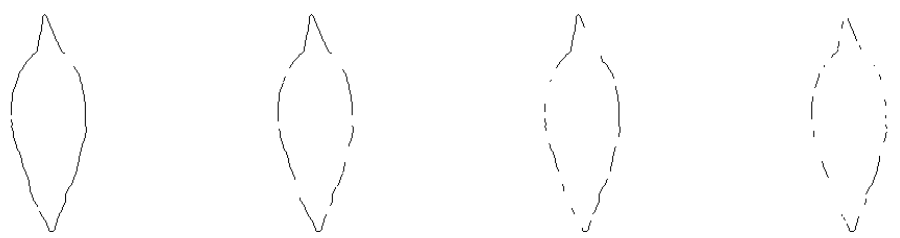

Figura A.9 - Exemplos de degradação randômica aplicada às formas de folhas. 


\section{A.3 Base de dados de esqueletos}

A análise de esqueletos é realizada sobre as mesmas 3 bases de dados utilizadas na análise de formas, a saber:

- Formas genéricas (198).

- Formas de peixes (199).

- MPEG-7 (200).

A extração dos esqueletos é realizada utilizando-se a esqueletonização espaço-escala (110), que utiliza a transformada da distância para obter as distâncias entre os elementos do contorno. Utilizam-se limiares incrementais até que apenas 20 pontos de extremidade estejam presentes no esqueleto final. A obtenção dos pontos de extremidade e de junção um esqueleto 8conectado é facilmente realizada por meio de operações morfológicas hit-or-miss utilizando um conjunto de máscaras adequadas (75). 


\section{APÊNDICE $B$}

\section{Reconhecimento de padrões}

Este trabalho trata exclusivamente de problemas de classificação supervisionada multiclasses (e.g. identificação vegetal por análise foliar). Nesse sentido optamos por utilizar a análise discriminante linear, ou LDA (do inglês linear discriminant analysis), em conjunto com um classificador bayesiano e k-vizinhos mais próximo KNN (do inglês k-nearest neighbors), para avaliar a qualidade dos métodos testados (202). A validação cruzada 10-fold é empregada para avaliar a capacidade de generalização dos modelos. Cada classificação é realizada 10 vezes obtendo assim uma medida mais confiável sobre a capacidade de representar o processo gerador dos dados.

\section{B.1 Análise discriminante linear}

A LDA é basicamente uma transformação geométrica no espaço de características com a finalidade de gerar novas características não correlacionadas com base em combinações lineares dos originais. Tal transformação visa obter a projeção que melhor separa as classes dadas (202).

Dada a matriz $S$, indicando a dispersão total entre os vetores de características definida como:

$$
S=\sum_{i=1}^{N}\left(\mathbf{x}_{i}-\mu\right)\left(\mathbf{x}_{i}-\mu\right)^{\prime}
$$

e a matriz $S_{i}$ indicando a dispersão total dos objetos da classe $C_{i}$ :

$$
S_{i}=\sum_{i \in C_{i}}\left(\mathbf{x}_{i}-\mu_{i}\right)\left(\mathbf{x}_{i}-\mu_{i}\right)^{\prime}
$$

podemos definir a variabilidade intra-classe $S_{\text {intra }}$ (indicando a dispersão combinada dentro de cada classe) e a variabilidade $S_{\text {inter }}$ (indicando a dispersão das classes em termos de seus 
centroides) como:

$$
\begin{gathered}
S_{\text {intra }}=\sum_{i=1}^{K} S_{i} \\
S_{\text {inter }}=\sum_{i=1}^{K} N_{i}\left(\mu_{i}-\mu\right)\left(\mu_{i}-\mu\right)^{\prime}
\end{gathered}
$$

onde $K$ é o número de classes, $N$ o número de amostras, $N_{i}$ o número de objetos na classe $i, C_{i}$ o conjunto de amostras da classe $i, \mu$ a média global e $\mu_{i}$ a média dos objetos da classe $i$. Para essas medidas de dispersão temos necessariamente que:

$$
S=S_{\text {intra }}+S_{\text {inter }}
$$

Dessa forma a i-ésima variável canônica é dada por:

$$
Z_{i}=a_{i 1} \mathbf{X}_{1}+a_{i 2} \mathbf{X}_{2}+\cdots+a_{i p} \mathbf{X}_{p}
$$

onde $p$ é o número de características do modelo e $a_{i j}$ são os elementos do autovetor $a_{i}=\left(a_{i 1}, a_{i 2}, \ldots, a_{i p}\right)$ da matriz $C$ dada por:

$$
C=S_{\text {inter }} * S_{\text {intra }}^{-1}
$$

Essa formulação leva a uma condição em que não há correlação entre $Z_{i}$ e $Z_{1}, Z_{2}, \ldots$, dentro das classes. De $p$-variáveis originais, $p$-variáveis canônicas podem ser obtidas. No entanto uma redução no número de variáveis a serem avaliadas é normalmente desejado, isso é, a informação contida nas $p$-variáveis originais pode ser substituída pela informação contida em $k$-variáveis não correlacionadas tal que $(k<p)$. Assim o sistema de variabilidade aleatória do vetor original com $p$-variáveis é aproximado pela variabilidade do vetor aleatório que contém $k$-variáveis canônicas. Optou-se nesse trabalho utilizar um número $k$ de variáveis canônicas que representa $>99.99 \%$ da variância total explicada pelas $k$ componentes dadas por:

$$
\frac{\sum_{i=1}^{k} \lambda_{i}}{\sum_{i=1}^{p} \lambda_{i}}
$$

onde $\lambda_{1}, \lambda_{2}, \ldots, \lambda_{p}$ são os autovalores da matriz $C$. 


\section{B.2 Classificador bayesiano}

O classificador Naive-Bayes é baseado na teoria da decisão bayesiana e um dos mais utilizados em aprendizado de máquina. O classificador é denominado ingênuo (naive) por assumir que os atributos são condicionalmente independentes. Ele combina as probabilidades condicionais e probabilidades a priori para gerar um modelo e realizar a classificação através da atribuição de cada objeto para a classe com máxima probabilidade a posteriori. Tal classificador é empregado utilizado as variáveis canônicas obtidas anteriormente pela análise LDA. Dessa forma uma redução no número de atributos é sempre obtida em relação ao conjunto original, bastando escolher o número de variáveis que obtém os melhores resultados.

Para $g$ grupos, a regra de Bayes atribui um objeto para o grupo $i$ quando:

$$
P(i \mid \mathbf{x})>P(j \mid \mathbf{x}), \text { for } \forall j \neq i
$$

Nesse caso, assumindo a hipótese de independência das variáveis, temos para cada variável aleatória:

$$
P(i \mid \mathbf{x})=\frac{P(i) \prod_{k=1}^{n} P\left(x_{k} \mid i\right)}{\prod_{k=1}^{n} P\left(x_{k}\right)}
$$

onde:

$$
P\left(x_{k} \mid i\right)=\frac{1}{\sqrt{2 \pi \sigma_{i k}^{2}}} e^{\frac{\left(x_{i}-\mu_{i k}\right)^{2}}{2 \sigma_{i k}^{2}}}
$$

sendo $P(\mathbf{x} \mid i)$ a probabilidade de obter um conjunto de características $\mathbf{x}$ dado que o objeto pertence ao grupo $i$ e $P(i)$ é a probabilidade a priori, i.e. a probabilidade de escolher o grupo de $i$ sem conhecer qualquer característica do objeto.

\section{B.3 Classificador Knn}

O classificador dos k-vizinhos mais próximos KNN (do inglês k-nearest neighbors) é uma variação do algoritmo NN (do inglês nearest neighbor) proposto por Cover e Hart (203) em 1967. Nesse trabalho os autores apresentam 2 distintos problemas de classificação: (1) ou conhece-se a distribuição conjunta dos dados e das classes do problema, caso em que uma análise de Bayes leva à regra ótima de decisão e ao mínimo erro teórico e (2) caso onde não se conhece nada sobre a distribuição além daquilo que é possível extrair a partir de exemplos 
conhecidos do problema.

Para o primeiro caso a regra de decisão é fortemente justificada. No segundo caso, porém, não se tem conviç̧ão sobre as regras criadas e a qualidade da classificação estará diretamente relacionada à qualidade dos dados disponíveis.

Nesse sentido uma heurística normalmente aceita para classificação é considerar que as observações suficientemente próximas (de acordo com alguma métrica estabelecida) pertencerão à mesma classe.

Formalmente temos o conjunto de amostras na forma $X=\left\{\mathbf{x}_{1}, \mathbf{x}_{2}, \ldots, \mathbf{x}_{n}\right\}$, representando as instâncias conhecidas do problema. Para determinar a classe de uma nova amostra $\mathbf{x}$ uma função de similaridade $\delta$ deve ser minimizada quanto mais semelhantes duas instâncias forem:

$$
\delta\left(\mathbf{x}^{\prime}, \mathbf{x}\right)=\min \delta\left(\mathbf{x}_{i}, \mathbf{x}\right) i=1,2, \ldots, n
$$

onde $\mathbf{x}^{\prime}$ é o vizinho mais próximo de $\mathbf{x}$. Atribui-se a classe do exemplo desconhecido como sendo igual a classe de seu vizinho mais próximo.

Uma extensão natural é considerar os k-vizinhos mais próximo do exemplo desconhecido, decidindo por voto qual será a classe escolhida. Nesse sentido a escolha mais natural da função de similaridade para observações p-dimensionais é a distância euclidiana dada por:

$$
\delta\left(\mathbf{x}_{1}, \mathbf{x}_{2}\right)=\sqrt{\sum_{i=1}^{p}\left(x_{1 i}-x_{2 i}\right)^{2}}
$$

A principal vantagem do algoritmo é sua simplicidade, dado que não é necessária uma etapa de treinamento (lazy). Assim como no classificador bayesiano, uma redução redução no número de atributos é realizada via LDA antes de se aplicar o classificador Knn.

\section{B.4 Métricas para avaliação de desempenho dos classifi- cadores}

Para avaliação do desempenho utilizamos a acurácia (também denominada probabilidade de acerto global ou taxa de acerto). O índice de acurácia é um parâmetro estatístico simples, derivado da matriz de confusão, que é dado pela divisão da soma dos valores da diagonal principal dessa matriz pela quantidade total de amostras usadas para o cálculo da mesma. Dada a matriz de confusão $M$, a acurácia de um classificador pode ser calculada por: 


$$
\text { Acurácia }=\frac{\sum_{i=1}^{r} m_{i i}}{n}
$$

onde $r$ é o número de linhas e colunas na matriz de confusão, $m_{i i}$ é a contagem das observações na linha $i$ e coluna $i$ e $n$ é o número total de observações.

Outra métrica utilizada é o índice Kappa tem por finalidade avaliar a concordância entre a classificação e a verdade (204). O índice Kappa trata-se de um índice consagrado na comunidade acadêmica para avaliar o grau de desempenho de uma regra de decisão qualquer quanto a sua exatidão. Muito utilizado em classificação de imagens de satélite, este índice também pode ser utilizado na avaliação de outros classificadores, pois, os dados da matriz de erros são discretos e com distribuição multinormal (204). Os valores desse índice são inferiores aos valores de precisão global pois traduzem o ganho de precisão relativo a uma distribuição aleatória dos indivíduos pelas classes. O índice Kappa é dado por:

$$
\widehat{K}=\frac{\theta_{1}-\theta_{2}}{1-\theta_{2}}
$$

onde

$$
\theta_{1}=\sum_{i=1}^{r} \frac{m_{i i}}{n}
$$

e

$$
\theta_{2}=\sum_{i=1}^{r} \frac{m_{i+} m_{+i}}{n^{2}}
$$

onde $m_{i+}$ é a soma da enésima linha e $m_{+i}$ é a soma da enésima coluna da matriz de adjacência.

Tanto a acurácia (ou simplesmente acerto) quanto o índice Kappa são índices amplamente utilizados no contexto de classificação multiclasses. Por outro lado, para problemas de recuperação de imagens por conteúdo é mais conveniente utilizar as medidas de precisão e revocação.

A precisão é uma medida de fidelidade, enquanto a revocação (também conhecida como 
cobertura ou sensibilidade) é uma medida de completude. No contexto de recuperação de informação a precisão é o número de elementos relevantes recuperados divididos pelo número total de elementos recuperados (Equação B.4.5) e a revocação é definida como o número de elementos relevantes recuperados dividido pelo número total de elementos relevantes existentes (que deveriam ter sido recuperados)(Equação B.4.6).

$$
\begin{gathered}
\text { Precisão }=\frac{\text { Número de elementos relevantes recuperados }}{\text { Número total de elementos recuperados }} \\
\text { Revocação }=\frac{\text { Número de elementos relevantes recuperados }}{\text { Número total de elementos relevantes }}
\end{gathered}
$$

Para a precisão o valor de 1 significa que cada resultado obtido por uma pesquisa foi relevante (mas não diz nada sobre se todos os elementos relevantes foram recuperados), enquanto o valor 1 para revocação significa que todos os elementos relevantes foram recuperados pela pesquisa (mas nada diz sobre quantos elementos irrelevantes também foram recuperados).

Por vezes pode existir uma relação inversa entre precisão e revocação, onde é possível aumentar uma ao custo de reduzir outra. Pode-se, por exemplo, aumentar a revocação recuperando mais elementos, ao custo de um número crescente de elementos irrelevantes recuperados (diminuindo a precisão). 